NBSIR 78-1420-3 $\mathrm{F}$

\title{
NBS Minimal BASIC Test Programs - Version 1 User's Manual
}

Volume 3 - Control Statements, Data Structure, Program Input

David E. Gilsinn

Charles L. Sheppard

Systems and Software Division Institute for Computer Sciences and Technology National Bureau of Standards

Washington, D.C. 20234

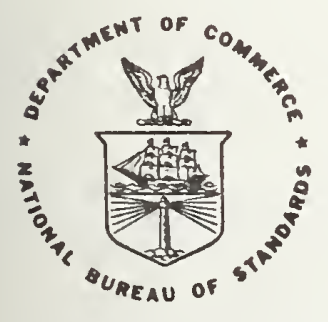

U.S. DEPARTMENT OF COMMERCE

NATIONAL BUREAU OF STANDARDS 


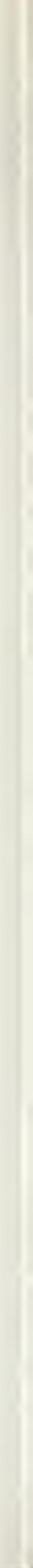


NBSIR 78-1420-3

\section{NBS MINIMAL BASIC TEST}

PROGRAMS - VERSION 1

\section{USER'S MANUAL}

Volume 3 - Control Statements, Data Structure, Program Input

David E. Gilsinn

Charles L. Sheppard

Systems and Software Division Institute for Computer Sciences and Technology National Bureau of Standards

Washington, D.C. 20234

U.S. DEPARTMENT OF COMMERCE, Juanita M. Kreps, Secretary

Dr. Sidney Harman, Under Secretary

Jordan J. Baruch, Assistant Secretary for Science and Technology

NATIONAL BUREAU OF STANDARDS, Ernest Ambler, Acting Director 
This volume is the third of four volumes that comprise the user's guide to the NBS Minimal BASIC test programs. The programs test whether a BASIC processor accepts the syntactical forms and produces semantically meaningful results according co the specifications given in BSR X3.60 Proposed American National Standard gor Minimal BASIC. The object of this volume is to complete the testing of the control structures, introduce new data structures, and test the user interactive capability of the language. There are sixty individual programs in this volume that cover looping structures, array variables, exception tests, subroutines, multiway branch structures, data declarations and interactive data inputs. The entire set of programs is available on tape.

KeY Mords: BASIC, BASIC standard, BASIC validation, compiler validation, computer programming language, computer standards 
D. Introduction.

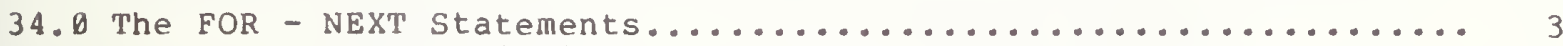

Program Listing.............................. 5

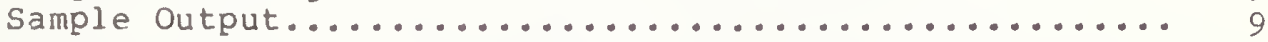

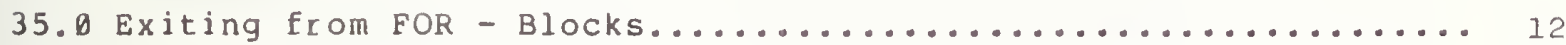

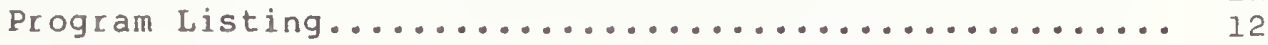

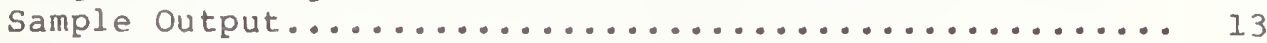

36. D Syntax Diagnostic - A FOR - Statement Without a Matching

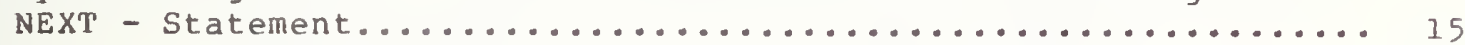

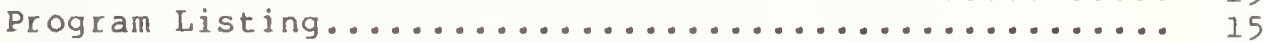

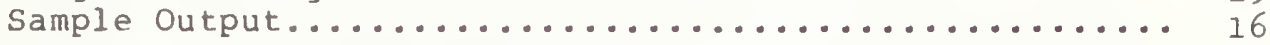

37. Dyntax Diagnostic - A NEXT - Statement without a Matching FOR -

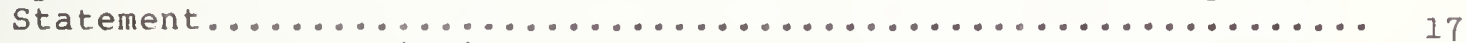

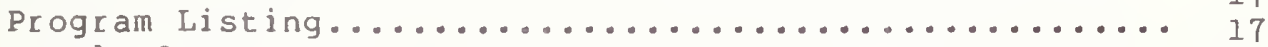

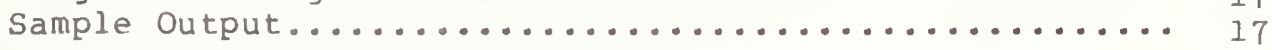

38.0 Semantic Error - The Interleaving of Two FOR - Blocks......... 19

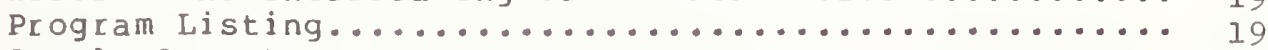

Sample Output............................. 20

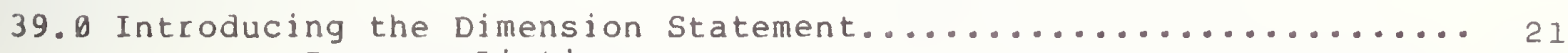

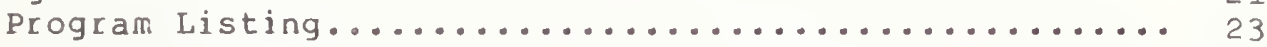

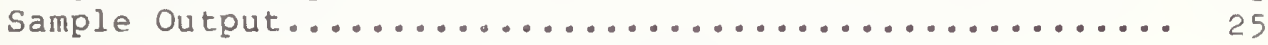

40.0 Extending IF - THEN Capabilities by Using One - Dimensional

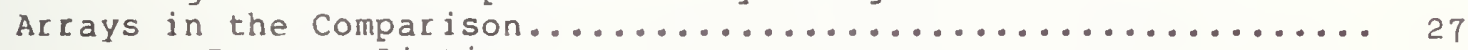

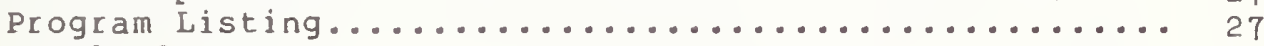

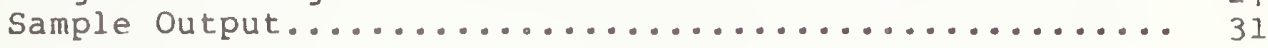

41.0 Extending IF - THEN Capabilities by Using Two - Dimensional

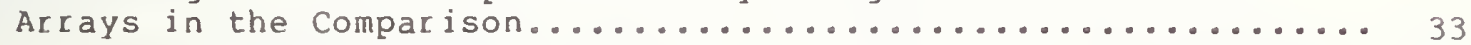

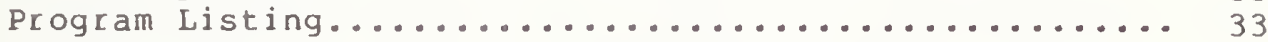

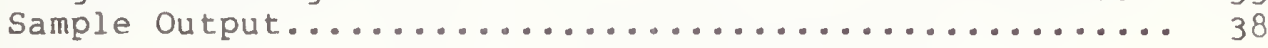

42. 0 The ABS Function with Subscripted Variables for Arguments...... 39

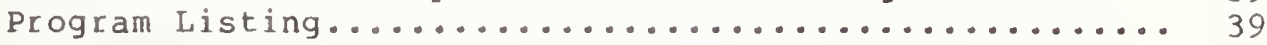

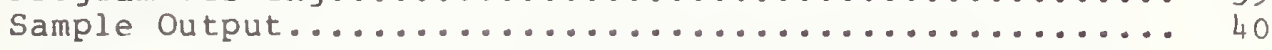

43.0 Using Elementary Operations on Subscripted Variables Assigned Same Type Constants............................... 42

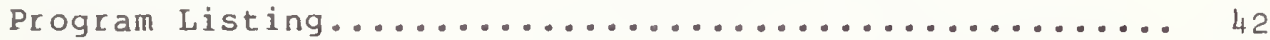

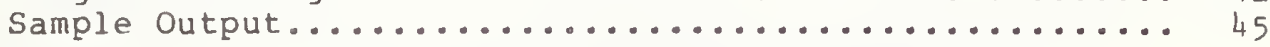

44. D Using Elementary Operations on Subscripted Variables Assigned

Same Type Constants (Continued)....................... 48

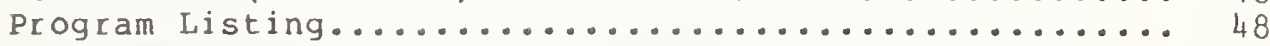

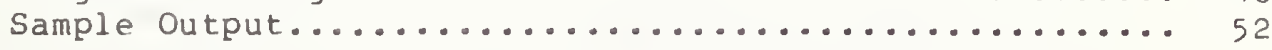

45.0 Using Elementary Operations on Subscripted Variables Assigned

Mixed Type Constants.............................. 56

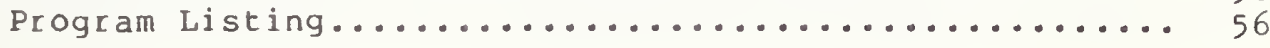




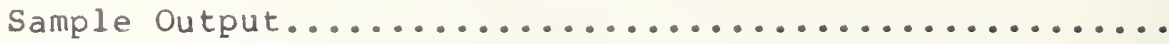

46. Using Elementary Operations on Subscripted Variables Assigned

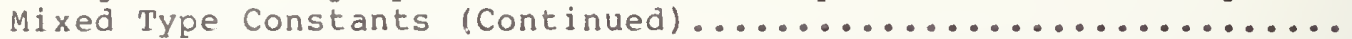

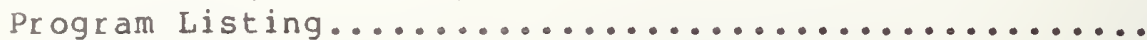

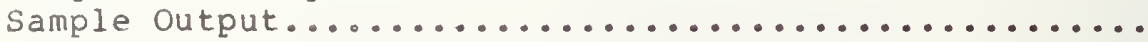

47.0 Using Elementary Operations on Subscripted Variables Assigned Mixed Type Constants (Continued)

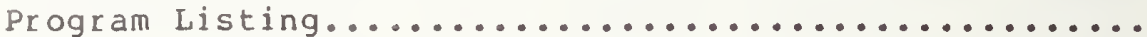

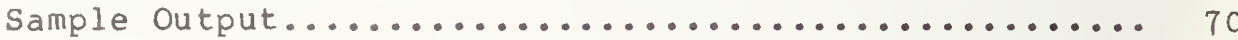

48. 0 Addition of More Than Two Terms Containing Array Elements...... 73

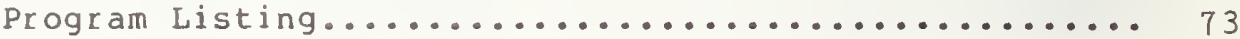

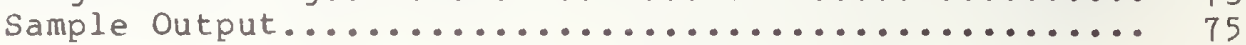

49.0 Multiplication of More Than Two Terms.................. 77

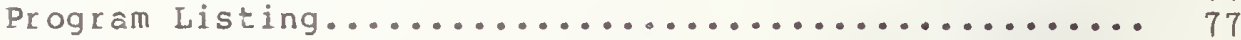

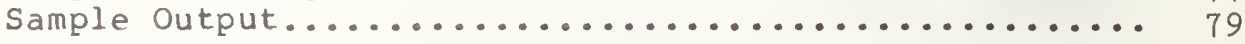

50. Hierarchy of Operators and Parentheses................... 81

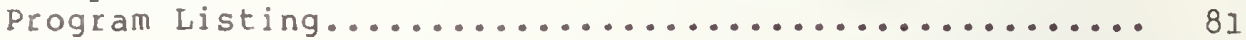

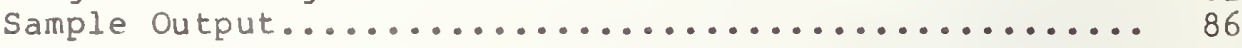

51. Evaluation of Expressions that have a Variety of Operators.... 89

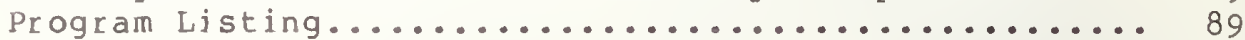

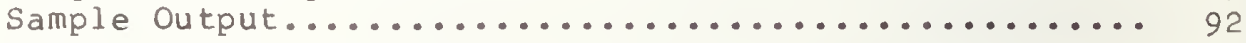

52. Exception Test - Zero Raised to a Negative Power............. 94

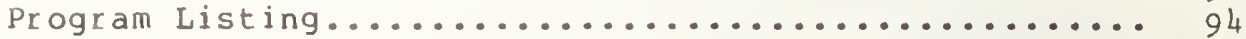

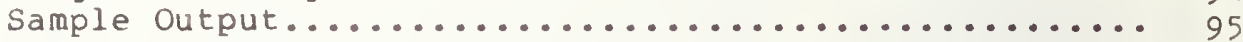

53.0 Exception Test - A Negative Number Raised to a Non - Negative

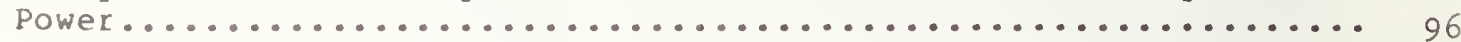

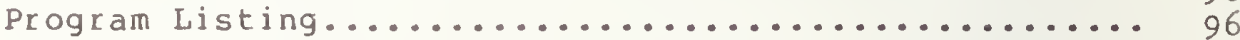

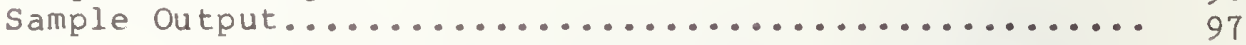

54. O Semantic Error - Subscripted Variable with Different Numbers

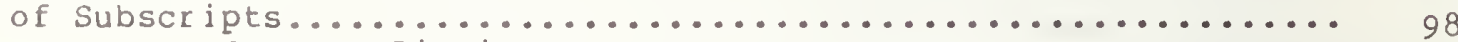

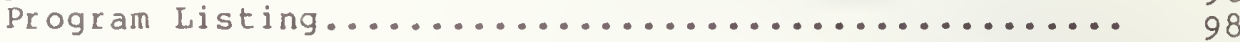

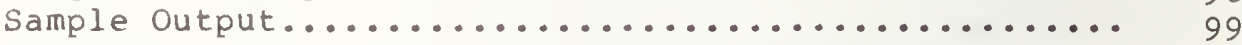

55.0 Exception Test - A Subscript is not in the Range of the Implicit Dimensioning Bounds........................ 100

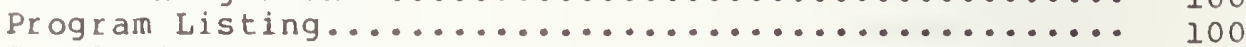

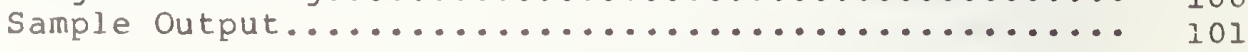

56. Exception Test - A subscript is not in the Range of an

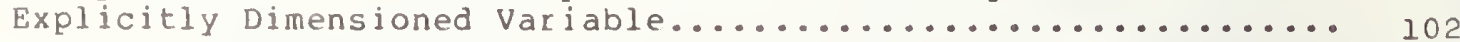

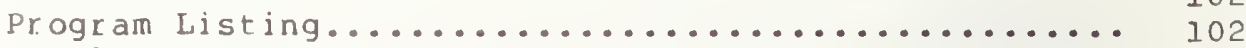

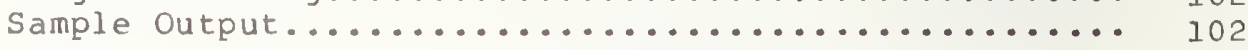

57.0 Attempting String Overflow by Variable Assignment........... 104

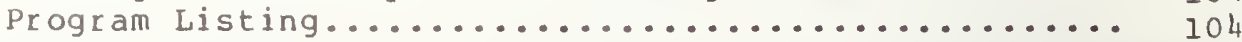

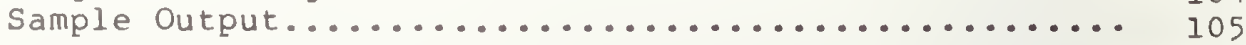

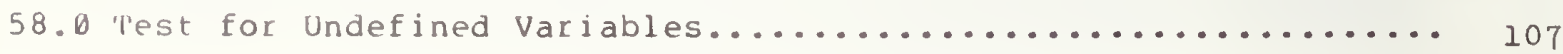




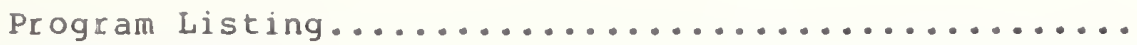

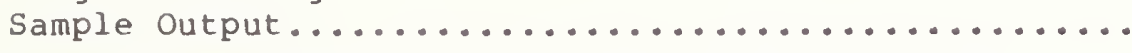

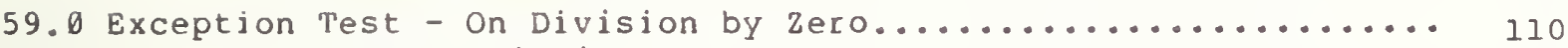

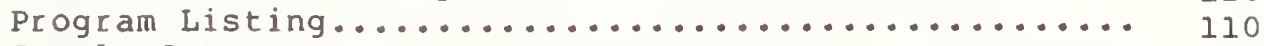

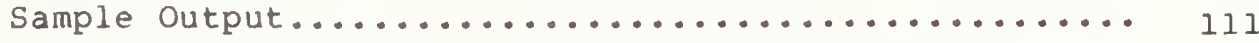

60. Exception Test - On Expression Evaluation Resulting in

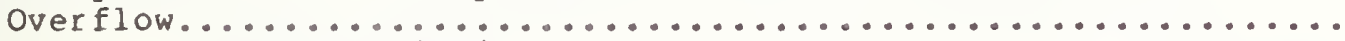

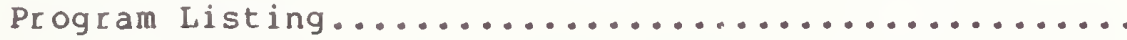

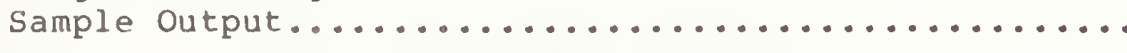

61.0 Semantic Test - On the Magnitude of a Nonzero Numeric Constant

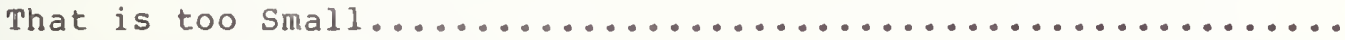

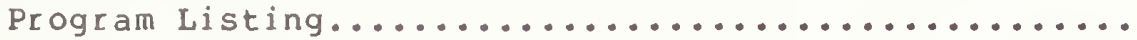

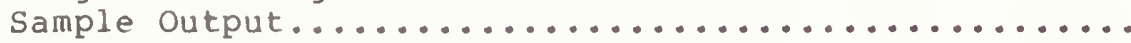

62. Exception Test - On the Magnitude of a Nonzero Numeric Constant

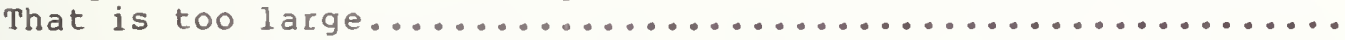

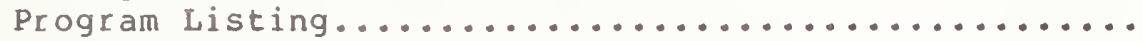

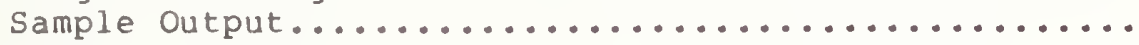

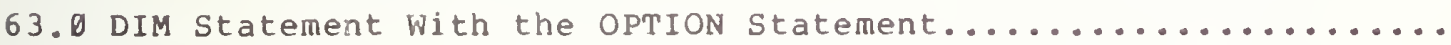

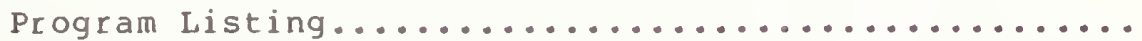

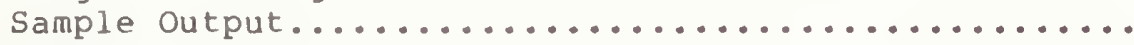

64. Using the OPTION BASE - Statement to Change Implicit Array

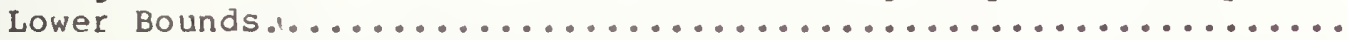

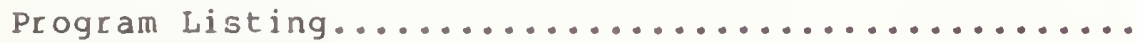

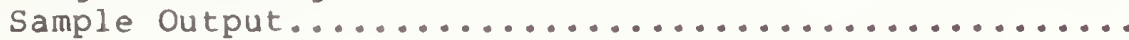

65. Testing the Assignment of Zero for an Expression Causing

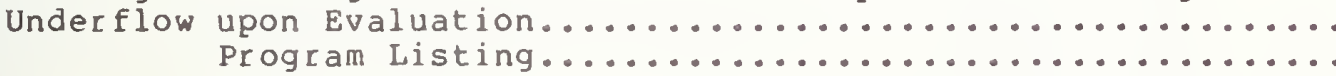

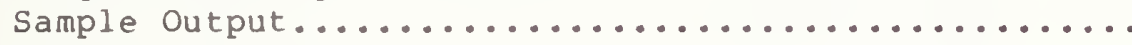

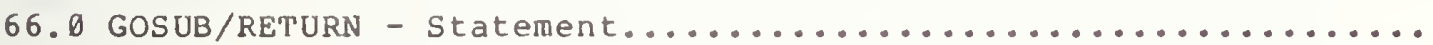

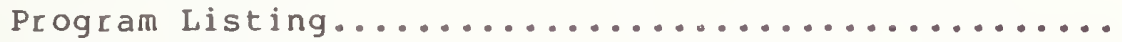

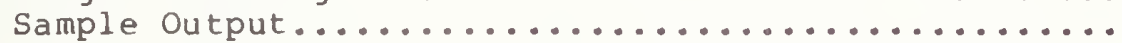

67.0 Semantic Error - Test on Gosub Transfer to an Illegal Line

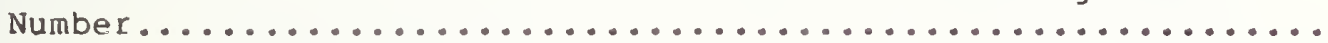

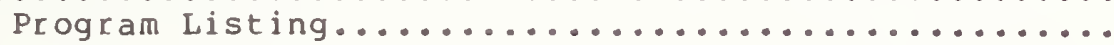

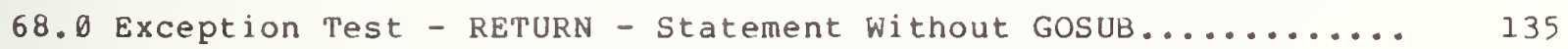

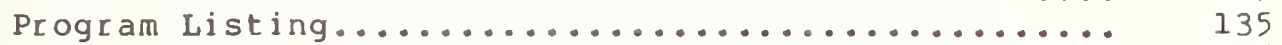

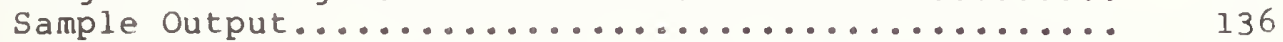

69.0 Testing Roundoff to Six Significant Digits of Constants of

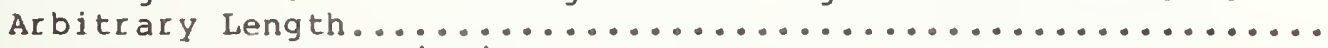

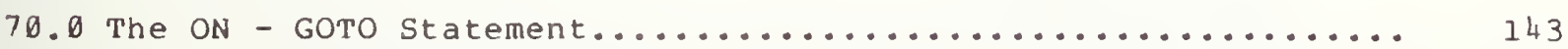

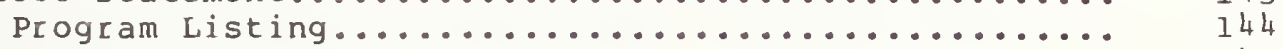

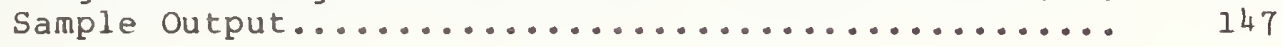


71. Semantic Diagnostic - ON - GOTO Statement Referring to a

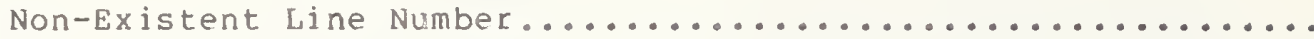

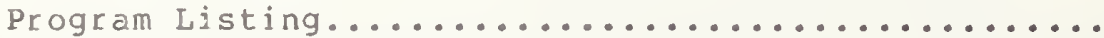

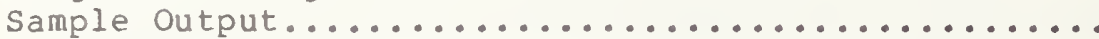

72.0 Exception Test - Value of ON - GOTO Expression Less than One.. I50

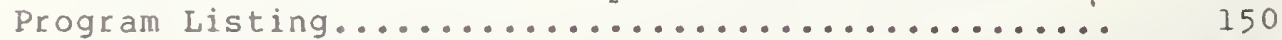

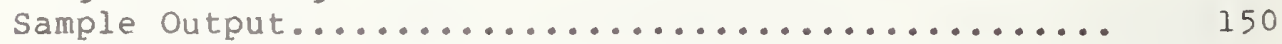

73. Exception Test - Value of ON - GOTO Expression Greater than

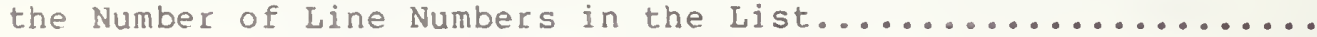

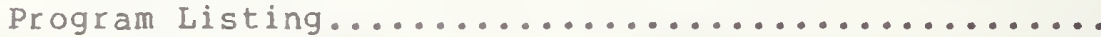

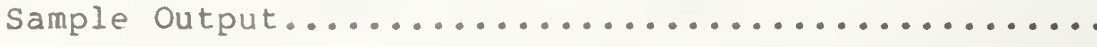

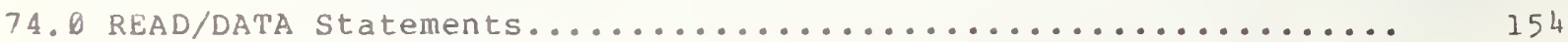

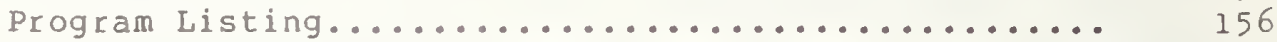

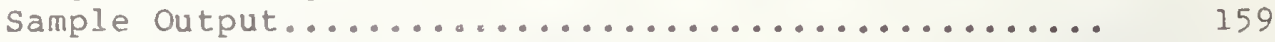

75.0 Exception Test - READ - Statement Encounters Insufficient

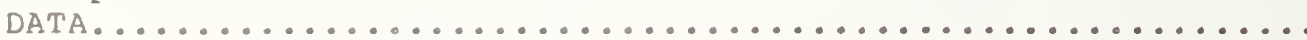

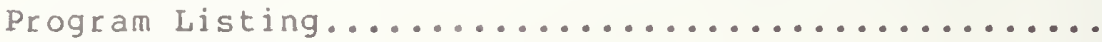

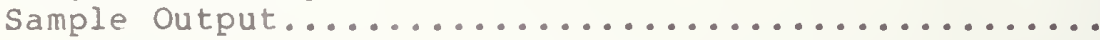

76.0 Exception Test - Non-Matching String Datum Assigned to a

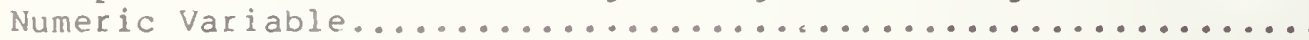

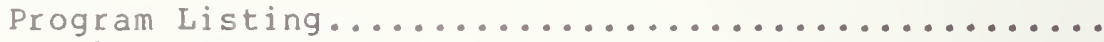

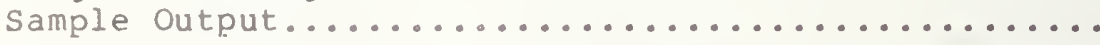

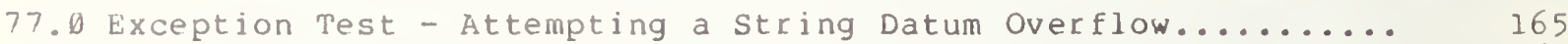

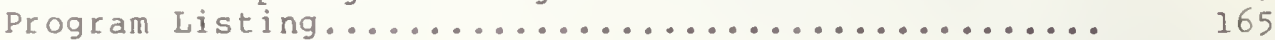

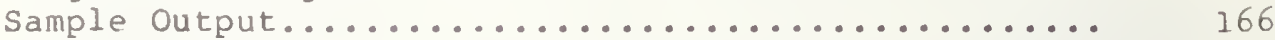

78. Semantic Interpretation - A Numeric Value in a DATA List

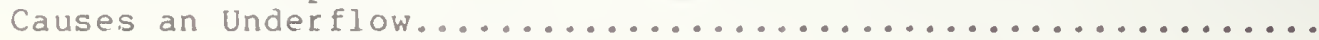

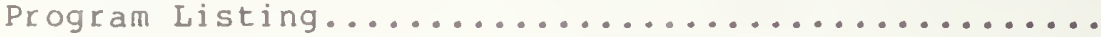

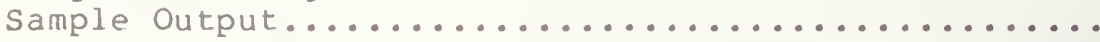

79. Exception Test - A Numeric Value in a DATA Statement Causes

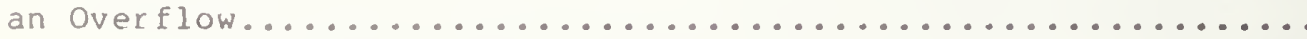

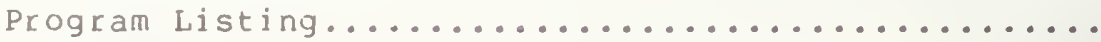

80. Exception Test - Overflow Caused by a Numeric Value in a

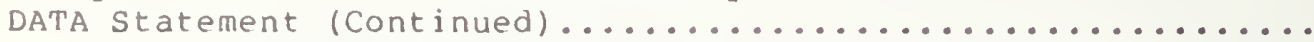

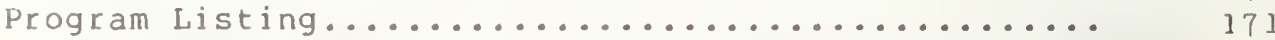

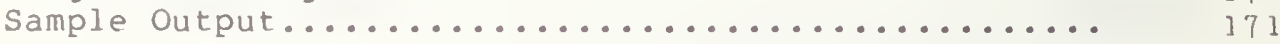

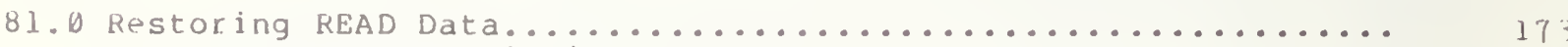

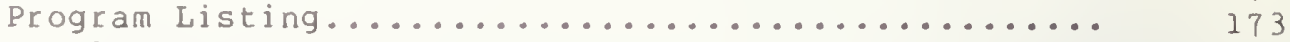

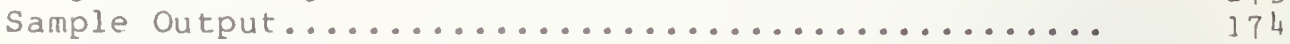

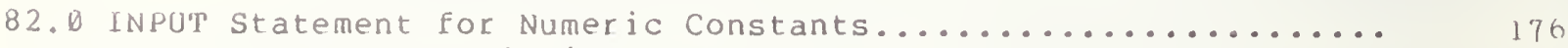

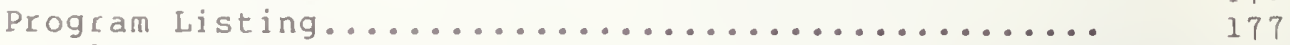

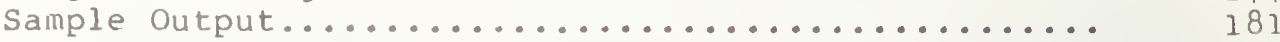

83. I INPU'T of Numeric Data to Subscripted Variables and Unquoted

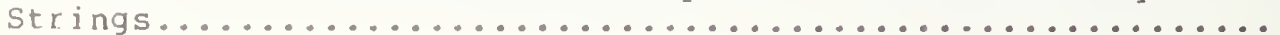




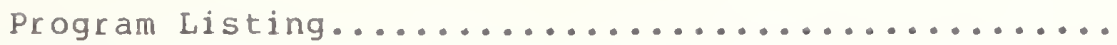

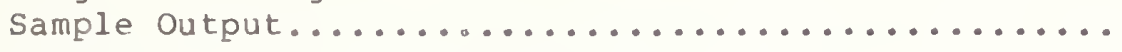

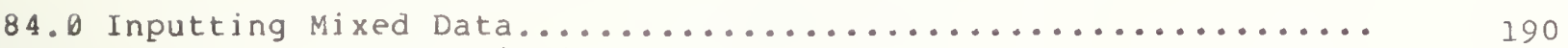

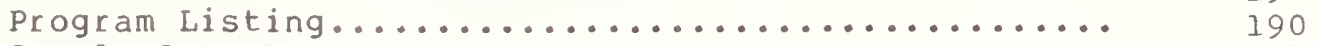

Sample Output.............................. 194

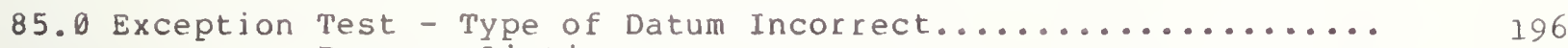

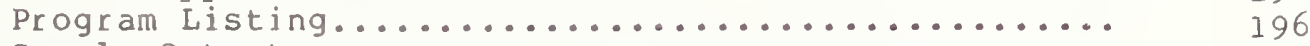

Sample Output............................ 197

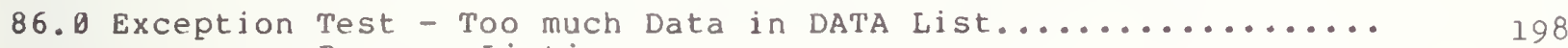

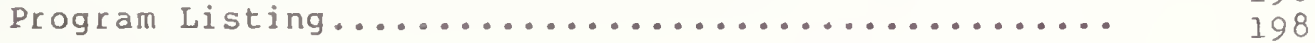

Sample Output............................. 199

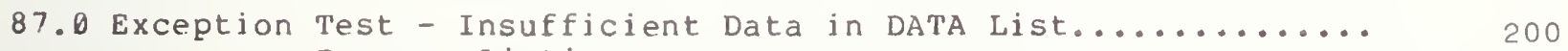

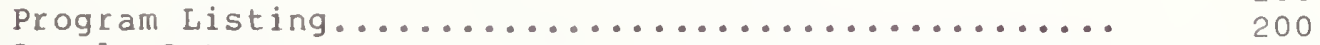

Sample Output........................... 201

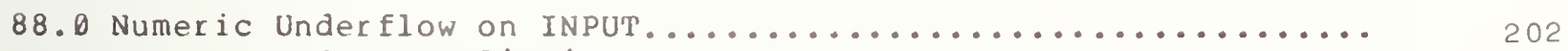

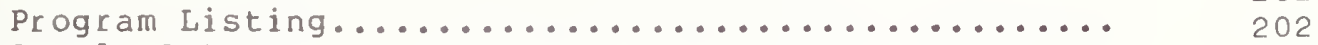

Sample Output............................ 202

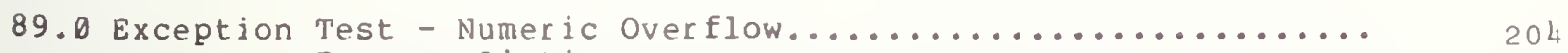

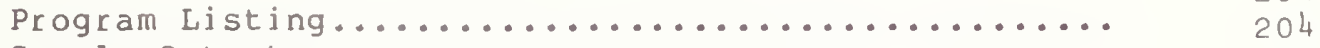

Sample Output............................ 205

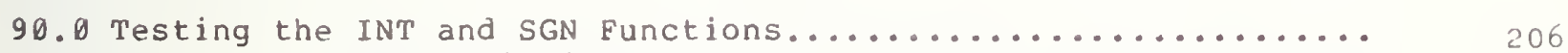

Program Listing.......................... 206

Sample Output........................... 208

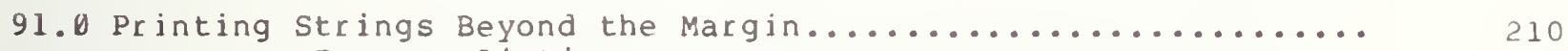

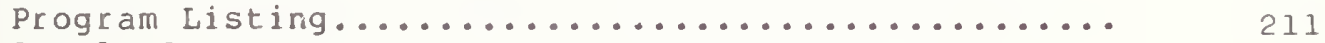

Sample output........................... 214

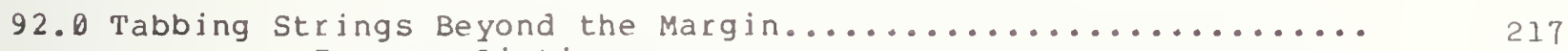

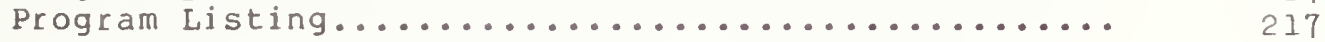

Sample output............................ 220

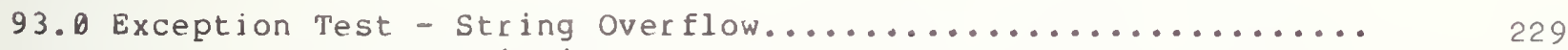

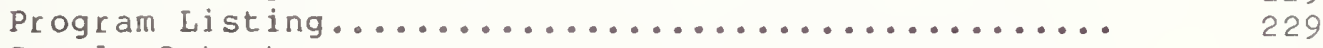

Sample Output............................ 230 


\subsection{INTRODUCTION}

This volume is the third in a set of four volumes that comprise the user's guide to the NBS Minimal BASIC test programs. There are sixty individual programs in this volume that cover looping structures, array variables, exception tests, subroutines, multiway branch structures, data declarations and the interactive data inputs. As in the previous volumes the user is assumed to be familiar with the American National standard for Minimal BASIC, BSR x 3.60 .

The first tests execute various forms of FOR - NEXT statements. These include tests that use loops with and without the step clause. Although the standard does not specify the depth to which loops can be nested, one test executes a nest of three deep to accomodate at least the looping needed to handle a matrix within some iterative algorithms consisting of one loop. The matrix itself is doubly dimensioned. Another test checks the control variable on exiting from a loop. There are finally some error detection routines for looping.

A natural extension to the looping tests is the introduction of dimensioned variables. These programs first test implicit and explicit dimensioning without the OPTION statement. The OPTION statement in Minimal BASIC allows the user to redefine the lower bound of array indices, which is assumed to be $\theta$ unless altered by the OPTION BASE statement. Next, arrays are used in simple expressions which control some conditional branches. These branch statements are then used to test more complex arithmetic expressions that make use of arrays. Many of the tests of arithmetic expression evaluation are similar to previous arithmetic tests, but in the present volume the expressions also use arrayed variables as well as simple variables and constants. There are a number of exception tests included, as for example, checking for subscripts out of bounds. The OPTION statement is then introduced and tested by checking whether out of bounds errors are detected when the zero-th element of an array is called for after the opTION BASE was used to specify a lower array bound of one, for example.

Up to this point only the elementary direct transfer GoTo and conditional branch IF-THEN have been tested and used. Two new control structures are now introduced. The tests first examine the GOSUB and RETURN statements. Although no minimal depth of subroutine nesting is specified, one of the tests assumes the capability of handling at least four GosuB levels. There are also some exception tests associated with the GosuB capability. The next control structure introduced after the GosuB statement is the ON-GOTO statement. The main issue in this statement is whether the expression used after the $O N$ is rounded by the test system to the nearest integer rather than truncated. Severa! tests execute different cases for this statement type, including diagnostic and exception tests.

The final statement types tested in this volume allow insertion of data into a program either as a list or through an external media. The first of these is the DATA statement. Several issues are tested in these routines. For example not only does the READ statement have to assign the proper sequential datum to the READ 1 ist item but it must be able to detect whether the datum is compatible with the variable. String data can be specified in two ways. Each of these has to be examined. Such exceptions as whether there is insufficient or too much data have to be tested. Finally the 
RESTORE statement has to be tested in order to determine that the data list can be reread. Although the DATA statement is one way of entering data to a program, another way is by means of the INPUT statement that calls for interaction with an external data source. Again the tests not only had to test whether data could be entered but whether it was compatible with what the program assumes is being entered, whether there is too much or too little data being entered, or whether leading and trailing string spaces are accepted or ignored.

The last tests in this volume consider what happens when strings are too long to fit within the margin. The tests include ones to determine how the system handles the tabbing of a string beyond the margin. In general the system must determine how many margin widths fit within the number of spaces requested, skip that many 1 ines and then print the item in the appropriate column computed by a specified formula. The last test uses the INPUT capability to test the exception handling capability of the test system when string overflow is encountered. 


\subsection{THE FOR-NEXT STATEMENTS}

This unit tests several uses of the For-statement and the NEXT-statement. They provide for the construction of loops, if the following conditions are met: (1) the control variable is any simple numeric variable: and, (2) both FOR and NEXT have the same control variable. In the absence of the STEP clause, the increment is always +1 .

The sequence of statements from the FOR-statement and NEXT-statement forms a block referred to as the FoR-block. FOR-blocks can be nested lone can be contained within another), but they cannot be interleaved. All FOR-blocks are inactive at the initiation of a program but become active upon execution of the FOR-statement. It remains active until it is exited via its NEXT-statement, or until control is transferred to a For-statement (which may or may not be the one associated with that FOR-block) having the same control variable. However, control can exit a FoR-block via a control statement in which case the FOR-block should remain active. When exit from a FOR-block is via a NEXT-statement, the value of the control variable should be the first value not used. For the precise specifications a user is referred to section 11 of BSR $\times 3.60$.

\subsection{EOR/NEXT, Without a STEP Clause}

The objective of this subsection is to verify that in the absence of a STEP clause in a FOR-statement, the implementation will assume the increment to be +1 .

\subsubsection{Initial-Value and Limit Are Integers}

The objective here is to initiate the use of the For-statement by using integer values only.

\subsubsection{Different Initial and Limit Values}

In this test each loop of the FOR-block is counted, and the final value of the counter, $C$, determines whether the test passed or failed. There is also a variable, $T$, in the FOR-block that keeps a running total of the values assigned to the control variable, i.e. I in this case. On output there should be a message indicating whether the test failed or passed. If the test failed then the following message should be printed: TEST FAILED. If the test passed then the following message should be printed: TEST PASSED.

\subsubsection{Equal Initial and Limit Values}

This test shows that looping should not terminate until an increment causes the value of the control variable to exceed the value of the limit, unless there is an exit via a control statement. The actions of the c and the T variabies are the same as in section 34.1 .1 .1 and so is the output.

\subsubsection{Fractions Contained in the Limit}

The purpose of this test is to continue loop testing in the absence of the STEP clause increments, but using numbers in the control variable limits with fractional values. To have a limit containing a fraction with an integer initial value means that incrementing should cause the control variable to be either less than or greater than the limit, thus never 
reaching the limit in the absence of the STEP clause. The actions of the $C$ and the $T$ variables are the same as in test 34.1 .1 .1 , and so is the output.

\subsection{FOR/NEXT Using Step Clause}

The objective here is to use the STEP clause as a parameter in the FOR-statement.

\subsubsection{Using Fractional Increments}

This test verifies that the processor recognizes and, within machine accuracy considerations, will increment a loop control variable with a fractional step in the proper manner.

\subsubsection{For an Increasing Control Value}

The STEP clause for this test is a fraction while its other parameters are integers. The $C$ and $T$ variables are again used. The $T$ variable for this test is testing for added increments of +.5 , since +.5 is the value for the STEP clause in this test. The output for this test should be similar to the output in test 34.1 .1 .1 .

\subsubsection{For a Decreasing Control Value}

The object of this test is to show that looping of a FOR-block, when the initial value is to be decreased in value, should not terminate until the control variable has been assigned a value less than the value of the limit, unless there is an exit via a control statement. As in the previous test, $C$ and $T$ variables are used. The $T$ variable for this test is testing for added decrements of -.5 , since -.5 is the value for the STEP clause in this test. The output for this test should be the same as the output in test 34.1.1.1.

\subsubsection{Using Integer Increments}

The objective of this test is to use the STEP clause for increments where the assigned STEP parameters are integer valued.

\subsubsection{For Decreasing the Control Value}

This test shows some of the various ways in which the STEP clause can be used to decrease the value of the initial value to a desired limit value. The output for all tests below is similar to test 34.1 .1 .1 .

\subsection{Positive to Positive}

The object here is to test decreasing the control variable's value from a positive number to a smaller positive number. The value for the STEP clause in this test is -2 .

\subsection{Positive to Negative}

The object here is to test decreasing the initial value from a positive number to a negative number in step increments of -4 .

\subsection{Negative to Negative}


The object here is to test decreasing the initial-value from one negative number to another negative number in increments of -1 .

\subsubsection{For Increasing Control Variable}

This test is constructed to increase the control variable's value from one negative number to another negative number in increments of 2 .

\subsubsection{Fractions}

The object of this test is to show that the initial value is allowed to contain a fraction. The control variable will be stepped forward each time by +2 .

\subsection{Nesting FOR-Blocks, Three Deep}

The object of this test is to test that For-blocks can be nested to a depth of three. That is, three FoR-blocks can be active at one time.
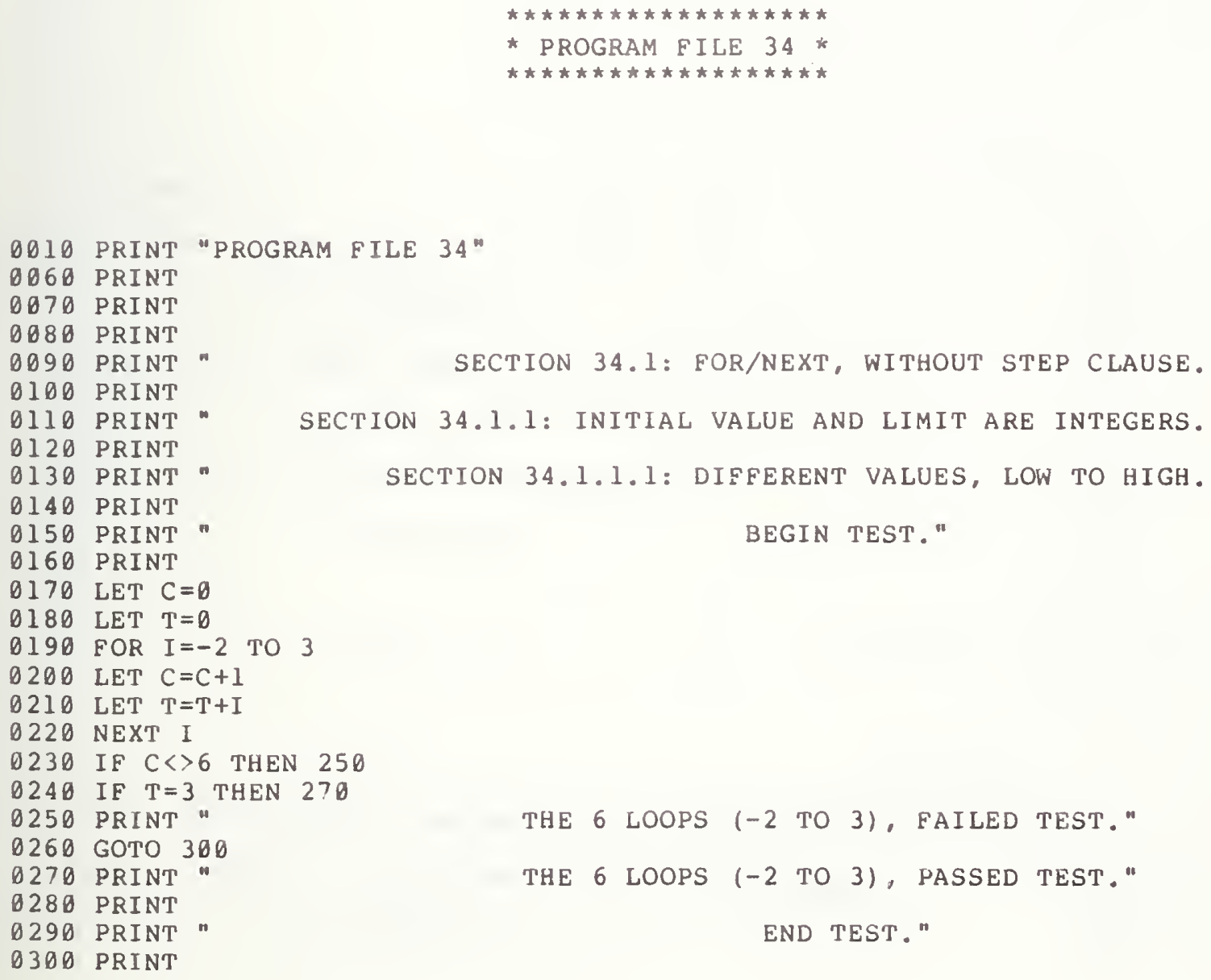


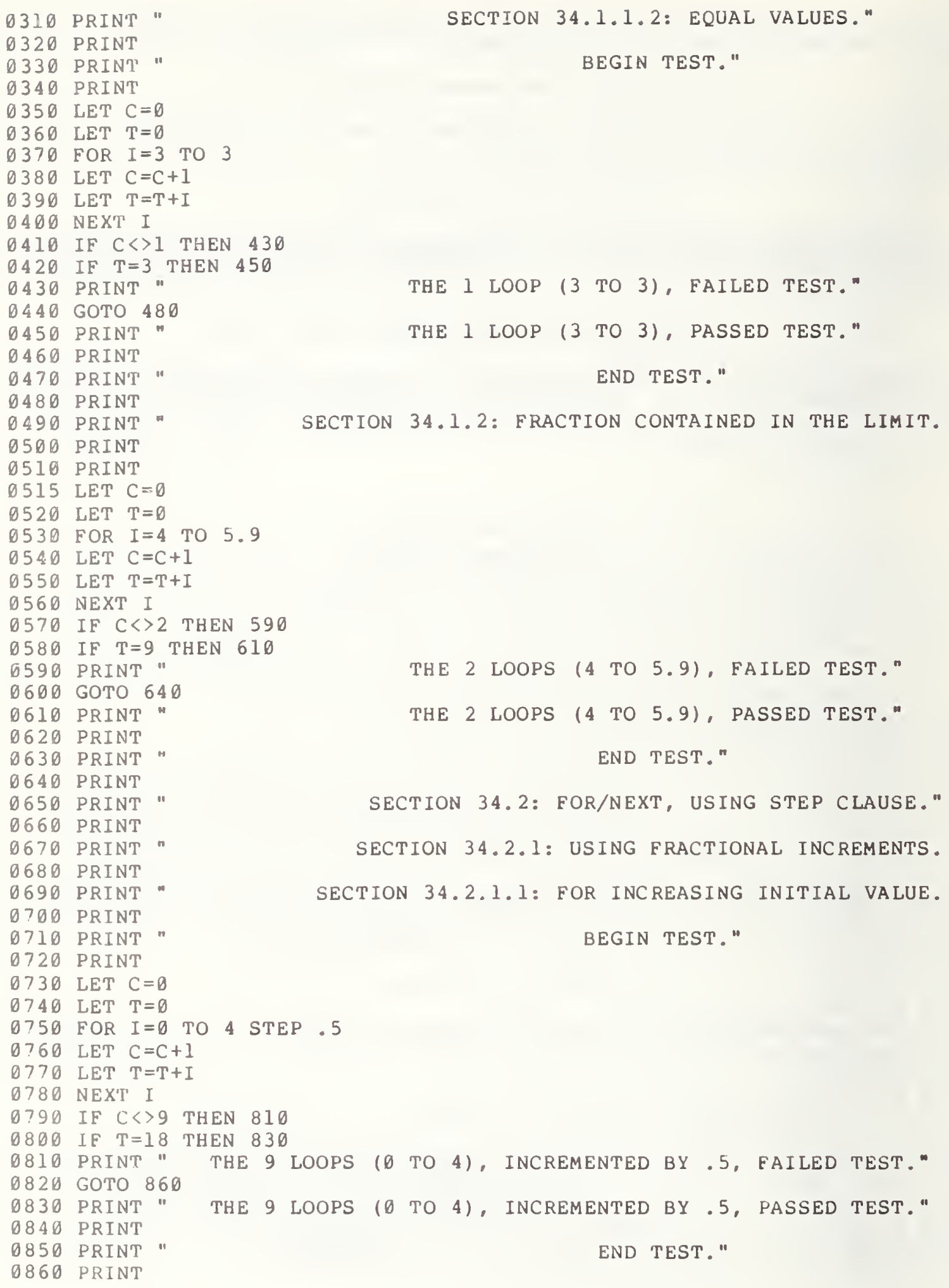




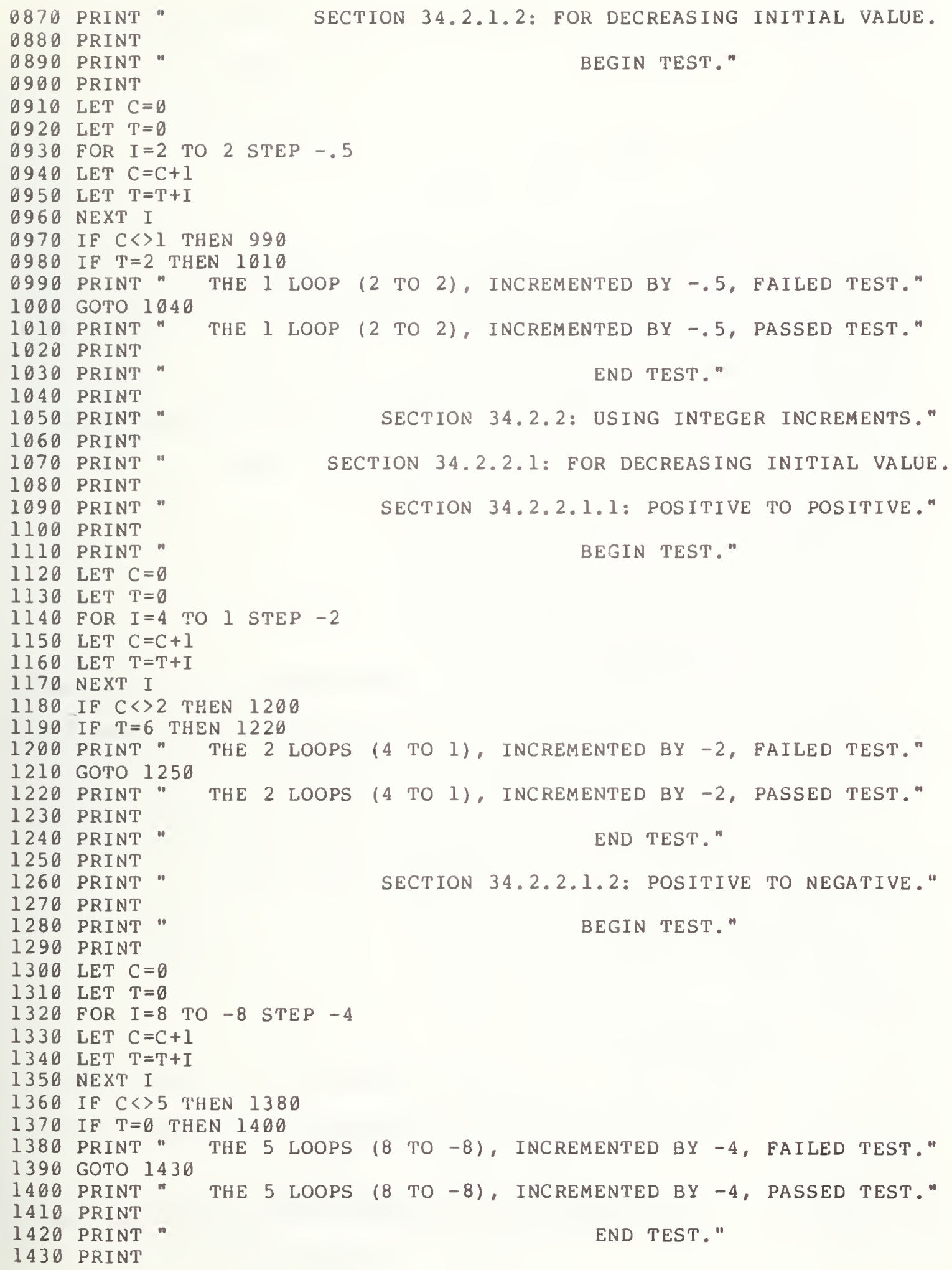




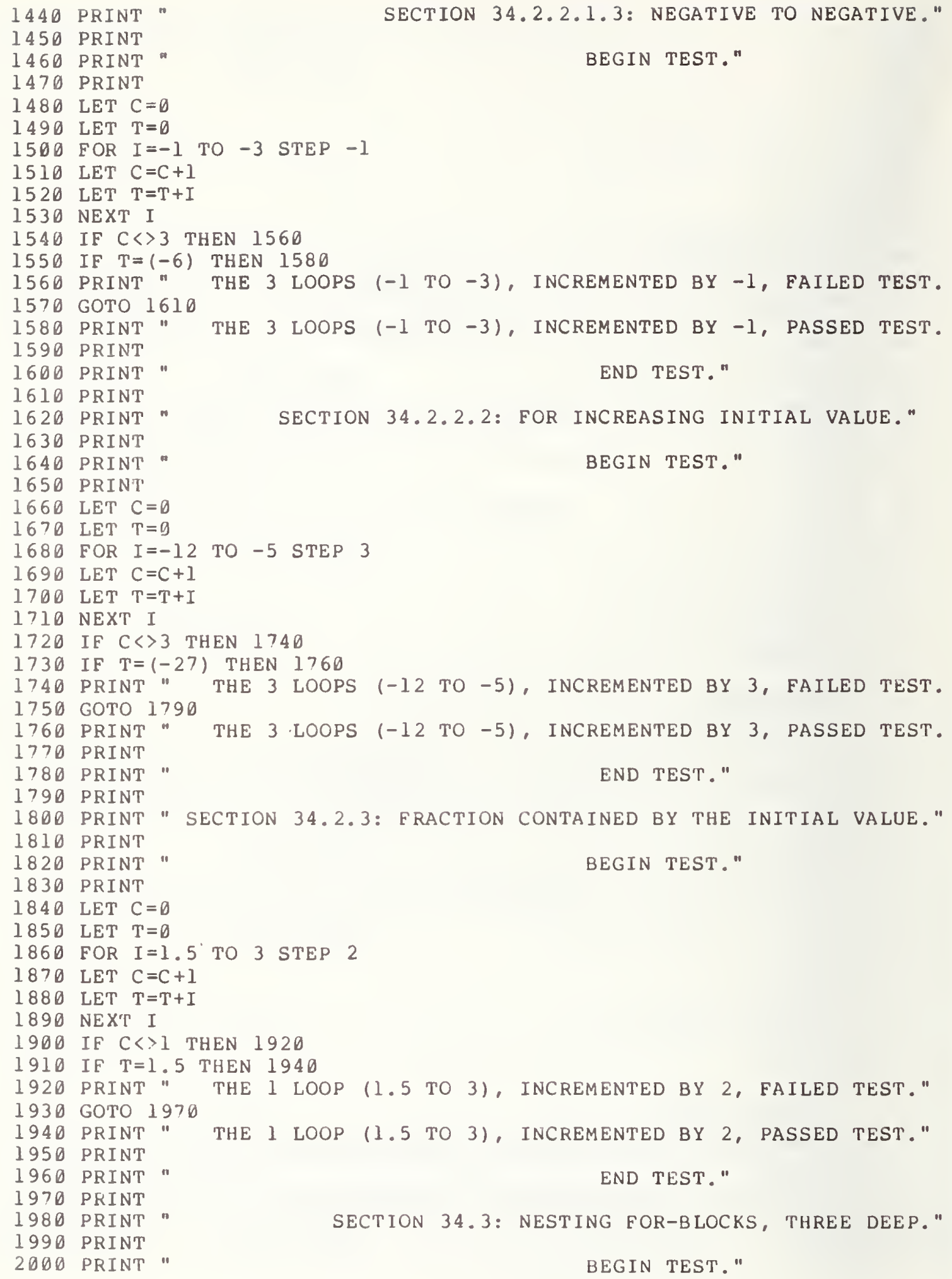




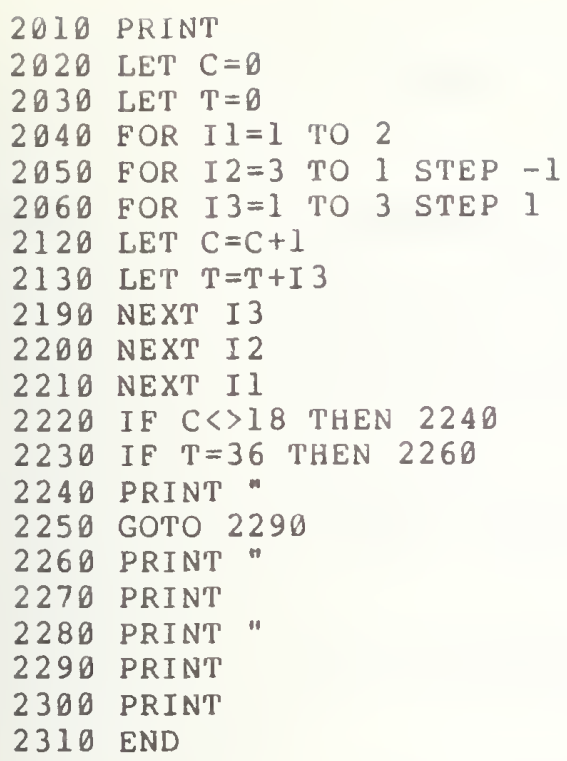

* SAMPLE OUTPUT *

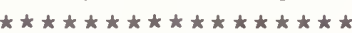

PROGRAM FILE 34

SECTION 34.1: FOR/NEXT, WITHOUT STEP CLAUSE. SECTION 34.1.1: INITIAL VALUE AND LIMIT ARE INTEGERS. SECTION 34.1.1.1: DIFFERENT VALUES, LOW TO HIGH. BEGIN TEST. THE 6 LOOPS (-2 TO 3), PASSED TEST. END TEST. SECTION 34.1.1.2: EQUAL VALUES. BEGIN TEST . THE 1 LOOP ( 3 TO 3), PASSED TEST. END TEST. 
SECTION 34.1.2: FRACTION CONTAINED IN THE LIMIT. THE 2 LOOPS (4 TO 5.9), PASSED TEST.

END TEST .

SECTION 34.2: FOR/NEXT, USING STEP CLAUSE. SECTION 34.2.1: USING FRACTIONAL INCREMENTS. SECTION 34.2.1.1: FOR INCREASING INITIAL VALUE. BEGIN TEST .

THE 9 LOOPS ( 0 TO 4 ), INCREMENTED BY .5, PASSED TEST. END TEST .

SECTION 34.2.1.2: FOR DECREASING INITIAL VALUE. BEGIN TEST.

THE 1 LOOP (2 TO 2), INCREMENTED BY -.5, PASSED TEST. END TEST. SECTION 34.2.2: USING INTEGER INCREMENTS. SECTION 34.2.2.1: FOR DECREASING INITIAL VALUE. SECTION 34.2.2.1.1: POSITIVE TO POSITIVE. BEGIN TEST .

THE 2 LOOPS (4 TO 1), INCREMENTED BY -2, PASSED TEST. END TEST . SECPION 34.2 .2 .1 .2 : POSITIVE TO NEGATIVE. BEGIN TEST .

THE 5 LOOPS ( 8 TO -8 ), INCREMENTED BY - 4, PASSED TEST. END TEST. SECTION 34.2.2.1.3: NEGATIVE TO NEGATIVE. BEGIN TEST.

THE 3 LOOPS (-1 TO -3$)$, INCREMENTED BY -1 , PASSED TEST. END TEST.

SECTION 34.2.2.2: FOR INCREASING INITIAL VALUE. BEGIN TEST . 
THE 3 LOOPS (-12 TO -5), INCREMENTED BY 3, PASSED TEST. END TEST.

SECTION 34.2.3: FRACTION CON'TAINED BY THE INITIAL VALUE. BEGIN TEST.

THE 1 LOOP (1.5 TO 3), INCREMENTED BY 2, PASSED TEST. END TEST.

SECTION 34.3: NESTING FOR-BLOCKS, THREE DEEP. BEGIN TEST.

3 NESTED LOOPS, PASSED TEST. END TEST. 


\subsection{EXITING FROM FOR-BLOCKS}

\subsection{FOR-Block Exiting Via Control Statement}

This routine tests exiting from a FOR-block via a control statement. In this routine the control statement is the IF-THEN-statement. Since the first FOR-block for this test does not exit naturally (via its NExT-statement), there should be only 11 loops performed and a $T$ variable sum of 30 . The output is similar to test 34.1 .1 .1 .

\subsection{Compatability Between Initial-Value, Limit, and STEP Clause}

This routine tests the compatibility between the initial value, the limit and the increment. There are two cases which determine this compatibility: (l) if the initial value is smaller than the limit, then the increment's value must be positive; and (2) if the initial value is larger than the limit, then the increment's value must be negative. If either case is violated, no looping in the FOR-block should be performed. In this test the initial value, the limit, and the increment are not compatible, therefore the number of loops should be zero. The output is similar to test 34.1.1.1.

\subsection{Normal Exit Via NEXT-Statement}

The object here is to test the value of the control variable upon exiting via the NEXT-statement. Its value should be the first value not used. For output refer to test 34.1 .1 .1 .

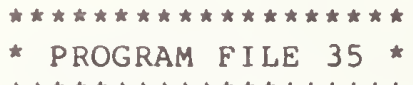

OOIO PRINT "PROGRAM FILE 35 "

0060 PRINT

0070 PRINT

๑080 PRINT

0090 PRINT "

0100 PRINT

0110 PRINT "

OI20 PRINT

0130 LET $C=0$

0140 LET $T=\emptyset$

0150 FOR $I=1$ TO 10

0160 LET $\mathrm{C}=\mathrm{C}+\mathrm{I}$

0170 LE'T $T=T+I$

0180 IF I=5 THEN 200

0190 NEXT I

Ø200 IF I $=5$ THEN 240

0210 PRINT " THE SYSTEM FAILED TO RETAIN THE INCREMENTED INITIAL" 
Q220 PRINT "VALUE VIA a CONTROL STATEMENT."

0230 GOTO 350

0240 FOR J=2 TO 4

0250 FOR $I=2$ TO 3

0260 LET $\mathrm{C}=\mathrm{C}+1$

0270 LET $\mathrm{T}=\mathrm{T}+\mathrm{I}$

0280 NEXT I

0290 NEXT J

0300 IF $C<>11$ THEN 320

0310 IF $\mathrm{T}=30$ THEN 340

0320 PRINT"

0330 GOTO 370

0340 PRINT"

0350 PRINT

Q 360 PRINT "

0370 PRINT

0380 PRINT " SECTION 35.2 COMPATIBILITy/INITIAL VALUE, Limit AND STEP." 0390 PRINT

0400 PRINT

BEGIN TEST."

0410 PRINT

0420 LET $C=0$

(1430 FOR I=4 TO 2 STEP I

0440 LET $\mathrm{C}=\mathrm{C}+1$

0450 NEXT I

0460 IF $C=0$ THEN 490

0470 PRINT "THE SKIPPING OF (4 TO 2), INCREMENTED BY 1, FAILED TEST." 0480 GOTO 520

0490 PRINT " THE SKIPPING OF (4 TO 2), INCREMENTED BY 1, PASSED TEST."

0500 PRINT

0510 PRINT

END TEST."

0520 PRINT

0530 PRINT

0540 PRINT

0550 PRINT "

THE 11 LOOPS (EXIT VIA IF/THEN), FAILED TEST."

THE 11 LOOPS (EXIT VIA IF/THEN), PASSED TEST."

0560 PRINT

0570 LET $C=0$

0580 FOR $I=1$ TO 6

0590 LET $C=C+1$

0600 NEXT I

0610 IF $C<>6$ THEN 630

0620 IF I=? THEN 650

0630 PRint "CONTRol Value of 7 (EXIT Via next-STatement), Eailed test." 0640 GOTO 680

0650 PRINT "CONTROL VALUe OF 7 (EXIT VIA NEXT-STATEMENT), PASSEd TEST." 0660 PRINT

0670 PRINT *

END TEST."

0680 PRINT

0690 PRINT

0700 END

SECTION 35.3: NORMAL EXIT VIA NEXT-STATEMENT." BEGIN TEST." 
PROGRAM FILE 35

SECTION 35.1: FOR-BLOCK EXITING VIA CONTROL STATEMENT. BEGIN TEST .

THE 11 LOOPS (EXIT VIA IF/THEN), PASSED TEST. END TEST.

SECTION 35.2 COMPATIBILITy/INITIAL VALUE, LIMIT AND STEP. BEGIN TEST 。

THE SKIPPING OF ( 4 TO 2), INCREMENTED BY 1 , PASSED TEST. END TEST. SECTION 35.3: NORMAL EXIT VIA NEXT-STATEMENT. BEGIN TEST .

CONTROL VAlue of 7 (EXIt ViA neXt-STATEMENT), PASSED TEST. END TEST. 


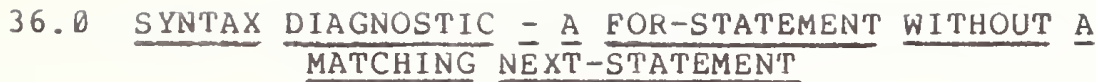

This routine and the next two perform tests on the FOR-NEXT statement which should be diagnosed as errors. These are specifically constructed to demonstrate the diagnostic capability of the language processor. Although no exceptions have been specified with regard to FOR-NEXT statements the situations tested here are considered significant and require a processor to report the error.

The objective of this test is to verify that the execution of a FOR-statement without a matching NEXT-statement will be recognized as a syntactic error. This error must be recognized and reported. It should result in the execution of the program being suspended. There should be some form of imp! ?mentation-defined diagnostic on output.

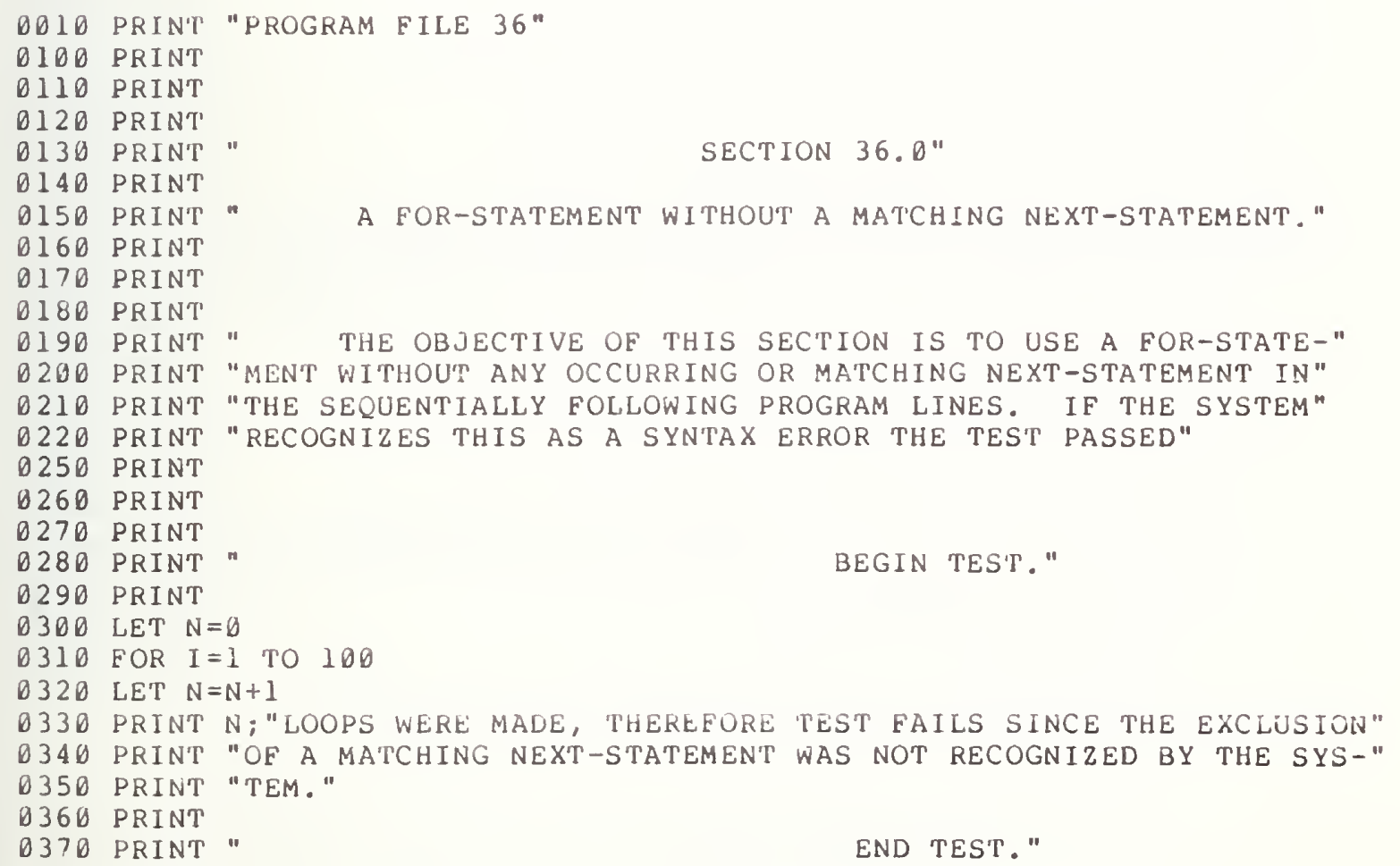

END TEST."

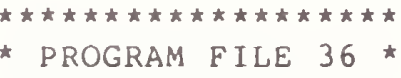

$\star \star t * t+t+t * t * t+t+t *$

0380 PRINT

0390 END 


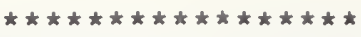

* SAMPLE OUTPUT *

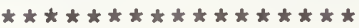

In order for this test to pass, an error must be diagnosed and reported. For example, a possible error diagnostic for this program might be:

? FOR WITHOUT NEXT IN LINE 310 


\section{SYNTAX DIAGNOSTIC - A NEXT-STATEMENT WITHOUT A MATCHING $\overline{\text { FOR }} \overline{\text { STATEMENT }}$}

The objective of this test is to verify that upon the execution of a program, which contains a NEXT-statement but no matching FoR-statement, the implementation will report a diagnosed error. The test is specifically constructed without a matching FOR-statement for the NEXT-statement in statement 260 of Program File 37. On output, there should be an implementation-specific diagnostic, but it should point to the fact that the NEXT-statement has no associated FOR-statement.

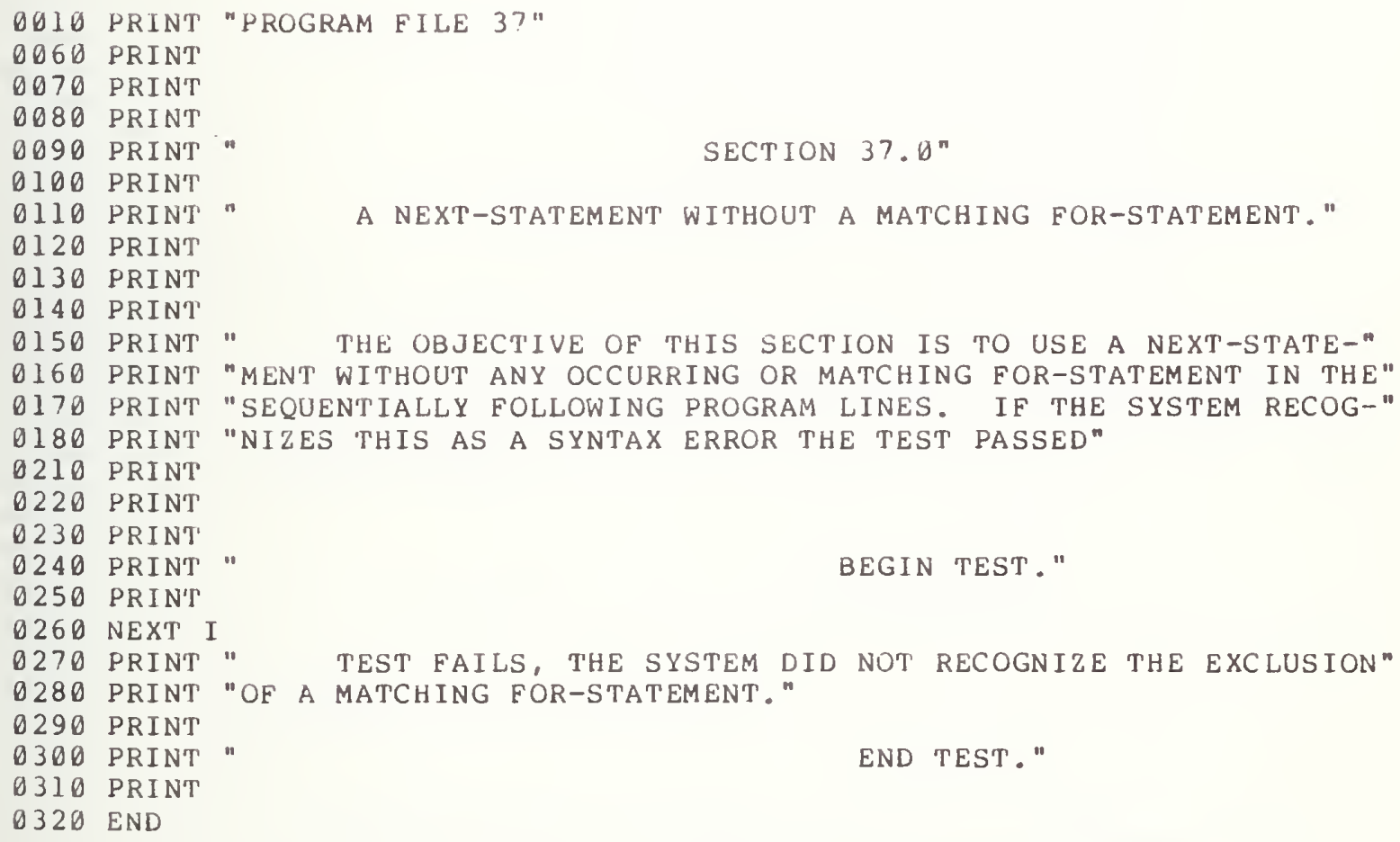

BEGIN TEST."

END TEST." 


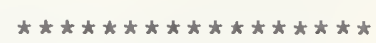

A fatal error diagnostic is required as output. Again, the exact diagnostic is implementation specific, but a possible message might be:

? NEXT WITHOUT FOR IN LINE 260 


\subsection{SEMANTIC ERROR = THE INTERLEAVING OF TWO FOR-BLOCKS}

The objective of this test is to verify that upon the execution of a program which contains two For-blocks that are interleaved--i.e... a NEXT-statement is matched with a FOR-statement with a different control variable-- the implementation will diagnose and report an error. The test contains two FOR-blocks that are interleaved by associating FoR-statements at lines 270 and 280 with NEXT-statements at 1 ines 300 and 310 respectively in Program File 38. On output, there should be an implementation-specific diagnostic.

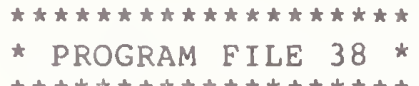

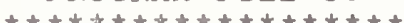

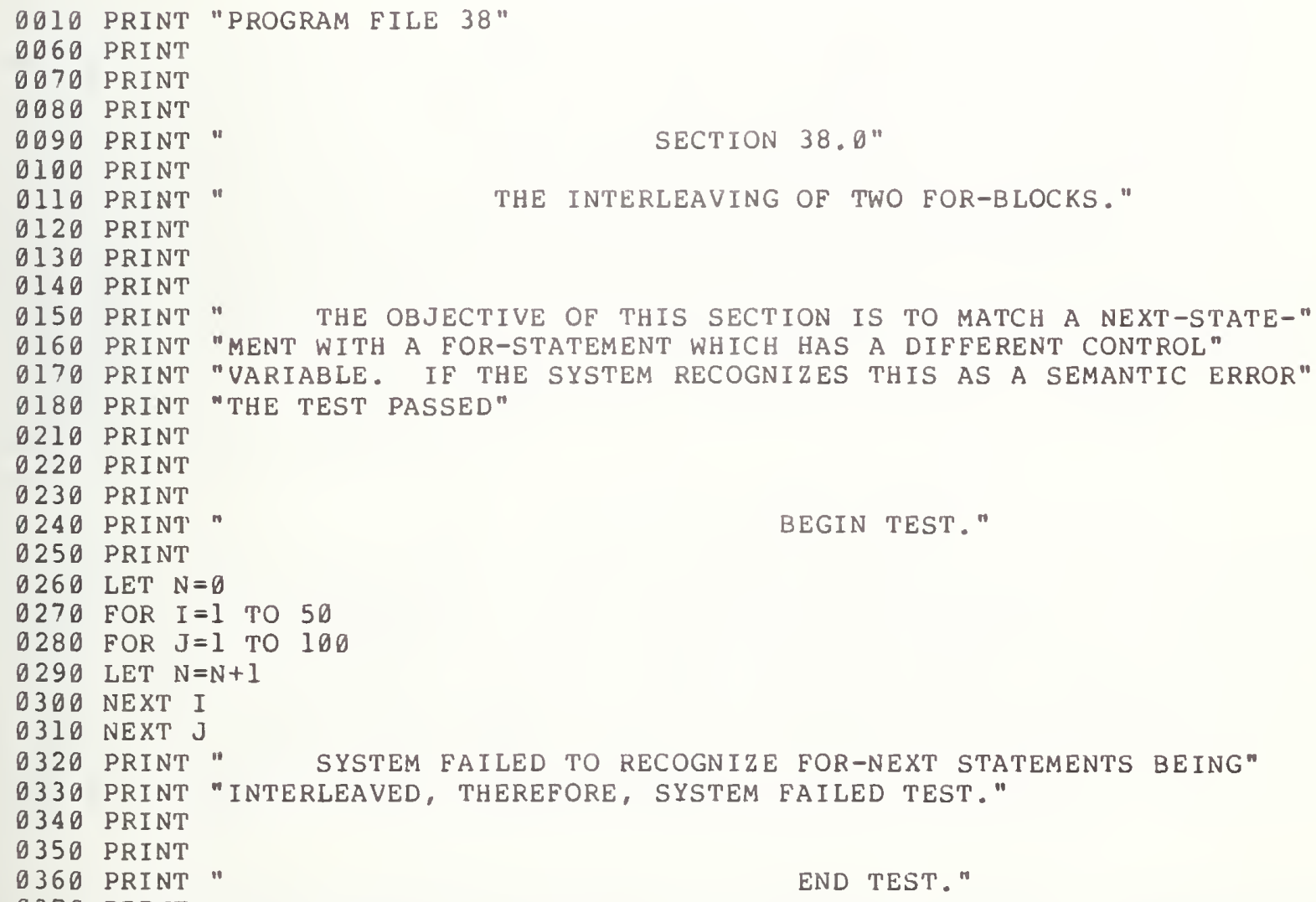

0370 PRINT

0380 END 
Again, as in the past two error tests, the system fails if there is no diagnostic given. The following two diagnostic messages are not necessarily ideal, but as a combination do indicate the problem source:

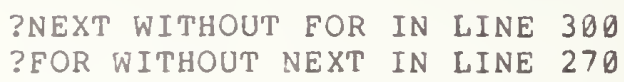

The point of these messages is that the system is not looking for an associated FOR-statement in a higher level block or for a NEXT-statement in a lower level block. 


\section{0 INTRODUCING THE DIMENSION STATEMENT}

The tests in the next several sections are for the dimension-statemerit which reserves space for arrays, that can be either one or two dimensional. If a dimension-statement is not used to allocate storage, then a default space allocation is made. In section 39.1 this default will be tested. The default means that unless declared otherwise in a dimension-statement, all array subscripts have a lower bound of zero and a upper bound of ten. Therefore, under default there should be space reserved for 11 elements in one-dimensional arrays and 121 elements in two-dimensional arrays. But, by use of a dimension-statement, the subscript(s) of an array may be declared to have an upper bound other than ten, and by use of the OPTION-statement, the subscripts of all arrays may be declared to have a lower bound of either one or zero. The reader is referred to section 15 on array declaration in BSR X3.60 for the specification.

\subsection{Implicit Dimensioning}

The object here is to verify that implementations recognize default space allocations for arrays.

\subsubsection{One-Dimensional Arrays}

The object is to test the default space allocation for one-dirnensional arrays. In this case, space should be reserved for 11 elements. In the first part of the test, the subscripted variables $A(\theta), A(1), A(2), \ldots$ $A(10)$ of the implicit dimensional array $A(I)$ are assigned the values $0,1,2$. ... 10 respectively. In the second part, there is a check made on the assignment of the eleven elements to the array $A(I)$. This is done by the use of a counter, C, and the total sum. Al, of the eleven elements. There should be a count of eleven array elements and the sum of the elements should be 55 . On output there should be a message to the following effect, if the test failed: IMPLICIT SINGLE DIMENSIONING TEST, FAILED. If the test passed, then the following message should be printed: IMPLICIT SINGLE DIMENSIONING TEST, PASSED. Another failure of the test could occur if a system diagnostic indicated that an array element could not be accessed. If in fact tne system indicates failure to dimension an array, then the system entirely fails implicit single dimensioning.

\subsubsection{Two-Dimensional Arrays}

The object is to test the default space allocation for two-dimensional arrays. Space should be reserved for 121 elements. In the first part of this test the subscripted variables $B(\theta, \theta), B(\theta, 1), B(\theta, 2), \ldots, B(1 \theta, 10)$ of the implicit dimensioned array $B(I, J)$ are assigned the sum $I+J$. In the second part of the test, a check is made on whether space was reserved for the 121 elements of array $B(I, J)$. This is accomplished through the use of a counter, $C$. The counter keeps track of the number of loops performed by a FOR-block, while the sum of all elements stored in array B(I,J) is computed. The final count for this test should be l2l and the sum of the elements should be 1210 .

On output, there should be one of two messages printed. If the test fails, then the following message should be printed: IMPLICIT DOUBLE DIMENSIONING TEST. FAILED. If the test passes then the following message should be printed: IMPLICIT DOUBLE DIMENSIONING TEST, PASSED. 


\subsection{The Dimension-Statement Without the OPTION-Statement}

The object of this test is to verify that the implementation recognizes array declarations by the dimension-statement for both one- and two-dimensional arrays.

\subsubsection{Used With One-Dimensional Arrays}

The object of this test is to verify that, by use of the dimension-statement, an array can be declared to have an upper bound greater than 10. It would still retain its lower bound of zero. In the first part of the test, the subscripted variables $D(\theta), D(1), D(2), \ldots, D(20)$ of array $D(I)$ are assigned the values of $1,2,3, \ldots, 21$, respectively. In the second part of this test, the array allocation of 21 elements for $D(I)$ is accessed in order to verify the previous assignment. This is accomplished by use of a loop counter, $C$ and a total sum variable, Dl. The number of loop counts for this test should be 21 , and the sum of the array elements should be 231 .

If the test fails, then the following message should be printed: USE OF DIM FOR SINGLE DIMENSIONING, FAILED TEST. If the test passes, then the following message should be printed: USE OF DIM FOR SINGLE DIMENSIONING, PASSED TEST.

\subsubsection{Used With Two-Dimensional Arrays}

The object of this test is to verify that, by use of the dimension-statement, two-dimensional arrays can be declared to have upper bounds greater than 10 for each dimension. This is accomplished in three steps. In step one, the first subscript upper bound dimensioned greater than 10 for array $N(I, J)$ while the second subscript remains less than 10 . The subscripted variable $N(I, I)$ is assigned the value $I+1$. The subscripted variables $N(0,2), N(1,2), N(2,2), \ldots, N(20,2)$ are each assigned the negative value of the first integer of their respective pair of subscripted integers. Finally $N(I, \theta)$ is assigned the value 1 . As a check on the space allocation for each element of array $N(20,2)$, all members of the array are added and the value should be 42. In the second step, an array $P(2,20)$ is dimensioned. The first subscript of the array $P(I, J)$ remains less than 10 while the second subscript is allowed to be greater than 10. The subscripted variables $P(1,0), P(1,1), P(1,2), \ldots, P(2,20)$ are each assigned a value equal to the product of the subscripts. As a verification of the space allocation, all members of the array $P(2,20)$ are added to each other and their sum should be 630. In the third dimensioning, both the first and second subscripts of the array $R(I, J)$ are simultaneously allowed to have upper bounds greater than 10 . For this part of the test, each array element $R(I, J)$ is assigned the sum $I+J$. The total sum of all the array elements $R(I, J)$ should be 8820 .

On output, there should be one of two possible messages. If the test fails then the following message should be printed: DIM FOR DOUBLE DIMENSIONING, EAILED TEST. If the test passes the following message should be printed: DIM FOR DOUBLE DIMENSIONING, PASSED TEST. 


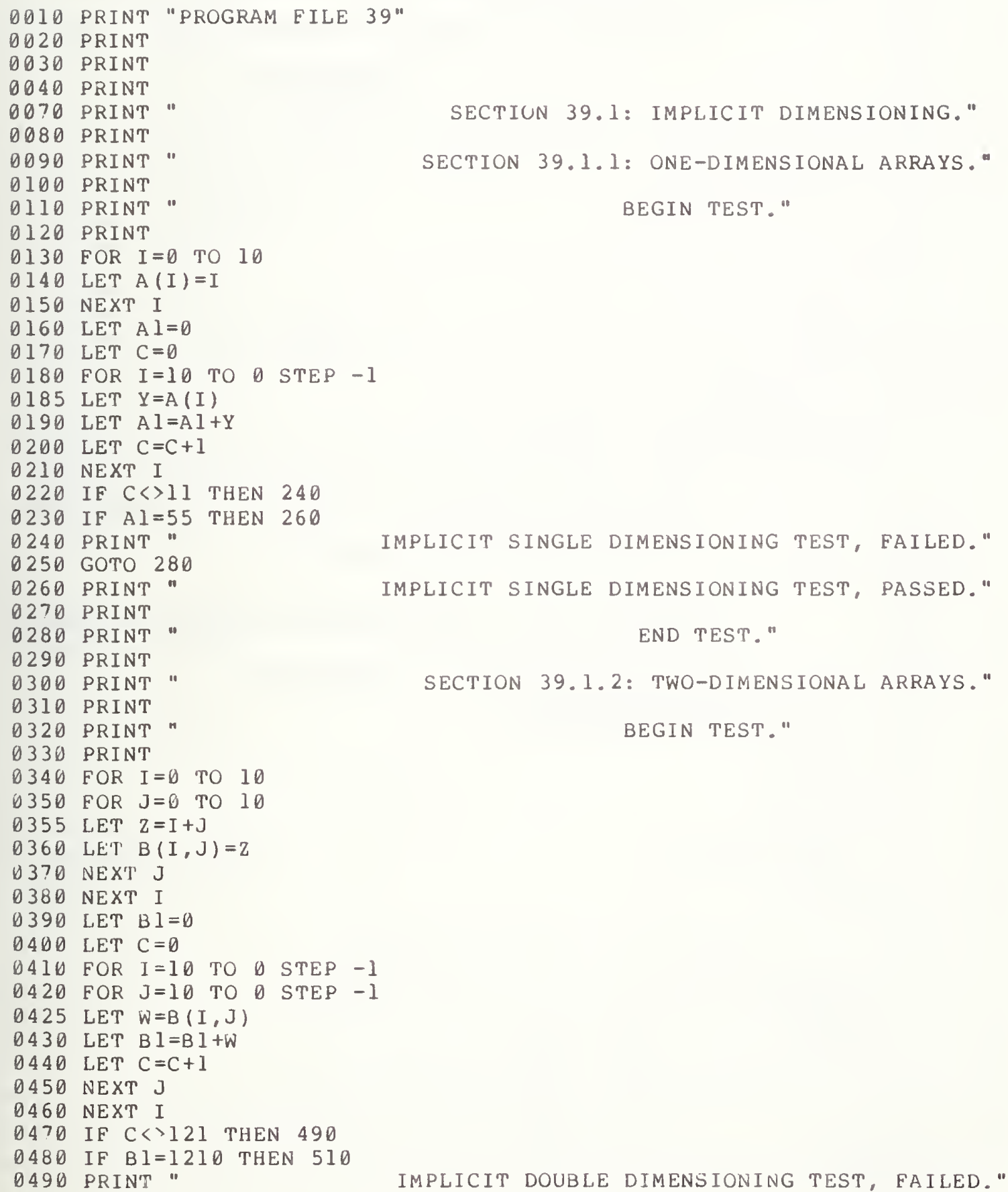




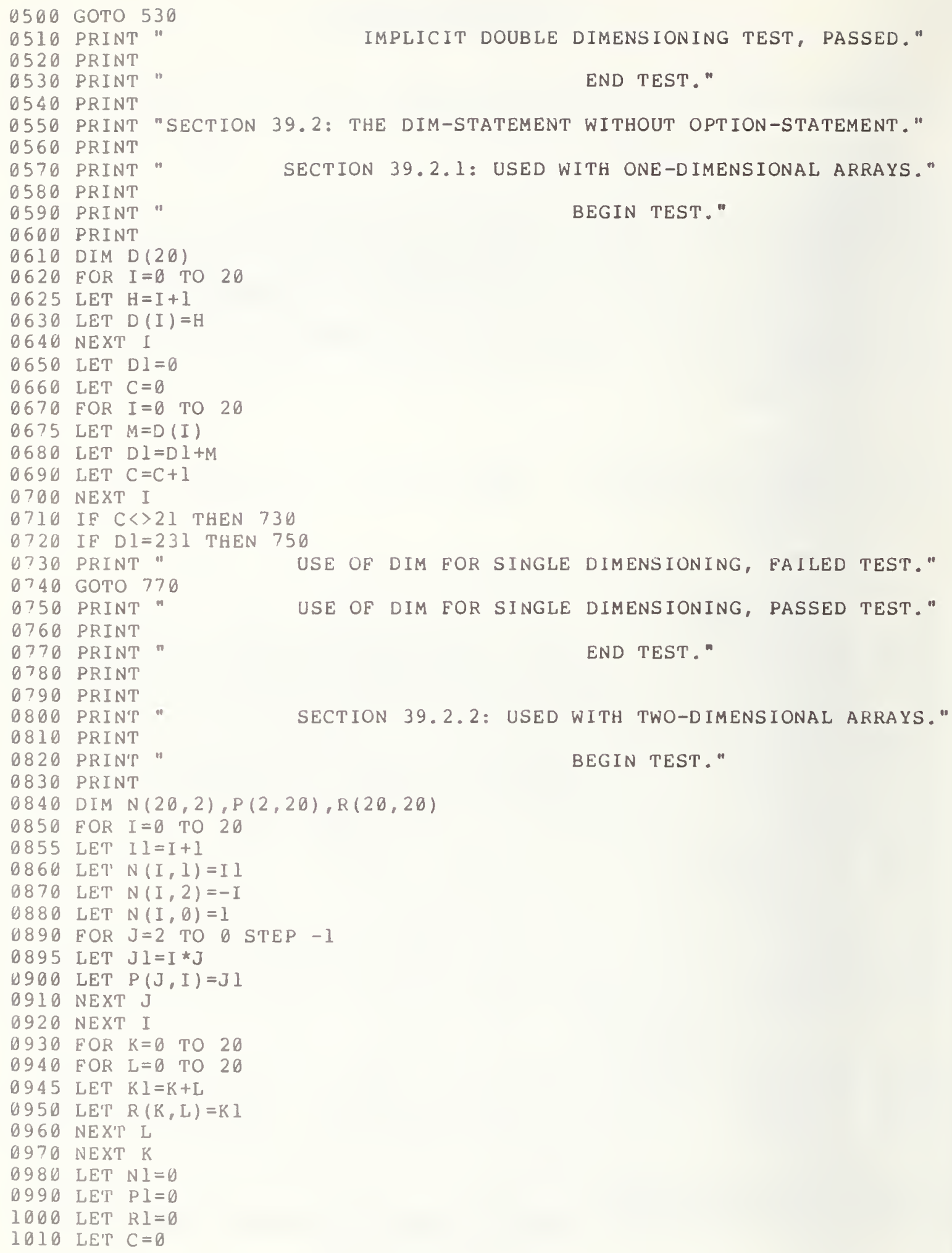




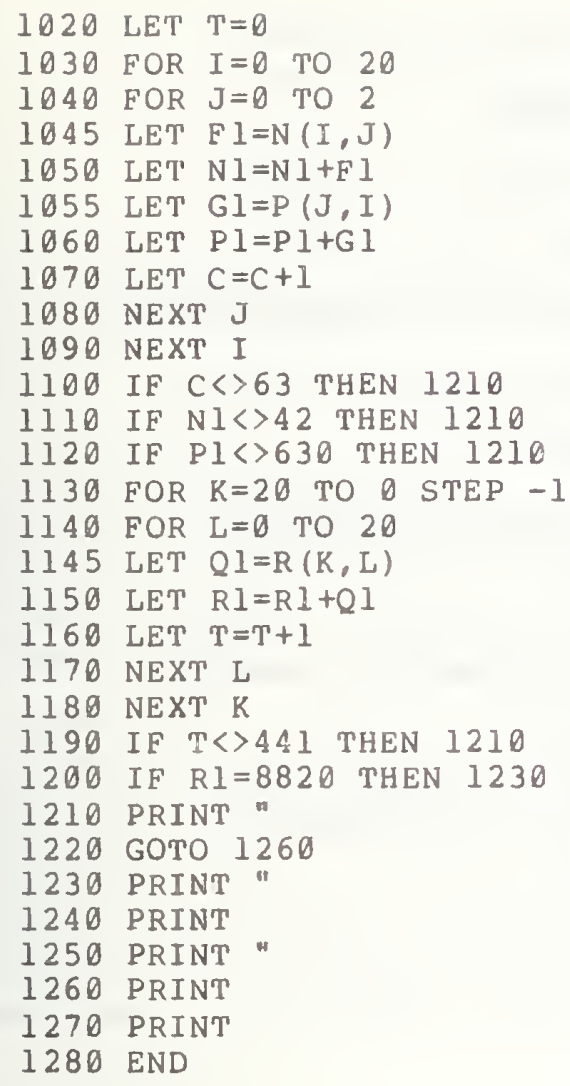

DIM FOR DOUBLE DIMENSIONING, FAILED TEST." DIM FOR DOUBLE DIMENSIONING, PASSED TEST." END TEST."

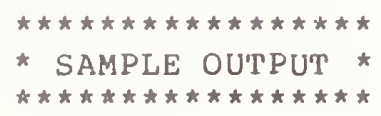

PROGRAM FILE 39

SECTION 39.1: IMPLICIT DIMENSIONING.

SECTION 39.1.1: ONE-DIMENSIONAL ARRAYS.

BEGIN TEST.

IMPLICIT SINGLE DIMENSIONING TEST, PASSED.

END TEST. 
SECTION 39.1.2: TWO-DIMENSIONAL ARRAYS.

BEGIN TEST.

IMPLICIT DOUBLE DIMENSIONING TEST, PASSED.

END TEST.

SECTION 39.2: THE DIM-STATEMENT WITHOUT AN OPTION-STATEMENT. SECTION 39.2.1: USED WITH ONE-DIMENSIONAL ARRAYS. BEGIN TEST.

USE OF DIM FOR SINGLE DIMENSIONING, PASSED TEST. END TEST.

SECTION 39.2.2: USED WITH TWO-DIMENSIONAL ARRAYS. BEGIN TEST.

DIM FOR DOUBLE DIMENSIONING, PASSED TEST. END TEST. 


\subsection{EXTENDING IF-THEN CAPABILITIES BY USING ONE-DIMENSIONAL ARRAYS IN THE COMPA RISON}

Since subscripted variables have already been introduced in previous tests, they are now added to the list of possible numeric expressions that can be compared in an IF-THEN-statement. The objectve of the next two test programs is to extend the IF-THEN-statement capability by using subscripted variables.

This section will concentrate on testing relation operations between single dimensioned arrays, simple variables and constants. The first comparisons made are between elements of the same array. Next, an array element is compared with a variable on the left of the relational operator and then the test is reversed. Finally, an element of the array is compared against a constant. There is a two column output of which the first heading is "Comparisons", and the second heading is "Results of IF-THEN Comparisons".

The first column of output 1 ists the numerical values that are being compared for each of the relations. The next six columns form a table containing the six relation symbols $=,\langle\rangle,\langle\rangle,\rangle=$, and $<=$. This table should appear blank (or empty), unless an error was made in a relation comparison, in which case an asterisk should appear in the column of the relational symbol for which the comparison was not evaluated properly. For example, if two numbers are equal, then a comparison should be correctly evaluated as false and the correct transfer made. Otherwise, an asterisk would appear in the table under the < column.

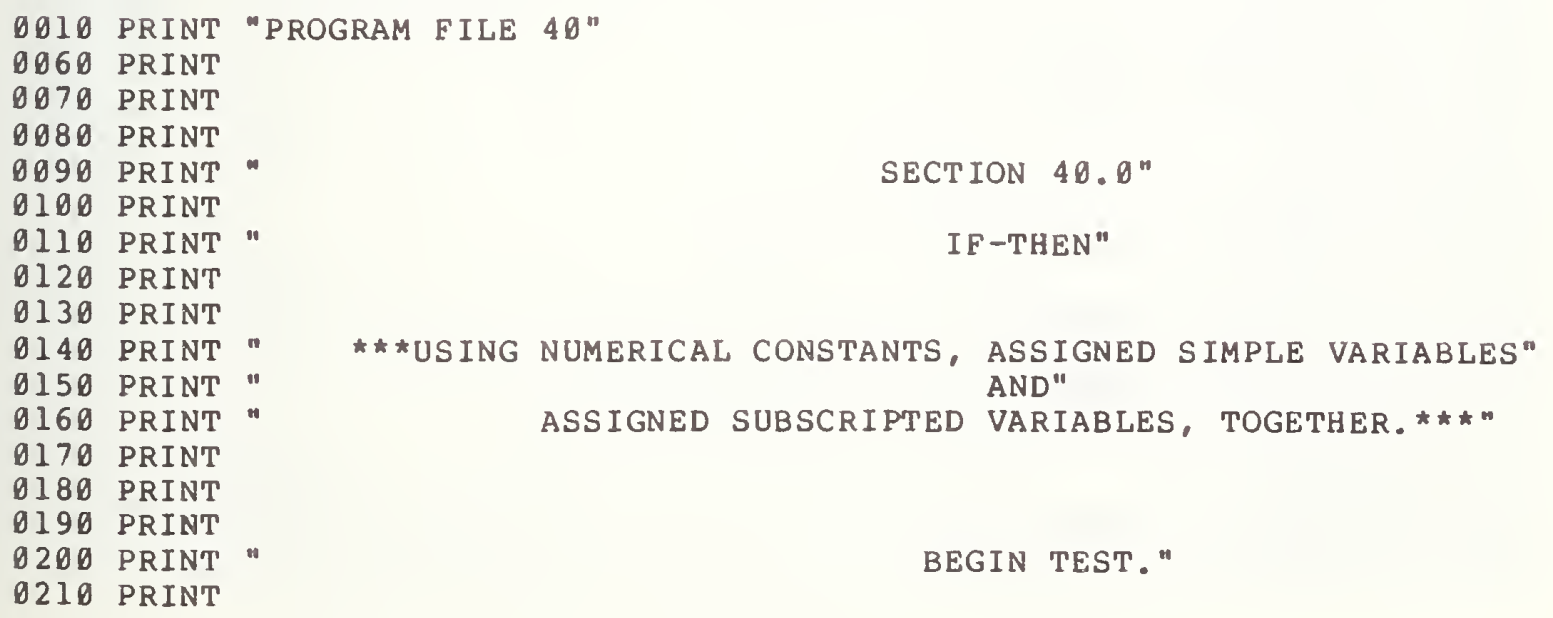




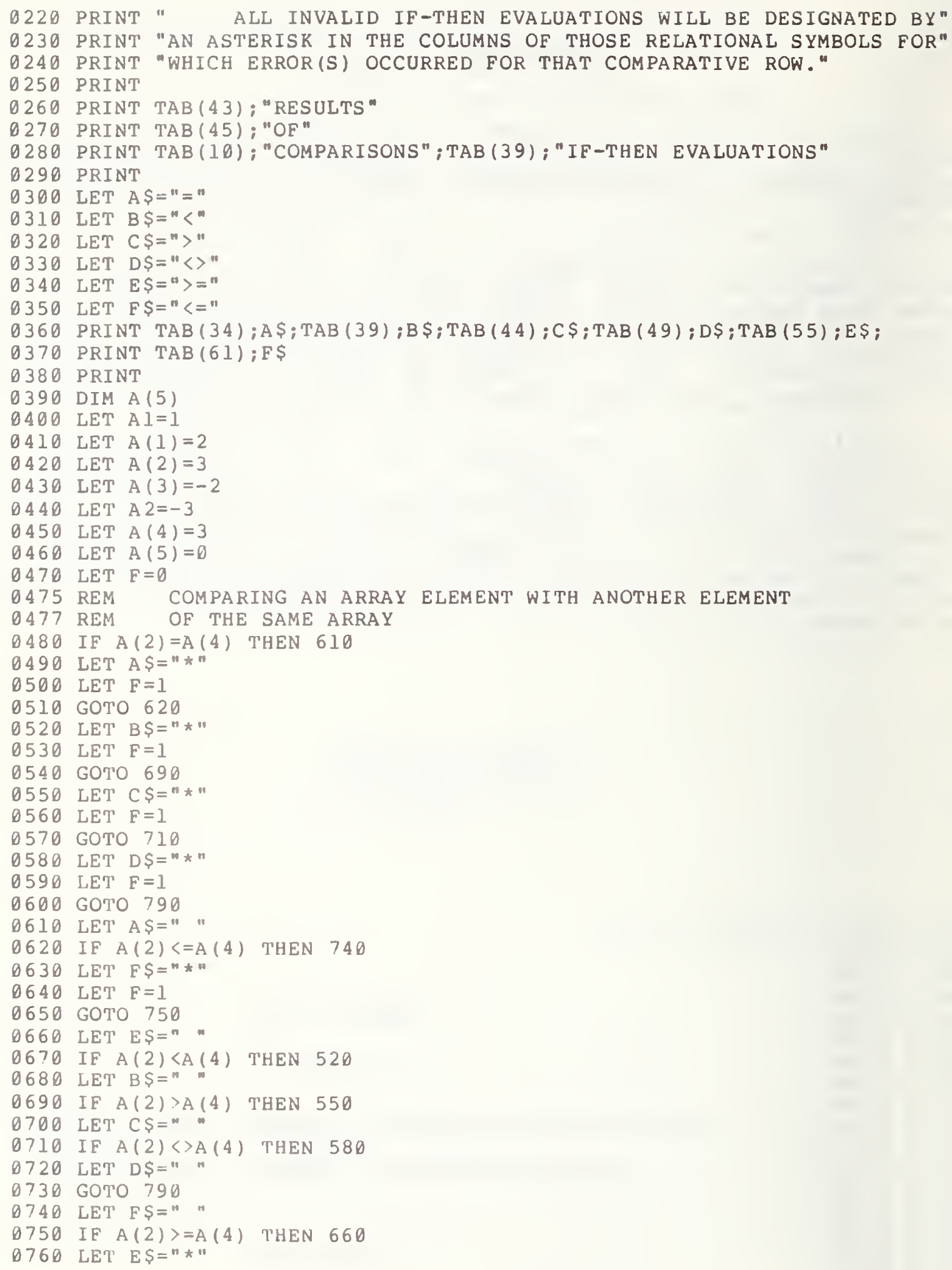




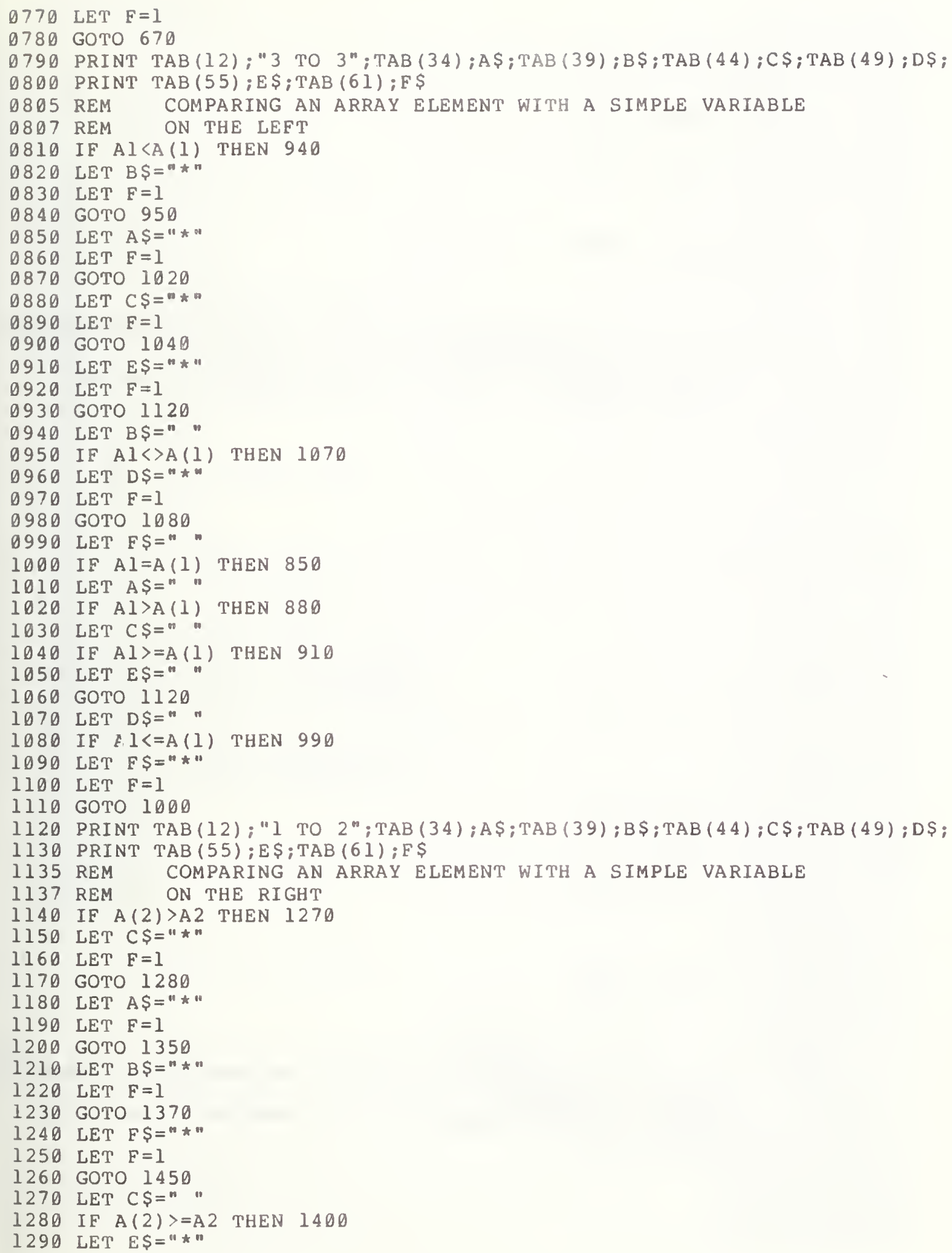




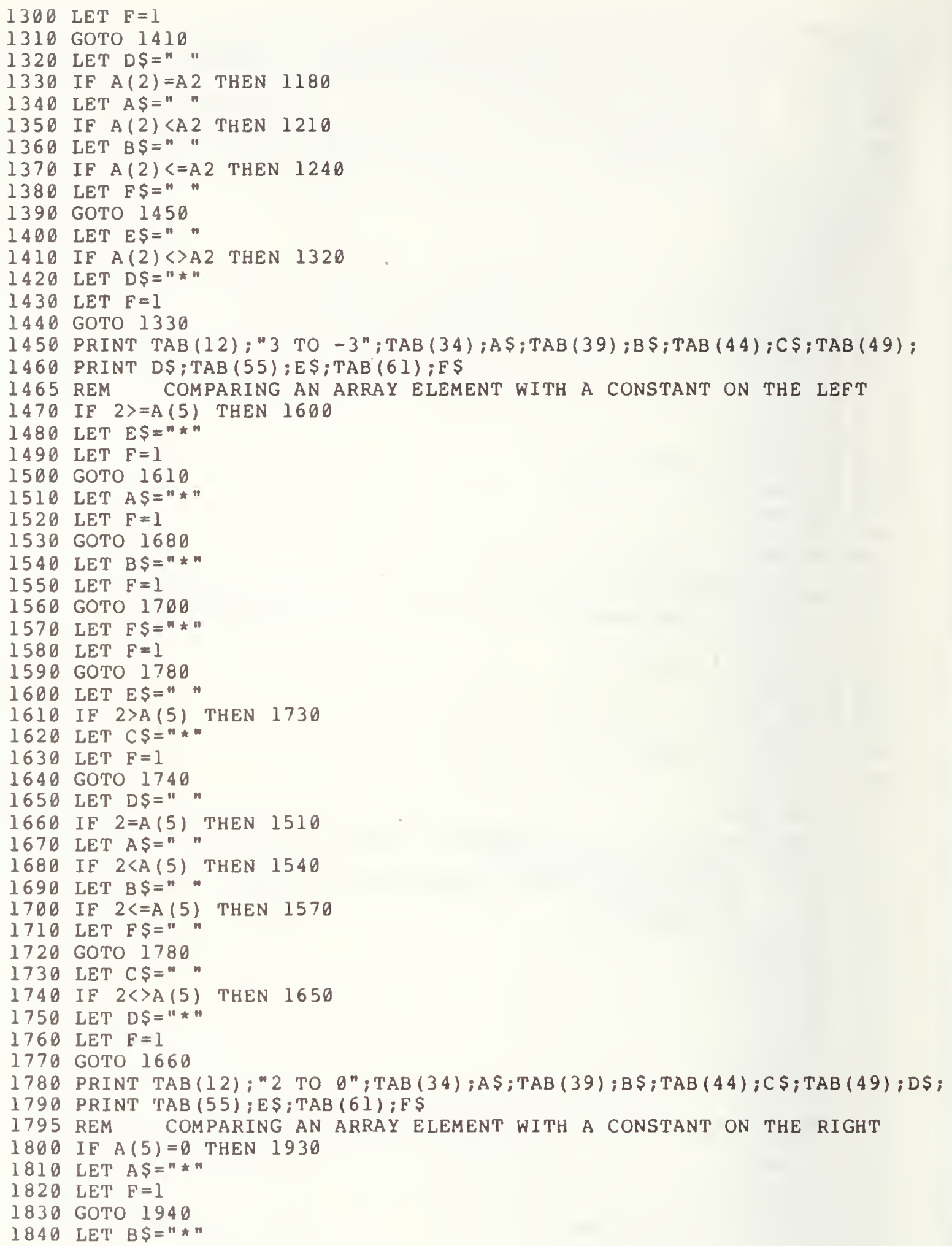




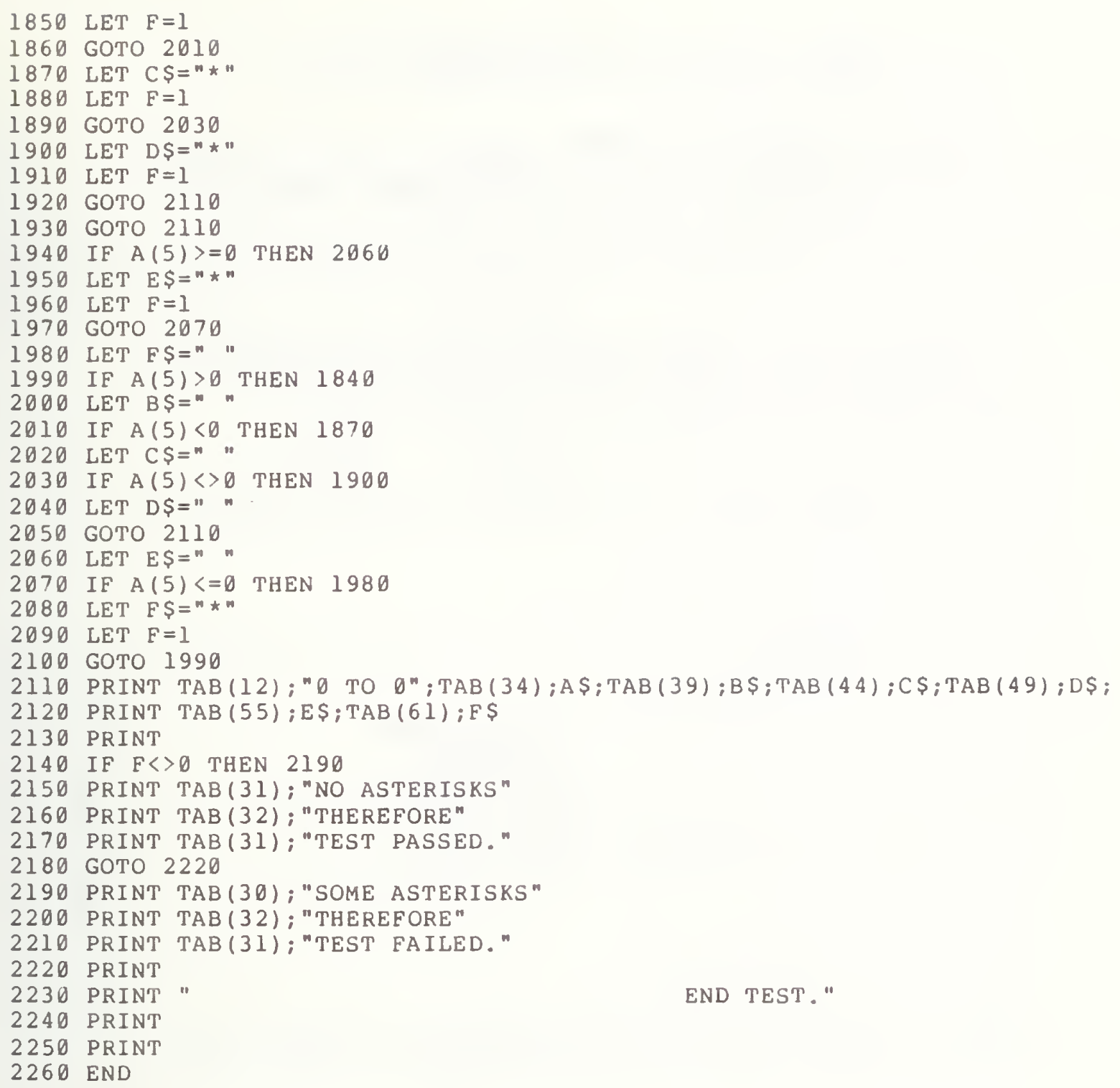

PROGRAM FILE 40 


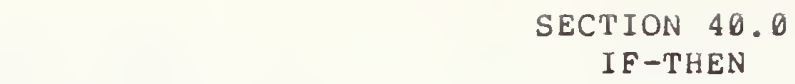

**\#USING NUMERICAL CONSTANTS, ASSIGNED SIMPLE VARIABLES AND ASSIGNED SUBSCRIPTED VARIABLES, TOGETHER, * * *

\section{BEGIN TEST.}

ALL INVALID IF-THEN EVALUATIONS WILL BE DESIGNATED BY AN ASTERISK IN THE COLUMNS OF THOSE RELATIONAL SYMBOLS FOR WHICH ERROR(S) OCCURRED FOR THAT COMPARATIVE ROW.

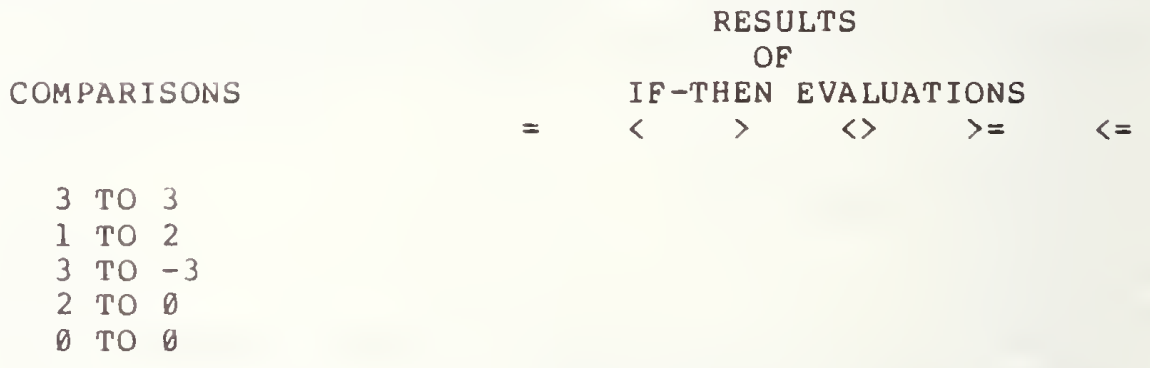

NO ASTERISKS

THEREFORE

TEST PASSED.

END TEST. 


\subsection{EXTENDING IF-THEN CAPABILITIES BY USING TWO-DIMENSIONAL ARRAYS IN THE COMPARISON}

The program below is nearly parallel in structure to that in section 40.0. The output format is also much the same. This test program, however, exercises the use of a two dimensioned array in the comparison expression. It begins by comparing a two-dimensional array element with itself, then with a constant, thirdly with array elements from another doubly dimensioned array, fourthly with simple variables, and finally with array elements from a singly dimensioned array.

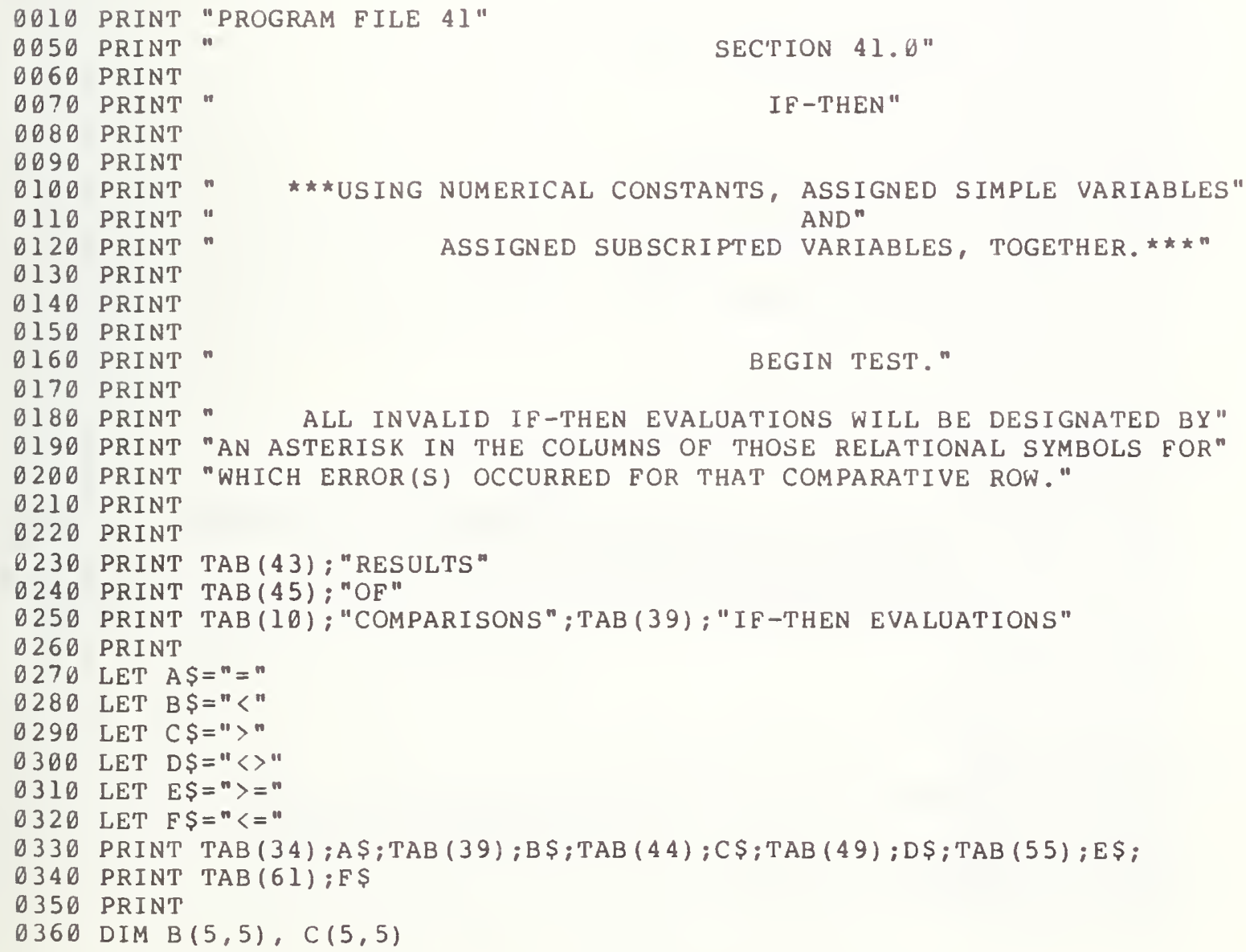




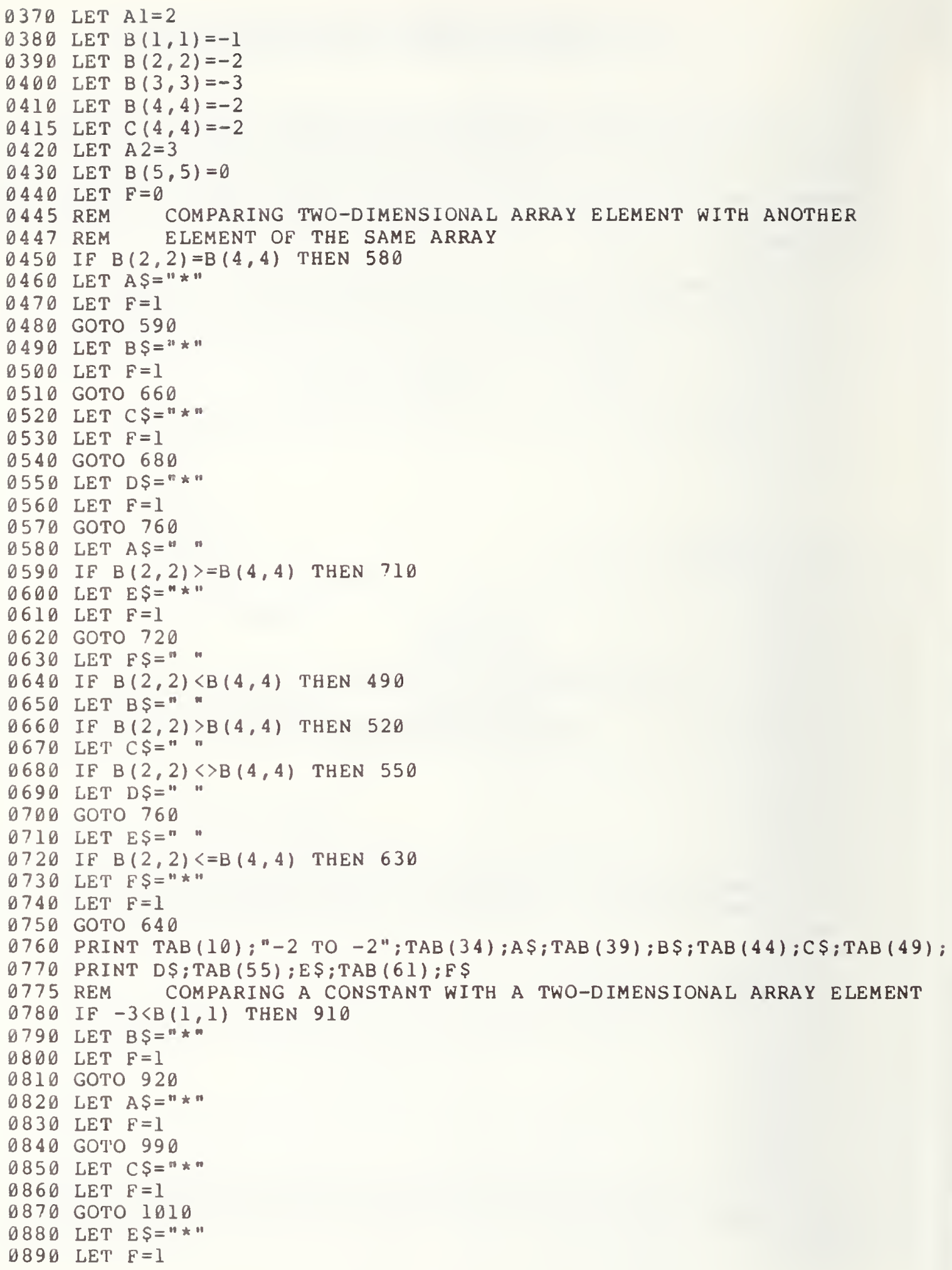




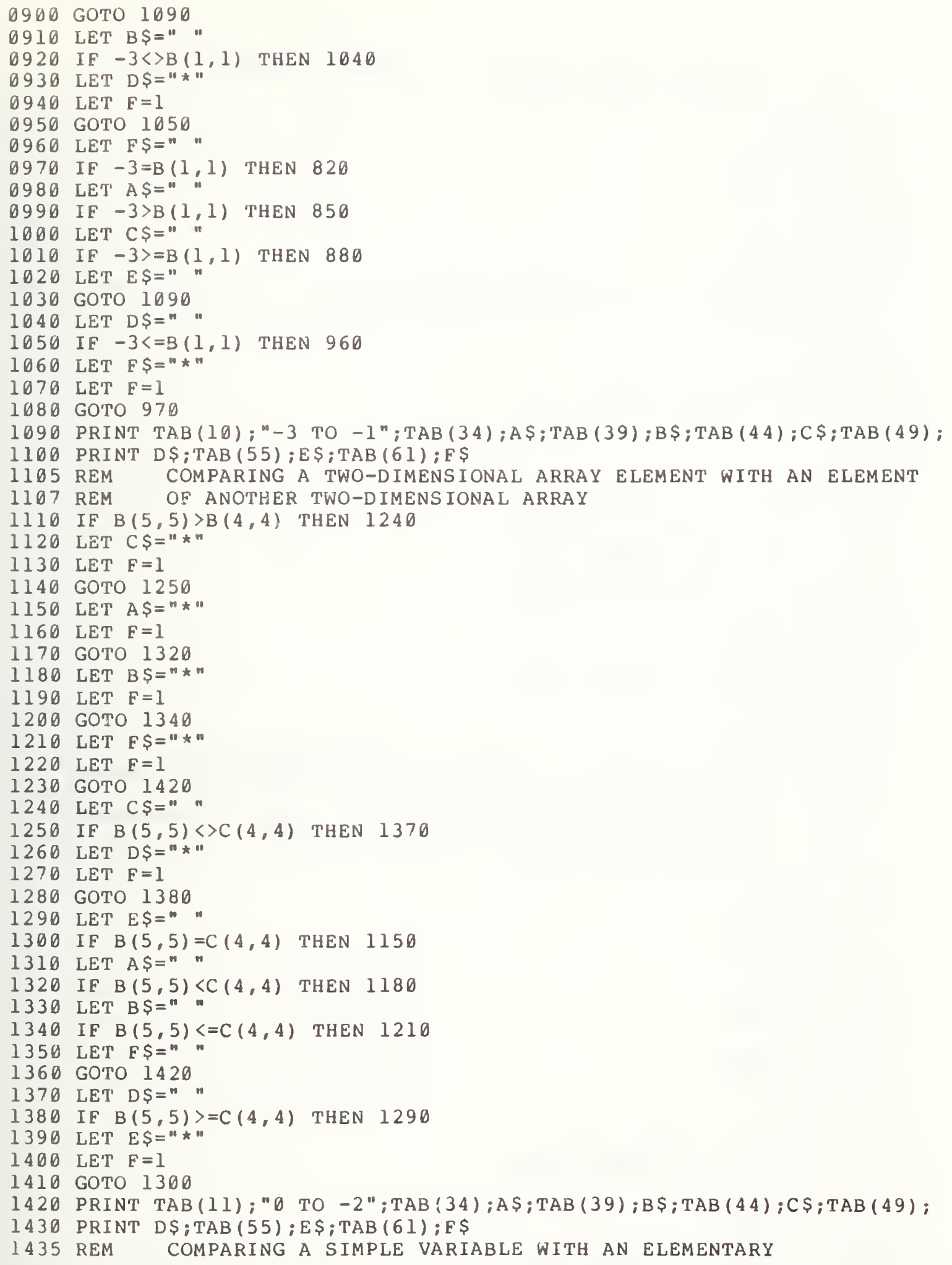




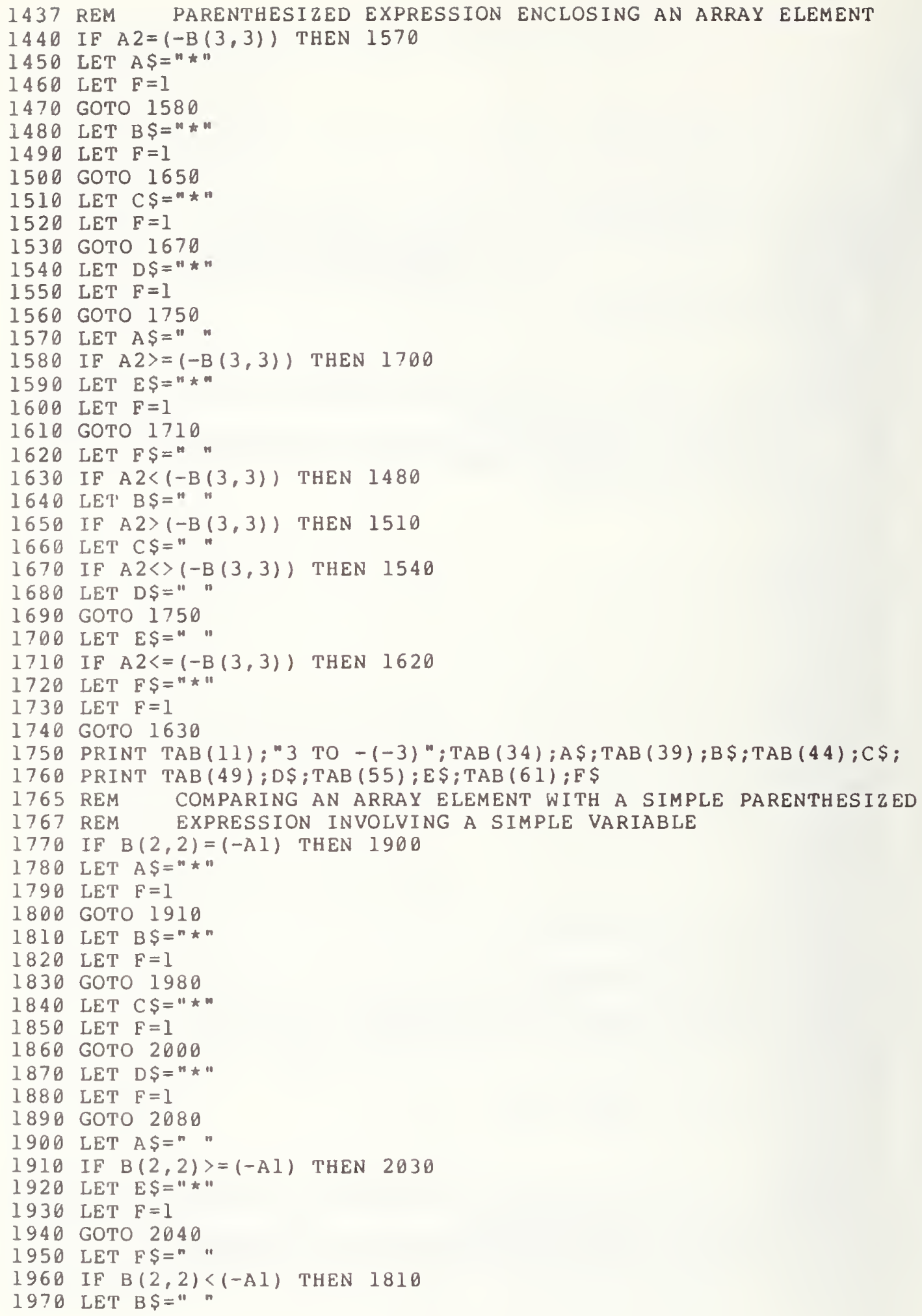




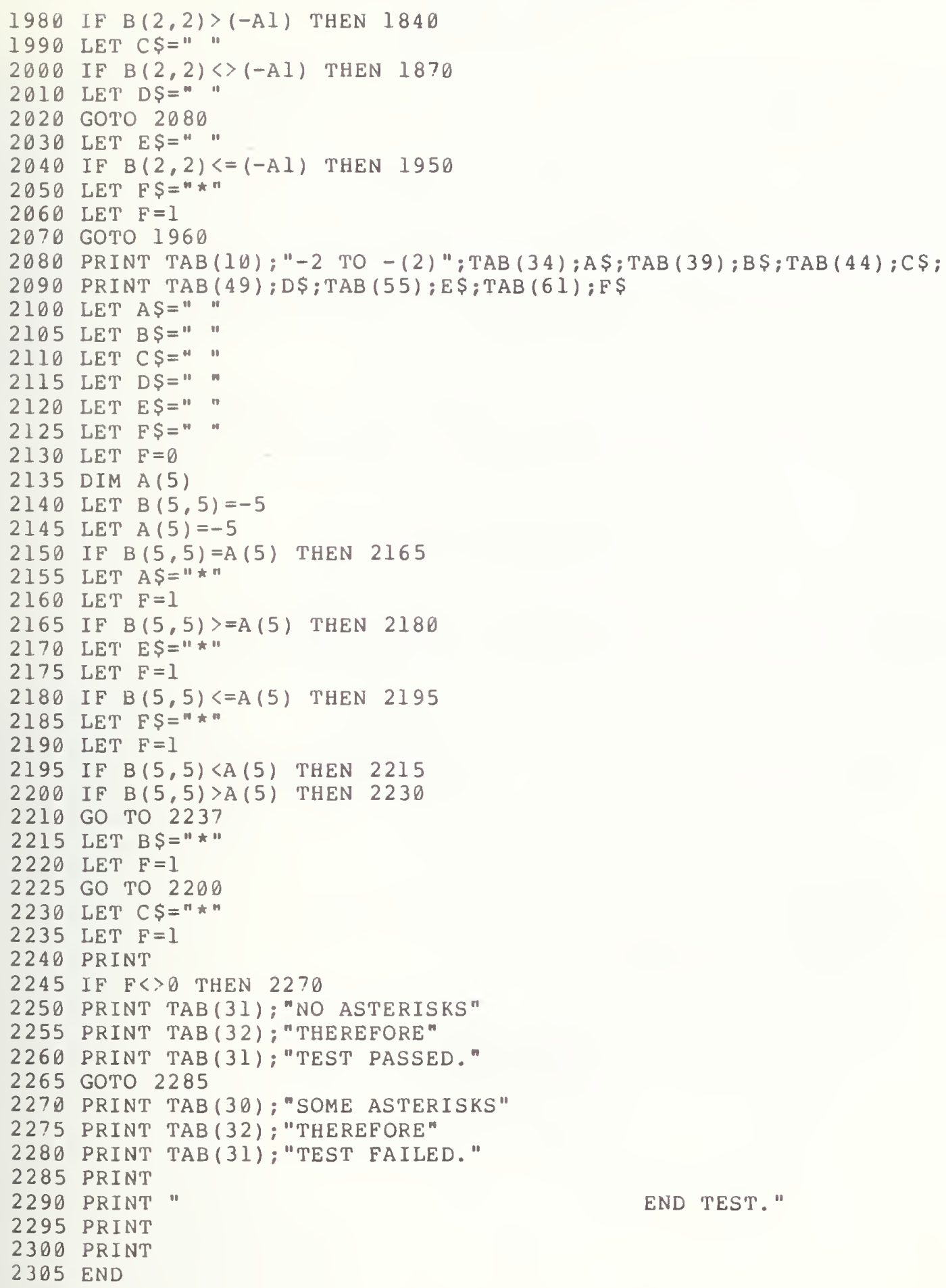




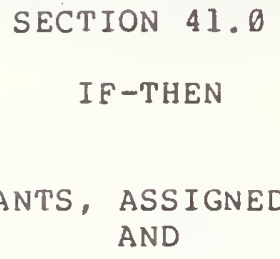

BEGIN TEST .

ALL INVALID IF-THEN EVALUATIONS WILL BE DESIGNATED BY AN ASTERISK IN THE COLUMNS OF THOSE RELATIONAL SYMBOLS FOR WHICH ERROR(S) OCCURRED FOR THAT COMPARATIVE ROW.

COMPARISONS

-2 TO -2

-3 TO -1

b TO -2

3 TO $-(-3)$

-2 TO $-(2)$

-5 TO -5

\section{RESULTS}

OF IF-THEN EVALUATIONS$$
=
$$

<> $\quad>=$
$<=$

\footnotetext{
NO ASTERISKS

THEREFORE

TEST PASSED.

END TEST .
} 


\subsection{THE ABS FUNCTION WITH SUBSCRIPTED VARIABLES} FOR ARGUMENTS

This test verifies that the absolute value function allows subscripted variables as arguments. In this test, both negative and positive numerical constants are assigned to one and two dimensioned variables. The assigned constants are of NR1, NR2, and NR3 form. The subscripted variables are then used as the arguments of the ABS function.

The output has three columns. The first column is labeled "Value of Argument", the second is labeled "True Evaluation", and the third is labeled "System Evaluation". The first column lists the constants that were assigned to the subscripted variable, the second column lists the implementation output expected, and the third column lists the test system evaluation. If any value in the third column is inaccurate, then an asterisk should appear beside it.

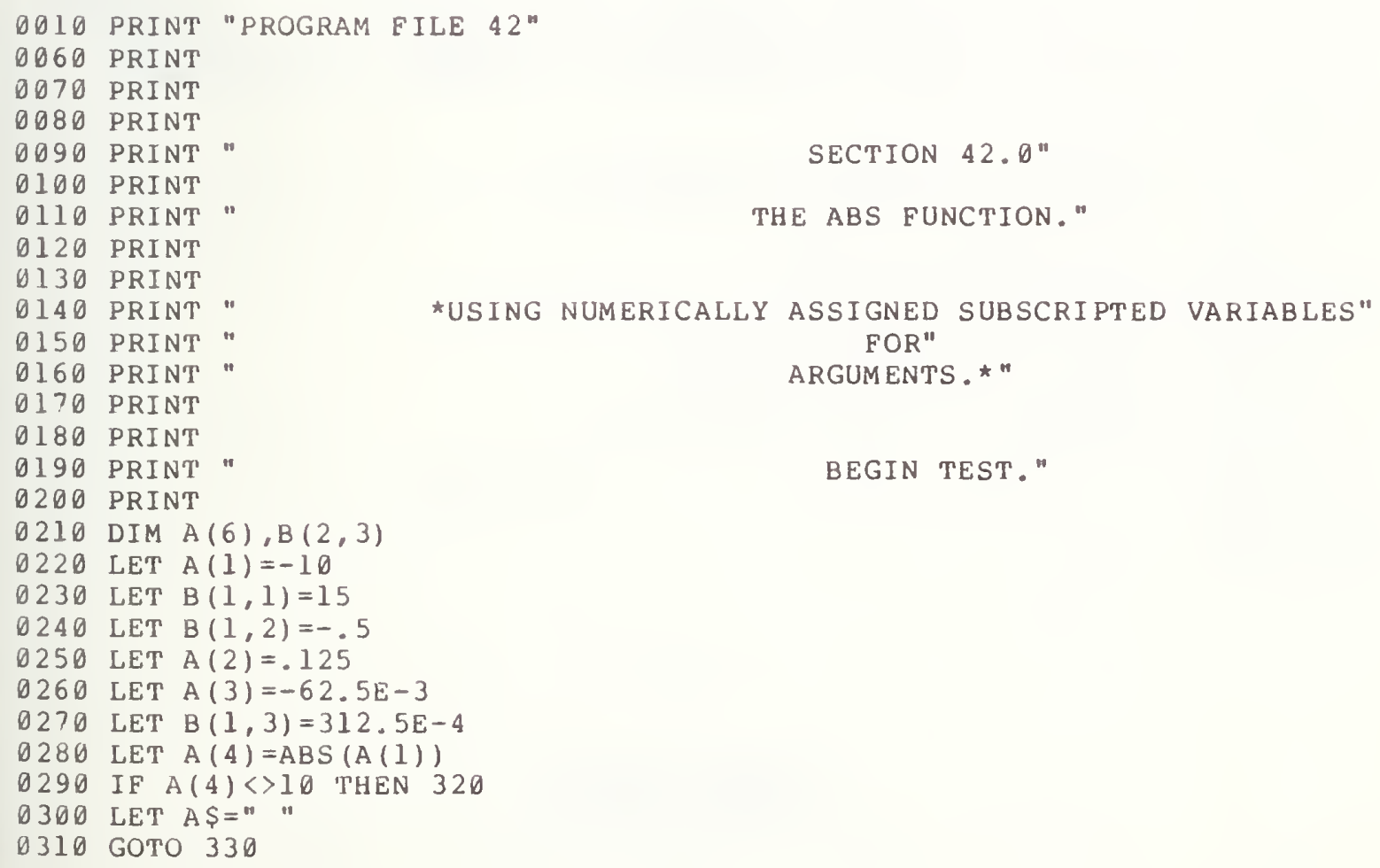




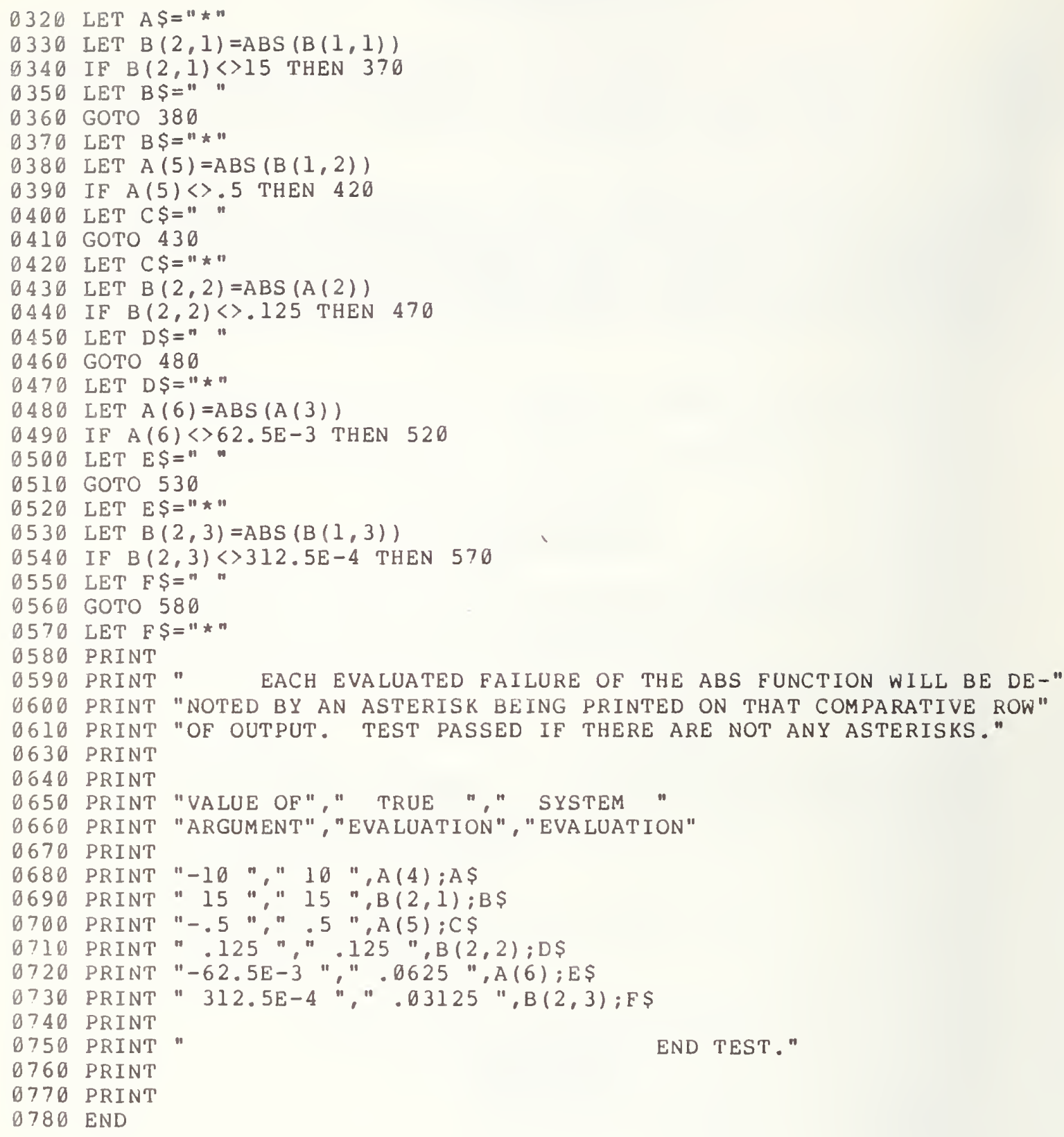


PROGRAM FILE 42

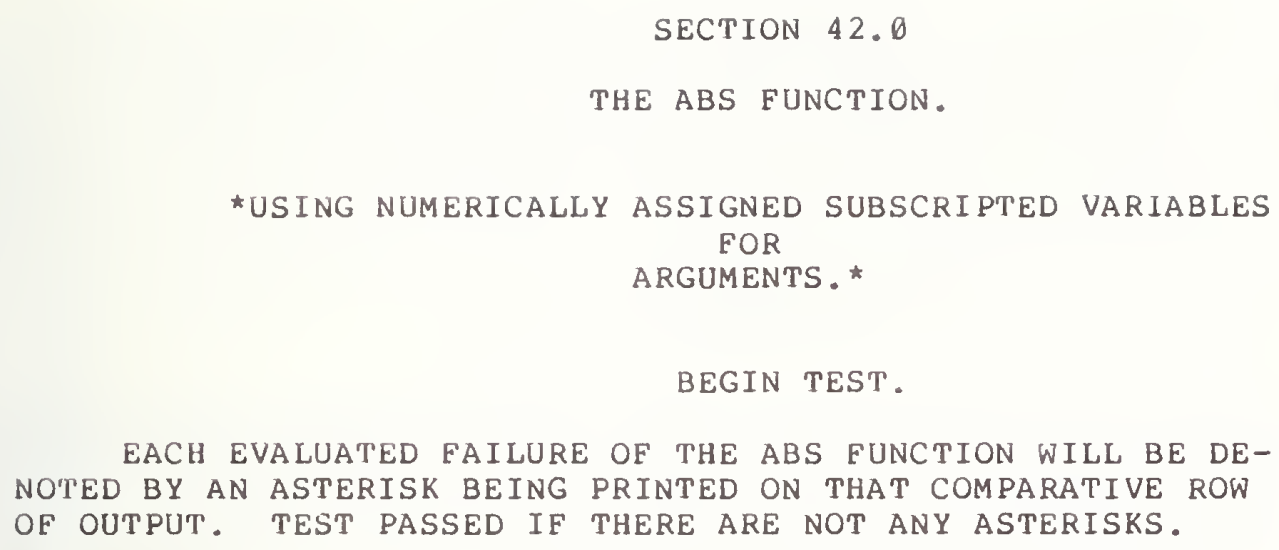

$\begin{array}{lll}\begin{array}{l}\text { VALUE OF } \\ \text { ARGUMENT }\end{array} & \begin{array}{c}\text { TRUE } \\ \text { EVALUATION }\end{array} & \begin{array}{c}\text { SYSTEM } \\ \text { EVALUATION }\end{array} \\ -10 & 10 & 10 \\ 15 & 15 & 15 \\ -.5 & .5 & .5 \\ .125 & .125 & .125 \\ -62.5 \mathrm{E}-3 & .0625 & .0625 \\ 312.5 \mathrm{E}-4 & .03125 & .03125 \\ & & \end{array}$




\section{0 USING ELEMENTARY OPERATIONS ON SUBSCRIPTED VARIABLES ASSIGNED SAME TYPE CONSTANTS}

The next several tests verify that the implementation will continue to maintain six digits of precision for the operations addition, subtraction, multiplication, division, and involution when subscripted variables are used as terms or factors of numerical expressions. The first test below uses arrays assigned constants of the same type. This isolates any error to that associated with operating on array elements and not to the constants assigned to them.

\subsection{Addition}

The objective of this test is the same as for section 22.1, except in this case the numerical constants have been assigned to subscripted variables rather than simple variables. There are four different addition exercises performed, one for each of the type constants NR1, NR2, and NR3, and implicit point scaled. Each exercise adds a double- and a single-dimensional array element. This test has the same output format described in section 22.1 .

\subsection{Subtraction}

The objective here is the same as section 22.2, except in this test the numerical constants have been assigned to subscripted variables instead of simple variables. The four different subtraction exercises have been constructed so that the output format is similar to that in section 22.2 .

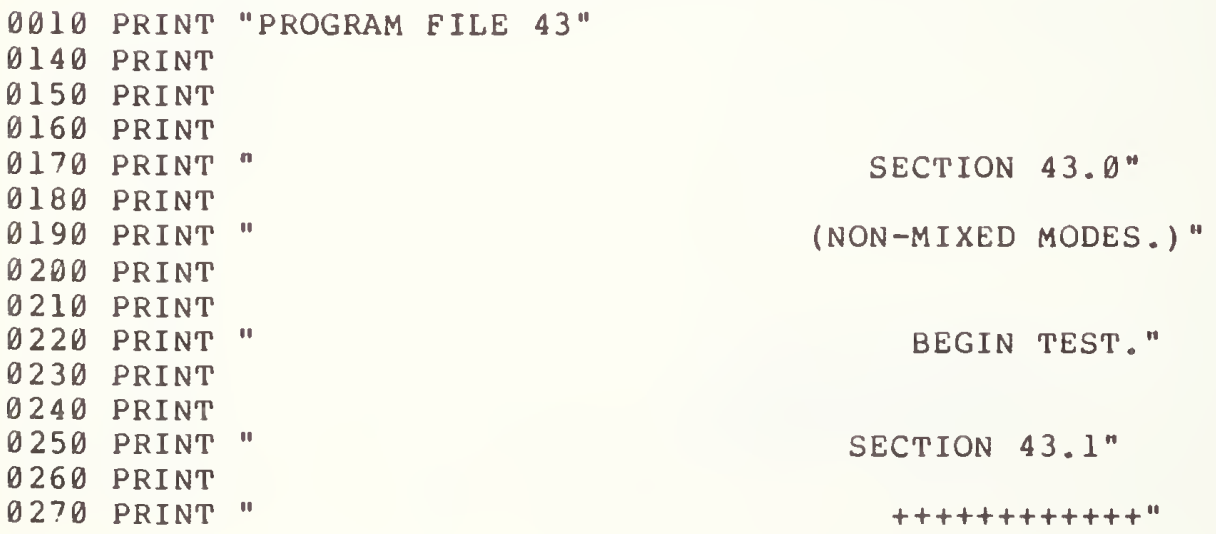




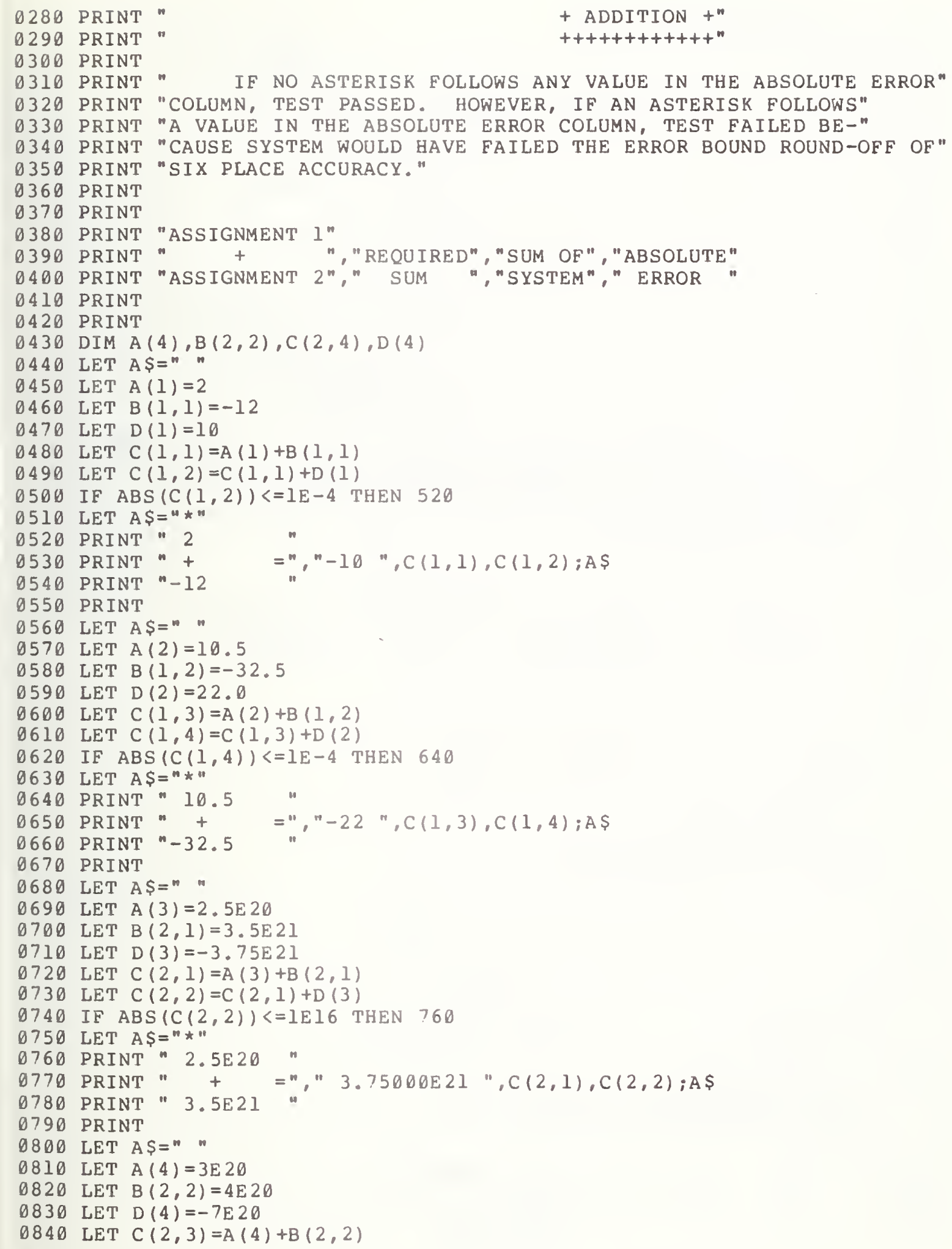




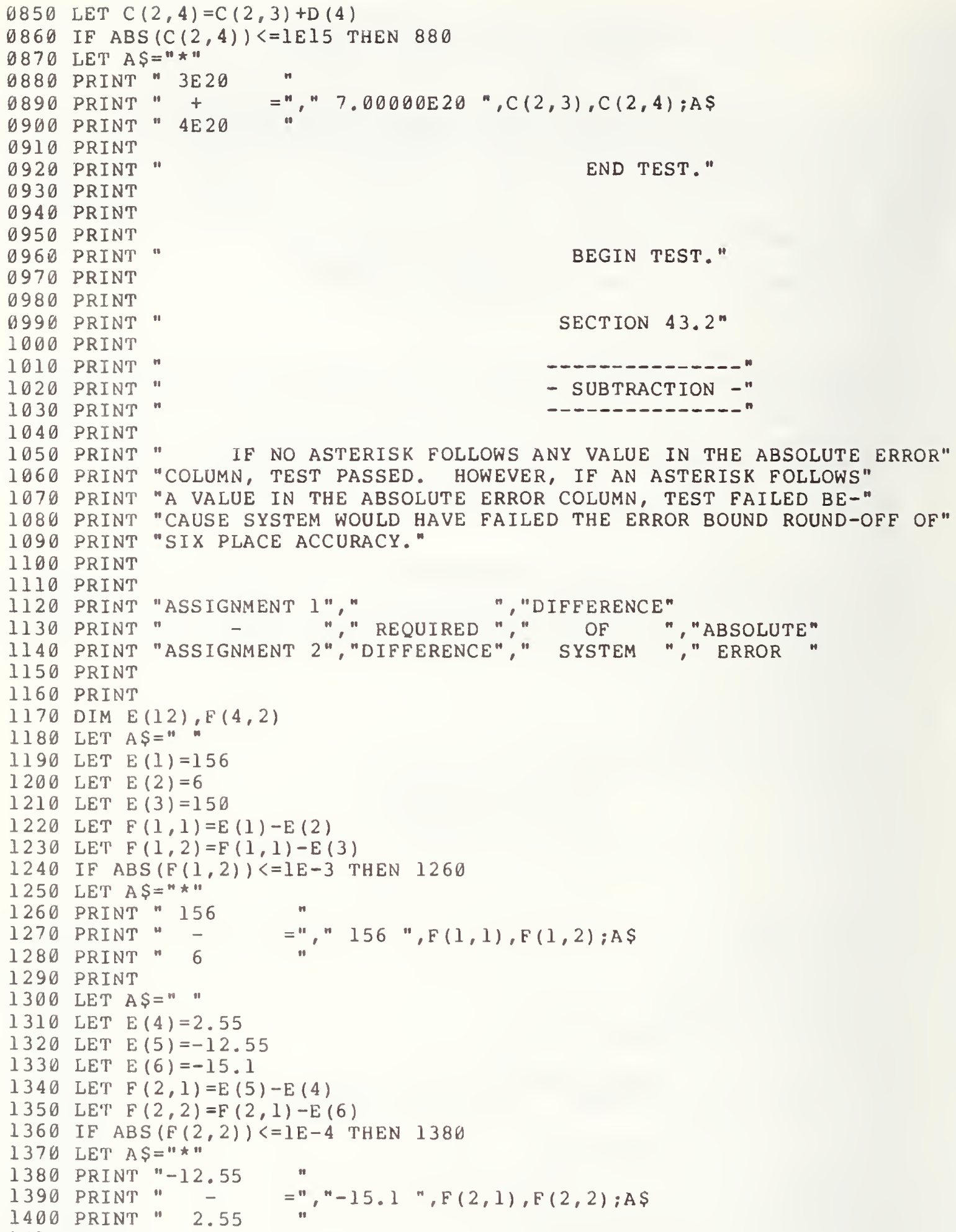




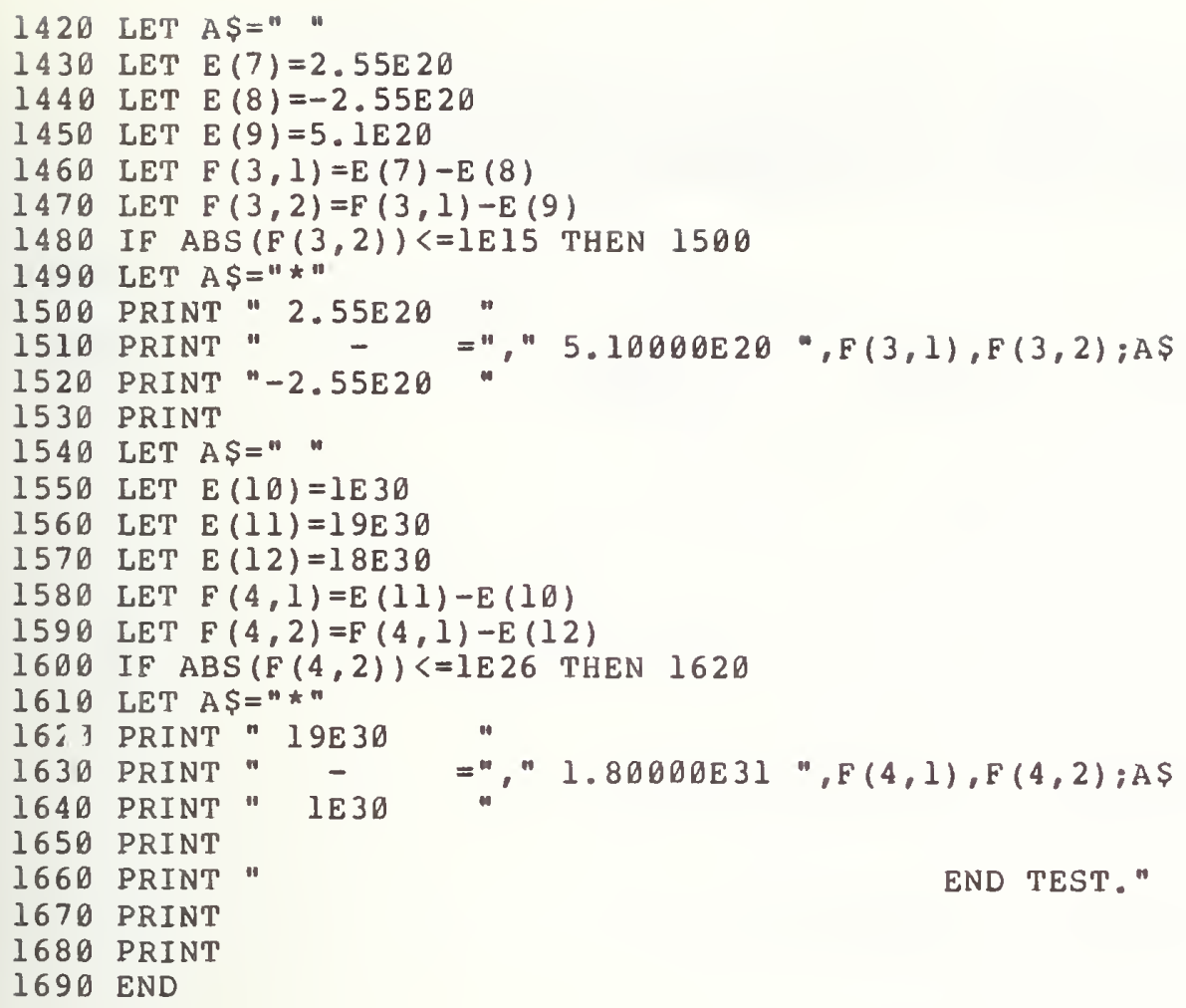

PROGRAM FILE 43

\author{
SECTION 43.0 \\ (NON-MIXED MODES.) \\ BEGIN TEST. \\ SECTION 43.1

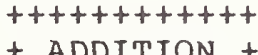


IF NO ASTERISK FOLLOWS ANY VALUE IN THE ABSOLUTE ERROR COLUMN, TEST PASSED. HOWEVER, IF AN ASTERISK FOLLOWS A VALUE IN THE ABSOLUTE ERROR COLUMN, TEST FAILED BECAUSE SYSTEM WOULD HAVE FAILED THE ERROR BOUND ROUND-OFF OF SIX PLACE ACCURACY.

\begin{tabular}{|c|c|c|c|}
\hline+ & REQUIRED & SUM OF & ABSOLUTE \\
\hline ASS IGNMENT & SUM & SYSTEM & ERROR \\
\hline $\begin{array}{l}2 \\
+ \\
-12\end{array}$ & -10 & -10 & 0 \\
\hline $\begin{array}{c}10.5 \\
+ \\
-32.5\end{array}=$ & -22 & -22 & 0 \\
\hline
\end{tabular}

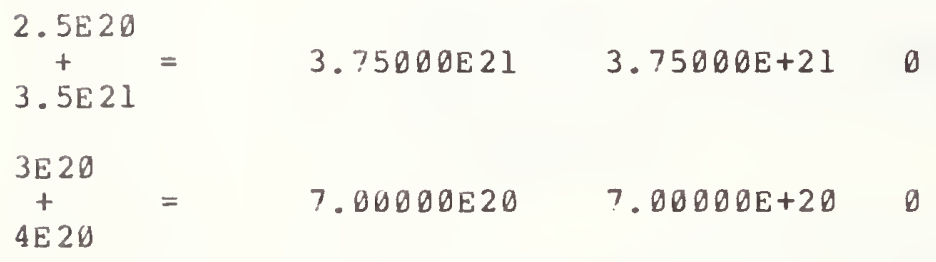

END TEST.

BEGIN TEST.

SECTION 43.2

- SUBTRACTION -

IF NO ASTERISK FOLLOWS ANY VALUE IN THE ABSOLUTE ERROR COLUMN, TEST PASSED. HOWEVER, IF AN ASTERISK FOLLOWS

A VALUE IN THE ABSOLUTE ERROR COLUMN, TEST FAILED BE-

CAUSE SYSTEM WOULD HAVE FAILED THE ERROR BOUND ROUND-OFF OF SIX PLACE ACCURACY.

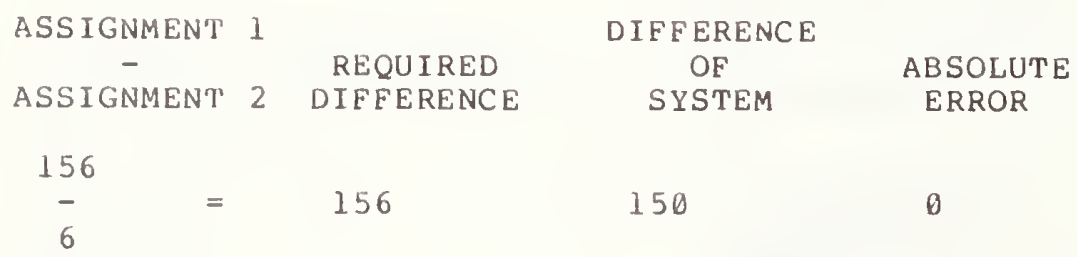




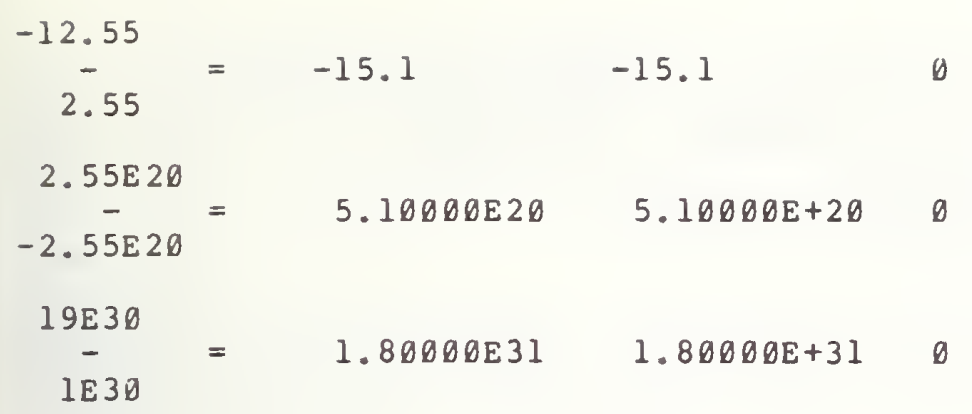

END TEST. 


\section{0 USING ELEMENTARY OPERATIONS ON SUBSCRIPTED VARIABLES ASS IGNED SAME TYPE CONSTANTS (CONTINUED)}

\subsection{Multiplication}

This test is similar to section 23.1, except in this test the numerical constants have been assigned to subscripted variables instead of simple variables. The four cases exercised in 43.1 and 43.2 are used with a similar output to section 23.1 .

\subsection{Division}

The objective of this test is similar to section 23.2, except in this test the numerical constants have been assigned to subscripted variables instead of simple variables. Again, the four separate exercises are used and the output is similar to section 23.2 .

\subsection{Involution}

The objective of this test is similar to test 23.3 , except in this test the numerical constants have been assigned to subscripted variables instead of simple variables. The four separate exercises are used and the output is similar to section 23.3 .

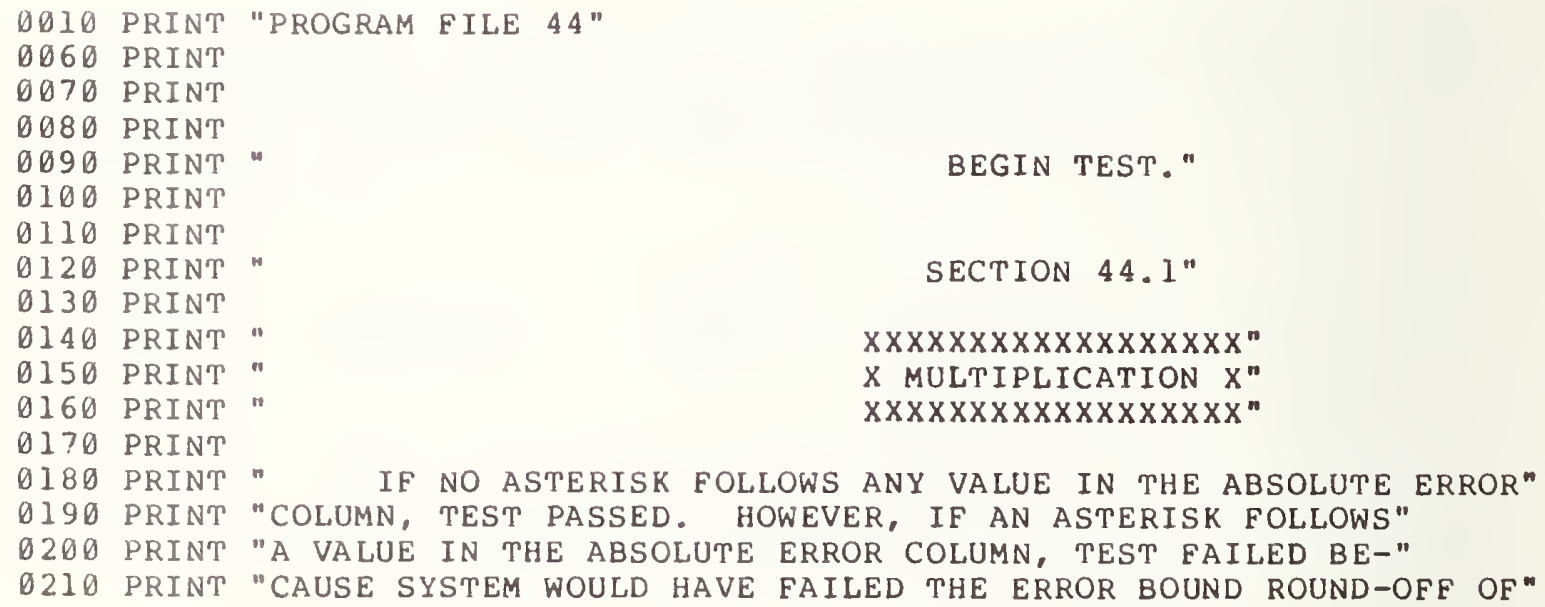




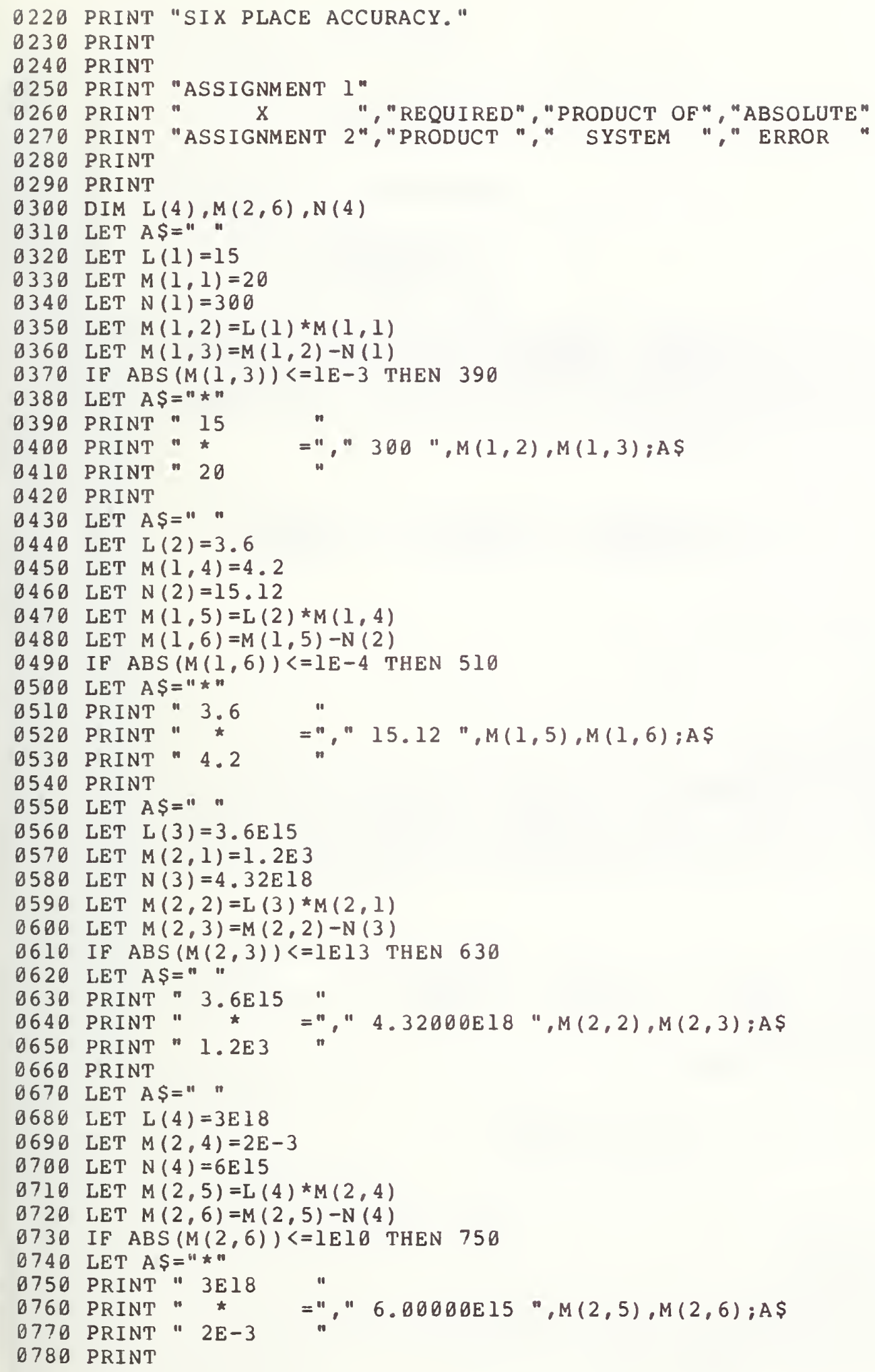




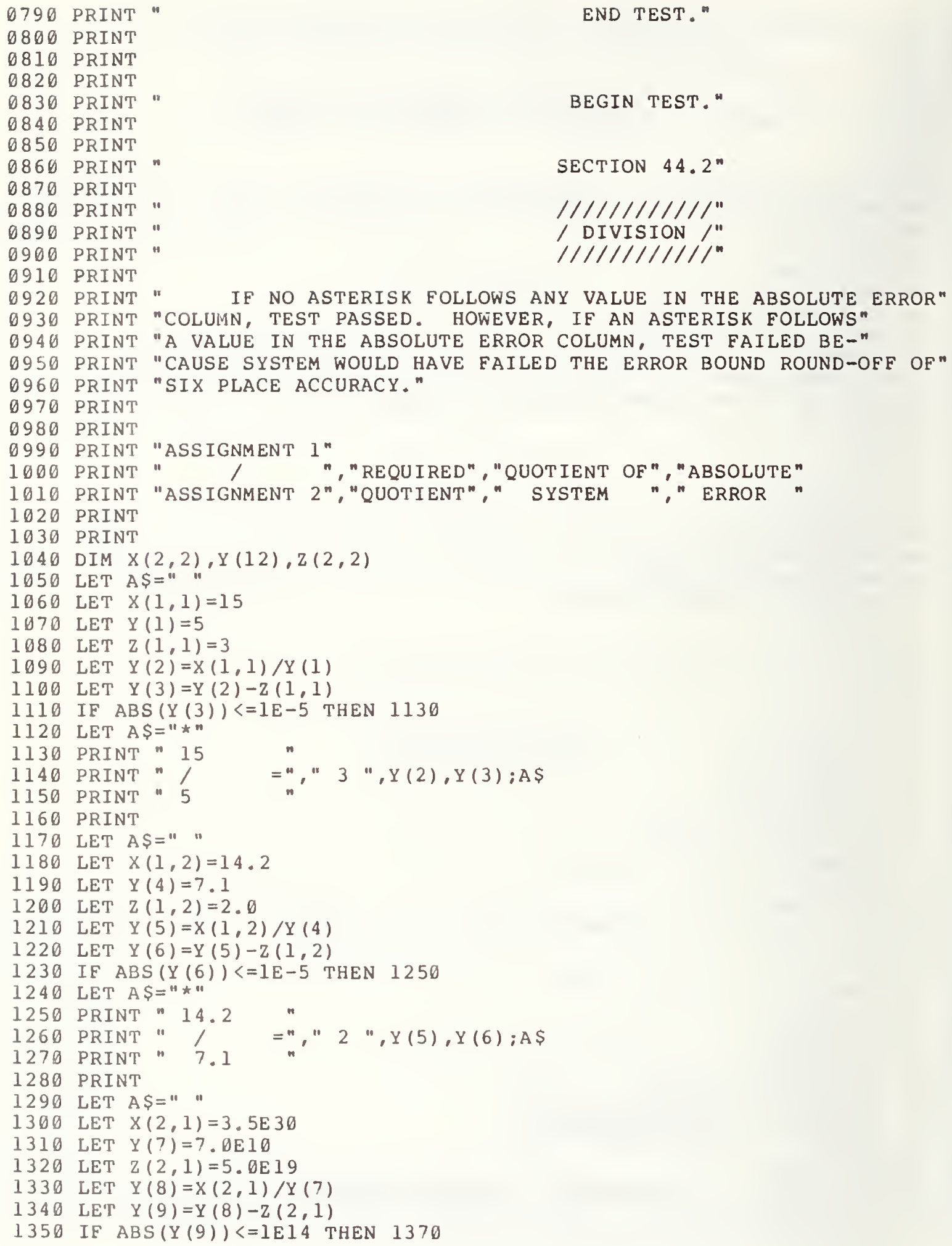


1360 LET $A \$=" \star *$

1370 PRINT " $3.5 E 30$

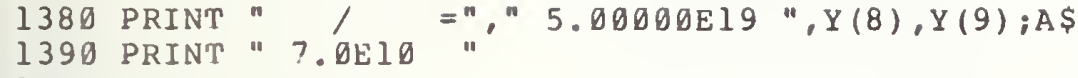

1400 PRINT

1410 LET AS=" "

1420 LET $X(2,2)=18 E 20$

1430 LET $Y(10)=9 \mathrm{E}-2$

1440 LET $Z(2,2)=2 \mathrm{E} 22$

1450 LET $Y(11)=X(2,2) / Y(10)$

1460 LET $Y(12)=Y(11)-Z(2,2)$

1470 IF $\operatorname{ABS}(Y(12))<=l E 17$ THEN 1490

1480 LET $A \$="$ *"

1490 PRINT " $18 E 20$

1500 PRINT "
1510 PRINT " $9 E-2=", " 2.00000 E 22$ ",Y(11), Y(12);A\$

1520 PRINT

1530 PRINT

1540 PRINT

END TEST."

1550 PRINT

1560 PRINT

1570 PRINT

1580 PRINT

1590 PRINT

1600 PRINT

1610 PRINT

1620 PRINT

1630 PRINT

1640 PRINT

1650 PRINT

1660 PRINT

1670 PRINT

1680 PRINT

1690 PRINT

1700 PRINT

1710 PRINT

1720 PRINT

1730 PRINT

1740 PRINT

1750 PRINT

1760 PRINT

"ASS IGNMENT I"

IF NO ASTERISK FOLLOWS ANY VALUE IN THE ABSOLUTE ERROR"

"COLUMN, TEST PASSED. HOWEVER, IF AN ASTERISK FOLLOWS"

"a VAlue in the absolute eRROR COLUMn, test FAILed Be-"

"CAUSE SYSTEM WOULD HAVE FAILED THE ERROR BOUND ROUND-OFF OF"

"SIX PLACE ACCURACY."

1770 PRINT

1780 PRINT

1790 DIM F $(6,2), G(4), H(4)$

1800 LET A $\$="$ "

1810 LET $F(1,1)=-5$

1820 LET $G(1)=4$

1830 LET $F(1,2)=625$

1840 LET H $(1)=F(1,1)^{\wedge} \mathrm{G}(1)$

1850 LET $F(2,1)=\mathrm{H}(1)-\mathrm{F}(1,2)$

1860 IF $\operatorname{ABS}(F(2,1))<=1 E-3$ THEN 1880

1870 LET A $\$=" *$ "

1880 PRINT" $" 5$

1890 PRINT "

1900 PRINT " 4

BEGIN TEST."

SECTION $44.3^{n}$

- INVOLUTION an

1910 PRINT

1920 LET AS=" " 


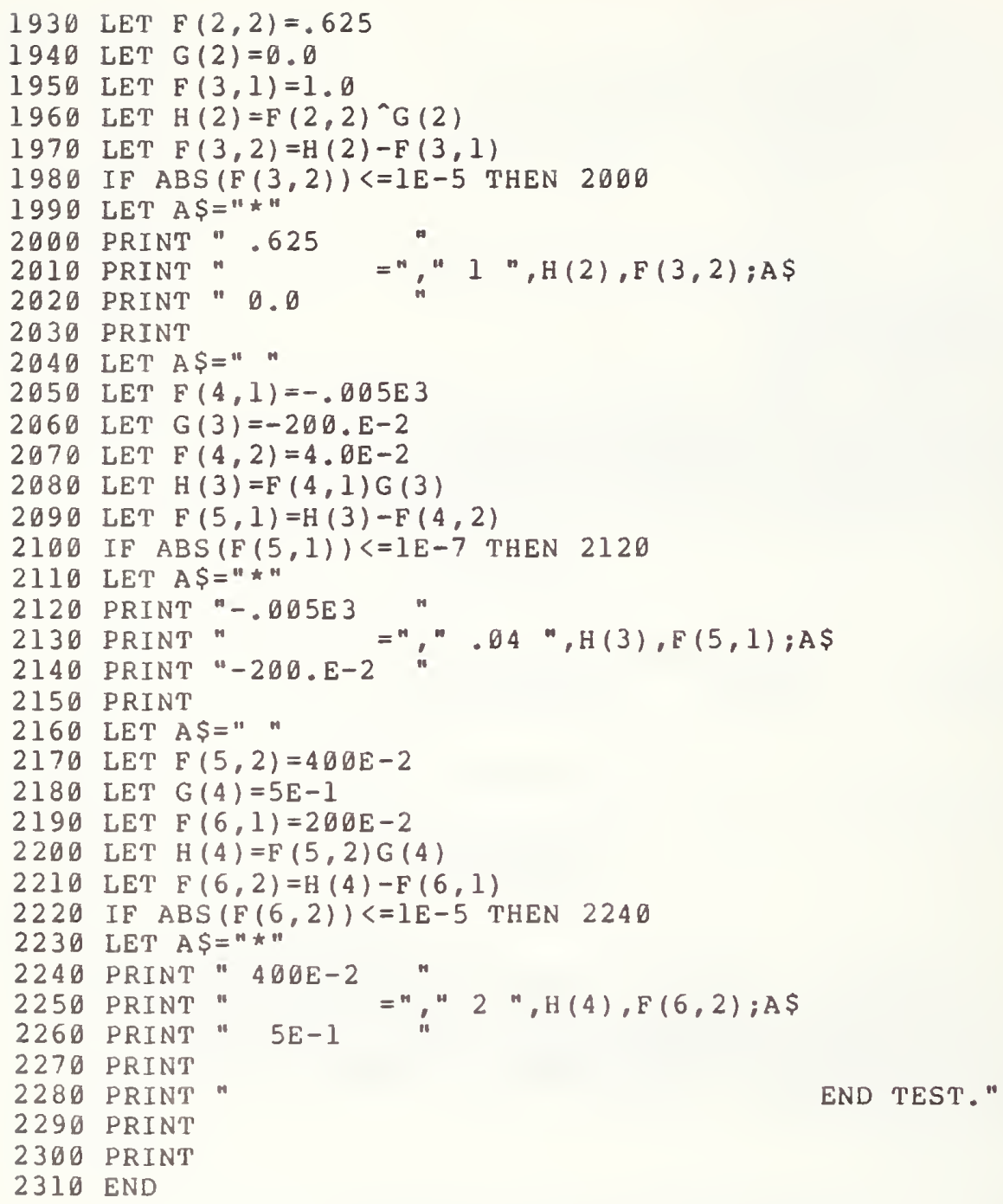

PROGRAM FILE 44 
IF NO ASTERISK FOLLOWS ANY VALUE IN THE ABSOLUTE ERROR COLUMN, TEST PASSED. HOWEVER, IF AN ASTERISK FOLLOWS

A VALUE IN THE ABSOLUTE ERROR COLUMN, TEST FAILED BECAUSE SYSTEM WOULD HAVE FAILED THE ERROR BOUND ROUND-OFF OF SIX PLACE ACCURACY.

ASSIGNMENT 1

$X$ REQUIRED

ASSIGNMENT 2 PRODUCT

PRODUCT OF
SYSTEM

15

3. 6

* ${ }^{*}=15.12 \quad 15.12$

$3.6 \mathrm{E} 15$

* $=4.32000 \mathrm{E} 18 \quad 4.32000 \mathrm{E}+18 \quad 0$

$1.2 \mathrm{E} 3$

$3 \mathrm{E} 18$

$\underset{2 \mathrm{E}-3}{*}=6.00000 \mathrm{E} 15 \quad 6.00000 \mathrm{E}+15$

END TEST.

BEGIN TEST.

SECTION 44.2

$1 / / / / / / / 1 /$

/ DIVISION /

$/ / / / / / / / 1 /$

IF NO ASTERISK FOLLOWS ANY VALUE IN THE ABSOLUTE ERROR COLUMN, TEST PASSED. HOWEVER, IF AN ASTERISK FOLLOWS A VALUE IN THE ABSOLUTE ERROR COLUMN, TEST FAILED BECAUSE SYSTEM WOULD HAVE FAILED THE ERROR BOUND ROUND-OFF OF SIX PLACE ACCURACY.

ASSIGNMENT 1

/ REQUIRED QUOTIENT OF ABSOLUTE

ASSIGNMENT 2 QUOTIENT SYSTEM ERROR 


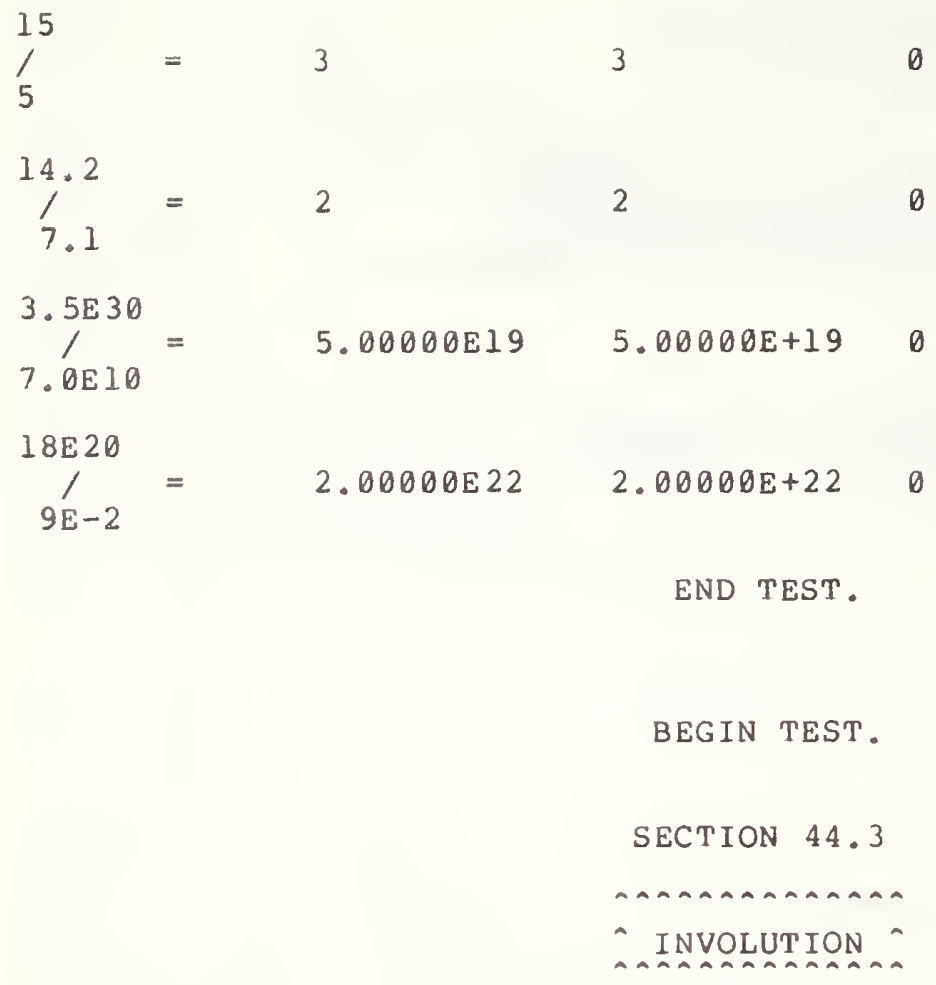

IF NO ASTERISK FOLLOWS ANY VALUE IN THE ABSOLUTE ERROR COLUMN, TEST PASSED. HOWEVER, IF AN ASTERISK FOLLOWS A VALUE IN THE ABSOLUTE ERROR COLUMN, TEST FAILED BECAUSE SYSTEM WOULD HAVE FAILED THE ERROR BOUND ROUND-OFF OF SIX PLACE ACCURACY.

\begin{tabular}{|c|c|c|c|}
\hline $\begin{array}{l}\text { ASSIGNMENT } \\
\text { ASSIGNMENT }\end{array}$ & $\begin{array}{l}\text { REQUIRED } \\
\text { POWER }\end{array}$ & $\begin{array}{l}\text { POWER OF } \\
\text { SYSTEM }\end{array}$ & $\begin{array}{l}\text { ABSOLUTE } \\
\text { ERROR }\end{array}$ \\
\hline$\stackrel{-5}{4}_{4}^{-5}=$ & 625 & 625 & 0 \\
\hline$:_{0.0}^{625}=$ & 1 & 1 & 0 \\
\hline $\begin{array}{l}-.005 E 3 \\
-200 \cdot E-2\end{array}=$ & .04 & .04 & 0 \\
\hline $\begin{array}{l}400 E-2 \\
5 E-1\end{array}=$ & 2 & 2 & 0 \\
\hline
\end{tabular}


END TEST. 


\subsection{USING ELEMENTARY OPERATIONS ON SUBSCRIPTED VARIABLES ASSIGNED MIXED TYPE CONSTANTS}

\section{Addition}

The objective of this test is similar to section 24.1 , except in this test the numerical constants have been assigned to subscripted variables instead of simple variables. There are six separate exercises performed in this routine. First, NRI and NR2 assigned constants are added. Second, NRI and NR3 assigned constants are added. Third, NRl and implicit point scaled constants are assigned, added, then followed by the addition of an NR2 number. Fourth, NR2 and NR3 are combined. Fifth, NR2 and implicit point scaled are combined and, finally, NR3 and implicit point scaled are combined. The output is similar in format to section 24.1 .

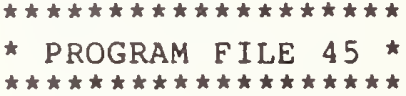

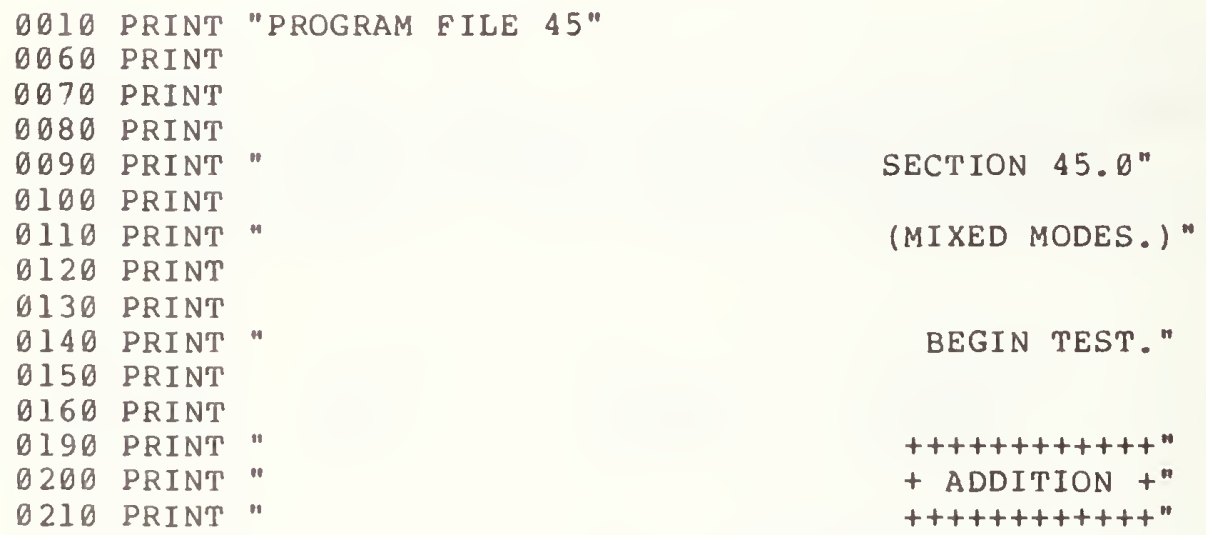

0220 PRINT

0230 PRINT

0240 PRINT

D250 PRINT

0260 PRINT

"IF NO ASTERISK FOLLOWS ANY VALUE IN THE ABSOLUTE ERROR"

"COLUMN, TEST PASSED. HOWEVER, IF AN ASTERISK FOLLOWS"

"A VALUE IN THE ABSOLUTE ERROR COLUMN, TEST FAILED BE-"

0270 PRINT

"CAUSE SYSTEM WOULD HAVE FAILED THE ERROR BOUND ROUND-OFF OF"

"SIX PLACE ACCURACY."

6280 PRINT

0290 PRINT

0300 PRINT

0310 PRINT

0320 PRINT

"ASSIGNMENT 1 "

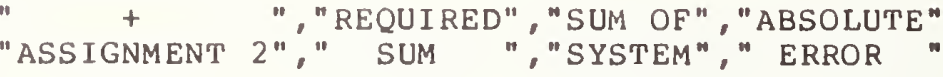

0330 PRINT

0340 PRINT 


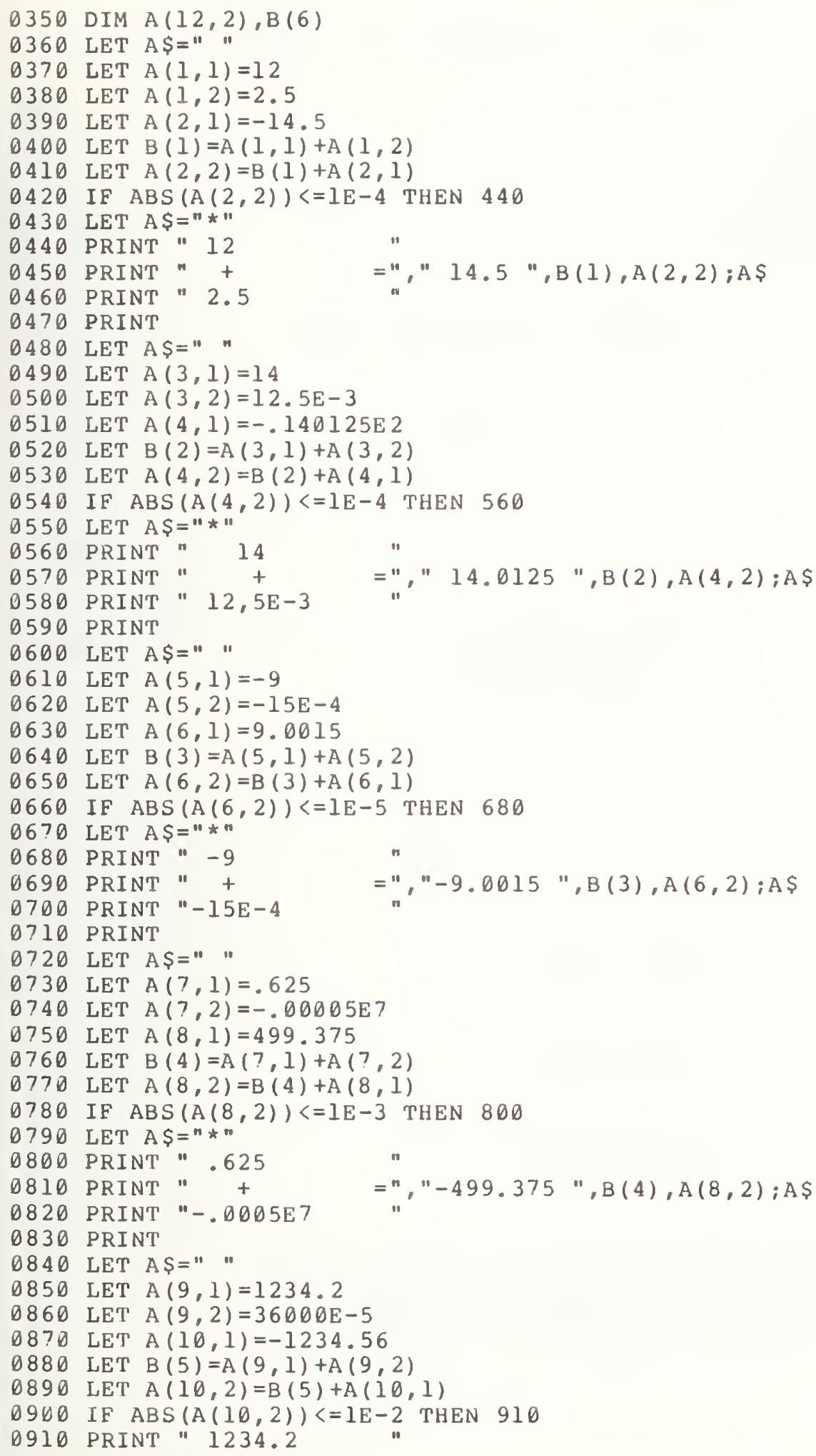



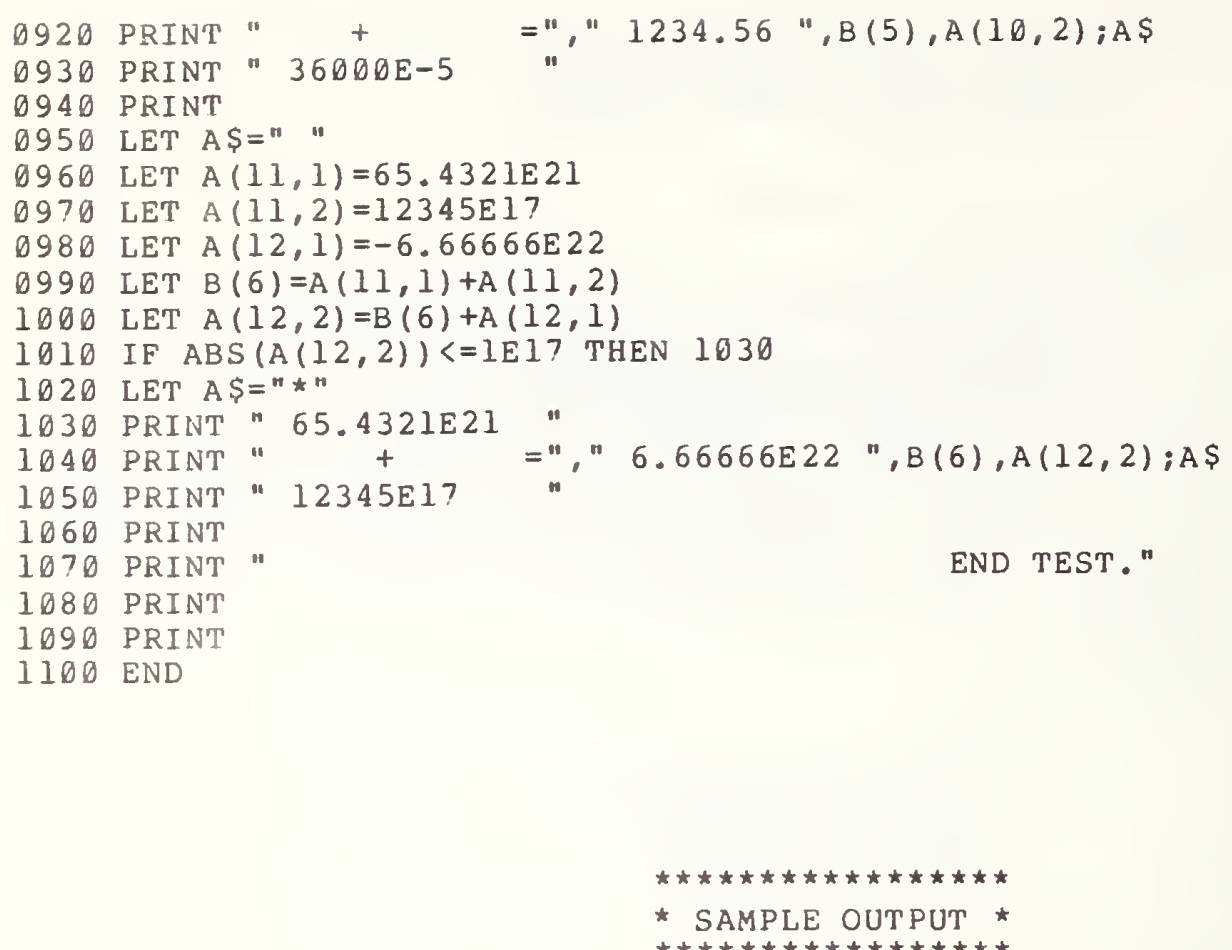

PROGRAM FILE 45

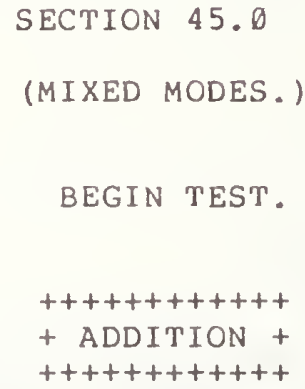

IF NO ASTERISK FOLLOWS ANY VALUE IN THE ABSOLUTE ERROR COLUMN, TEST PASSED. HOWEVER, IF AN ASTERISK FOLLOWS A VALUE IN THE ABSOLUTE ERROR COLUMN, TEST FAILED BECAUSE SYSTEM WOULD HAVE FAILED THE ERROR BOUND ROUND-OFF OF SIX PLACE ACCURACY. 


\begin{tabular}{|c|c|c|c|c|}
\hline+ & & REQUIRED & SUM OF & \\
\hline ASSIGNMENT & 2 & SUM & SYSTEM & \\
\hline $\begin{array}{l}12 \\
+ \\
2.5\end{array}$ & $=$ & 14.5 & 14.5 & $\theta$ \\
\hline $\begin{array}{c}14 \\
+ \\
12,5 E-3\end{array}$ & $=$ & 14.0125 & 14.0125 & $a$ \\
\hline $\begin{array}{l}-9 \\
+ \\
-15 E-4\end{array}$ & $=$ & -9.0015 & -9.0015 & $a$ \\
\hline $\begin{array}{c}.020 \\
+ \\
-.0005 E 7\end{array}$ & $=$ & -499.375 & -499.375 & a \\
\hline $\begin{array}{l}1234.2 \\
+ \\
36000 \mathrm{E}-5\end{array}$ & $=$ & 1234.56 & 1234.56 & $\theta$ \\
\hline $\begin{array}{c}65.4321 E 21 \\
+ \\
12345 E 17\end{array}$ & $=$ & $6.66666 \mathrm{E} 22$ & $6.66666 \mathrm{E}+22$ & \\
\hline
\end{tabular}

END TEST. 


\subsection{USING ELEMENTARY OPERATIONS ON SUBSCRIPTED VARIABLES ASSIGNED MI XED TYPE CONSTANTS (CONTINUED)}

The objective of this subtraction test is the same as for section 24.2, except in this test the numerical constants have been assigned to subscripted variables instead of simple variables. Six similar exercises to those discussed in section 45.0 are used with the output being similarly formatted to section 24.2 .

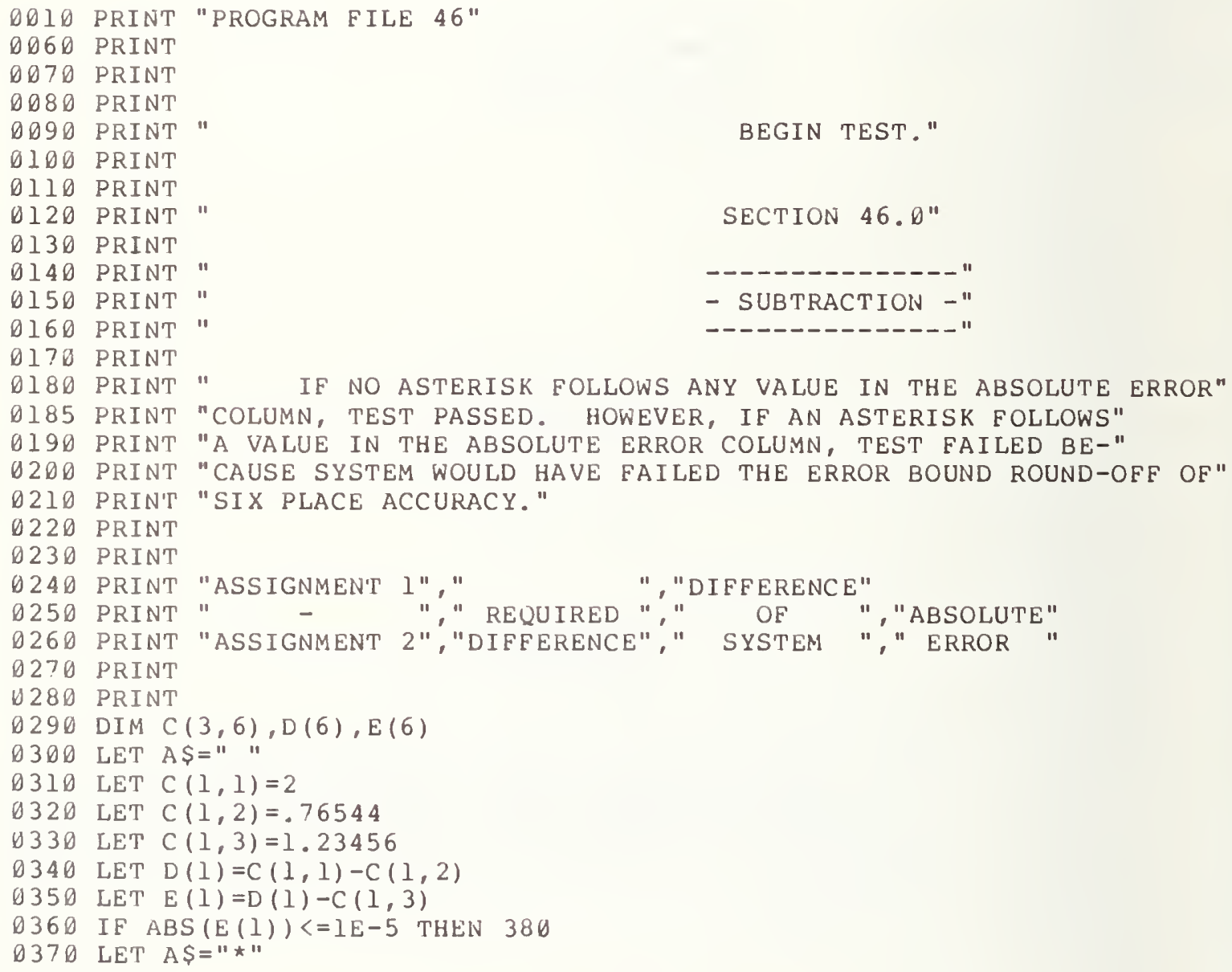

BEGIN TEST."

SECTION $46.0^{\prime \prime}$

IF NO ASTERISK FOLLOWS ANY VALUE IN THE ABSOLUTE ERROR" "COLUMN, TEST PASSED. HOWEVER, IF AN ASTERISK FOLLOWS"

"A VALUE IN THE ABSOLUTE ERROR COLUMN, TEST FAILED BE-" "CAUSE SYSTEM WOULD HAVE FAILED THE ERROR BOUND ROUND-OFF OF" "SIX PLACE ACCURACY." 


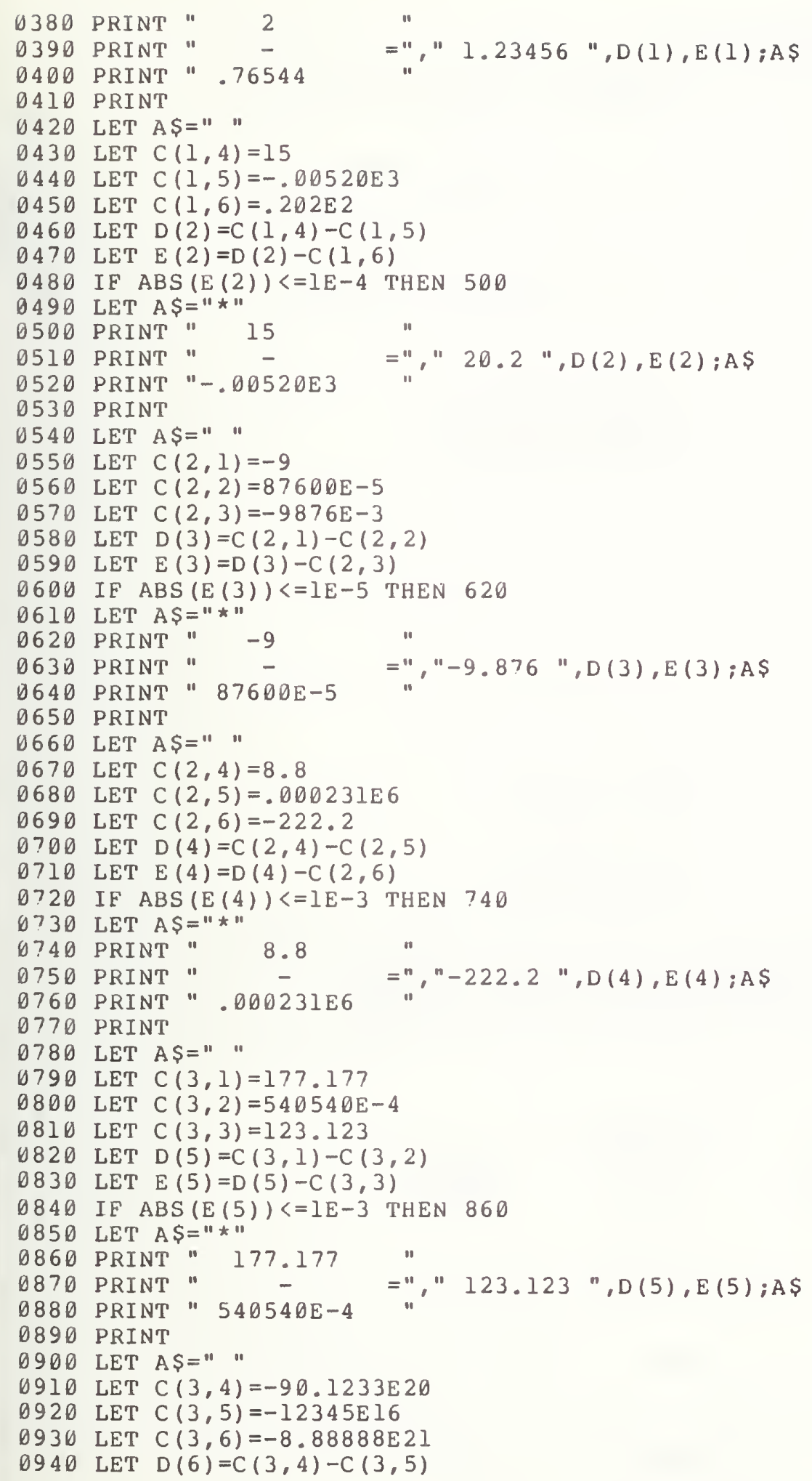


9950 LET $\mathrm{E}(6)=\mathrm{D}(6)-\mathrm{C}(3,6)$

0960 IF ABS $(E(6))<=1 E 16$ THEN 970

0970 PRINT " $-90.1233 \mathrm{E} 20$

ด980 PRINT"

9990 PRINT" -12345E16 "," $"-8.88888 E 21 "$ "D (6), E (6) ;AS

1000 PRINT

1010 PRINT"

END TEST."

1020 PRINT

1630 PRINT

$1 \emptyset 4 \emptyset$ END

PROGRAM FILE 46

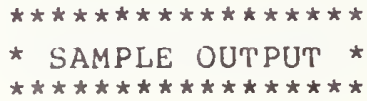

BEGIN TEST.

SECTION 46.0

- SUBTRACTION -

IE NO ASTERISK FOLLOWS ANY VALUE IN THE ABSOLUTE ERROR COLUMN, TEST PASSED. HOWEVER, IF AN ASTERISK FOLLOWS A VALUE IN THE ABSOLUTE ERROR COLUMN, TEST FAILED BECAUSE SYSTEM WOULD HAVE FAILED THE ERROR BOUND ROUND-OEF OF SIX PLACE ACCURACY.

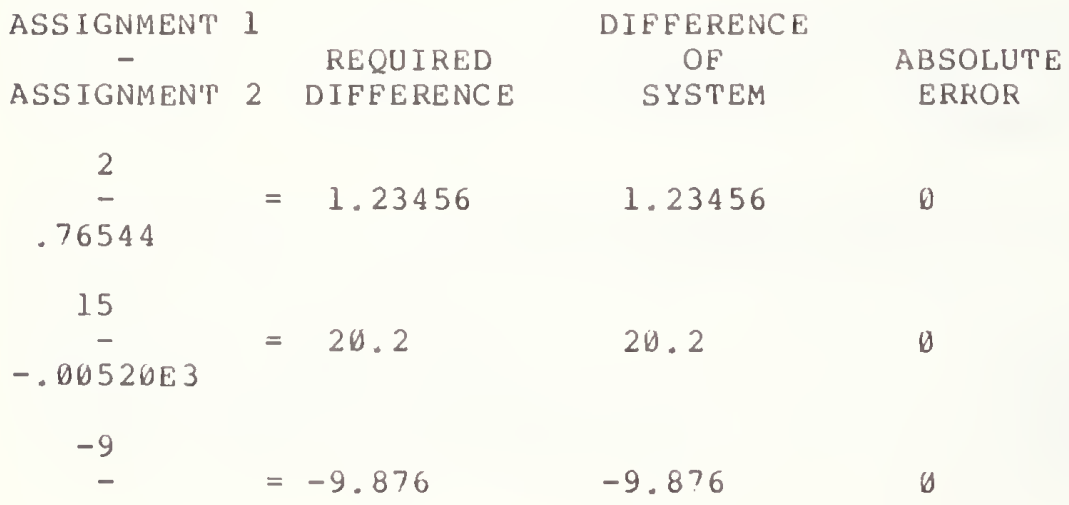


$87600 \mathrm{E}-5$

$$
8.8
$$

$.000231 E 6$

$$
=-222.2
$$

177.177

$5405 \overline{4} 0 \mathrm{E}-4$

$=123.123$

123.123

b

$-90.1233 E 20$

$-123 \overline{4} 516$

$$
=-8.88888 \mathrm{E} 21-8.88888 \mathrm{E}+21 \quad 0
$$

END TEST. 


\section{U USING ELEMENTARY OPERATIONS ON SUBSCRIPTED VARIABLES ASSIGNED MIXED TYPE CONSTANTS (CONTINUED)}

\subsection{Multiplication}

The objective of this test is the same as in section 25.1, except in this test the numerical constants have been assigned to subscripted variables instead of simple variables. As in sections 45.0 and 46.0 , this routine uses six exercises to check the accuracy of simple mixed type multiplication. The output is similar to section 25.1

\subsection{Division}

The objective of this test is the same as in section 25.2, except in this test the numerical constants have been assigned to subscripted variables instead of simple variables. Again, six exercises are used and the output is similar to section 25.2 .

\section{3 Involution}

The objective of this test is the same as in section 25.3, except in this test the numerical constants have been assigned to subscripted variables instead of simple variables. Six exercises are used and the output is similar to section 25.3 .

Q010 PRINT "PROGRAM FILE $47 "$

DO6D PRINT

ด07ด PRINT

0080 PRINT

OO9O PRINT

OIOO PRINT

DIIO PRINT

0120 PRINT"

D 130 PRINT

0140 PRINT"

U150 PRINT"

OI6Ø PRINT "

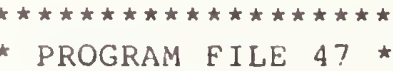

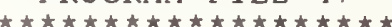

OI7D PRINT

OI80 PRINT"

O 190 PRINT "COLUNN

D200 PRINT "A VALUE IN THE ABSOLUTE ERKOR, COLUMN, TEST FAILED BE-" 


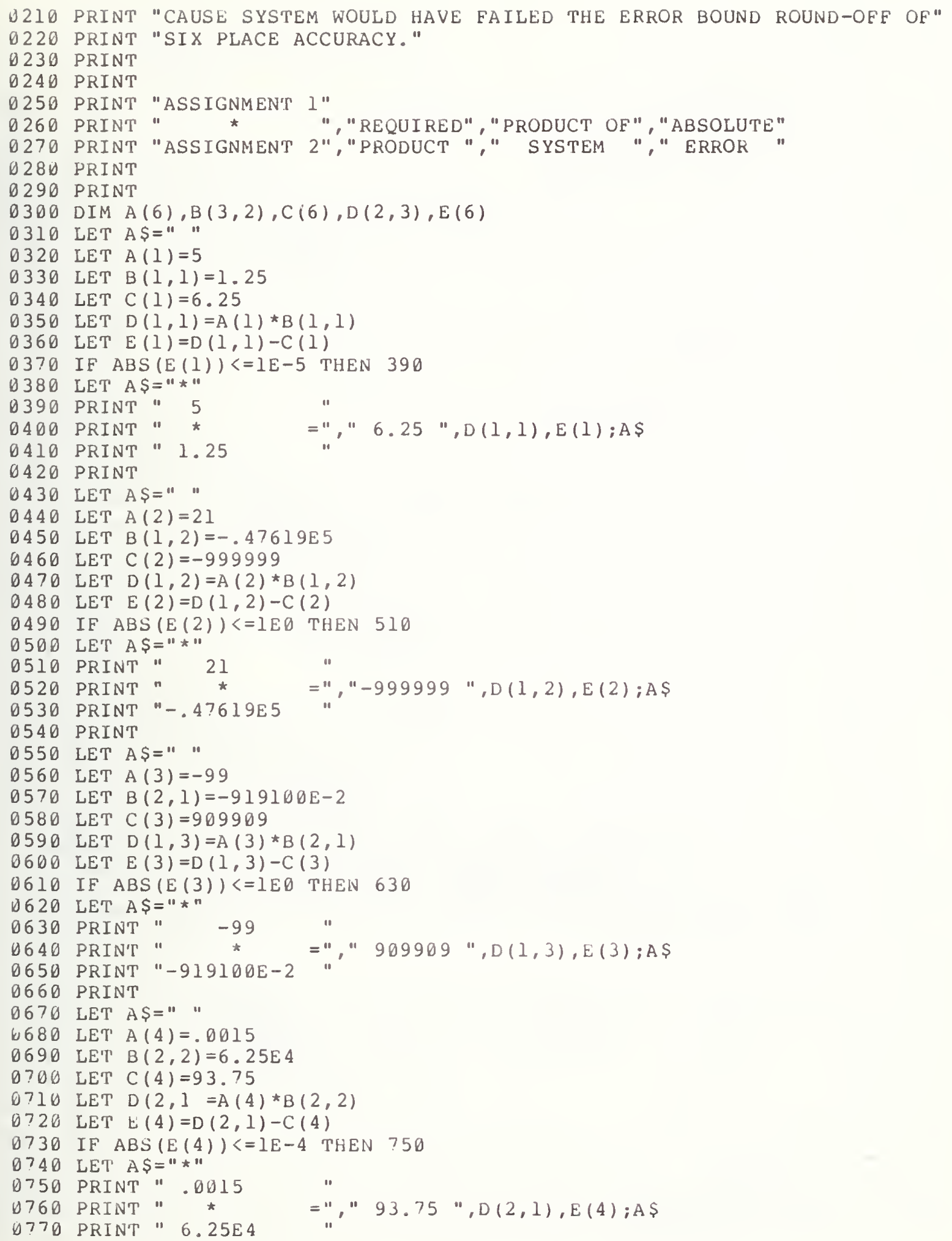




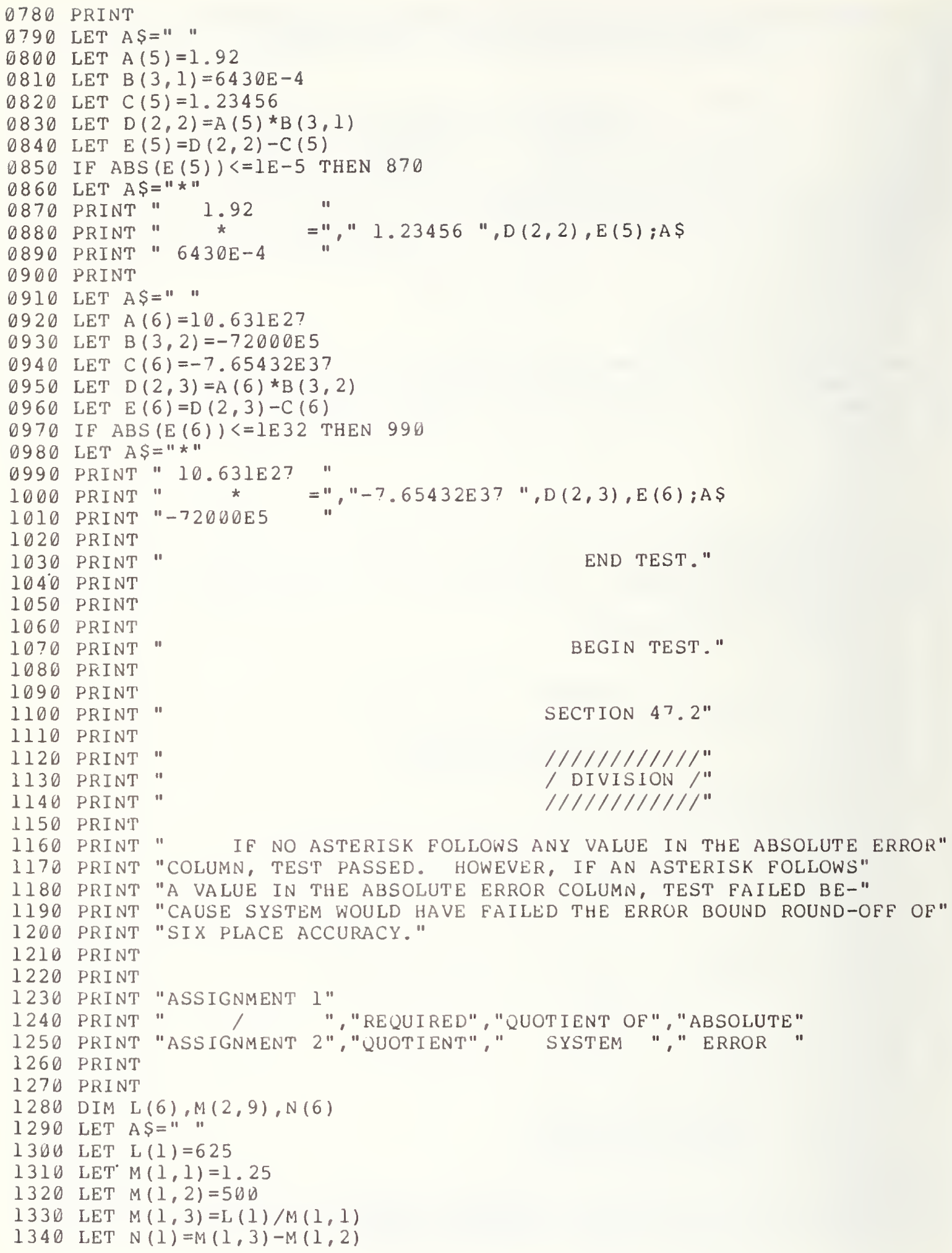




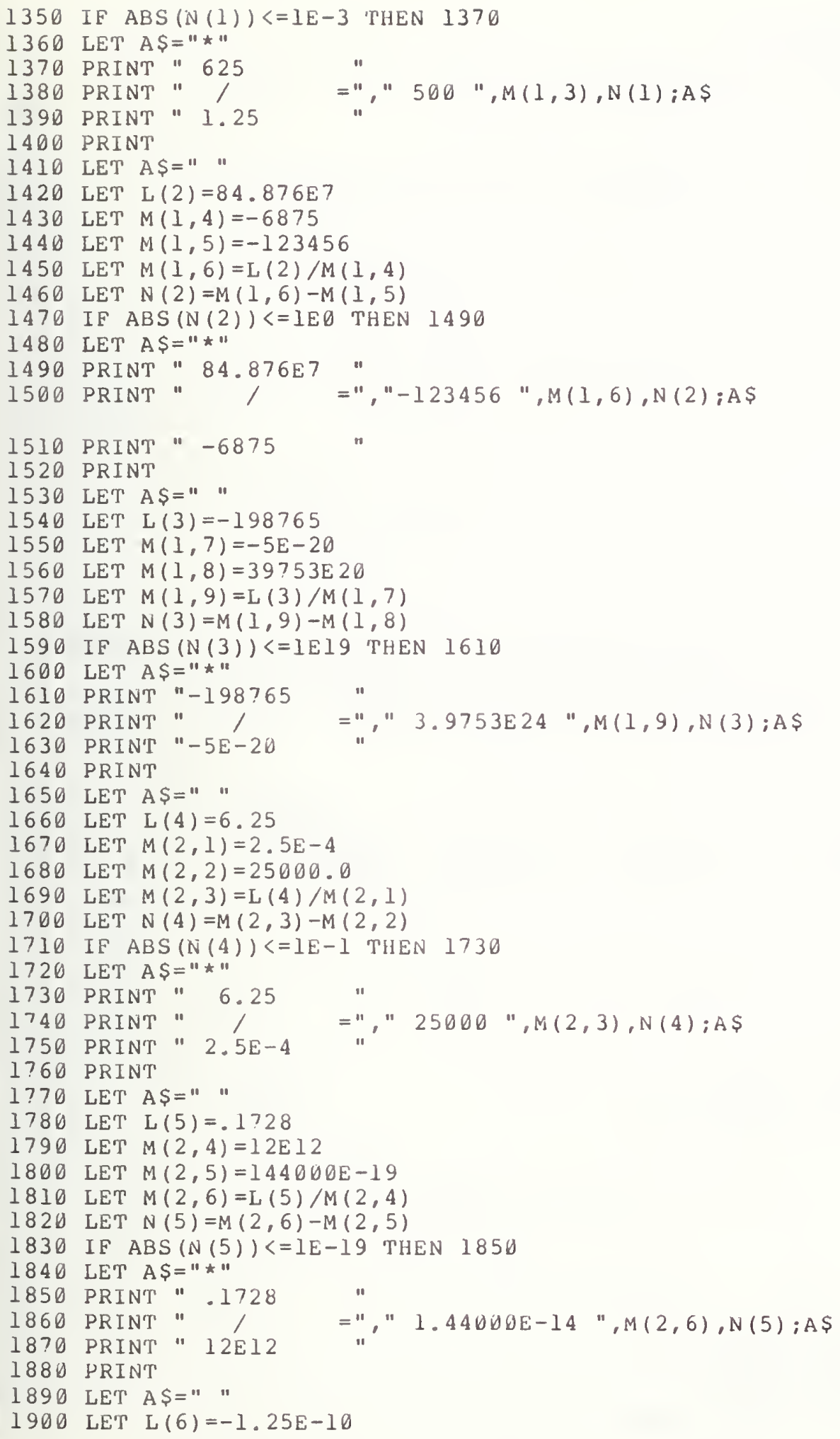




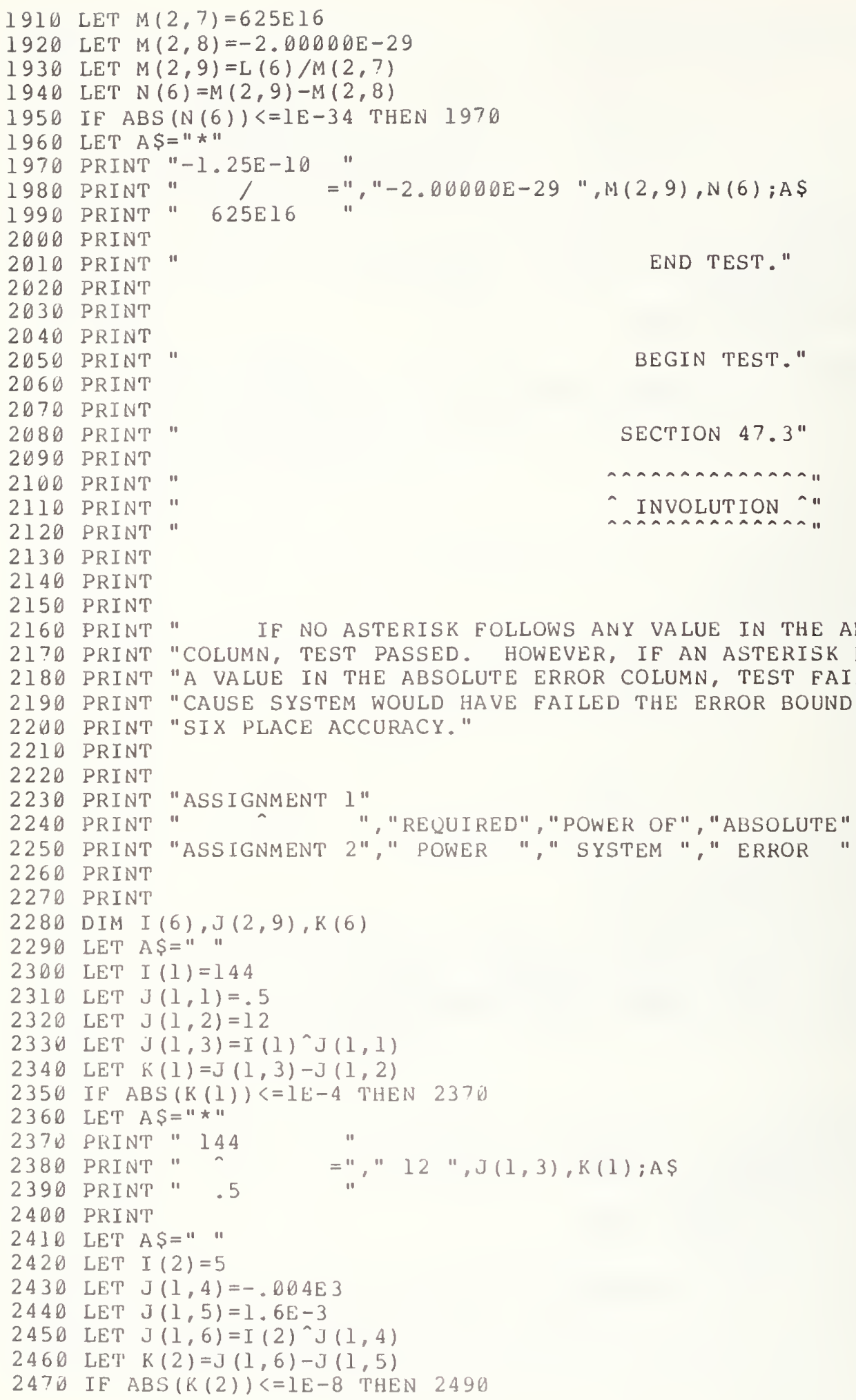


2480 LET A $\$="$ *"

2490 PRINT"

2500 PRINT"

2510 PRINT " -.004E 3

$=", " .0016 ", J(1,6), K(2) ; A S$

2520 PRINT

2530 LET A $\$=" ~ "$

2540 LET $I(3)=65536$

2550 LET $J(1,7)=-625 E-4$

2560 LET $J(1,8)=5 E-1$

2570 LET $J(1,9)=I(3) \wedge J(1,7)$

2580 LET $K(3)=\mathrm{J}(1,9)-\mathrm{J}(1,8)$

2590 IF $A B S(K(3))<=1 E-6$ THEN 2610

2600 LET $A \$=n * "$

2610 PRINT" 65536

2620 PRINT" "

2630 PRINT " $-625 \mathrm{E}-4$

$=", " .5$ " $, J(1,9), K(3) ; A \$$

2650 LET A $\$="$ "

2660 LET $I(4)=.03125$

2670 LET $J(2,1)=-.0002 E 3$

2680 LET $J(2,2)=2$

2690 LET $J(2,3)=I(4) \wedge J(2,1)$

2700 LET $K(4)=J(2,3)-J(2,2)$

2710 IF $A B S(K(4))<=1 E-5$ THEN 2730

2720 LET $A \$=" * \|$

2730 PRINT" .03125

2740 PRINT" "

2760 PRINT

2779 LET $A \$=" ~ "$

2780 LET $I(5)=1.2$

2790 LET $J(2,4)=5000 \mathrm{E}-3$

2800 LET $J(2,5)=2.48832$

2810 LET $J(2,6)=I(5) \wedge J(2,4)$

2820 LET $K(5)=J(2,6)-J(2,5)$

2830 IF ABS $(K(5))<=1 E-5$ THEN 2850

2840 LET $A S=" \star * n$

2850 PRINT " 1.2

2860 PRINT " 2870 PRINT " $5000 \mathrm{E}-3=", 2.48832 ", \mathrm{~J}(2,6), \mathrm{K}(5)$;A

2880 PRINT

2890 LET A $\$="$ "

2900 LET I $(6)=1.024 \mathrm{E} 13$

2910 LET $J(2,7)=-10 E-2$

2920 LET $J(2,8)=5 E-2$

2930 LET $\mathrm{J}(2,9)=\mathrm{I}(6)^{\wedge} \mathrm{J}(2,7)$

2940 LET $K(6)=J(2,9)-J(2,8)$

2950 IF ABS $(K(6))<=1 E-7$ THEN 2970

2960 LET $A \$=" * "$

2970 PRINT " $1.024 E 13$ "

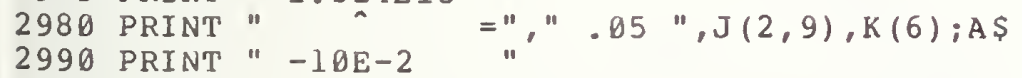

3000 PRINT

3010 PRINT "

3020 PRINT

3030 PRINT

3040 END

END TEST." 


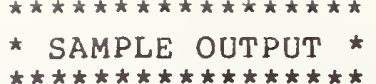

PROGRAM FILE 47

BEGIN TEST.

SECTION 47.1

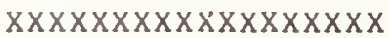

$X$ MULTIPLICATION $X$

XXXXXXXXXXXXXXXXXX

IF NO ASTERISK FOLLOWS ANY VALUE IN THE ABSOLUTE ERROR COLUMN, TEST PASSED. HOWEVER, IF AN ASTERISK FOLLOWS A VALUE IN THE ABSOLUTE ERROR COLUMN, TEST FAILED BECAUSE SYSTEM WOULD HAVE FAILED THE ERROR BOUND ROUND-OFF OF SIX PLACE ACCURACY.

$\begin{array}{cllcc}\text { ASSIGNMENT } & 1 & & & \\ \star & & \text { REQUIRED } & \text { PRODUCT OF } & \text { ABSOLUTE } \\ \text { ASSIGNMENT } & 2 & \text { PRODUCT } & \text { SYSTEM } & \text { ERROR }\end{array}$

5

1.25

$=6.25$

6.25

b

21

* $=-999999 \quad-999999 \quad 0$

$-.47619 \mathrm{E} 5$

$-99$

$-919100 \mathrm{E}-2$

.0015

*

$=93.75$

93.75

0

6. $25 \mathrm{E} 4$

1.92

$\star$

$=1.23456$

1. 23456

b

$6430 \mathrm{E}-4$

$10.631 \mathrm{E2} 2$

$\underset{-72000 \mathrm{E} 5}{\star}=-7.65432 \mathrm{E} 37 \quad-7.65432 \mathrm{E}+37$ 
END TEST.

$$
\begin{aligned}
& \text { BEGIN TEST. } \\
& \text { SECTION } 47.2 \\
& / / / / / / / / / / \\
& / \text { DIVISION }
\end{aligned}
$$

IF NO ASTERISK FOLLOWS ANY VALUE IN THE ABSOLUTE ERROR COLUMN, TEST PASSED. HOWEVER, IF AN ASTERISK FOLLOWS

A VALUE IN THE ABSOLUTE ERROR COLUMN, TEST FAILED BECAUSE SYSTEM WOULD HAVE FAILED THE ERROR BOUND ROUND-OFF OF SIX PLACE ACCURACY.

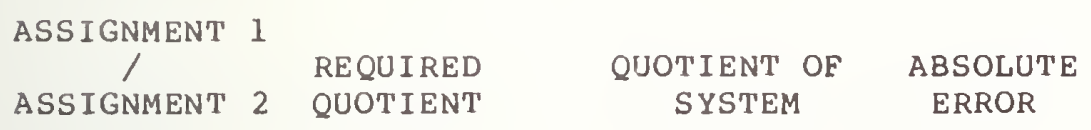

END TEST.

BEGIN TEST.

SECTION 47.3 
IF NO ASTERISK FOLLOWS ANY VALUE IN THE ABSOLUTE ERROR COLUMN, TEST PASSED. HOWEVER, IF AN ASTERISK FOLLOWS A VALUE IN THE ABSOLUTE ERROR COLUMN, TEST FAILED BECAUSE SYSTEM WOULD HAVE FAILED THE ERROR BOUND ROUND-OFF OF SIX PLACE ACCURACY.

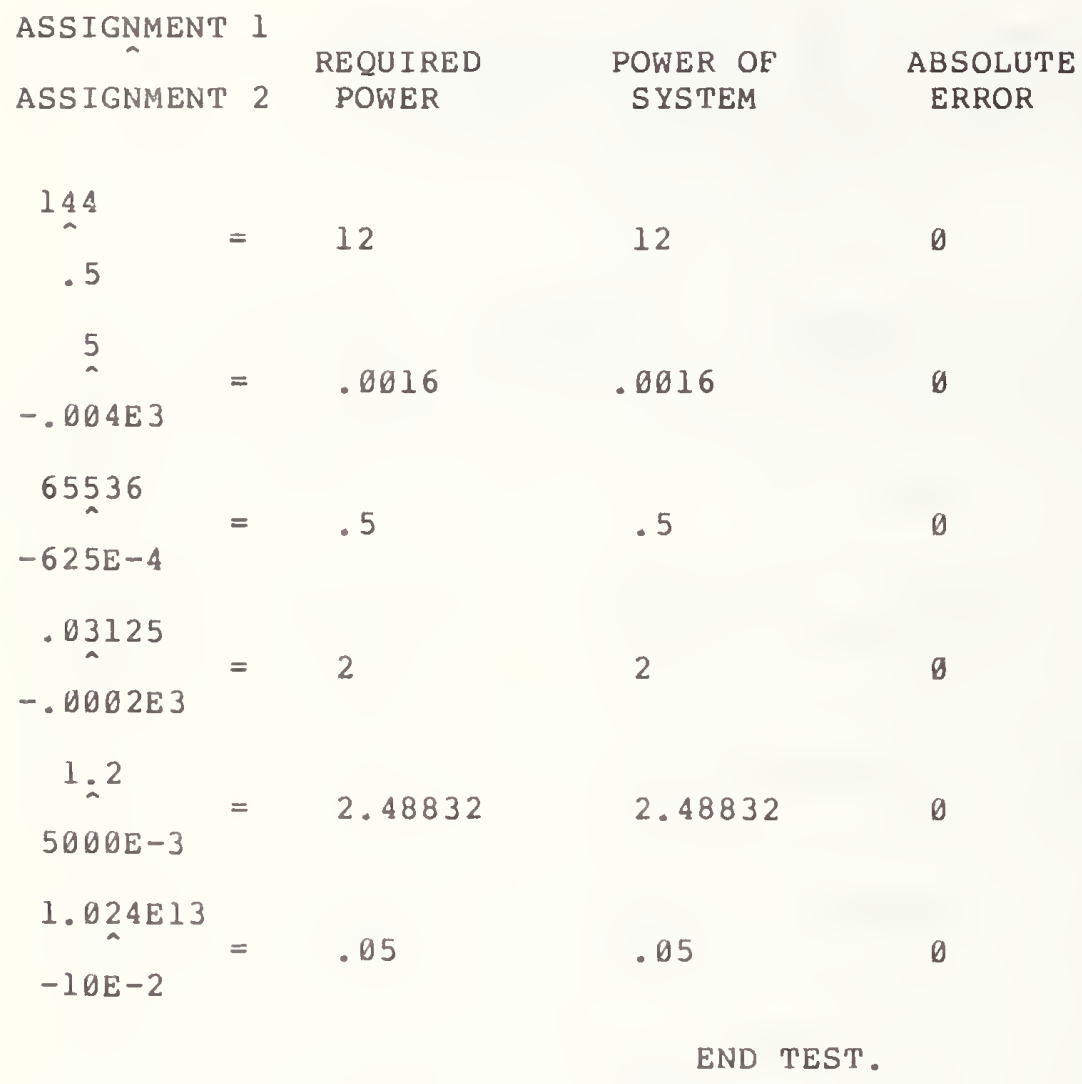




\subsection{ADDITION OF MORE THAN TWO TERMS CONTAINING A RRAY $\overline{\text { ELEMENTS }}$}

The objective of this section is to continue the testing of standard conforming numerical expressions. In particular, in this case we exercise the addition of several terms involving array elements. From previous tests we can have confidence in the addition operation on two terms. Here we are extending the capability one more step.

\subsection{Using Subscripted Variables}

The objective of this test is the same as in section 28.2, except in this test the numerical constants have been assigned to subscripted variables instead of simple variables. In this section two expressions are computed, one with five and the other with six terms. They combine single- and double-dimensional arrays. The output is similar to section 28.2 .

\subsection{Mixing Constants, and Variables}

The objective of this test is the same as in section 28.3 , except in this test subscripted variables are used along with the numerical constants and simple variables to construct numerical expressions. Two expressions are computed, one with seven and the other with eight terms. Constants, simple variables and arrays are combined to form the expressions.

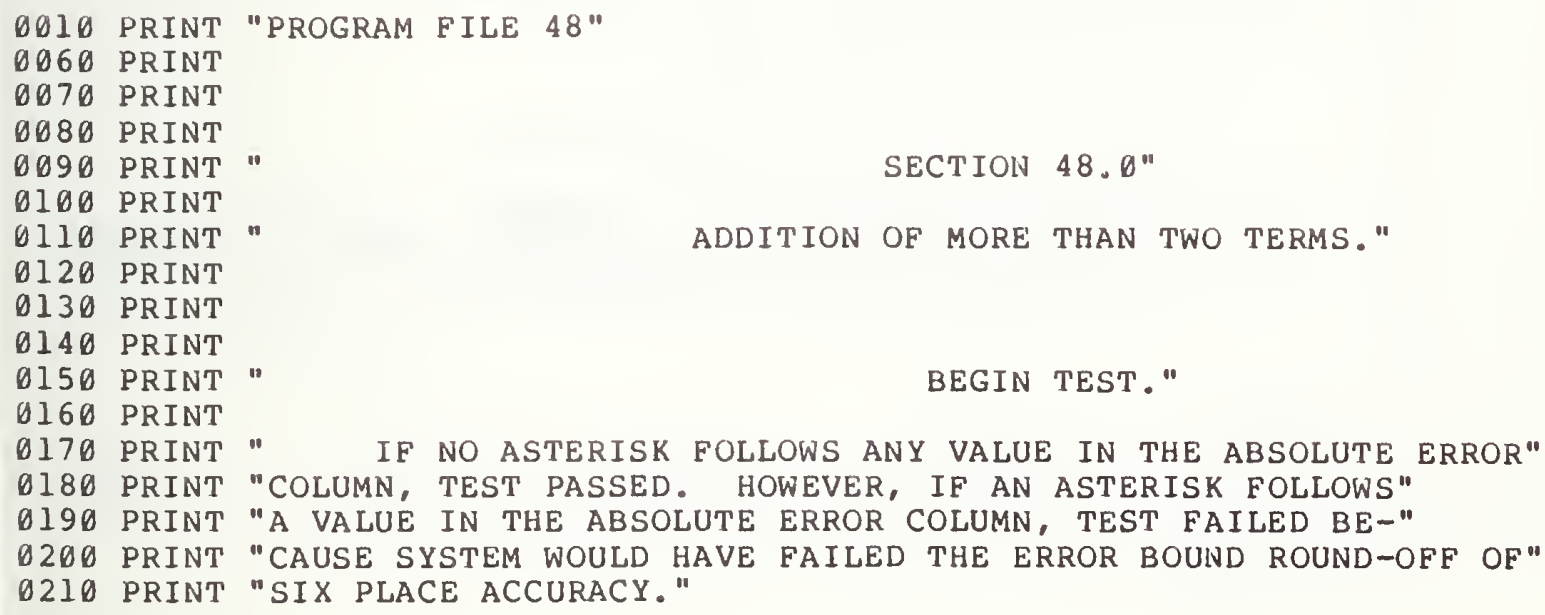

0210 PRINT "SIX PLACE ACCURACY."

\author{
SECTION $48.0^{\prime \prime}$ \\ ADDITION OF MORE THAN TWO TERMS." \\ BEGIN TEST."
}

IF NO ASTERISK FOLLOWS ANY VALUE IN THE ABSOLUTE ERROR"

"COLUMN, TEST PASSED. HOWEVER, IF AN ASTERISK FOLLOWS"

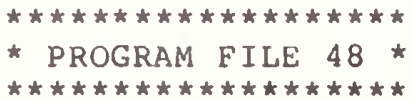




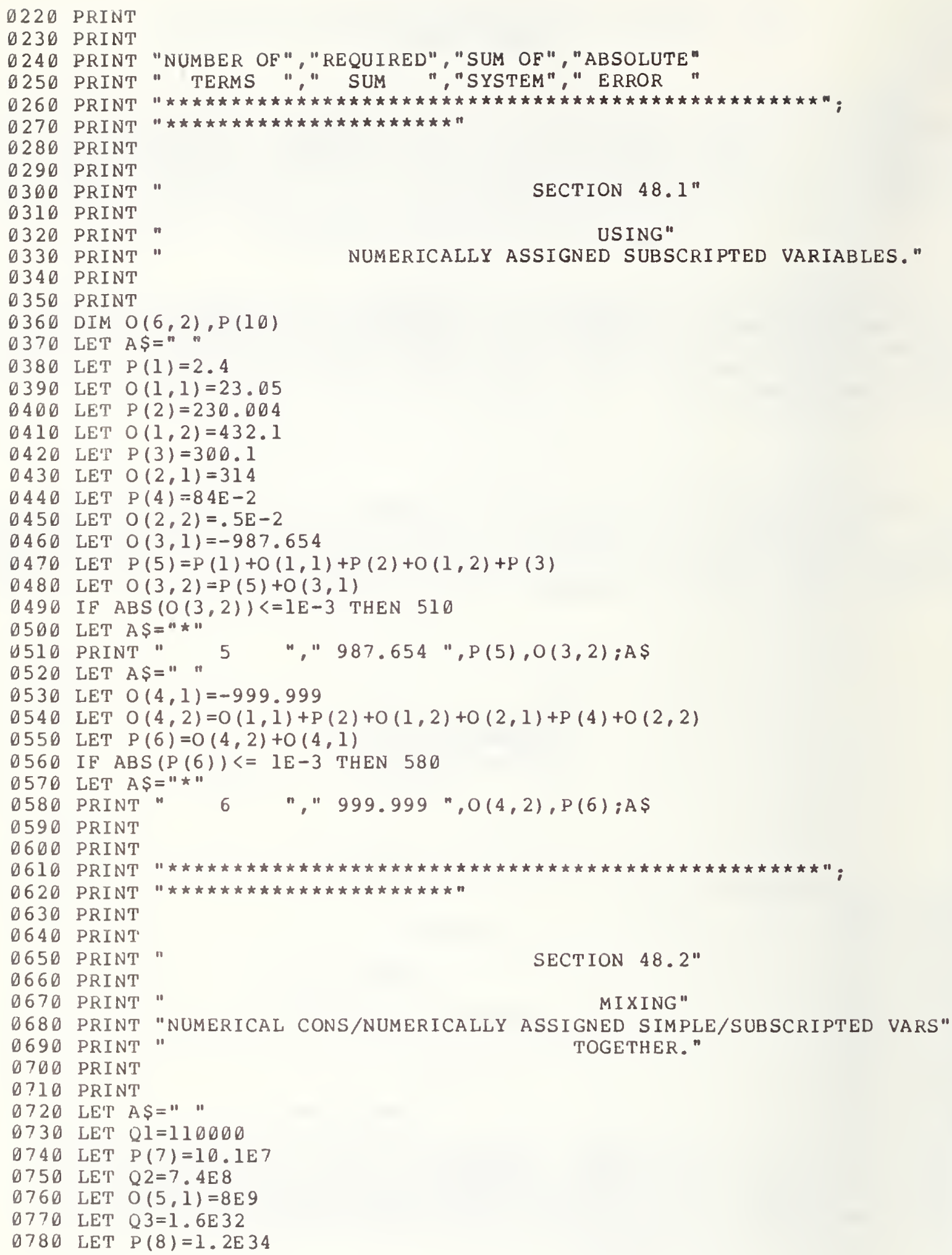




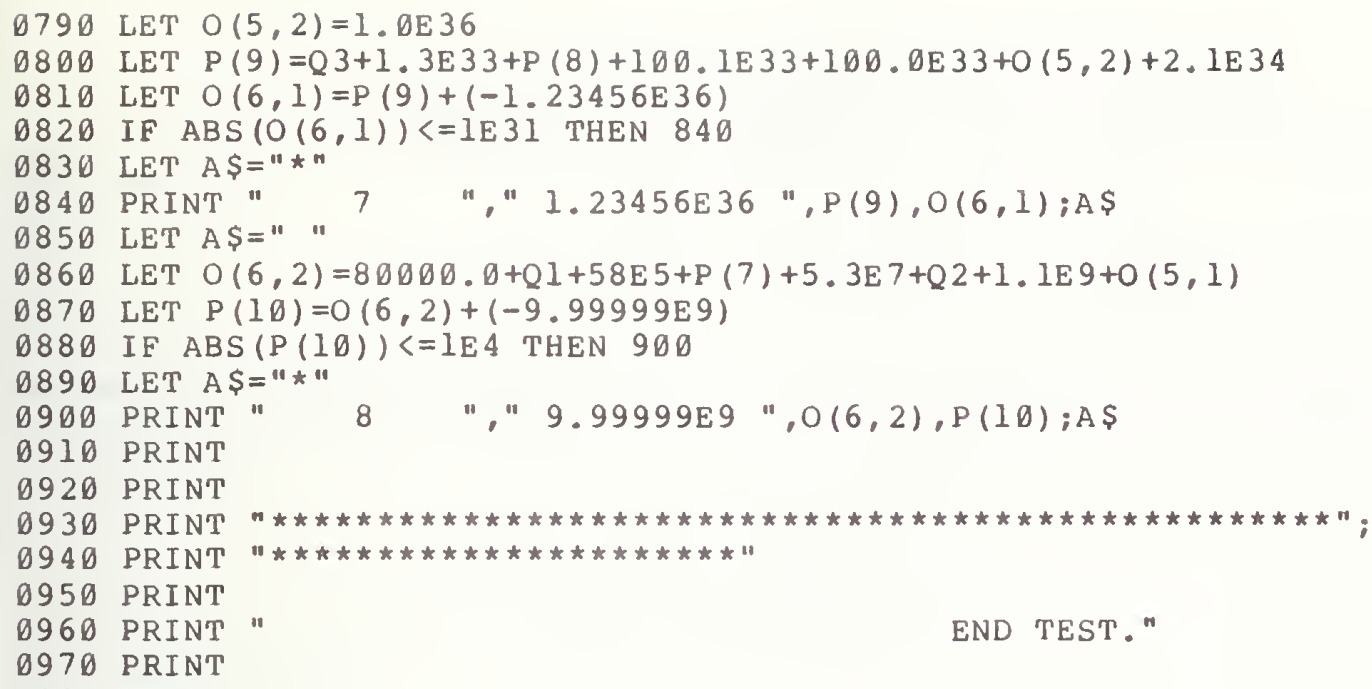

PROGRAM FILE 48

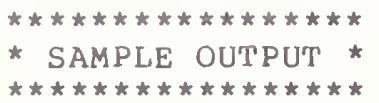

SECTION 48.0

ADDITION OF MORE THAN TWO TERMS.

BEGIN TEST.

IF NO ASTERISK FOLLOWS ANY VALUE IN THE ABSOLUTE ERROR COLUMN, TEST PASSED. HOWEVER, IF AN ASTERISK FOLLOWS A VALUE IN THE ABSOLUTE ERROR COLUMN, TEST FAILED BECAUSE SYSTEM WOULD HAVE FAILED THE ERROR BOUND ROUND-OFF OF SIX PLACE ACCURACY.
NUMBER OF
REQUIRED
SUM OF
ABSOLUTE TERMS SUM
SYSTEM
ERROR 
SECTION 48.1

US ING

NUMERICALLY ASSIGNED SUBSCRIPTED VARIABLES.

$\begin{array}{llll}5 & 987.654 & 987.654 & 0 \\ 6 & 999.999 & 999.999 & 0\end{array}$

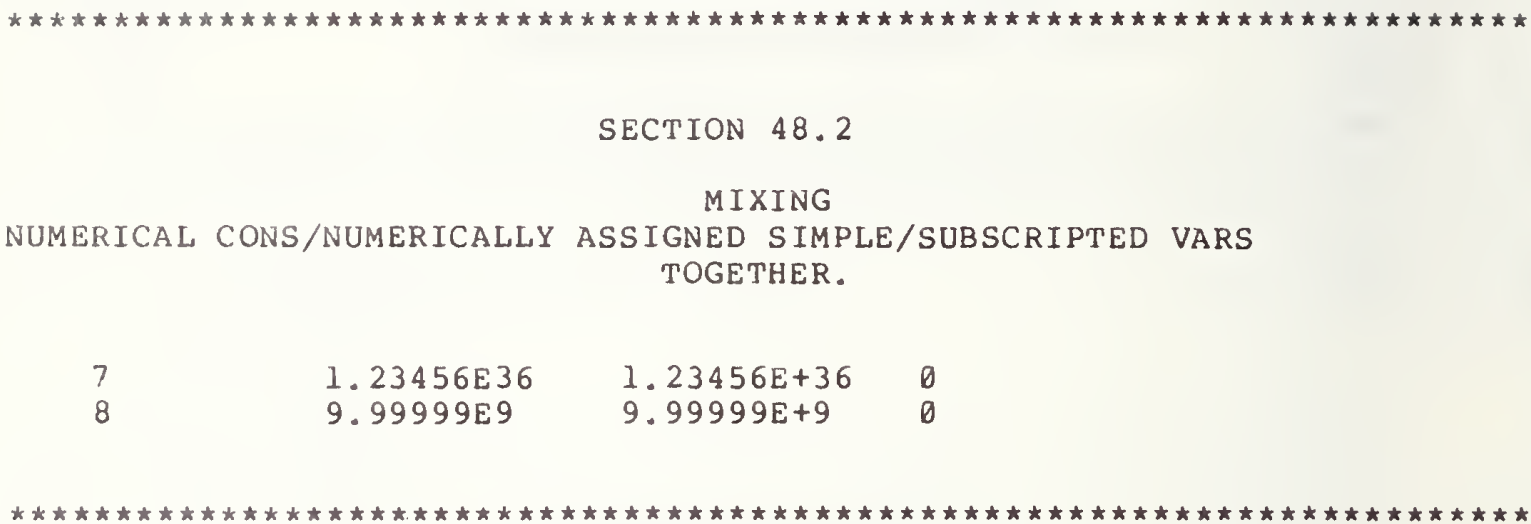

END TEST. 


\subsection{MULTIPLICATION OF MORE THAN TWO TERMS}

This section continues the testing of standard conforming numerical expressions.

\subsection{Using Subscripted Variables}

The objective of this test is the same as in section 29.2, except in this test the numerical constants have been assigned to subscripted variables instead of simple variables. Two expressions of five and six factors each are computed. The output is similar to that of section 29.2.

\subsection{Mixing Constants and Variables}

The objective of this test is the same as in section 29.3, except in this test subscripted variables along with numerical constants and simple variables are used in the construction of numerical expressions. Two expressions of seven and eight terms respectively are computed. The output is similar to that of section 29.3 .
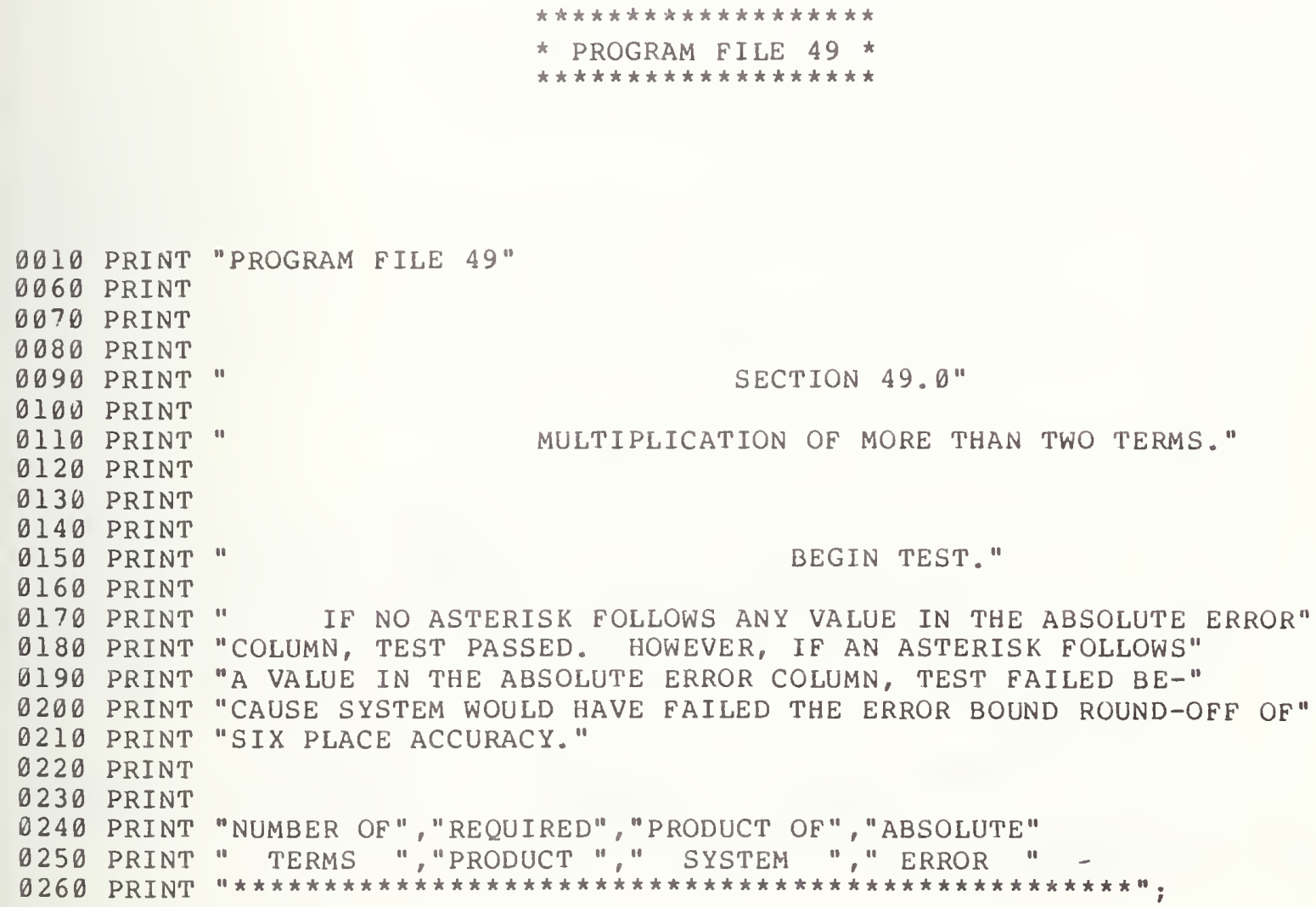


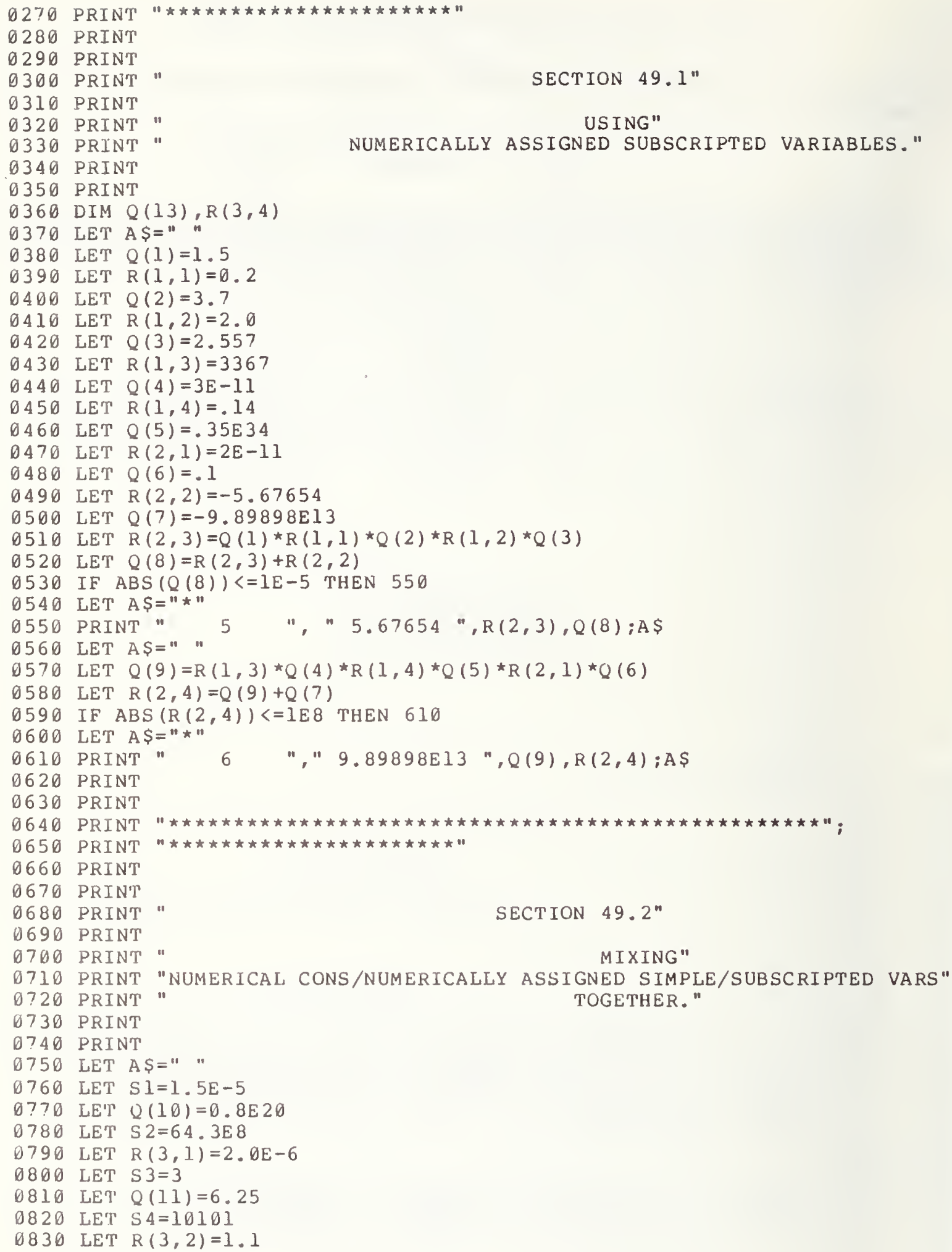


$0840 \operatorname{LET} Q(12)=\mathrm{S} 1 * .2 \mathrm{E} 8 * \mathrm{Q}(10) * .4 \mathrm{E}-10 * \mathrm{~S} 2 * .1 \mathrm{E}-5 * \mathrm{R}(3,1)$

$0850 \operatorname{LET} \quad \mathrm{R}(3,3)=\mathrm{Q}(12)+(-1.23456 \mathrm{E} 10)$

0860 IF $\operatorname{ABS}(\mathrm{R}(3,3))<=1$ E 5 THEN 880

0870 LET A $\$=" * "$

0880 PRINT" 7 ", $1.23456 \mathrm{E} 10 ", Q(12), \mathrm{R}(3,3)$;A

0890 LET AS=" "

$0900 \operatorname{LET} R(3,4)=375 \mathrm{E} 10 * \mathrm{~S} 3 * 1.6 \mathrm{E}-12 * \mathrm{Q}(11) * 4 \mathrm{E} 21 * \mathrm{~S} 4 * .2 \mathrm{E}-10 * \mathrm{R}(3,2)$

0910 LET $Q(13)=R(3,4)+(-9.99999 \operatorname{El} 6)$

0920 IF ABS $(Q(13))<=1$ El1 THEN 940

0930 LET A $\$=" * *$

0940 PRINT " 8 ", " 9.99999E16 ",R(3,4), Q(13);A

0950 PRINT

0960 PRINT

0970 PRINT

0980 PRINT

0990 PRINT

1000 PRINT

END TEST."

1010 PRINT

1020 PRINT

1030 END

PROGRAM FILE 49

* SAMPLE OUTPUT $\star$

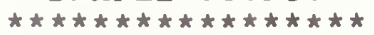

SECTION 49.0

MULTIPLICATION OF MORE THAN TWO TERMS.

BEGIN TEST.

IF NO ASTERISK FOLLOWS ANY VALUE IN THE ABSOLUTE ERROR COLUMN, TEST PASSED. HOWEVER, IF AN ASTERISK FOLLOWS A VALUE IN THE ABSOLUTE ERROR COLUMN, TEST FAILED BECAUSE SYSTEM WOULD HAVE FAILED THE ERROR BOUND ROUND-OFF OF SIX PLACE ACCURACY.

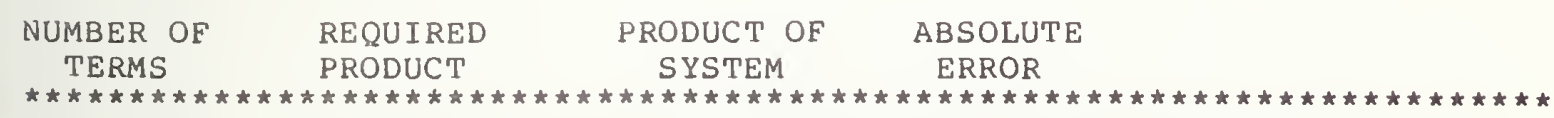


SECTION 49.1

US ING

NUMERICALLY ASSIGNED SUBSCRIPTED VARIABLES.

$\begin{array}{llll}5 & 5.67654 & 5.67654 & 0 \\ 6 & 9.89898 \mathrm{E} 13 & 9.89898 \mathrm{E}+13 & 0\end{array}$

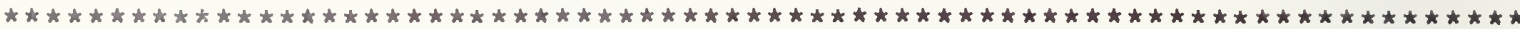

SECTION 49.2

MIXING

NUMERICAL CONS/NUMERICALLY ASSIGNED SIMPLE/SUBSCRIPTED VARS TOGETHER.

$\begin{array}{llll}7 & 1.23456 \mathrm{E} 10 & 1.23456 \mathrm{E}+10 & 0 \\ 8 & 9.99999 \mathrm{E} 16 & 9.99999 \mathrm{E}+16 & 0\end{array}$

\section{END TEST.}




\subsection{HIERARCHY OF OPERATORS AND PARENTHESES}

The objective of this section is to reconstruct test section 30.0 with subscripted variables. This continues the testing of standard conforming numerical expressions.

\subsection{Operators of Equal Priority}

The objective of this test is the same as in section 30.1, except in this test the constants have been assigned to subscripted variables. There are five exercises in this test: left-to-right division, left-to-right subtraction, left-to-right involution, left-to-right subtraction and addition, and finally left-to-right division and multiplication. The output is similar to section 30.1 .

\subsection{Operators of Different Priorities without Parentheses}

The objective of this test is the same as in test section 30.2 , except in this test all numerical constants have been assigned to subscripted variables. In this part of the program there are three exercises to first test multiplication over addition or subtraction, division over addition or subtraction, and finally to test that involution takes precedence over all other operators. The output is similar to section 30.2 .

\subsection{Operators of Different Priorities with Parentheses}

The objective of this test is the same as in section 30.3 , except in this test all numerical constants have been assigned to subscripted variables. In this test, there are two sets ot exercises. The first employs simple expressions that use parentheses and finally there is an exercise using more complex expressions. The output is similar to section 30.3 .

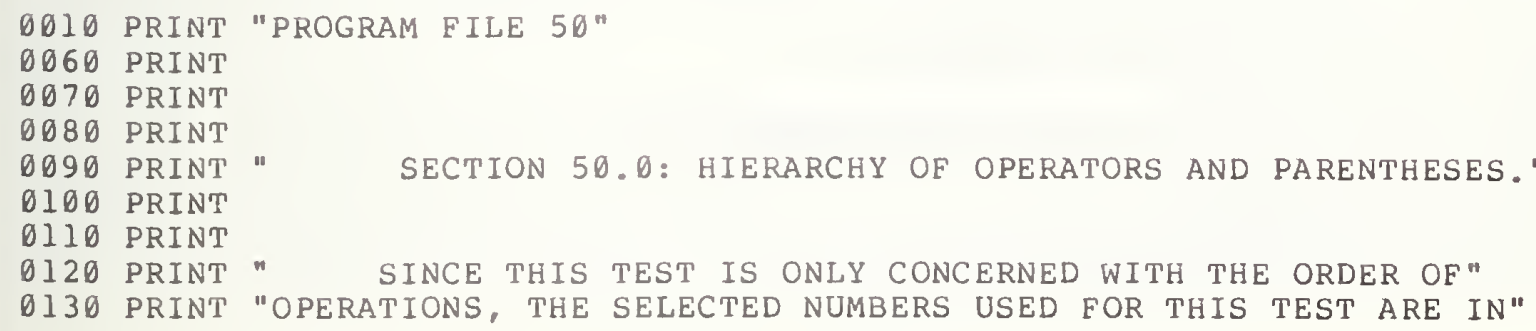




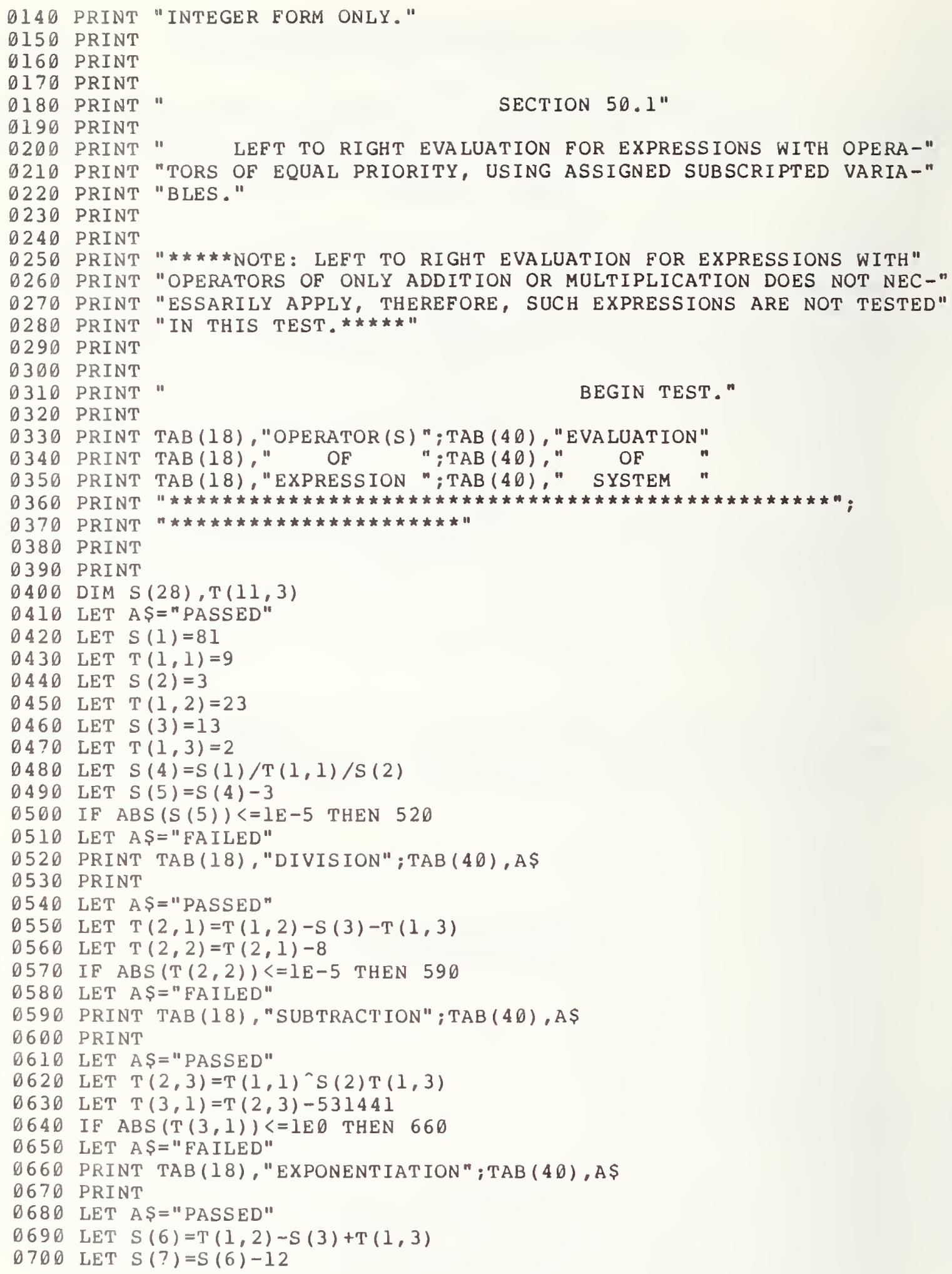




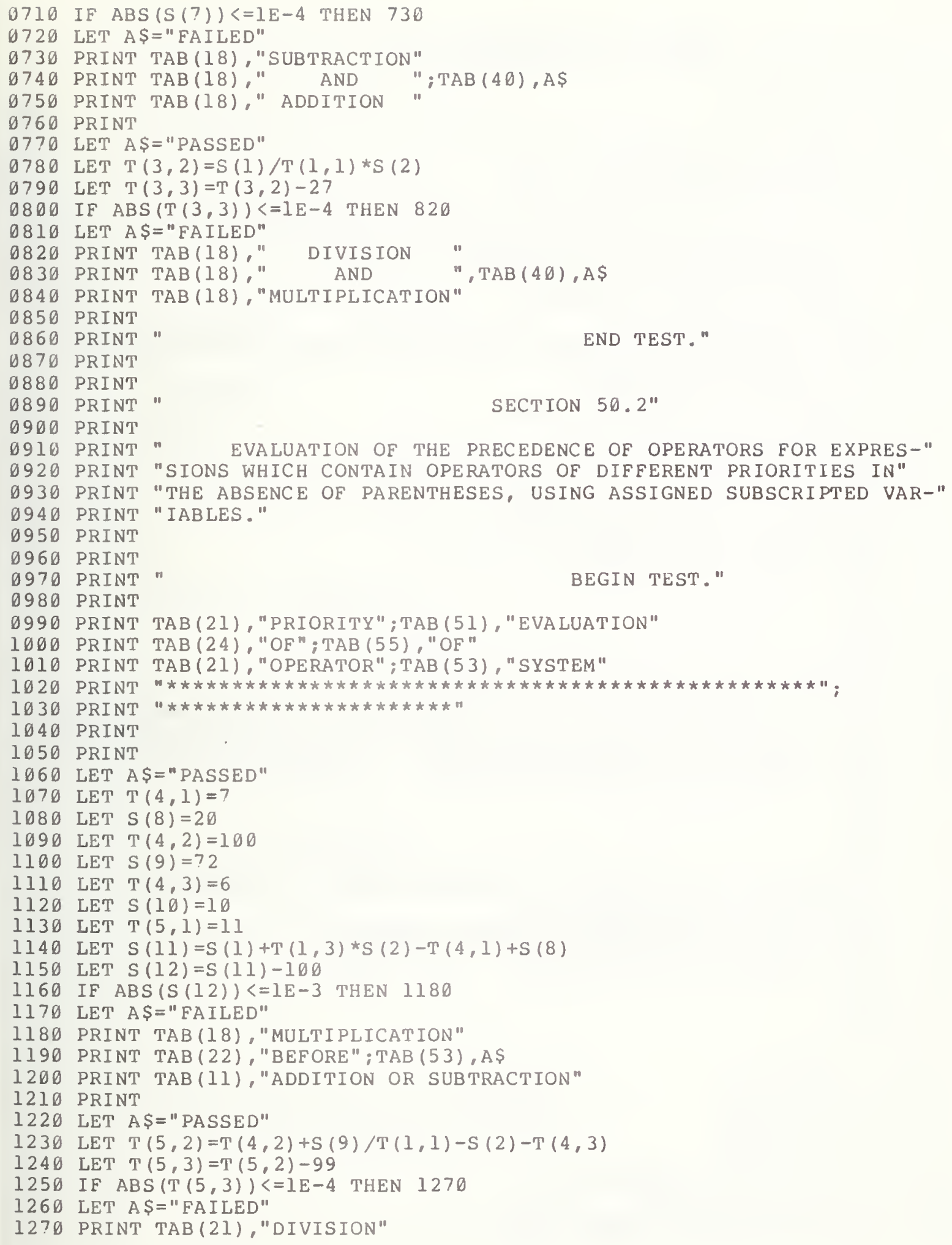




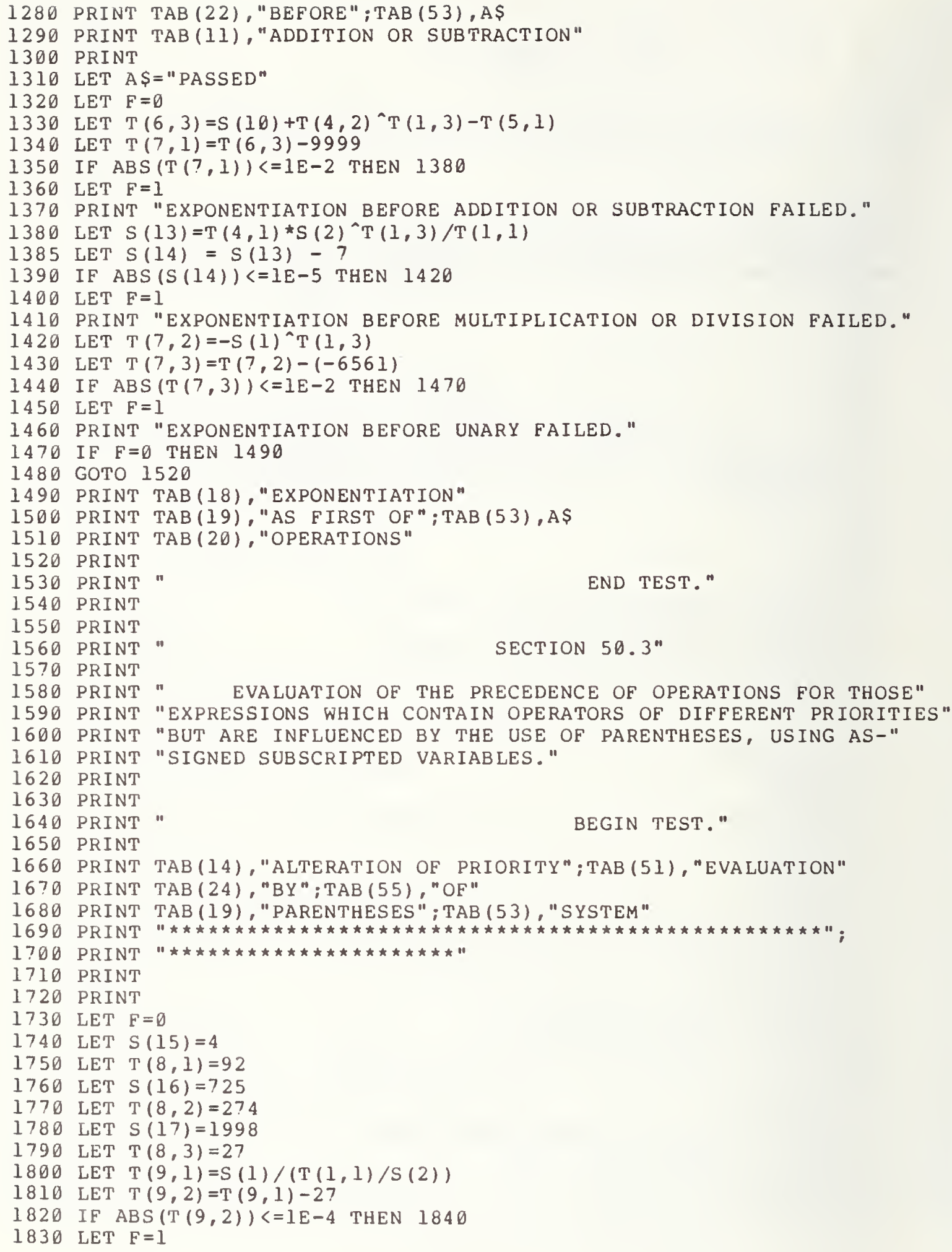


$1840 \operatorname{LET} S(18)=T(1,2)-(S(3)-T(1,3))$

1850 LET $S(19)=S(18)-12$

1860 IF $\operatorname{ABS}(\mathrm{S}(19))<=1 E-4$ THEN 1880

$187 \emptyset$ LET $F=1$

1880 LET $S(2 \theta)=S(15)^{\wedge}(S(2) T(1,3))$

1890 LET $S(21)=S(2 \theta)-262144$

1900 IF ABS $(S(21))<=1 E \emptyset$ THEN 1920

1910 LET $\mathrm{F}=1$

1920 LET $T(9,3)=T(1,2)-(S(3)+T(1,3))$

1930 LET $T(10,1)=T(9,3)-8$

1940 IF $\operatorname{ABS}(T(10,1))<=1 E-5$ THEN 1960

1950 LET $F=1$

1960 LET $S(22)=S(1) /(T(1,1) * S(2))$

1970 LET $S(23)=S(22)-3$

1980 IF $\operatorname{ABS}(\mathrm{S}(23))<=1 E-5$ THEN $20 \emptyset 0$

$199 \emptyset$ LET $F=1$

2000 IF $\mathrm{F}=\emptyset$ THEN 2030

2010 LET A $\$=" U N S U C C E S S F U L "$

2020 GOTO $204 \emptyset$

2030 LET A $=$ "SUCCESSEUL"

2040 PRINT TAB (18), "EXPRESSIONS OF"

2050 PRINT TAB (18), "LEFT TO RIGHT"; TAB (51), A

$2 \emptyset 6 \emptyset$ PRINT TAB (2ø), "EVALUATION"

$207 \emptyset$ PRINT

$208 \emptyset$ LET $F=\emptyset$

$209 \emptyset \operatorname{LET} T(10,2)=(\mathrm{S}(1)+\mathrm{T}(1,3)) *(\mathrm{~S}(2)-\mathrm{T}(4,1))+\mathrm{S}(8)$

$2100 \operatorname{LET} T(10,3)=T(10,2)-(-312)$

2110 IF $\operatorname{ABS}(T(10,3))<=1 E-3$ THEN 2130

2120 LET $F=1$

2130 LET $S(24)=(T(4,2)+T(8,1)) /(T(1,1)-S(2))-T(4,3)$

2140 LET $S(25)=S(24)-26$

2150 IF $\operatorname{ABS}(\mathrm{S}(25))<=1 \mathrm{E}-4$ THEN 2170

2160 LET $F=1$

$217 \emptyset$ LET $S(26)=(S(16)+T(8,2))^{\wedge}(S(15)-T(1,3))+S(17)$

2180 LET $S(27)=S(26)-999999$

2190 IF ABS (S (27)) <=1EØ THEN 2210

2200 LET $F=1$

2210 LET $T(11,1)=(T(5,1) * S(2))^{\wedge}(T(1,1) / S(2)) / T(8,3)$

2220 LET $\mathrm{T}(11,2)=\mathrm{T}(11,1)-1331$

2230 IF $\operatorname{ABS}(\mathrm{T}(11,2))<=1 \mathrm{E}-2$ THEN 2250

2240 LET $F=1$

2250 LET T $(11,3)=(-S(1))^{\wedge} \mathrm{T}(1,3)$

2260 LET $S(28)=T(11,3)-6561$

$2270 \mathrm{IF} \operatorname{ABS}(\mathrm{S}(28))<=1 \mathrm{E}-2$ THEN 2290

2280 LET $F=1$

2290 IF $\mathrm{F}=\emptyset$ THEN 2320

2300 LET A $\$=$ "UNSUCCESSFUL"

2310 GOTO 2330

2320 LET A $\$="$ SUCCESSFUL"

2330 PRINT TAB (14), "EXPRESSIONS EVALUATED"

2340 PRINT TAB(18), "BY PRIORITY OF";TAB(51), AS

2350 PRINT TAB(19), "THE OPERATOR"

2360 PRINT

23? 0 PRINT

2380 PRINT

2396 PRINT

2400 END

END TEST." 
$\star$ SAMPLE OUTPUT $\star$

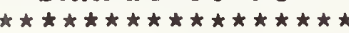

PROGRAM EILE 50

SECTION 50.0: HIERARCHY OF OPERATORS AND PARENTHESES.

SINCE THIS TEST IS ONLY CONCERNED WITH THE ORDER OF OPERATIONS, THE SELECTED NUMBERS USED FOR THIS TEST ARE IN INTEGER FORM ONLY.

SECTION 50.1

LEFT TO RIGHT EVALUATION FOR EXPRESSIONS WITH OPERATORS OF EQUAL PRIORITY, USING ASSIGNED SUBSCRIPTED VARIABLES.

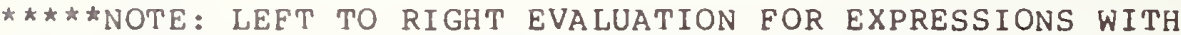
OPERATORS OF ONLY ADDITION OR MULTIPLICATION DOES NOT NECESSARILY APPLY, THEREFORE, SUCH EXPRESSIONS ARE NOT TESTED

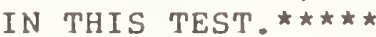

BEGIN TEST .

$\begin{array}{cc}\text { OPERATOR (S) } & \text { EVALUATION } \\ \text { OF } & \text { OF } \\ \text { EXPRESSION } & \text { SYSTEM }\end{array}$

$\begin{array}{cc}\text { DIVISION } & \text { PASSED } \\ \text { SUBTRACTION } & \text { PASSED } \\ \text { EXPONENTIATION } & \text { PASSED } \\ \text { SUBTRACTION } & \\ \text { AND } & \text { PASSED } \\ \text { ADDITION } & \\ \text { DIVISION } & \\ \text { AND } & \\ \text { MULTIPLICATION }\end{array}$

PASSED 


\section{SECTION 50.2}

EVALUATION OF THE PRECEDENCE OF OPERATORS FOR EXPRESSIONS WHICH CONTAIN OPERATORS OF DIFEERENT PRIORITIES IN THE ABSENCE OF PARENTHESES, USING ASSIGNED SUBSCRIPTED VARIAB LES.

\section{BEGIN TEST .}

$\begin{array}{ll}\text { PRIORITY } & \text { EVALUATION } \\ \text { OF } & \text { OF } \\ \text { OPERATOR } & \text { SYSTEM }\end{array}$

MULT I PLICATION

BEFORE

PASSED

ADDITION OR SUBTRACTION

DIVISION

BEFORE

PASSED

ADDITION OR SUBTRACTION

EXPONENTIATION

AS FIRST OF

PASSED

OPERATIONS

END TEST.

SECTION 50.3

EVALUATION OF THE PRECEDENCE OF OPERATIONS FOR THOSE EXPRESSIONS WHICH CONTAIN OPERATORS OF DIFFERENT PRIORITIES BUT ARE INFLUENCED BY THE USE OF PARENTHESES, USING ASSIGNED SUBSCRIPTED VARIABLES.

\section{BEGIN TEST.}

$\begin{array}{ll}\text { ALTERATION OF PRIORITY } & \text { EVALUATION } \\ \text { BY } & \text { OF } \\ \text { PARENTHESES } & \text { SYSTEM }\end{array}$


EVALUATION

EXPRESSIONS EVALUATED

BY PRIORITY OF

THE OPERATOR

SUCCESSFUL

END TEST. 


\subsection{EVALUATION OF EXPRESSIONS THAT HAVE A VARIETY OF OPERATORS}

In this test expressions are formed from numerical constants, numerically assigned simple and assigned subscripted variables. Each expression is characterized by either the absence of parentheses, use of non-nested parentheses, or nested parentheses. The objective of this test is the same as in test section 32.0, except in this test subscripted variables are included along with the numerical constants and simple variables for the construction of the numeric expressions. Three exercises are performed. Each exercise includes the evaluation of eight expressions. In the first exercise, no parentheses are used in order to test left-to-right precedence. In the second exercise, parentheses are used but are not nested in order to test that evaluation within parentheses takes place first and then that left-to-right precedence is observed. Finally, expressions with nested parentheses are evaluated. Output is similar to section 32.0 .

\begin{tabular}{|c|c|c|}
\hline 0010 & PRINT & "PROGRAM FILE 51 " \\
\hline 0060 & PRINT & \\
\hline 070 & PRINT & \\
\hline 080 & PRIN'T & \\
\hline 090 & PRINT & SECTION $51.0 "$ \\
\hline 100 & PRINT & \\
\hline 110 & PRINT & EVALUATION OF EXPRESSIONS WHICH HAVE A VARIETY OF OP-" \\
\hline 120 & PRINT & "ERATORS AND ARE OF ONE OF THREE CATEGORIES:" \\
\hline 130 & PRINT & \\
\hline 140 & PRINT & (1) NO PARENTHESES," \\
\hline 150 & PRINT & (2) NON-NESTED PARENTHESES, AND" \\
\hline 160 & PRINT & (3) NESTED PARENTHESES." \\
\hline 170 & PRINT & \\
\hline 180 & PRINT & "ALSO, "THESE EXPRESSIONS ARE FORMED FROM THE USE OF NUMERI-" \\
\hline 190 & PRINT & "CAL CONSTANTS, NUMERICALLY ASSIGNED SIMPLE VARIABLES, AND" \\
\hline 00 & PRINT & "NUMERICALLY ASSIGNED SUBSCRIPTED VARIABLES." \\
\hline 210 & PRINT & \\
\hline 0 & PRINT & \\
\hline 30 & PRINT & TAB (18)," CATEGORY ";TAB (36), "EVALUATION" \\
\hline$\theta$ & PRINT & " :ТАB (36)," \\
\hline & PRINT & TAB (18), "EXPRESSION" ; TAB (36)," SYSTEM \\
\hline & PRINT & 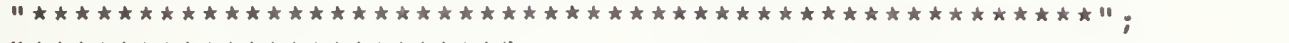 \\
\hline & PRINT & 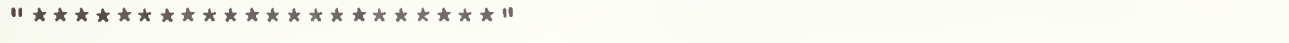 \\
\hline & PRINT & \\
\hline & PRINT & \\
\hline & PRINT & BEGIN TEST." \\
\hline & RINT & \\
\hline
\end{tabular}




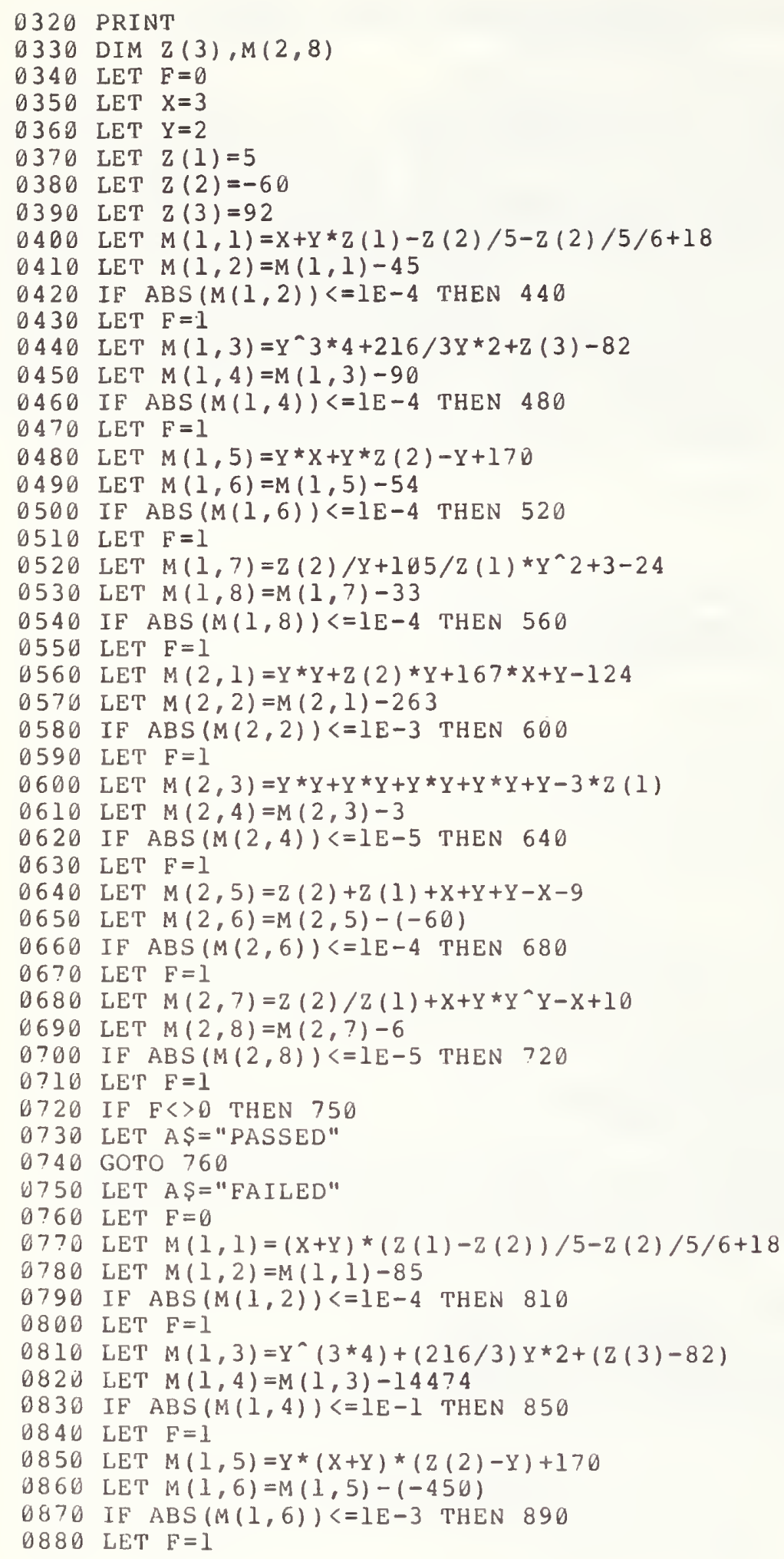




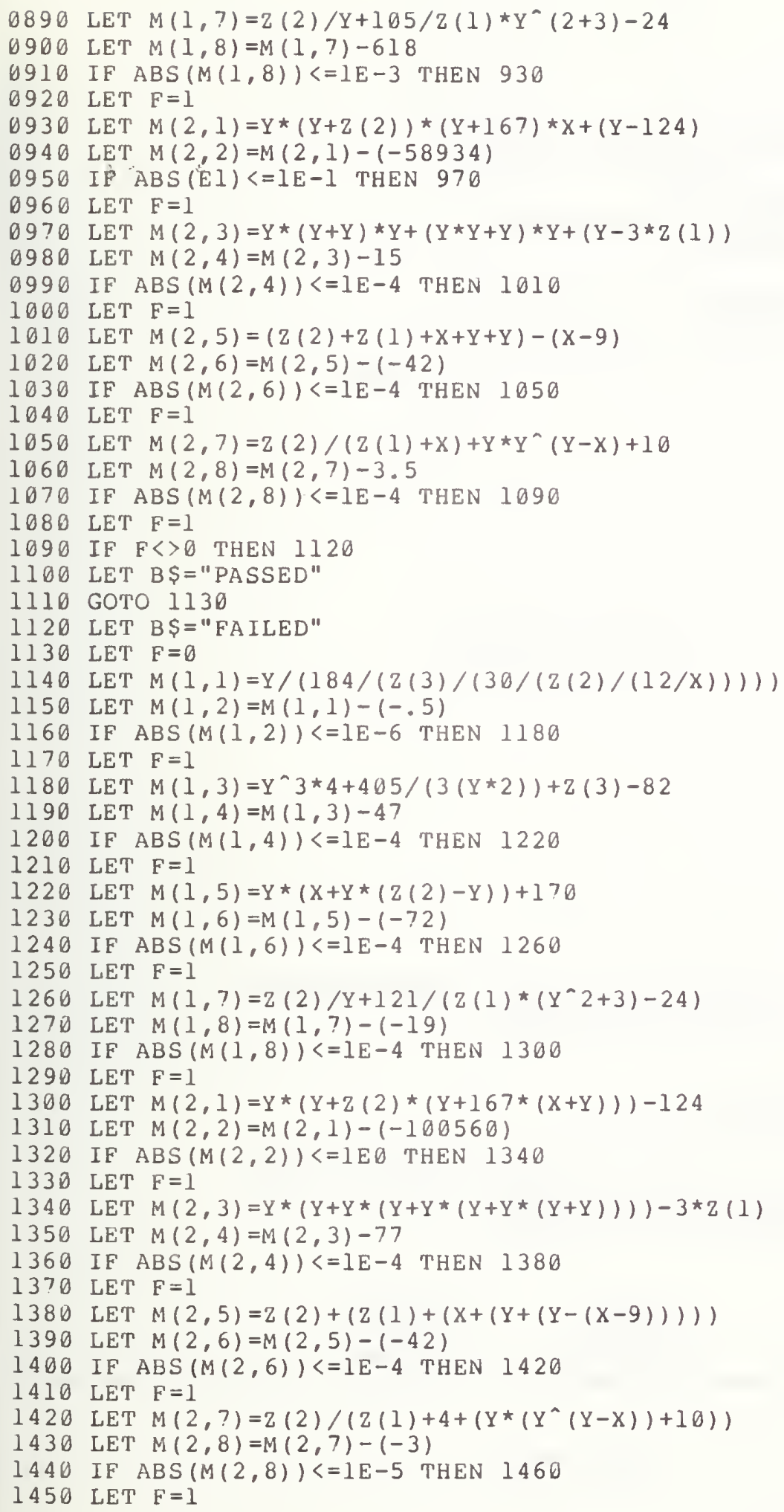


1460 IF $F<>0$ THEN 1490

1470 LET $C \$="$ PASSED"

1480 GOTO 1500

1490 LET $C \$=" F A I L E D "$

1500 PRINT TAB (18)," NO "

1510 PRINT TAB (18)," PARENTHESES" ; TAB (38), AS

1520 PRINT

1530 PRINT TAB (18), "PARENTHESES"

1540 PRINT TAB(18)," BUT ";TAB(38),B\$

1550 PRINT TAB (18),"NON-NESTED "

1560 PRINT

1570 PRINT TAB $(18), "$ NESTED "

1580 PRINT TAB (18), "PARENTHESES" ; TAB (38), C $\$$

1590 PRINT

1600 PRINT"

END TEST."

1610 PRINT

1620 PRINT

1630 END

PROGRAM FILE 51

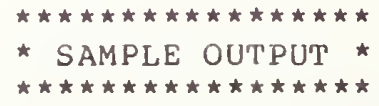

SECTION 51.0

EVALUATION OF EXPRESSIONS WHICH HAVE A VARIETY OF OPERATORS AND ARE OF ONE OF THREE CATEGORIES:

(1) NO PARENTHESES,

(2) NON-NESTED PARENTHESES, AND

(3) NESTED PARENTHESES.

ALSO, THESE EXPRESSIONS ARE FORMED FROM THE USE OF NUMERICAL CONSTANTS, NUMERICALLY ASSIGNED SIMPLE VARIABLES, AND NUMERICALLY ASSIGNED SUBSCRIPTED VARIABLES.

CATEGORY

OF

EXPRESSION
EVALUATION

OF SYSTEM 
NO

PARENTHESES PASSED

PARENTHESES

BUT

NON-NESTED

PASSED

NESTED

PARENTHESES

PASSED

END TEST. 


\title{
52.0 EXCEPTION TEST = ZERO RAISED TO A NEGATIVE POWER
}

The objective of this test is to verify that the implementation recognizes zero raised to a negative power as an exception with a specified recovery procedure. In this case it means that upon recognition of this error, the implementation should supply machine infinity and continue program execution. The test has a statement at line 290 which allows zero to be raised to a negative power. Some systems may generate diagnostics that refer to this line number. On the other hand, this test prints a statement that informs the user on what he should expect so that the user can for himself determine whether the implementation has performed according to the standard. In particular, the user must look for the machine infinity for his particular system.

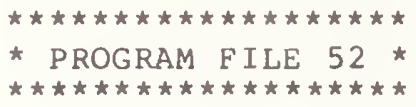

\author{
0010 PRINT "PROGRAM FILE 52 " \\ 0100 PRINT \\ 0110 PRINT \\ 0120 PRINT \\ 0130 PRINT" \\ SECTION $52.0 "$ \\ 0140 PRINT \\ 0150 PRINT"
}

0160 PRINT

0170 PRINT

0180 PRINT

0190 PRINT

0200 PRINT

0210 PRINT

" THE OBJECTIVE OF THIS SECTION IS TO DETERMINE WHETHER "

"IMPLEMENTATION WILL CONSIDER ZERO BEING RAISED TO A NEGA-"

"TIVE POWER AS A NONFATAL ERROR; THAT IS, UPON RECOGNITION"

0220 PRINT "OF SUCH AN ERROR, IMPLEMENTATION SHOULD SUPPLY ITS MACHINE"

0230 PRINT "INFINITY AND CONTINUE PROGRAM EXECUTION."

0240 PRINT

0250 PRINT

0260 PRINT

0270 PRINT

0280 PRINT

0290 LET $A=0^{\wedge}-5$

0300 PRINT " IF THE NUMERICAL VALUE, WHICH SHOULD BE PRINTED FOLLOW-"

0310 PRINT "ING THIS MESSAGE, IS RECOGNIZED BY THE USER AS THE MACHINE "

0320 PRINT "INFINITY FOR THE SYSTEM BEING TESTED, THEN IMPLEMENTATION "

0330 PRINT "WILL HAVE PASSED THE TEST."

0340 PRINT

0350 PRINT A

0360 PRINT

0370 PRINT"

0380 PRINT

END TEST." 


\author{
SECTION 52.0 \\ (ZERO RAISED TO A NEGATIVE POWER.)
}

THE OBJECTIVE OF THIS SECTION IS TO DETERMINE WHETHER IMPLEMENTATION WILL CONSIDER ZERO BEING RAISED TO A NEGATIVE POWER AS A NONFATAL ERROR; THAT IS, UPON RECOGNITION OF SUCH AN ERROR, IMPLEMENTATION SHOULD SUPPLY ITS MACHINE INFINITY AND CONTINUE PROGRAM EXECUTION.

BEGIN TEST.

? ZERO TO A NEGATIVE POWER IN LINE 290

IF THE NUMERICAL VALUE, WHICH SHOULd BE PRINTED FOLLOWING THIS MESSAGE, IS RECOGNIZED BY THE USER AS THE MACHINE INFINITY FOR THE SYSTEM BEING TESTED, THEN IMPLEMENTATION WILL HAVE PASSED THE TEST.

$1.70141 \mathrm{E}+38$

END TEST. 
The objective of this test is to verify that the implementation recognizes a negative power raised to a non-integral power as an exception with no recovery procedure. This means that the error should be reported and program execution should be suspended pending user-directed restart procedures. In this test, there is a statement at line 270 that has a neyative number raised to a non-integral power. A diagnostic should be the only output unless a translator is used that executes line by 1 ine. In that case, a fatal diagnostic should appear after the statement BEGIN TEST.

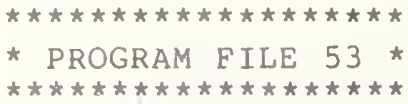

\begin{abstract}
0010 PRINT "PROGRAM FILE $53 "$
0060 PRINT

0070 PRINT

0080 PRINT

$\emptyset 090$ PRINT

ØI0 PRINT

0110 PRINT

0120 PRINT

0130 PRINT

0140 PRINT

Ø150 PRINT

0160 PRINT

Ø170 PRINT

0180 PRINT

0190 PRINT

0200 PRINT

0210 PRINT
\end{abstract}

0220 PRINT

D 230 PRINT

0240 PRINT

0250 PRINT"

BEGIN TEST."

0260 PRINT

$\emptyset 270$ LET $A=(-25)^{\star} .5$

0280 PRINT A; "HAS BEEN PRINTED, THEREFORE, TEST FAILS WHICH MEANS THE" Ø290 PRINT "SYSTEM DID NOT RECOGNIZE PROPERLY A NEGATIVE NUMBER BEING" $030 \emptyset$ PRINT "RAISED TO A NON-INTEGRAL POWER."

0310 PRINT

0320 PRINT

END TEST."

0330 PRINT

0340 END 
* SAMPLE OUTPUT *

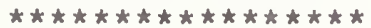

PROGRAM FILE 53

SECTION 53.0

(A NEGATIVE NUMBER RAISED TO A NON-INTEGRAL POWER.)

THE OBJECTIVE OF THIS SECTION IS TO DETERMINE WHETHER UPON EVALUATION OF THE OPERATION OF INVOLUTION RESULTING IN A NEGATIVE NUMBER BEING RAISED TO A NON-INTEGRAL POWER WILL THE SYSTEM CONSIDER THIS AS A FATAL ERROR. THAT IS, WILL THE SYSTEM SUSPEND PROGRAM EXECUTION IN SUCH A WAY THAT USER-DIRECTED RESTART PROCEDURES ARE REQUIRED? IF THIS PROCEDURE IS TAKEN, THEN THE TEST WILL HAVE PASSED.

BEGIN TEST .

? ABSOLUTE VALUE RAISED TO POWER IN LINE 270 
The objective of this test is to determine whether the implementation recognizes an occurrence of the same subscripted variable with a different number of subscripts as an error. The routine uses the array $A$ as both a single and double dimensioned array. If an implementation recognizes this error, the output of the test should be a diagnostic that indicates that in lines 340 to 360 there is an array used with different sets of subscripts. However, since this is a semantic rather than a syntactic error some systems may allow one and two - dimensioned arrays to use the same variable name. This test is meant to be informative to the user.

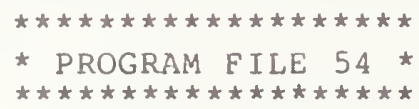

0010 PRINT "PROGRAM FILE $54 "$
0120 PRINT
0130 PRINT
0140 PRINT "
0150 PRINT "
0160 PRINT "
0170 PRINT " (THE SAME SUBSCRIPTED VARIABLE WITH DIFFERENT NUMBERS OF"
0180 PRINT"

0190 PRINT

0200 PRINT

0210 PRINT

0220 PRINT

0230 PRINT

" THE OBJECTIVE OF THIS SECTION IS TO DETERMINE WHETHER"

0240 PRINT

"THE USE OF THE SAME SUBSCRIPTED VARIABLE WITH BOTH ONE SUB-"

0250 PRINT

O 260 PRINT

"SCRIPT AND TWO SUBSCRIPTS IN THE SAME PROGRAM IS ALLOWED" "BY THE SYSTEM. IF THE SYSTEM RECOGNIZES THIS AS A FATAL"

0290 PRINT

0300 PRINT

0310 PRINT

0320 PRINT

0330 PRINT

0340 LET $A(1)=2$

0350 LET $A(5,5)=A(1)+64$

0360 PRINT A $(5,5)$ : "HAS BEEN PRINTED, "THEREFORE, TEST FAILS WHICH MEANS"

O 370 PRINT "THE SYSTEM DID NOT RECOGNIZE PROPERLY THE SAME SUBSCRIPTED"

0380 PRINT "VARIABLE OCCURRING WITH DIFFERENT" NUMBERS OF SUBSCRIPTS."

0390 PRINT

0400 PRINT

BEGIN TEST."

0410 PRINT

END TEST."

$\emptyset 420$ END 
If this program executes then the test system recognizes the same subscripted variable with one and two - dimensional arrays. However, if a system does not then a possible error diagnostic for this program might be:

? DIMENSION ERROR IN LINE 350 
The objective of this test is to verify that the implementation will recognize when the values of a subscripted variable are not within the appropriate range. In the present case we test whether the implementation recognizes an exception when a subscript is assigned a value greater than 10 if that array has not been declared in a dimension-statement. There is a statement in which a subscripted variable has a subscript value greater than ID yet that subscripted variable is not a declared array that might allow for such a subscript value. On output, there should be a fatal diagnostic that might indicate a dimensioning error in line 330.

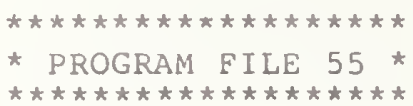

$0 \emptyset 10$ PRINT "PROGRAM FILE 55"

Ø๑60 PRINT

0070 PRINT

Ө७० PRINT

0090 PRINT

0100 PRINT

0110 PRINT

O120 PRINT

0130 PRINT

0140 PRINT

0150 PRINT

0160 PRINT

0170 PRINT

$\emptyset 180$ PRINT

0190 PRINT

0200 PRINT

0210 PRINT

0220 PRINT

0230 PRINT

0240 PRINT

0250 PRINT

0270 PRINT

0290 PRINT

0300 PRINT

0310 PRINT"

0320 PRINT

0330 LET A $(15)=2$

0 340 PRINT A (15); "HAS BEEN PRINTED, THEREFORE, TEST FAILS WHICH MEANS"

0350 PRINT "THE SYSTEM DID NOT RECOGNIZE PROPERLY THAT THE SUBSCRIPT"

0360 PRINT "BEING USED WAS OUT OF THE RANGE OF THE IMPLICIT DIMENSION-"

0370 PRINT "ING BOUND."

SECTION $55.0^{n}$

IN THE RANGE OF THE IMPLICIT DIMENSION-" ING BOUNDS.)"

THE OBJECTIVE OF THIS SECTION IS TO DETERMINE WHETHER" "THE USE OF A SUBSCRIPT WHICH IS NOT IN THE RANGE OF THE" "IMPLICIT DIMENSIONING BOUNDS IS ALLOWED BY THE"

"SYSTEM. IF THE SYSTEM RECOGNIZES THIS AS A FATAL ERROR" "(THAT IS, SUSPENDING PROGRAM EXECUTION SUCH THAT USER-DI-" "RECTED RESTART PROCEDURES ARE REQUIRED), THEN THE TEST WILL" "HAVE PASSED."

BEGIN TEST." 
PROGRAM FILE 55

\section{SECTION 55.0}

(A SUBSCRIPT IS NOT IN THE RANGE OF THE IMPLICIT DIMENSIONING BOUNDS.)

THE OBJECTIVE OF THIS SECTION IS TO DETERMINE WHETHER THE USE OF A SUBSCRIPT WHICH IS NOT IN THE RANGE OF THE IMPLICIT DIMENSIONING BOUNDS IS ALLOWED BY THE SYSTEM. IF THE SYSTEM RECOGNIZES THIS AS A FATAL ERROR (THAT IS, SUSPENDING PROGRAM EXECUTION SUCH THAT USER-DIRECTED RESTART PROCEDURES ARE REQUIRED), THEN THE TEST WILL HAVE PASSED.

BEGIN TEST. 
The objective of this test is to verify that the implementation recognizes the assignment of a value to a location greater than the upper bound of the array declaration as an exception. This test has a statement in which an assigned value to the subscript is larger than the upper bound of the array declaration. A fatal diagnostic on output is required. It might indicate that there is a dimension error in line 170.

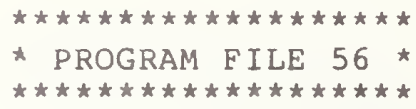

0010 PRINT "PROGRAM FILE 56"

0060 PRINT

0070 PRINT

0080 PRINT

DO90 PRINT"

OI00 PRINT"

OIIO PRINT

0120 PRINT

0130 PRINT

O140 PRINT

0150 PRINT

0160 DIM A(100)

0170 LET $A(101)=64$

0180 PRINT A(I01); "HAS BEEN PRINTED, THEREFORE, TEST FAILS WHICH MEANS"

O190 PRINT "THE SYSTEM DID NOT RECOGNIZE PROPERLY THAT THE SUBSCRIPT"

0200 PRINT "BEING USED WAS OUT OF THE RANGE OF THE EXPLICIT DIMENSION-"

0210 PRINT "ING BOUND."

0220 PRINT

0230 PRINT

SECTION 56. 0 "

FATAL ERROR TEST ON DIMENSIONED VARIABLES" (THE EXPLICIT CASE.)"

D240 PRINT

END TEST."

0250 END

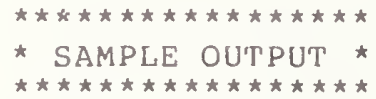


PROGRAM FILE 56

SECTION 56.0

FATAL ERROR TEST ON DIMENSIONED VARIABLES

(THE EXPLICIT CASE.)

BEGIN TEST.

? DIMENSION ERROR IN LINE 170 
The objective of this test is to generate a string overflow to determine whether the implementation will recognize this as an error and provide an appropriate diagnostic. Since a string expression is either a string constant or string variable, two cases must be considered. However, string constants up to the maximum allowed line length have previously been tested. This test, then, will only test string variable assignment. The standard specifies that string variables can have assigned to them, during the execution of a program, a character string from zero to 18 characters. This test attempts to assign strings longer than 18 characters in length. This is an informative test since a portable standard conforming program should only use string variables with assignments of 18 or fewer characters. Implementations that accept the assignment of strings longer than 18 characters are not required to inform the user that this program contains assigned strings, longer than 18 characters. The reader is referred to section 6.4 of BSR $\times 3.60$ for the precise specifications.

The test has been constructed with several statements that allow strings of various lengths greater than 18 characters to be assigned to string variables. The lengths of the strings used are 19, 20, 30, 40, 50 , and 58 characters in length.

If a diagnostic is generated, then it most likely will terminate the program. Some systems, however, accept long assigned strings. Therefore, since multi-line statements are not permitted, this error test may not generate a diagnostic for systems allowing long strings. This is acceptable since the implementation could not be made to overflow with respect to strings.

0010 PRINT "PROGRAM FILE 57"

0060 PRINT

$\emptyset 070$ PRINT

$008 \emptyset$ PRINT

$\emptyset 09 \emptyset$ PRINT

OIDØ PRINT

DIID PRINT

$\emptyset 120$ PRINT

0130 PRINT

0140 PRINT

O150 PRINT

$\emptyset 160$ PRINT

0170 PRINT

$\emptyset 180$ PRINT

SECTION 5?.0: ERROR TEST ON STRING EXPRESSIONS."

* PROGRAM FILE 5 ? $\star \star$

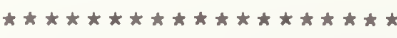

" THE OBJECTIVE OF THIS SECTION IS TO DETERMINE WHETHER" "THE ASSIGNING OF MORE THAN 18 CHARACTERS TO A STRING WOULD" "BE RECOGNIZED BY THE SYSTEM AS A EATAL ERROR. THAT IS, UP-" "ON SUCH AN ASSIGNMEN'T, PROGRAM EXECUTION WOULD BE SUSPENDED" "PENDING USER-DIRECTED RESTART PROCEDURES. IF THE SYSTEM" "RECOGNIZES SUCH ASSIGNMENTS AS FATAL ERRORS, THEN THE TEST" 
0190 PRINT "PASSES. HOWEVER, IF IT DOES NOT, THEN THE SYSTEM SATISEIES" $\emptyset 200$ PRINT "MORE THAN WHAT IS REQUIRED BY MINIMAL BASIC."

0210 PRINT

0220 PRINT

0230 PRINT

0240 PRINT"

0250 PRINT

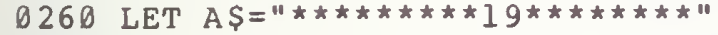

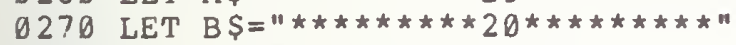

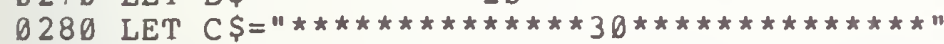

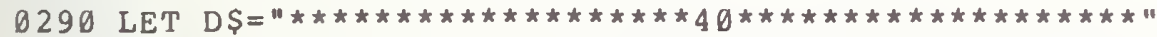

0300 LET ES="

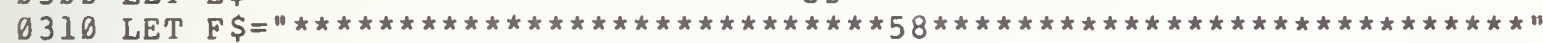

0320 PRINT $"$ IN THE OUTPUT BELOW, THE NUMBERS TOWARD THE CENTER OR"

0330 PRINT "IN THE CENTER OF THE ASTERISKS SIGNIFIES THE LENGTH OF THE"

0340 PRINT "CHARACTER STRINGS ASSOCIATED WITH EACH ASSIGNED STRING VAR-"

0350 PRINT "IABLE."

0360 PRINT

0370 PRINT AS

0380 PRINT BS

0390 PRINT CS

0400 PRINT DS

0410 PRINT ES

0420 PRINT F\$

0430 PRINT

0440 PRINT "

0450 PRINT

END TEST."

0460 END

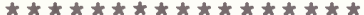

* SAMPLE OUTPUT $\star$

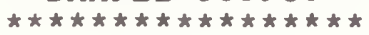

If a string overflow occurs then a diagnostic message such as:

?STRING TOO LONG IN LINE 260

might appear during execution. Otherwise, the user will get the following printed output:

PROGRAM FILE 57

SECTION 57.0: ERROR TEST ON STRING EXPRESSIONS. 
THE OBJECTIVE OF THIS SECTION IS TO DETERMINE WHETHER THE ASSIGNING OF MORE THAN 18 CHARACTERS TO A STRING WOULD BE RECOGNIZED BY THE SYSTEM AS A FATAL ERROR. THAT IS, UPON SUCH AN ASSIGNMENT, PROGRAM EXECUTION WOULD BE SUSPENDED PENDING USER-DIRECTED RESTART PROCEDURES. IF THE SYSTEM RECOGNIZES SUCH ASSIGNMENTS AS FATAL ERRORS, THEN THE TEST PASSES. HOWEVER, IF IT DOES NOT, THEN THE SYSTEM SATISFIES MORE THAN WHAT IS REQUIRED BY MINIMAL BASIC.

BEGIN TEST.

IN THE OUTPUT BELOW, THE NUMBERS TOWARD THE CENTER OR IN THE CENTER OF THE ASTERISKS SIGNIFIES THE LENGTH OF THE CHARACTER STRINGS ASSOCIATED WITH EACH ASSIGNED STRING VARIABLE.

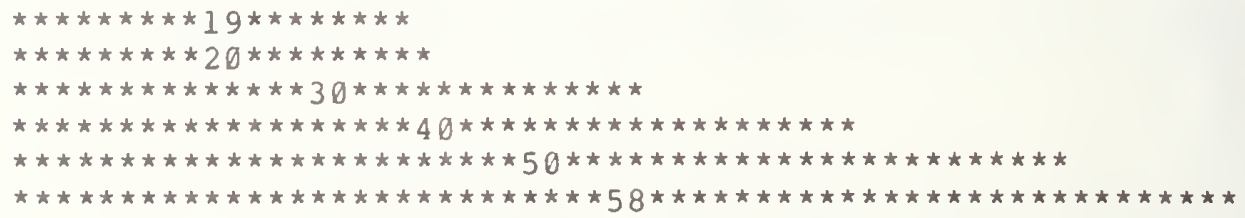

END TEST. 


\title{
58. 0 TEST FOR UNDEFINED VARIABLES
}

At initiation of a program, variables may or may not be assigned a specific value. The objective of this test is to determine which of the following three alternatives for associating implementation-defined initial values with variables is used for the implementation tested. The three alternatives are: (a) all variables receive unknown or arbitrary values (i.e.. the implementation takes no explicit action to initialize variables); (b) all numeric variables are assigned the value zero and all string variables the null string; or (c) all variables are recognizeably undefined in the sense that an error will result from any attempt to access the value of a variable before that variable is explicitly assigned a value. The standard recommends that the alternative (c) be adopted in order that a program be much more transportable. The reader should consult section 6.6 of BSR X3.60 for the specifications used here.

This test has numerical expressions that contain undefined variables, that is, a variable which has not been explicitly defined. Which of the above alternatives is practiced by the tested implementation will determine what kind of output there will be. If alternative (a) or (b) is practiced, then the value of the expression will be printed and this value should be followed by a statement to the user regarding the practice of the host implementation. Several runnings of the program would indicate (b) is used if the values $2,4,6,8$ are printed consistently. If not then (a) is followed. However, if alternative (c)--which is recommended by the ANSI Minimal BASIC Standard--is practiced, then the output should consist of some form of implementation-defined diagnostics.

\author{
DOI0 PRINT "PROGRAM FILE 58 " \\ 0060 PRINT \\ $\emptyset 07 \emptyset$ PRINT \\ $\emptyset \emptyset 80$ PRINT \\ DØ90 PRINT \\ $\emptyset 1 \emptyset \emptyset$ PRINT \\ ØII0 PRINT \\ Ө120 PRINT \\ O130 PRINT \\ $\emptyset 140$ PRINT \\ 0150 PRINT \\ $\emptyset 160$ PRINT \\ 0170 PRINT \\ 180 PRINT \\ 0190 PRINT \\ Ө200 PRINT \\ "I \\ SECTION 58.0: TEST FOR UNDEFINED VARIABLES." \\ " THE OBJECTIVE OF THIS SECTION IS TO DETERMINE WHETHER" \\ "THE SYSTEM WILL RECOGNIZE AN UNDEFINED VARIABLE AS A FATAL" \\ "ERROR, THAT IS, REQUIRING A VALUE TO HAVE BEEN ASSIGNED THE" \\ "VARIABLE BEFORE ANY EXPRESSION INVOLVING THAT VARIABLE IS" \\ "EXECUTED. IF THE SYSTEM SHOULD RECOGNIZE THE UNDEFINED" \\ "VARIABLE AS A FATAL ERROR (SUSPENDING PROGRAM EXECUTION" \\ "PENDING USER-DIRECTED RESTART PROCEDURES), THEN THE TEST" \\ "WILL HAVE PASSED; HOWEVER, IF THE SYSTEM DOES NOT MAKE THIS"
}

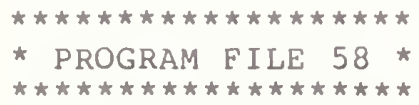




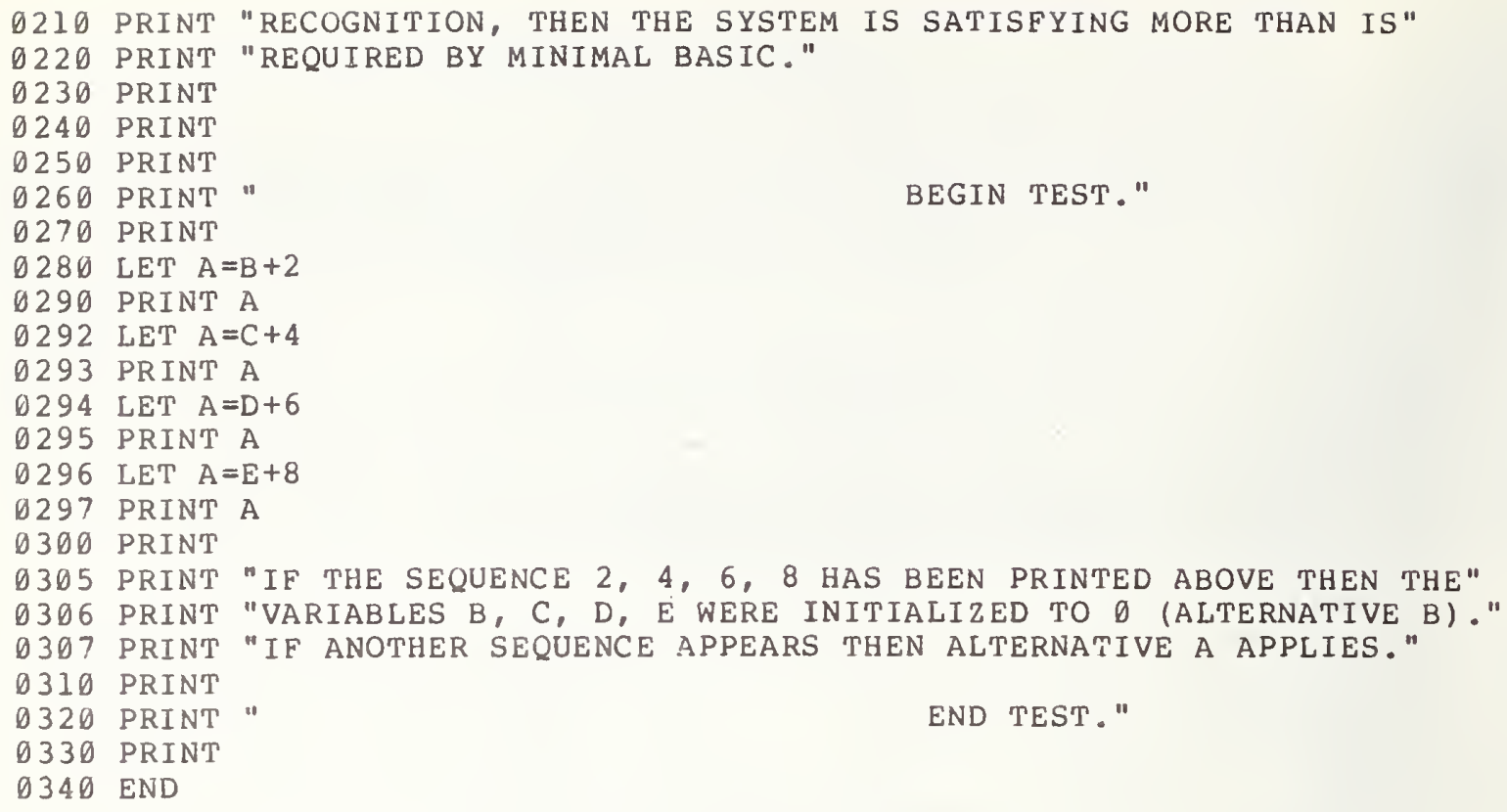

Otherwise, if alternative $B$ applied the following output might appear:

PROGRAM FILE 58

SECTION 58.6: TEST FOR UNDEFINED VARIABLES.

THE OBJECTIVE OF THIS SECTION IS TO DETERMINE WHETHER 
THE SYSTEM WILL RECOGNIZE AN UNDEFINED VARIABLE AS A FATAL ERROR, THAT IS, REQUIRING A VALUE TO HAVE BEEN ASSIGNED THE VARIABLE BEFORE ANY EXPRESSION INVOLVING THAT VARIABLE IS EXECUTED. IF THE SYSTEM SHOULD RECOGNIZE THE UNDEFINED VARIABLE AS A FATAL ERROR (SUSPENDING PROGRAM EXECUTION PENDING USER-DIRECTED RESTART PROCEDURES), THEN THE TEST WILL HAVE PASSED; HOWEVER, IF THE SYSTEM DOES NOT MAKE THIS RECOGNITION, THEN THE SYSTEM IS SATISFYING MORE THAN IS REQUIRED BY MINIMAL BASIC .

BEGIN TEST .

$$
\begin{aligned}
& 2 \\
& 4 \\
& 6 \\
& 8
\end{aligned}
$$

IF THE SEquence 2, 4, 6, 8 HAS BEen PRINTED ABOVE THEN The VARIABLES B, C, D, F WERE INITIALIZED TO $\emptyset$ (ALTERNATIVE B). IF ANOTHER SEQUENCE APPEARS THEN ALTERNATIVE A APPLIES.

END TEST 。 


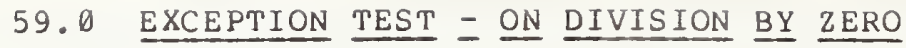

The objective of this test is to verify that the implementation recognizes a numerical expression involving division by zero as an exception with a recovery procedure. When the implementation recognizes this situation, it must supply the machine infinity with the sign of the numerator and continue program execution. The reader is referred to section 7.5 of BSR X3.60 for the specifications.

\subsection{Positive Numerator}

The objective of this test is to determine, in the event that the implementation does recognize division by zero as a recoverable error, that it will also recognize the sign of the numerator (in this case positive) and assign it to its machine infinity. This test has an expression at line 290 which, when evaluated, will involve division by zero. The numerator for the expression is positive. On output, this test requires that the implementation-supplied machine infinity printed and, preceding this value, there should be a message informing the user to look for the positive case of the machine infinity.

\subsection{Negative Numerator}

The objective of this test is the same as the stated objective for section 59.1, except that this test uses a negative numerator. The expression in this case is at 1 ine 470 .

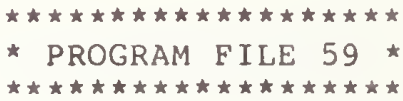

ØØID PRINT "PROGRAM FILE 59"

$\emptyset \emptyset 60$ PRINT

$\emptyset \emptyset 7 \emptyset$ PRINT

0080 PRINT

$\emptyset \emptyset 9 \emptyset$ PRINT

0100 PRINT

OII0 PRINT

Ø120 PRINT

0130 PRINT

OI40 PRINT

0150 PRINT

D160 PRINT

ด17ด PRINT

DI80 PRINT

0190 PRINT

0200 PRINT

D210 PRINT"

SECTION 59.1" 

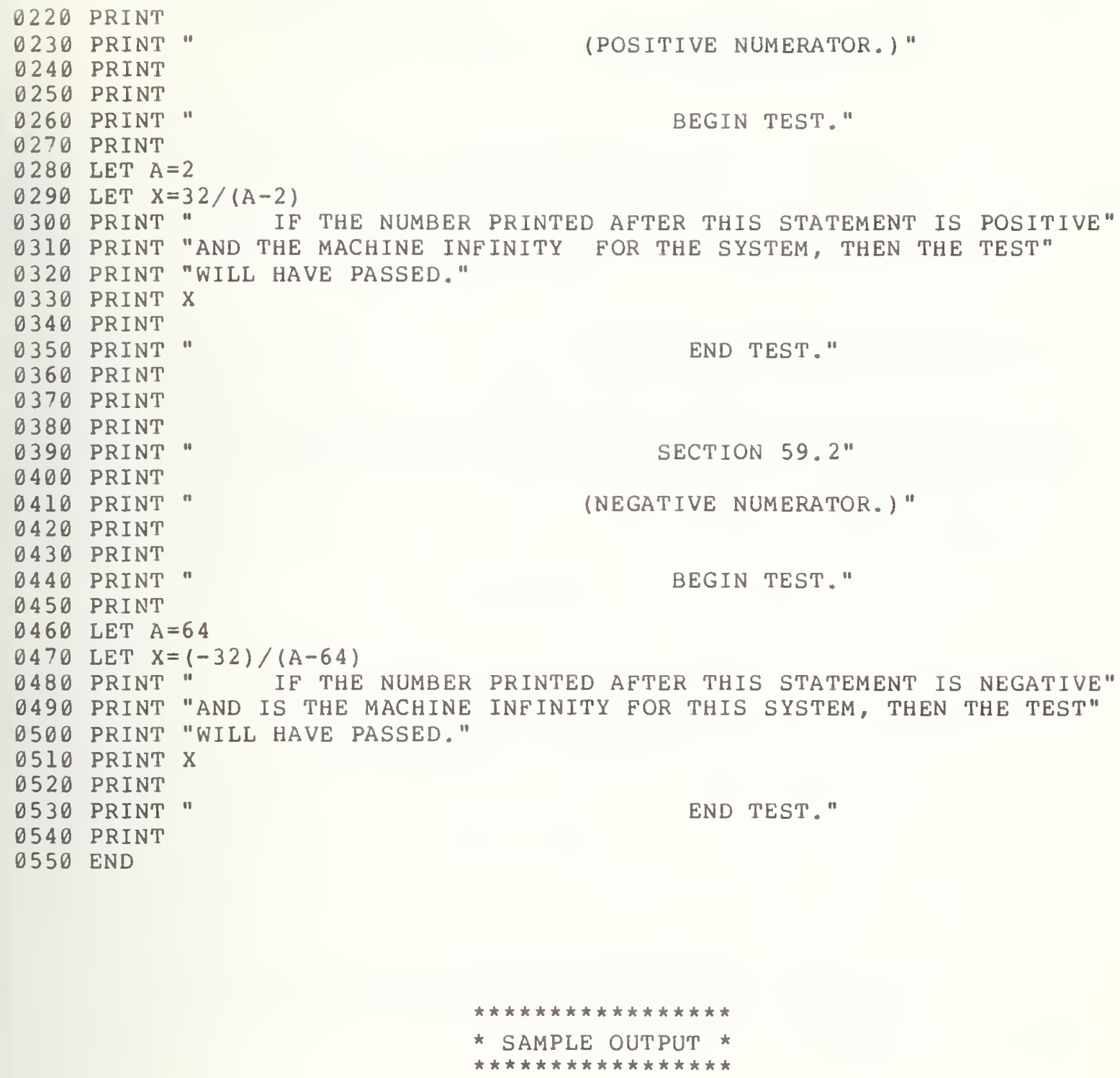

PROGRAM FILE 59

SECTION 59. 0 : NON-FATAL ERROR TEST FOR DIVISION BY ZERO.

THE OBJECTIVE OF THIS TEST IS TO DETEMINE WHETHER THE EVALUATION OF THE SYSTEM ON A EXPRESSION WHICH RESULTED IN DIVISION BY ZERO WILL CAUSE THE SYSTEM TO SUPPLY ITS 
MACHINE INFINITY WITH THE SIGN OF THE NUMERATOR AND A CONTINUATION OF PROGRAM.

$$
\text { SECTION } 59.1
$$

(POSITIVE NUMERATOR.)

$$
\text { BEGIN TEST. }
$$

?DIVISION BY ZERO IN LINE 290

IF THE NUMBER PRINTED AFTER THIS STATEMENT IS POSITIVE AND THE MACHINE INFINITY FOR THE SYSTEM, THEN THE TEST WILL HAVE PASSED.

$$
1.70141 E+38
$$

END TEST.

SECTION 59.2

(NEGATIVE NUMERATOR.)

BEGIN TEST.

?DIVISION BY ZERO IN LINE 470

IF THE NUMBER PRINTED AFTER THIS STATEMENT IS NEGATIVE AND IS THE MACHINE INFINITY FOR THIS SYSTEM, THEN THE TEST WILL HAVE PASSED.

$-1.70141 E+38$

END TEST. 


\subsection{EXCEPTION TEST - ON EXPRESSION EVALUATION RESULTING IN OVERFLOW}

The objective of this test is to verify that the implementation, when attempting to evaluate an expression causing an overflow, will recognize a recoverable exception. Following this overflow, the implementation should supply machine infinity with the algebraically correct sign. The reader is referred to section 7.5 of BSR $\times 3.60$ for the specifications.

\subsection{Positive Machine Infinity}

In this part of the test, we raise 999999 to the 99999 power, which, for all practical purposes, on existing computer systems, is sufficiently large to cause overflow. All of the numbers are kept within 6 digits so that roundof $f$ is not a factor. This test requires that the implementation-supplied machine infinity be printed. Preceding the output of the machine infinity, there should be a printed message informing the user what to look for, in order to verify that implementation passed or failed the test. In this case, the user is instructed to look for positive machine infinity. On the test system used machine infinity was $1.70141 \mathrm{E}+38$.

\subsection{Negative Machine Infinity}

Two cases are considered here. First, the negative number -999999 is raised to the odd power 99999 then, secondly, it is raised to the even power 88888. In the first case, the implementation should return machine infinity with a negative sign and in the second case, with a positive sign. The implementation supplied machine infinity is printed preceded by the appropriate sign for each case. The user is informed by message what to look for in terms of sign.
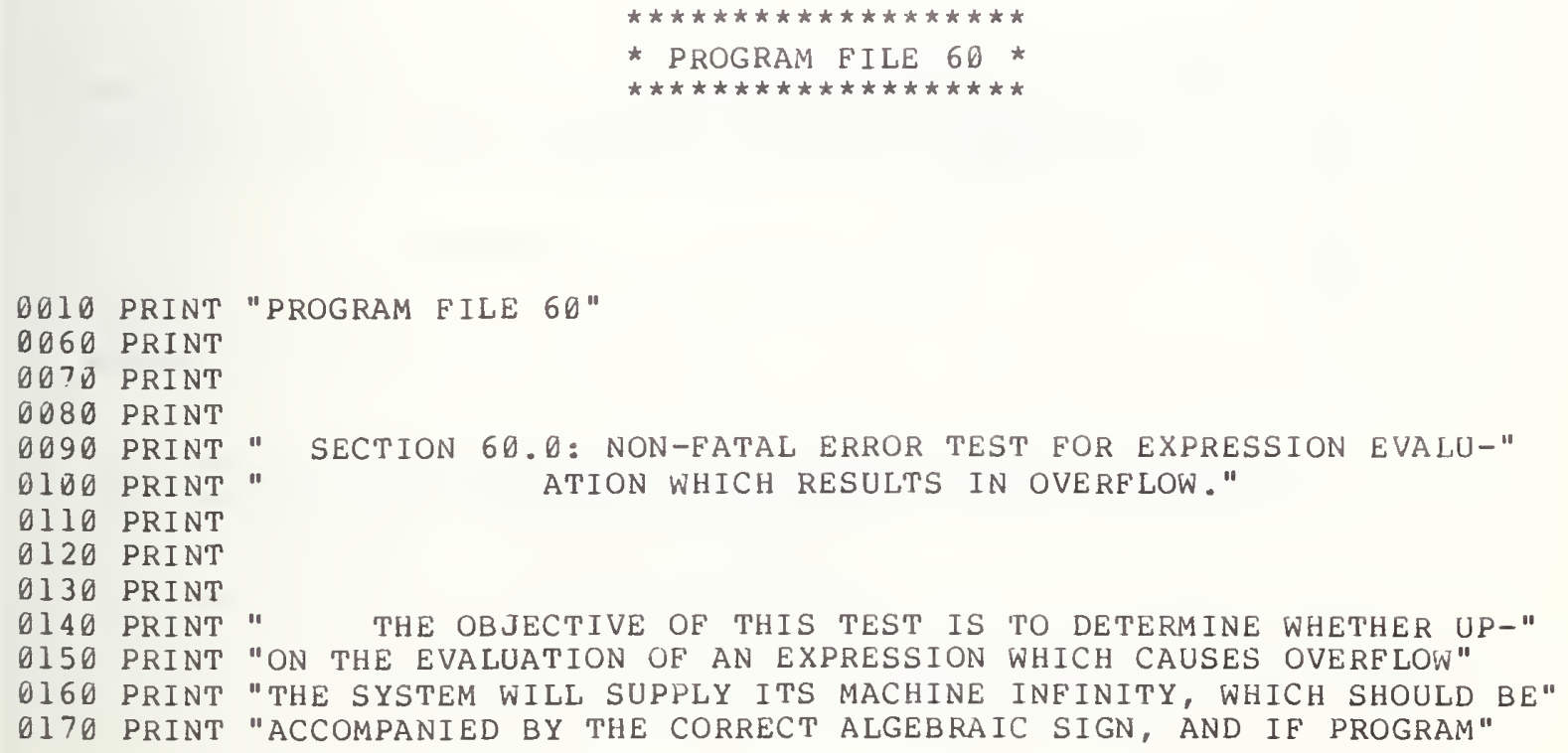


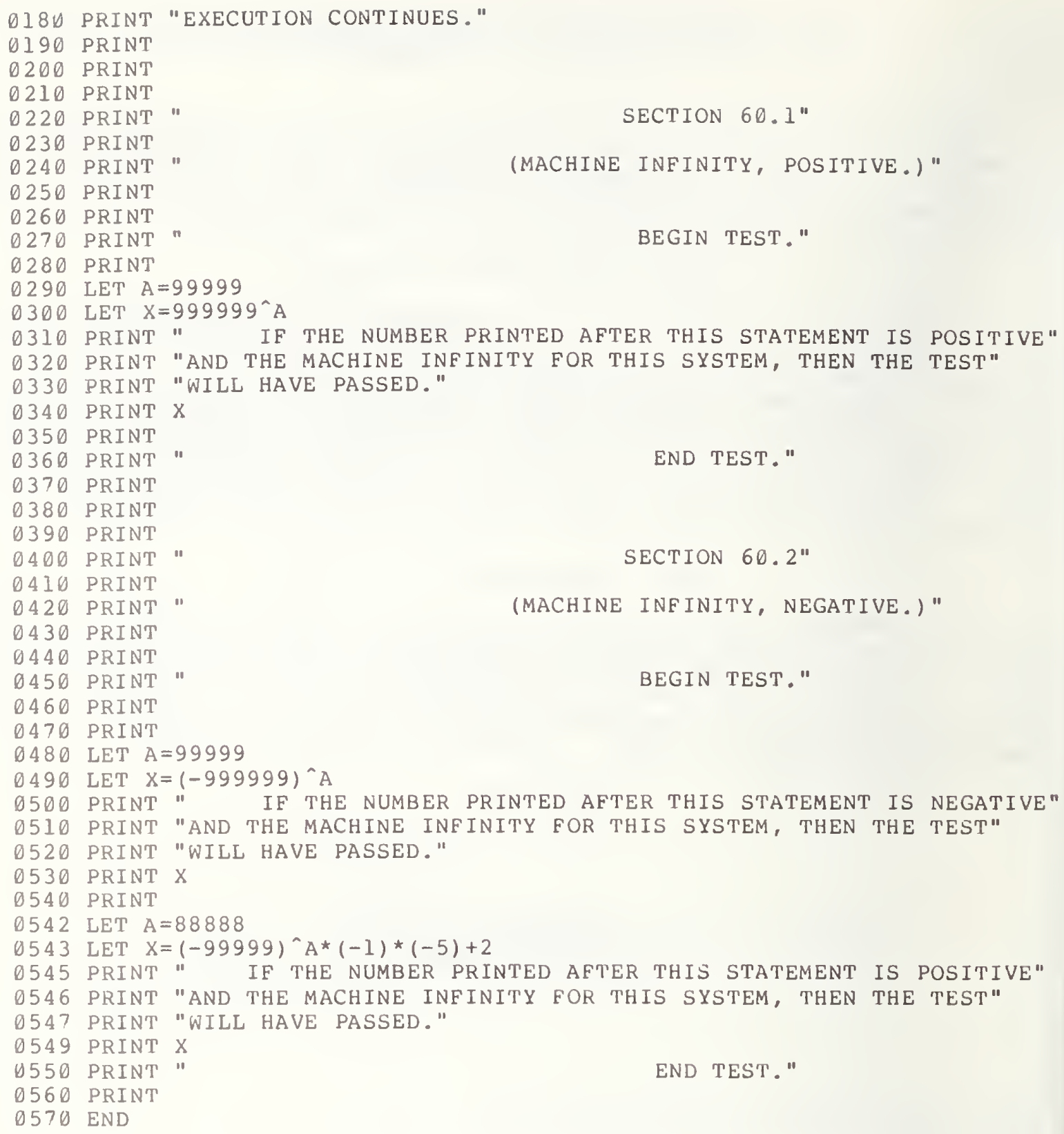

(MACHINE INFINITY, POSITIVE.) "

BEGIN TEST."

(MACHINE INFINITY, NEGATIVE.) "

\author{
BEGIN TEST."
}

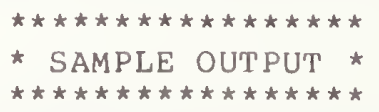


PROGRAM FILE 60

SECTION 60.0: NON-FATAL ERROR TEST FOR EXPRESSION EVALUATION WHICH RESULTS IN OVERFLOW.

THE OBJECTIVE OF THIS TEST IS TO DETERMINE WHETHER UPON THE EVALUATION OF AN EXPRESSION WHICH CAUSES OVERFLOW THE SYSTEM WILL SUPPLY ITS MACHINE INFINITY, WHICH SHOULD BE ACCOMPANIED BY THE CORRECT ALGEBRAIC SIGN, AND IF PROGRAM EXECUTION CONTINUES.

\author{
SECTION 60.1 \\ (MACHINE INFINITY, POSITIVE.) \\ BEGIN TEST.
}

?OVERFLOW IN LINE 300

IF THE NUMBER PRINTED AFTER THIS STATEMENT IS POSITIVE AND THE MACHINE INEINITY FOR THIS SYSTEM, THEN THE TEST WILL HAVE PASSED.

$1.70141 \mathrm{E}+38$

END TEST.

SECTION 60.2

(MACHINE INFINITY, NEGATIVE.)

BEGIN TEST.

?OVERFLOW IN LINE 490

IF THE NUMBER PRINTED AFTER THIS STATEMENT IS NEGATIVE AND THE MACHINE INFINITY FOR THIS SYSTEM, THEN THE TEST WILL HAVE PASSED.

$-1.70141 E+38$

? OVERFLOW IN LINE 543 
IF THE NUMBER PRINTED AFTER THIS STATEMENT IS POSITIVE AND THE MACHINE INFINITY FOR THIS SYSTEM, THEN THE TEST WILL HAVE PASSED.

$1.70141 E+38$

END TEST. 


\subsection{SEMANTIC TEST = ON THE MAGNITUDE OF A NONZERO NUMERIC CONSTANT THAT IS TOO SMALL}

The objective of this test is to verify that the implementation will recognize a numerical constant, with a magnitude outside the implementation-defined range, as a diagnosable error. Since numeric constants are expressions, their errors are handled in the same manner. If the magnitude of the constant is too small then the implementation should supply $\emptyset$ and continue. The ANSI Minimal BASIC standard does not require a diagnostic message in an underflow of this kind. If the magnitude is too large then the implementation should supply machine infinity with the appropriate sign. In the case of an overflow a diagnostic message is required. The reader is referred to section 7.4 of BSR X3.60 for the specifications.

This test will determine whether the implementation will supply a value of zero for an extremely small value which most present implementations cannot represent. For any value so close to zero that it is outside of the implementation-defined range, a value of zero should be supplied by the implementation and program execution continued.

This test uses a numerical constant, 10.0E-99999, which is too small to be represented on most present day machines. The constant is assigned on line 310 and diagnostics might refer to this line. On encountering this number, a processor should assign $\emptyset$ to $A$ and continue.

0010 PRINT "PROGRAM FILE 61"

0060 PRINT

0070 PRINT

$\square 080$ PRINT

090 PRINT " SECTION 61.0: SEMANTIC TEST ON THE MAGNITUDE OF A"

0100 PRINT

0110 PRINT

0120 PRINT

0130 PRINT

Ø140 PRINT " THE OBJECTIVE OF THIS SECTION IS TO DETERMINE WHETHER"

O150 PRINT "UPON THE ASSIGNMENT OF A NONZERO CONSTANT WHICH IS TOO"

O160 PRINT "SMALL FOR THE IMPLEMENTATION A ZERO WILL"

$\emptyset 170$ PRINT "BE SUPPLIED."

0200 PRINT

0210 PRINT

0220 PRINT

0280 PRINT

0290 PRINT

BEGIN TEST." 
0310 LET $A=10.0 E-99999$

Ø320 PRINT " IF THE NUMBER PRINTED AFTER THIS STATEMENT IS ZERO," Ø330 PRINT "THEN THE TEST WILL HAVE PASSED."

D 340 PRINT A

0350 PRINT

0360 PRINT"

END TEST."

๑370 PRINT

0380 END

PROGRAM FILE 61

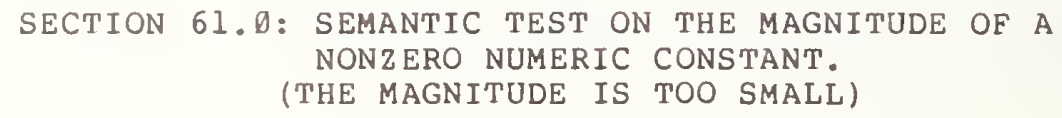

THE OBJECTIVE OF THIS SECTION IS TO DETERMINE WHETHER UPON THE ASSIGNMENT OF A NONZERO CONSTANT WHICH IS TOO SMALL FOR THE IMPLEMENTATION A ZERO WILL BE SUPPLIED.

\section{BEGIN TEST.}

IF THE NUMBER PRINTED AFTER THIS STATEMENT IS ZERO, THEN THE TEST WILL HAVE PASSED. (ด 


\subsection{EXCEPTION TEST - ON THE MAGNITUDE OF A NONZERO NUMERIC CONSTANT THAT IS TOO LA RGE}

\subsection{Positive Machine Infinity}

This test assigns a numerical constant $9.99999 E 99999$ to a simple variable. It requires the implementation-supplied machine infinity be printed. But, preceding the output of the machine infinity, there should appear a printed message informing the user what sign to look for preceding the printed constant. The reader is referred to section 7.5 of BSR $\times 3.60$.

\subsection{Negative Machine Infinity}

This test uses the numerical constant (-999999)E99999 assigned to a simple variable. On output, the test requires that the negative implementation-supplied machine infinity be supplied and printed. Before this value is printed, however, there should be an informative message to the user as to what value should be printed in order that the user can judge whether the implementation fails or passes the test.

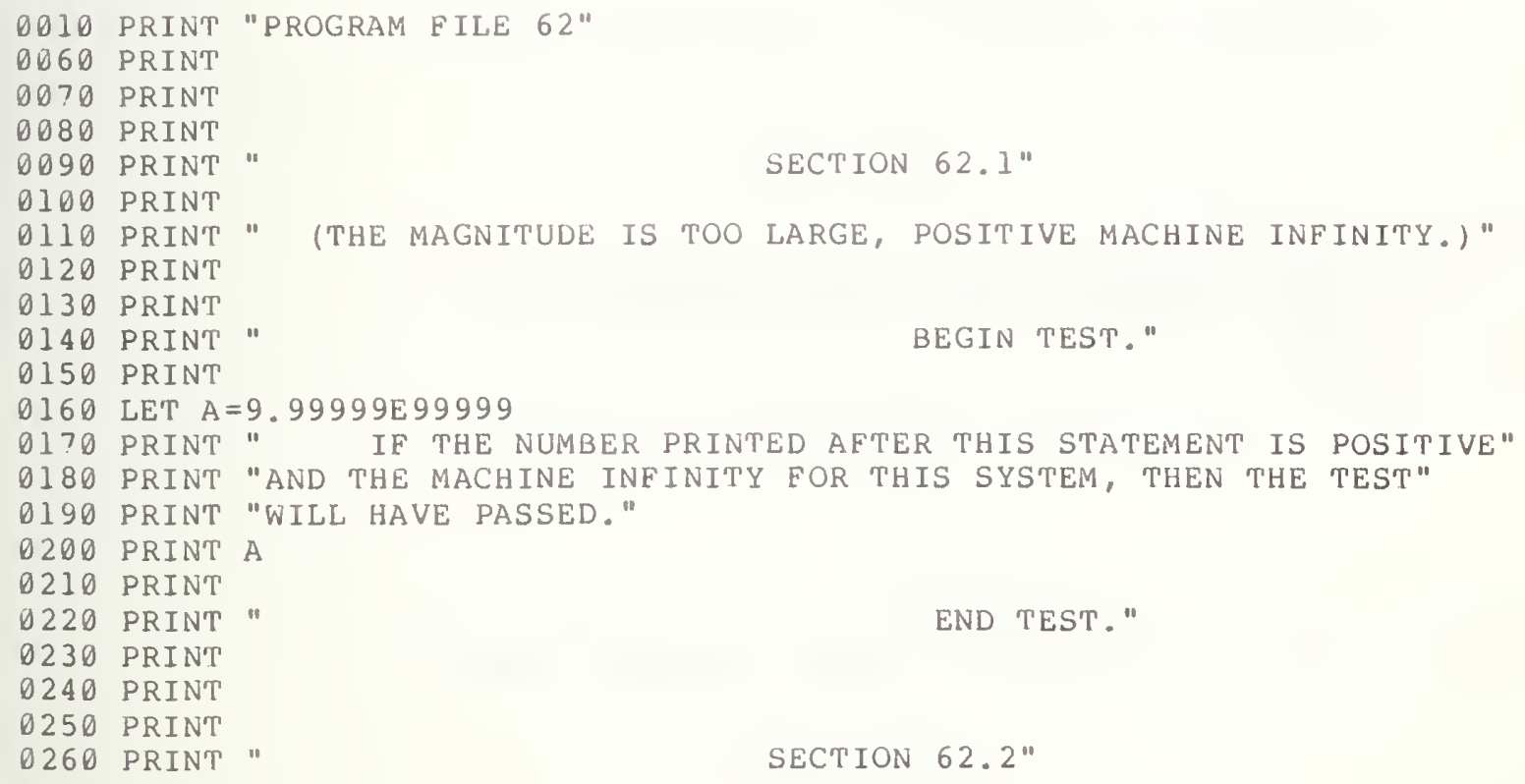


$\emptyset 27 \emptyset$ PRINT

0280 PRINT" (THE MAGNitUde IS TOO LARGE, NEGATIVE MACHINE INFINITY.)"

0290 PRINT

0300 PRINT

0310 PRINT

$\emptyset 320$ PRINT

0330 LET $A=-9.99999 E 99999$

0340 PRINT " IF THE NUMBER PRINTED AFTER THIS STATEMENT IS NEGATIVE"

0350 PRINT "AND THE MACHINE INFINITY FOR THIS SYSTEM, THEN THE TEST"

0360 PRINT "WILL HAVE PASSED."

0370 PRINT A

0380 PRINT

O390 PRINT

0400 PRINT

0410 END

END TEST."

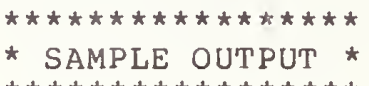

$* * * * * * * * t * t * * t * t *$

PROGRAM FILE 62

SECTION 62.1

(THE MAGNitude is TOO LARGE, POSITIVE MACHINE INFinity.)

BEGIN TEST.

?OVERFLOW IN LINE 160

IF THE NUMBER PRINTED AFTER THIS STATEMENT IS POSITIVE AND THE MACHINE INFINITY FOR THIS SYSTEM, THEN THE TEST WILL HAVE PASSED.

$1.70141 \mathrm{E}+38$

END TEST.

SECTION 62.2

(THE MAGNITUDE IS TOO LARGE, NEGATIVE MACHINE INFINITY.)

BEGIN TEST . 
?OVERFLOW IN LINE 330

IF THE NUMBER PRINTED AFTER THIS STATEMENT IS NEGATIVE AND THE MACHINE INFINITY FOR THIS SYSTEM, THEN THE TEST WILL HAVE PASSED.

$-1.70141 E+38$

END TEST. 


\section{DIM STATEMENT WITH THE OPTION STATEMENT}

The objective of this test is to verify that, in using the OPTION-statement with a lower bound of 1 , implementations will recognize any subscript value less than 1 as an exception. In this test arrays are explicitly dimensioned. The OPTION feature is in general not available in existing processors. As a result, a user may obtain a diagnostic referencing an illegal statement in line 255. For new processors with this feature, there should only be output diagnostics as in the sample output. A diagnostic is required for a subscript of range as specified in section 6.5 of BSR X3.60. For other specifications the user is referred to section 15 of BSR $\times 3.60$.

There should be an implementation-defined diagnostic for attempting to access the zero subscript element in lines 400 and 440 . However, execution of this program may terminate with a diagnostic reference to line 406 only. Should the implementation fail to recognize the error, the test has a message printed which will inform the user that the implementation has failed to recognize the subscripted error.

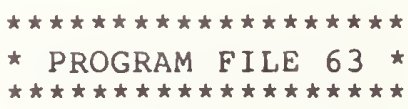

0010 PRINT "PROGRAM FILE 63"

$\emptyset \emptyset 6 \emptyset$ PRINT

$\emptyset 07 \emptyset$ PRINT

0080 PRINT

OD90 PRINT "

ØIØØ PRINT

O110 PRINT "

0120 PRINT

O130 PRINT

O140 PRINT

Ө150 PRINT

$\emptyset 16 \emptyset$ PRINT

$\emptyset 170$ PRINT

Ө180 PRINT

$\emptyset 19 \emptyset$ PRINT

0200 PRINT

$" \star \star \star \star \star$ NOTE: THE OBJECTIVE OF THIS PART IS TO DETERMINE"

"WHETHER THE SYSTEM RECOGNIZES WHEN AN UPPER BOUND OF ZERO"

"IS SPECIFIED FOR A SUBSCRIPT AS A FATAL ERROR (THAT IS,"

"SUSPENDING PROGRAM EXECUTION PENDING USER-DIRECTED RESTART"

"PROCEDURES) WHEN AN OPTION-STATEMENT SPECIFIES THAT ALL"

"LOWER BOUNDS ARE ONE. $\star \star \star \star \star " ~$

D 210 PRINT

0220 PRINT

0230 PRINT

0240 PRINT"

BEGIN TEST."

0250 PRINT

$\emptyset 255$ OPTION BASE 1

Ø260 DIM B $(15,15), C(25)$

0280 LET $\mathrm{B} I=0$ 
0290 LET B $2=0$

0300 LET $S I=0$

0310 LET S $2=0$

Q320 FOR $I=1$ TO 15

8330 LET $B(I, 12)=B 1^{\wedge} 2$

0340 LET $\mathrm{Bl}=\mathrm{B} 1+2$

B350 NEXT I

0360 FOR $I=1$ TO 15

0370 LET $S I=S I+B(I, 12)$

0380 NEXT I

0390 FOR $I=0$ TO 25

0400 LET $C(I)=(B 2+I)^{\wedge} 2$

0410 LET B $2=B 2+1$

0420 NEXT I

0430 FOR $I=0$ TO 25

0440 LET $S 2=S 2+C$ (I)

0450 NEXT I

0460 PRINT " WHETHER THERE ARE/ARE NOT ANY NUMERALS PRINTED BELOW" 04 ? 0 PRINT "THIS STATEMENT, THE SYSTEM HAS FAILED THE TEST."

0480 PRINT S1,S2

0490 PRINT

0500 PRINT

0510 PRINT

END TEST."

0520 END

PROGRAM FILE 63

\author{
SECTION 63.0
}

(DIM-STATEMENT WITH THE OPTION-STATEMENT.)

$\star \star \star \star \star N O T E:$ THE OBJECTIVE OF THIS PART IS TO DETERMINE WHETHER THE SYSTEM RECOGNIZES WHEN AN UPPER BOUND OF $Z$ ERO IS SPECIFIED FOR A SUBSCRIPT AS A FATAL ERROR (THAT IS, SUSPENDING PROGRAM EXECUTION PENDING USER-DIRECTED RESTART PROCEDURES) WHEN AN OPTION-STATEMENT SPECIFIES THAT ALL LOWER BOUNDS ARE ONE.*

BEGIN TEST. 
? ARRAY INDEX OUT-OF-BOUNDS IN LINE 400 


\subsection{USING THE OPTION BASE-STATEMENT TO CHANGE IMPLICIT ARRAY LOWER BOUNDS}

We know from previous tests that a program, written without OPTION BASE, using implicitly dimensioned arrays, will have $\theta$ as a lower bound for the arrays. However, when OPTION BASE is introduced, we can increase the lower bound of the arrays to 1 . Thus, in order to test that this is so, we must attempt to access the $\theta-t h$ element of an array in a program with the declaration OPTION BASE 1. A diagnostic is required by the standard, since a subscript of $\emptyset$ would be out of bounds for the arrays. Processors may flag line 80 as an illegal statement if they do not recognize the OPTION-statement.

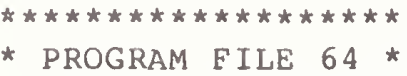

$\star * \star * \star * * * * * * \star * * * * \star \star * *$

DดI0 PRINT "PROGRAM FILE 64"

$\emptyset 020$ PRINT

$\emptyset \emptyset 30$ PRINT

0040 PRINT

0050 PRINT

$\emptyset 060$ PRINT

$\emptyset \emptyset 7 \emptyset$ PRINT"

$\emptyset \emptyset 8 \emptyset$ OPTION BASE 1

0090 FOR $I=10$ TO $\emptyset$ STEP - 1

0100 LET $A(I)=I$

$0110 \operatorname{LET} B(I, I)=I$

0120 NEXT I

0130 PRINT

0140 PRINT " $A(\theta)=" ; A(\theta), " B(\theta, \theta)=" ; B(\theta, \theta)$

0150 PRINT

$\emptyset 160$ PRINT "IF A $(\theta)=\emptyset$ AND $B(\theta, \theta)=\theta$, THEN THE OPTION BASE STATEMENT DID"

0170 PRINT " NOT AFFECT THE DEFAULT LOWER BOUND OF $\oslash$. TEST FAILED."

0180 PRINT

0190 PRINT

END TEST."

0200 PRINT

0210 END 
PROGRAM FILE 64

SECTION 64.0: OPTION BASE WITH IMPLICIT DIMENSIONING BEGIN TEST.

? ARRAY INDEX OUT-OF-BOUNDS IN LINE 100 


\subsection{TESTING THE ASSIGNMENT OF ZERO FOR AN EXPRESSION CAUSING UNDERFLOW UPON EVA $\overline{L U A T} \overline{I O N}$}

The objective of this test is to verify that the implementation will assign a value of zero to an expression that causes an underflow. In this case a simple variable is assigned a numerical value generated by raising 999999 to the -99999 power. This value is too small to be represented in general. On output, the test should print zero, after informing the user of this expected value. The reader is referred to section 7.4 of BSR X3.60 for this section.

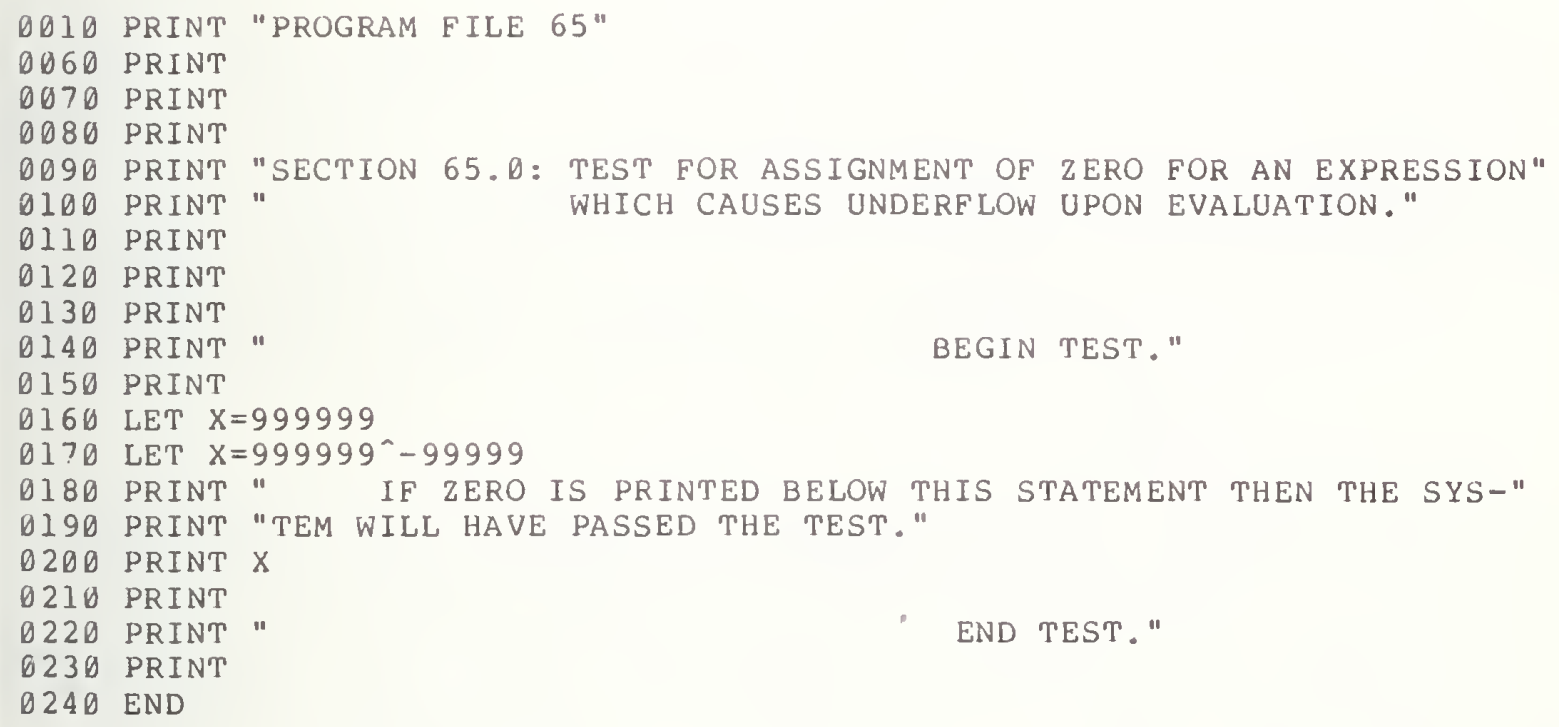


PROGRAM FILE 65

SECTION 65.0: TEST FOR ASSIGNMENT OF ZERO FOR AN EXPRESSION WHICH CAUSES UNDERFLOW UPON EVALUATION.

BEGIN TEST.

IF ZERO IS PRINTED BELOW THIS STATEMENT THEN THE SYSTEM WILL HAVE PASSED THE TEST.

$\emptyset$

END TEST. 


\section{$66 . \emptyset$ GOSUB/RETURN-STATEMENT}

This test unit verifies the relationship between the GosuB-statement and the RETURN-statement. These statement types allow subroutines to be written within a program. These subroutines differ from user-defined functions because they in general might produce more complicated results than a single value as the function routine would.

The action of the GOSUB and RETURN statements can be described in terms of a stack concept. Prior to execution of the first GOSUB-statement by the test, the stack should be empty. Each time a GosuB-statement is executed, the line number of the GOSUB-statement should be placed on top of the stack and execution of the program should continue at the line specified in the GOSUB-statement. Each time a RETURN-statement is executed, the line number on top of the stack should be removed from the stack and execution of the program should continue at the line following the one with that line number. Equal numbers of GOSUB-statements and RETURN-statements need not necessarily be executed before termination of a program. The reader should refer to section 10.4 of BSR $\times 3.60$ for the specifications.

\subsection{One GOSUB and One RETURN}

This test verifies that a GOSUB-statement and a RETURN-statement perform together. The control of the GOSUB-statement and the RETURN-statement is checked by a counter. $N$. If the control action proves to be proper, the value of $N$ should be 2 at the termination of the test. On output, there should be only one of two possible printed messages. These are statements to the effect that the test either failed or passed. If the test fails, then the following message should be printed: RELATION BETWEEN GOSUB/RETURN, FAILED TEST. If the test passes, then the following message should be printed: RELATION BETWEEN GOSUB/RETURN, PASSED TEST.

\subsection{Two GOSUB Statements Before a RETURN}

The objective of this test is to verify that two GosuB-statements can be executed without an intervening RETURN-statement. Through the use of a counter, $N$, the performance of the two GOSUB-statements is checked as well as the performance of the RETURN-statement in conjunction with the last GOSUB-statement. Upon proper performance of the two GOSUB-statements and the RETURN-statement, the value of the counter should be 3 . The output for this test should be a message indicating pass or fail. If the test fails, then the following message should be printed: TWO GOSUBS WITHOUT. INTERVENING RETURN, FAILED TEST. If the test passes, then the following message should be printed: TWO GOSUBS WITHOUT INTERVENING RETURN, PASSED TEST.

\subsection{Testing Proper GOSUB Returns}

The purpose of this test is to verify the stack-like relationship between GOSUB-statements and RETURN-statements through the use of nested GOSUB-statements with RETURN-statements. There are four levels of nesting performed by this test. The number of GOSUB-statements per level is equal to the number of its level. For each level of GOSUB-statements, there is only one RETURN-statement. This program also tests that an equal number of 
GOSUB-statements and RETURN-statements need not necessarily be executed before termination of a program. The output for this test should either be a fail or a pass message. If the test fails, then the following message should be printed: GOSUB NESTING, FAILED TEST. If the test passes, then the following message should be printed: GOSUB NESTING, PASSED TEST.
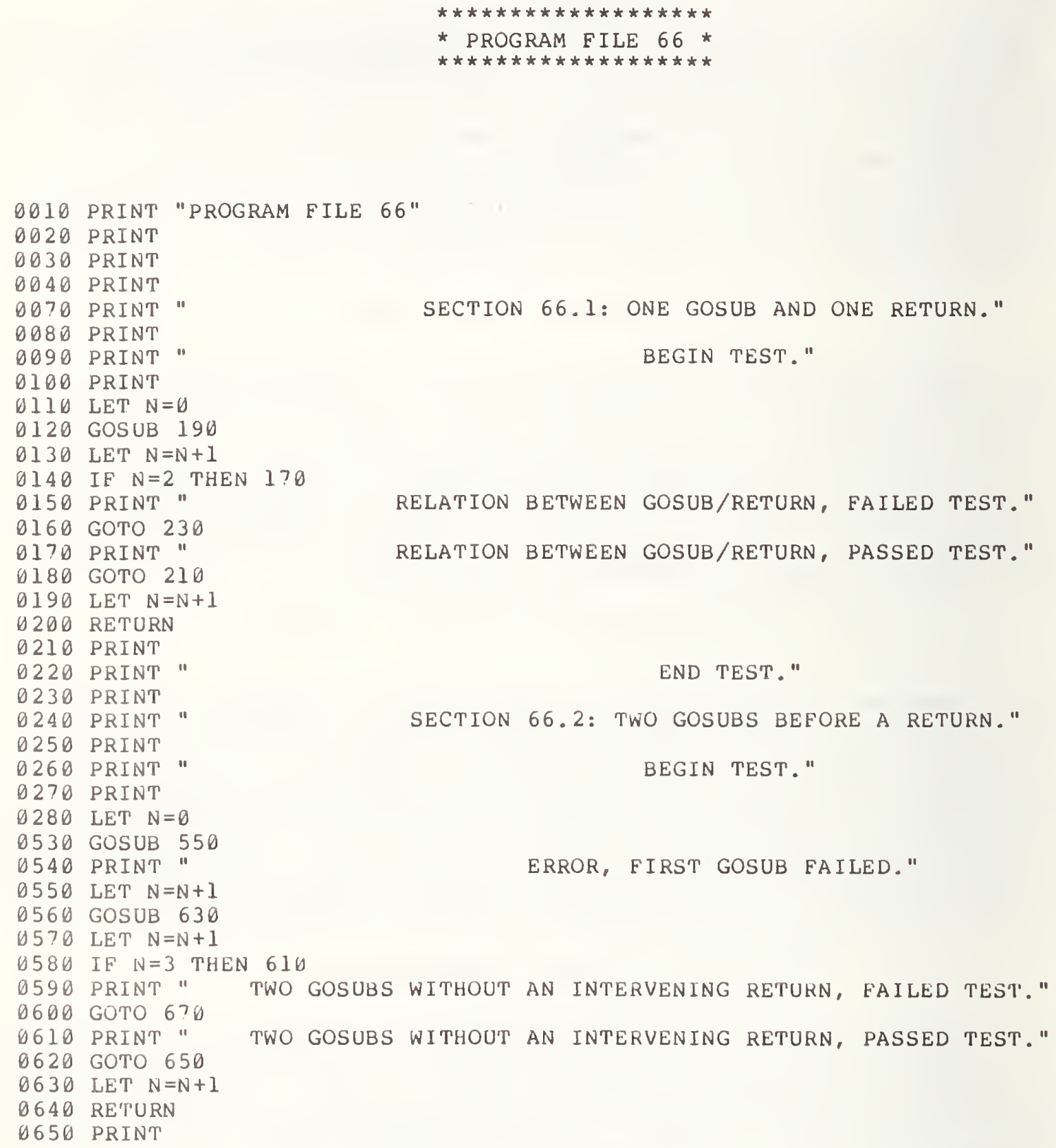


\section{END TEST.}

SECTION 66.2: TWO GOSUBS BEFORE A RETURN.

BEGIN TEST.

TWO GOSUBS WITHOUT AN INTERVENING RETURN, PASSED TEST. END TEST.

SECTION 66.3: TESTING PROPER GOSUB RETURNS BEGIN TEST.

GOSUB NESTING, PASSED TEST.

END TEST. 


\subsection{SEMANTIC ERROR $=\frac{\text { TEST }}{\text { LINEN }} \frac{\text { ON GOSUB }}{\text { NRBER }}$ TRANSFER TO AN ILLEGAL}

The objective of this test is to verify that the implementation will recognize a transfer by a GOSUB-statement to a non-existent line as an error. The test has a GOSUB-statement which uses a non-existent program line number as its designated transfer point in line 260. Although this error is not considered an exception it is not a meaningful construction and should be handled by an implementation with a diagnostic pointing to an illegal line number in line 260. After the diagnostic the program should be terminated. On output, there should be some form of implementation-defined diagnostic. However, the test does have a message printed should the implementation fail to recognize the error or ignore the line with the error. The reader is referred to section 10.4 of BSR X3.60 for the specifications.

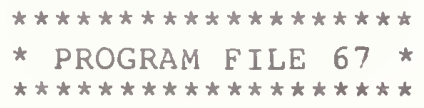

0010 PRINT "PROGRAM FILE 67"

0060 PRINT

00?ด PRINT

0080 PRINT

0090 PRINT

0100 PRINT

0110 PRINT

0120 PRINT

0130 PRINT

0140 PRINT

0150 PRINT

0160 PRINT

0170 PRINT

Ø180 PRINT

0190 PRINT

0200 PRINT

0210 PRINT

0220 PRINT

0230 PRINT"

BEGIN TEST."

0240 PRINT

0250 LET $\mathrm{F}=0$

0260 GOSUB 123

0270 IF $F=1$ THEN 300

0280 PRINT "TEST FAILED BECAUSE GOSUB-STATEMENT WAS IGNORED."

0290 GOTO 340

0300 PRINT "TEST FAILED BECAUSE TRANSFER WAS MADE TO NON-EXISTENT LINE." Q310 GOTO 340

0320 LET $\mathrm{F}=1$

0330 RETURN 
Ø340 PRINT

$\emptyset 350$ PRINT"

$\emptyset 360$ PRINT

0370 END
END TEST."

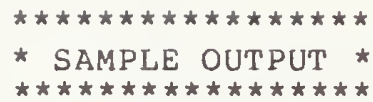

In order for this test to pass, an error must be diagnosed and reported. A possible error diagnostic for this program might be:

? UNDEFINED LINE NUMBER 123 IN LINE 260 


\subsection{EXCEPTION TEST $=$ RETURN-STATEMENT WITHOUT GOSUB}

The objective of this test is to verify that attempting to execute a RETURN-statement without having executed a corresponding GOSUB-statement will be diagnosed as an exception. This requires a diagnostic message and termination of the program since, there are no specified recovery procedures in the ANSI Minimal BASIC standard. On output, there should be some form of implementation-defined diagnostic describing the nature of the error. However, the test is constructed to allow, in the event that the implementation fails to recognize the error, the output of a message that will inform the user that the implementation failed the test. The reader is referred to section 10.5 of BSR X3.60.

D010 PRINT "PROGRAM FILE 68"

0060 PRINT

$007 \emptyset$ PRINT

0080 PRINT

0090 PRINT

0100 PRINT

$\emptyset 110$ PRINT

0120 PRINT

$\emptyset 130$ PRINT

0140 PRINT

0150 PRINT

0160 PRIN'

0170 PRIN

0180 PRINT

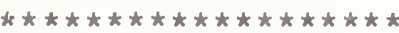

* PROGRAM FILE 68 *

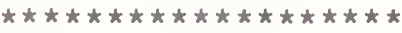

0190 PRINT

0200 PRINT

0210 PRINT

0220 PRINT

0230 PRINT

BEGIN TEST."

0240 PRINT

0250 RETURN

0260 PRINT "SYSTEM FAILED TEST."

0270 PRINT

0280 PRINT

SECTION 68.0: FATAL ERROR CHECK ON RETURN-STATEMENT."

0290 PRINT

END TEST."

0300 END 
SECTION 68.0: FATAL ERROR CHECK ON RETURN-STATEMENT.

THE OBJECTIVE OF THIS SECTION IS TO EXECUTE A RETURNSTATEMENT WITHOUT HAVING EXECUTED A CORRESPONDING GOSUBSTATEMENT SO THAT IT MAYBE DETERMINED WHETHER SUCH AN EXECUTION IS PERMISSIBLE BY THIS SYSTEM. IF THE SYSTEM SHOULD RECOGNIZE THIS EXECUTION AS A FATAL ERROR (THAT IS, SUSPENDING PROGRAM EXECUTION PENDING USER-DIRECTED RESTART PROCEDURES), THEN THE TEST WILL HAVE PASSED.

BEGIN TEST.

? RETURN BEFORE GOSUB IN LINE 250 


\subsection{TESTING ROUNDOFE TO SIX SIGNIFICANT DIGITS OF CONSTANTS \\ OF ARBITRARY LENGTH}

The objective of this test is to verify that although the accuracy, with which evaluation of an expression takes place, varies from implementation to implementation, each implementation should attempt to maintain at least six decimal digits of precision. For each test the output should contain a minimum of six significant digits. Furthermore, programs can contain numeric constants of an arbitrary number of digits, although an implementation may choose to round them to no less than six significant digits. The reader is referred to section 5.4 of BSR $\times 3.60$.

\subsection{Using Numerically Assigned Constants of Six or Fewer} Significant Digits

The objective of this test is to verify, for various numerical operations, that the implementation will maintain at least six decimal digits of precision. This test uses constants of six digits or fewer. Although rounding has been tested before for operations on numbers made up of less than or equal to six significant digits, this part of the test is included for completeness.

The test has a three column formatted output. In the first column, titled "True Rounded Values", there should be a list of the expected rounded values. In the second column, titled "System Rounded Values", there should be a list of the system evaluations, as rounded by the implementation. In the third column, titled "Absolute Error", there should be the listings of marginal differences between the expected rounded values and the respective implementation rounded values. If any value in the third column does not fall within the expected or allowed range of one unit error in the position of the sixth significant digit, then an asterisk should have appeared beside that difference.

\subsection{Using Numerically Assigned Constants of More Than Six Digits of Significance}

The objective of this test is to verify that the implementation will maintain at least six decimal digits of precision for numbers with an arbitrary number of digits of precision. This test uses assignment of constants that are composed of up to 17 decimal digits of precision. These assigninents are then used in various operations. On output, this test has the same output format described in section 69.1 .

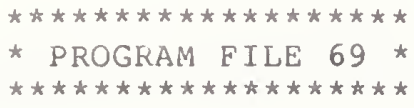




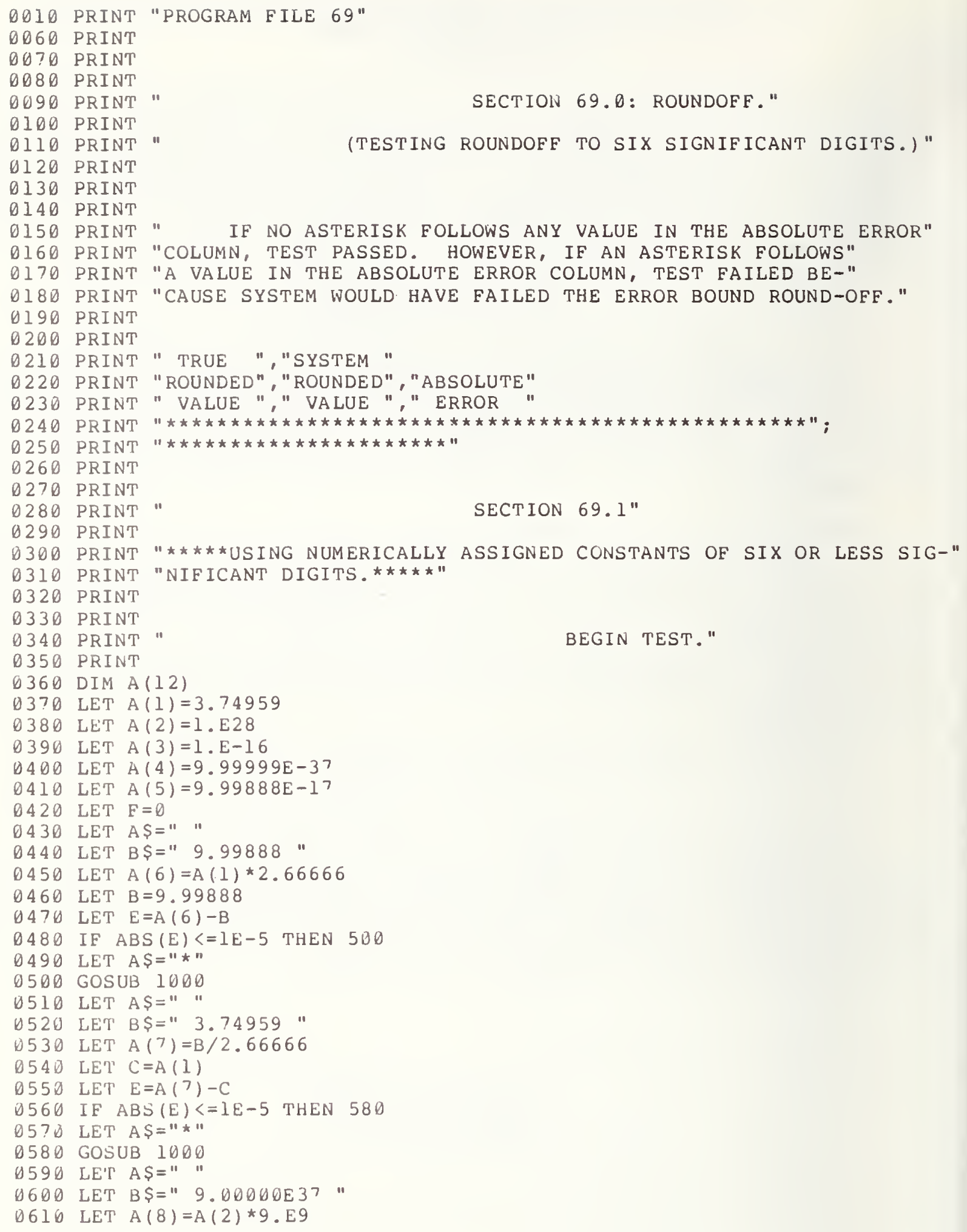




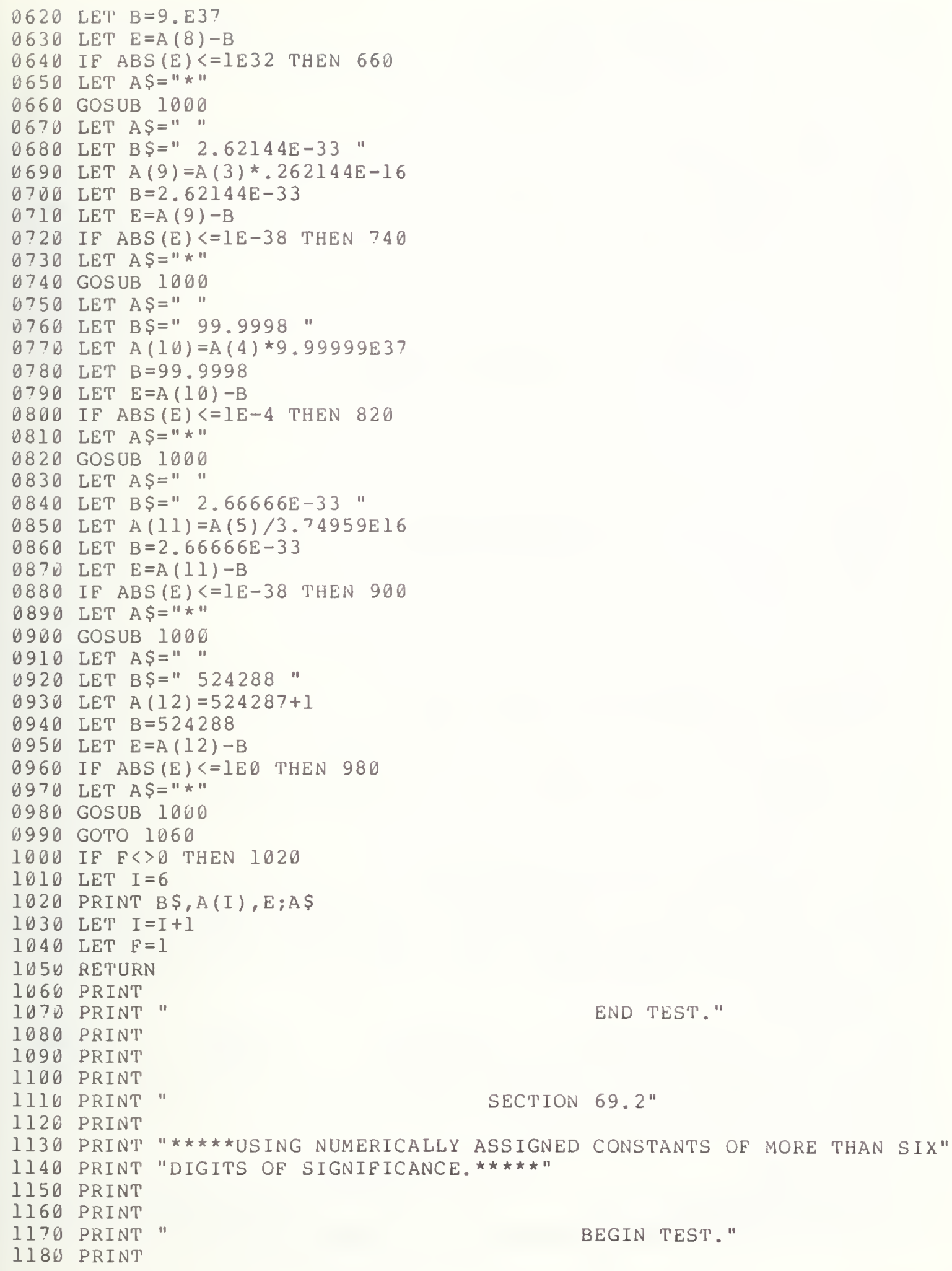




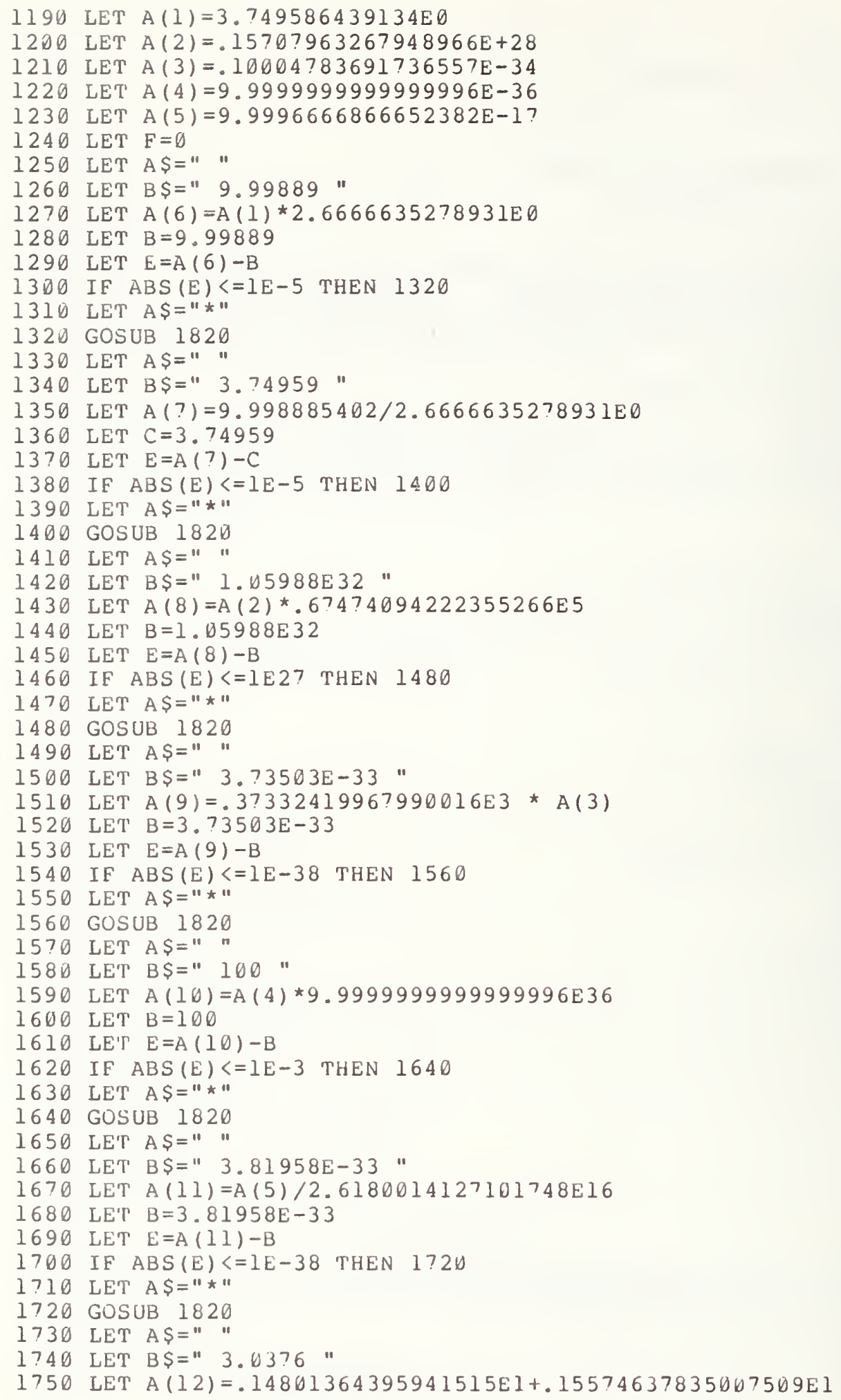


1760 LET $B=3.0376$

1770 LET $E=A(12)-B$

1780 IF ABS(E) $<=1 E-5$ THEN 1800

1790 LET $A \$=" * "$

1800 GOSUB 1820

1810 GOTO 1880

1820 IF $F<>0$ THEN 1840

1830 LET I $=6$

1840 PRINT $B \$, A(I), E ; A S$

1850 LET $I=I+1$

1860 LET $F=1$

1870 RETURN

1880 PRINT

1890 PRINT "

1900 PRINT

1910 PRINT

1920 END

END TEST."

PROGRAM FILE 69

SECTION 69.0: ROUNDOFF.

(TESTING ROUNDOFF TO SIX SIGNIFICANT DIGITS.)

IF NO ASTERISK FOLLOWS ANY VALUE IN THE ABSOLUTE ERROR COLUMN, TEST PASSED. HOWEVER, IF AN ASTERISK FOLLOWS

A VALUE IN THE ABSOLUTE ERROR COLUMN, TEST FAILED BE-

CAUSE SYSTEM WOULD HAVE FAILED THE ERROR BOUND ROUND-OFF.
TRUE
SYSTEM
ROUNDED
ROUNDED
VALUE
ABSOLUTE
ERROR
$\star \star \star * \star * \star *$
ERROR
SECTION 69.1

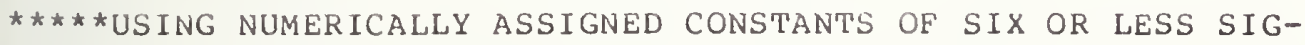 NIFICANT DIGITS. $* \star \star \star \star *$ 
BEGIN TEST.

$\begin{array}{lll}9.99888 & 9.99888 & 0 \\ 3.74959 & 3.74959 & 0 \\ 9.00000 \mathrm{E} 37 & 9.00000 \mathrm{E}+37 & 0 \\ 2.62144 \mathrm{E}-33 & 2.62144 \mathrm{E}-33 & 0 \\ 99.9998 & 99.9998 & 0 \\ 2.66666 \mathrm{E}-33 & 2.66666 \mathrm{E}-33 & 0 \\ 524288 & 524288 & 0\end{array}$

END TEST.

SECTION 69.2

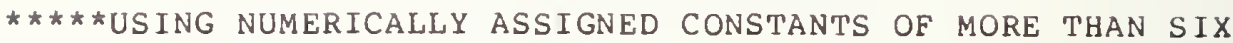
DIGITS OF SIGNIFICANCE. $* \star \star \star \star *$

BEGIN TEST.

$\begin{array}{lll}9.99889 & 9.99889 & 0 \\ 3.74959 & 3.74959 & 0 \\ 1.05988 \mathrm{E} 32 & 1.05988 \mathrm{E}+32 & 0 \\ 3.73503 \mathrm{E}-33 & 3.73503 \mathrm{E}-33 & 0 \\ 100 & 100 & 0 \\ 3.81958 \mathrm{E}-33 & 3.81958 \mathrm{E}-33 & 0 \\ 3.0376 & 3.0376 & 0\end{array}$

END TEST. 


\subsection{THE ON-GOTO STATEMENT}

This test verifies that the ON-GOTO statement for the test system can round its numeric expression to an integer and use that integer to select the appropriate line number from a list of line numbers following the GOTO. In particular, suppose that there are $\mathrm{N}$ line numbers. Then, if the statement expression is rounded to an integer $M$, this integer is either less than $I$, one of the integers from $I$ to $N$, or greater than $N$. If $M$ is one of the integers 1 to $\mathrm{N}$ then the control statement transfers control to the M-th line number in the list. Otherwise, the system must report an exception. The reader is referred to section 10 of BSR $\times 3.60$.

70.1 The ON-GOTO Numeric Expression, Using an Integer Within Range

The objective of this test is to show that the conditional transfer should be performed properly if the simple variable I, used in the ON-GOTO expression, is an integer from 1 to 5.5 is the list length. I is also the simple variable of a FOR-NEXT loop which uses integers for its initial value and limit, and has no STEP clause. The test informs the user when the transfer was not made by the ON-GOTO-statement to the correct statement. If there is no transfer, then the following message should be printed: THE 〈number〉 ON-GOTO TRANSFER, FAILED. Then, the following message should be printed: ERROR, TRANSFER SHOULD HAVE BEEN TO LINE NO. 〈number> IN LIST. That the transfer was actually made to the correct statement is determined by an IF-THEN statement. This tests the FOR-NEXT loop index. There is a counter that acts as a bookkeeper for the number of correct transfers, which in this case should be five. If this counter is not five, then the following message should be printed: ON-GOTO-STATEMENT, FAILED TEST. If the counter is five, then the following message should be printed: ON-GOTO-STATEMENT, PASSED TEST.

\subsection{The ON-GOTO Numeric Expression, As a Fraction Rounded to an Integer}

This test determines the round-off capability of the ON-GOTO-statement for numeric expressions. The Minimal BASIC standard requires rounding of the expression value to the nearest integer before performing the transfer. The numeric expression in this test is the simple control variable of a FOR-NEXT loop in which the initial value is incremented in steps of .5 to the limit. $K$ counts the number of passes through the loop. In this case there should be 5. On the first pass $(K=1)$, transfer should be to the first ON-GOTO $l$ ine number. On the second and third, the transfer should be to the second line number and finally, on the fourth and fifth passes, the transfer should be to the third line number. There is then one transfer to the first number and two each to the second and third line numbers. These counts are tested by the variables $A, B$, and $C$, respectively. If the ON-GOTO statement fails and the program continues, then a message follows: THE 〈number〉 ON-GOTO TRANSFER, FAILED. The second possible message is as follows: ERROR, TRANSFER SHOULD HAVE BEEN TO LINE NO. 〈number> IN LIST. Finally, the variables A, B, and C are each used to keep count of the number of transfers made by the ON-GOTO statement to the line numbers in the ON-GOTO 1 ist. The values of the correct number of transfers by $A, B$, and $C$ should be 1,2 , and 2 respectively. Proper transfers by the ON-GOTO-statement are determined by IF-THEN-statements which are placed at each of the line numbers of the 
ON-GOTO list. If upon completion of the FOR-NEXT loopings, the values of the counters $A, B$, and $C$ are not 1,2 , and 2 respectively, the following message should be printed: ON-GOTO-STATEMENT, FAILED TEST. If the value or the counters $A, B$, and $C$ are in order, then the following message should be printed: ON-GOTO-STATEMENT, PASSED TEST.

70.3 The ON-GOTO Numeric Expression, As An Expression of More Than One Term

This test verifies the proper evaluation and use for transfer control of an expression of more than one term by the ON-GOTO-statement. For this test, as for the previous tests, the evaluation should be based on the nearest integer value of the expression. Through the use of FOR-NEXT loops, different values are assigned for the evaluation of the numeric expression by the ON-GOTO-statement. The values of the numeric expression should be 1,2 , 3, 4, and 5. These values should be the position indices of the line numbers in the ON-GOTO list. Within the FOR-NEXT loop, there are two checks on the ON-GOTO-statement, and two counters. The first counter again keeps count of which transfer is being made and is used in the first error message. In the second error message, it acts as a pointer to the correct line number in the ON-GOTO list. The two messages should be the same as in the past two tests. Upon completion of the FOR-NEXT loops, as a means for checking the proper performance of the ON-GOTO-statement, the value of the second counter is checked for a value of 5. If the value of the count is not five, then the following message should be printed: ON-GOTO-STATEMENT, FAILED TEST. If the value of the count is five, then the following message should be printed: ON-GOTO-STATEMENT, PASSED TEST.

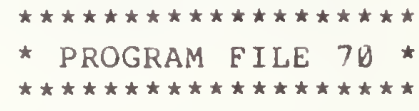

\begin{tabular}{|c|c|c|}
\hline 0010 & PRINT "PROGRAM & FILE $70^{\prime \prime}$ \\
\hline 0020 & PRINT & \\
\hline 0030 & PRINT & \\
\hline 0040 & PRINT & \\
\hline 0050 & PRINT" & SECTION $7 \emptyset .0$ : THE ON-GOTO STATEMENT" \\
\hline 0080 & PRINT & \\
\hline 0090 & PRINT " & SECTION 70.1: THE ON-GOTO NUMERIC EXPRESSION" \\
\hline 0100 & PRINT & \\
\hline 0110 & PRINT " & USING AN INTEGER WITHIN RANGE" \\
\hline 0120 & PRINT & \\
\hline 0130 & PRINT" & BEGIN TEST." \\
\hline 0140 & PRINT & \\
\hline 0150 & LET $K=\emptyset$ & \\
\hline 160 & LET $N=0$ & \\
\hline$y$ & FOR $I=1 \quad \eta O 5$ & \\
\hline & ET $K=K+1$ & \\
\hline
\end{tabular}


0190 ON I GOTO $220,240,260,280,300$

0200 PRINT TAB (20); "THE"; ; "ON-GOTO TRANSFER, FAILED."

0210 PRINT

0220 IF $I=1$ THEN 320

0230 GOTO 340

0240 IF I=2 THEN 320

0250 GOTO 340

0260 IF $I=3$ THEN 320

0270 GOTO 340

$\emptyset 280$ IF $I=4$ THEN 320

0290 GOTO 340

0300 IF I $=5$ THEN 320

0310 GOTO 340

0320 LET $\mathrm{N}=\mathrm{N}+1$

0330 GOTO 350

0349 PRINT "ERROR, TRANSFER SHOULD HAVE BEEN TO LINE NO.";K;"IN LIST."

0350 NEXT I

0360 PRINT

0370 IF $N=5$ THEN 400

0380 PRINT "

0390 GOTO 430

0400 PRINT "

0410 PRINT

0420 PRINT"

0430 PRINT

0440 PRINT "

0450 PRINT

0455 PRINT "

0457 PRINT

0460 PRINT "

0470 PRINT

0480 LET $A=0$

0490 LET $B=0$

0500 LET $C=0$

0510 LET $K=0$

$0520 \mathrm{FOI}[=1$ TO 3 STEP . 5

0530 LET $K=K+1$

0540 ON I GOTO $570,590,620$

B550 PRINT TAB $(20)$; "THE"; $\mathrm{K}$;"ON-GOTO TRANSFER, FAILED."

0560 PRINT

0570 IF $I=1$ THEN 730

0580 GOTO 640

0590 IF $I=1.5$ THEN 750

0600 IF $I=2.0$ THEN 750

B610 GOTO 640

0620 IF $I=2.5$ THEN 770

0630 IF $I=3.0$ THEN 770

0640 IF $K=1$ THEN 680

0650 IF $K>=4$ THEN 700

0660 LET $F=2$

0670 GOTO ?10

0680 LET $F=1$

0690 GOTO 710

0700 LET $F=3$

0710 PRINT "ERROR, TRANSFER SHOULD HAVE BEEN TO LINE NO.";F;"IN LIST." 0720 GOTO 780

0730 LET $A=A+1$ 


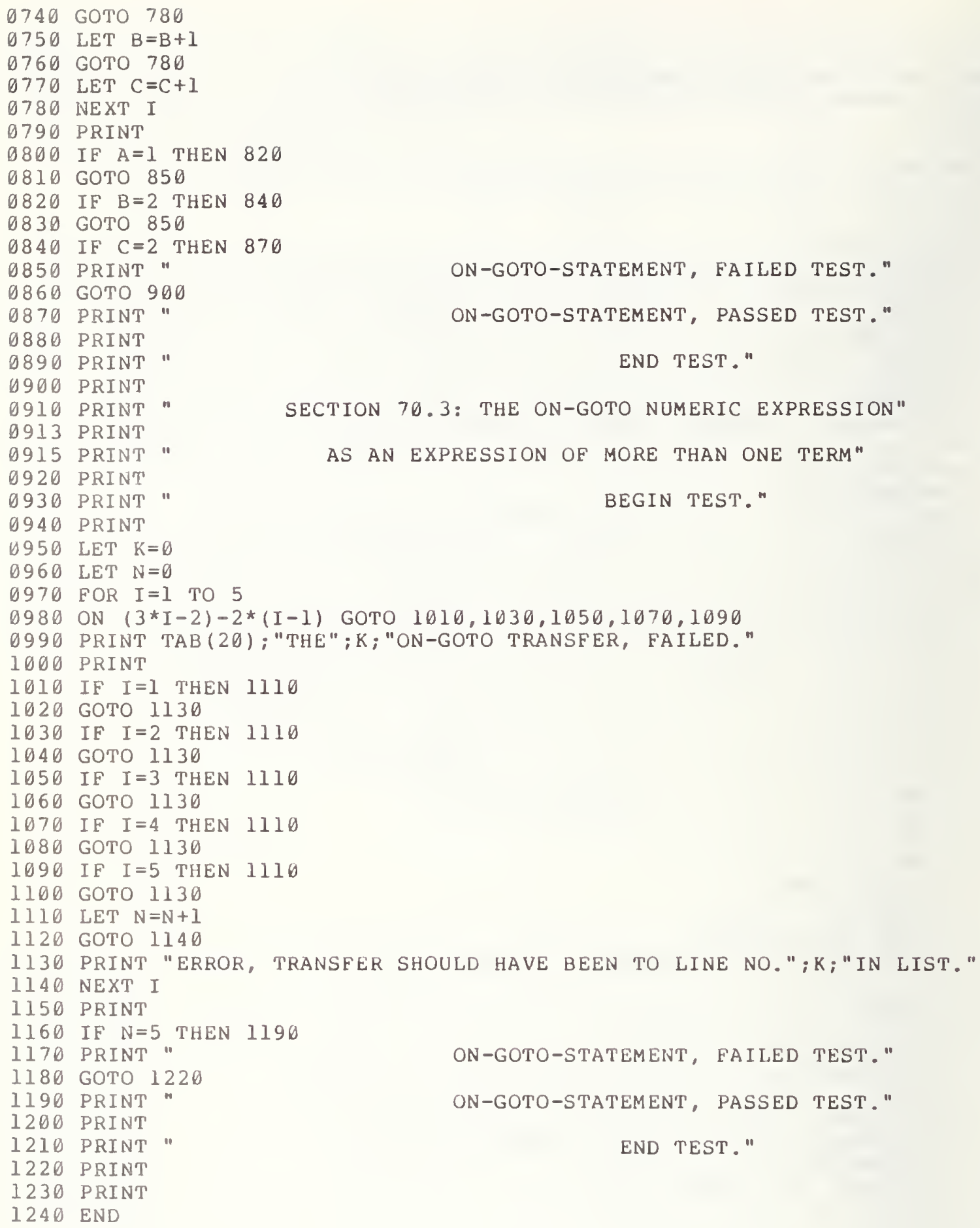

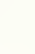




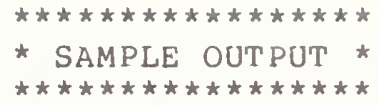

PROGRAM FILE ?0

SECTION 70.0: THE ON-GOTO STATEMENT

SECTION 70.1: THE ON-GOTO NUMERIC EXPRESSION

USING AN INTEGER WITHIN RANGE

BEGIN TEST.

ON-GOTO-STATEMENT, PASSED TEST .

END TEST.

SECTION 70.2: THE ON-GOTO NUMERIC EXPRESSION

AS A FRACTION ROUNDED TO AN INTEGER

BEGIN TEST .

ON-GOTO-STATEMENT, PASSED TEST.

END TEST

SECTION 70.3: THE ON-GOTO NUMERIC EXPRESSION

AS AN EXPRESSION OF MORE THAN ONE TERM

BEGIN TEST .

ON-GOTO-STATEMENT, PASSED TEST.

END TEST. 
This test verifies that the implementation will recognize when a transfer to an illegal line number is attempted by the ON-GoTo statement. In particular, the objective is to determine whether an attempted transfer of this sort in line 380 will be considered by the implementation as an error requiring a diagnostic and program termination. On output, there should be some form of implementation-defined diagnostic. However, should the implementation fail to recognize this error, the program prints a message which tells the user that the implementation failed the test. The reader is referred to section 10.4 of BSR $\times 3.60$.

\author{
ØIØ PRINT "PROGRAM FILE $71 "$ \\ 0020 PRINT \\ 0030 PRINT \\ 0040 PRINT \\ $009 \emptyset$ PRINT \\ 0100 PRINT \\ OII0 PRINT \\ Q120 PRINT \\ $013 \emptyset$ PRINT \\ 0140 PRINT \\ D150 PRINT \\ 0160 PRINT \\ 0170 PRINT \\ Ø180 PRINT " \\ ๑190 PRINT" \\ $\emptyset 200$ PRINT" \\ 0210 PRINT " \\ 0220 PRINT" \\ 0230 PRINT" \\ 0240 PRINT \\ ఏ250 PRINT "IF BOTH OF THE ABOVE REFERRALS ARE CONSIDERED FATAL ERRORS," \\ 0260 PRINT \\ 0270 PRINT \\ 0280 PRINT \\ 0290 PRINT \\ 0310 PRINT \\ 0320 PRINT \\ 0330 PRINT \\ 0340 PRINT \\ 0350 PRINT \\ 0360 PRINT \\ SECTION 71. 0 : FATAL ERROR TEST - ON-GOTO-STATEMENT." \\ " THE OBJECTIVE OF THIS SECTION IS TO DETERMINE WHETHER" \\ "THIS SYSTEM RECOGNIZES THE FOLLOWING AS FATAL ERRORS (THAT" \\ "IS, SUSPENDING PROGRAM EXECUTION PENDING USER-DIRECTED RE-" \\ "START PROCEDURES): " \\ (1) WHEN AN ON-GOTO-STATEMENT REFERS TO A NON-EXISTENT" \\ LINE NUMBER, OR" \\ (2) WHEN THE INTEgER OBTAINED AS THE VALUE OF AN EX-" \\ PRESSION IN AN ON-GOTO-STATEMENT IS LESS THAN ONE" \\ OR GREATER THAN THE NUMBER OF LINE NUMBERS IN THE" \\ LIST." \\ "THEN THE TEST WILL HAVE PASSED." \\ (A REFERRAL TO A NON-EXISTENT LINE NUMBER.)" \\ BEGIN TEST."
}


0370 LET $X=1$

D 380 ON X GOTO 159

0390 PRINT "SYSTEM FAILED TEST."

0400 PRINT

0410 PRINT "

0420 PRINT

END TEST."

0430 END

In order for this test to pass, a fatal error must be diagnosed and reported. A possible error diagnostic for this program might be:

? UNDEFINED LINE NUMBER 159 IN LINE 380 


\section{EXCEPTION TEST = VALUE OF ON-GOTO EXPRESSION LESS THAN ONE}

This test verifies that the implementation recognizes the numeric expression evaluation with values less than one as an exception. The test has an ON-GOTO-statement which uses an expression that should round to an integer less than one at line 170. In this case the expression is a simple variable with a value of .3 that should be rounded to $\theta$. On output, there should be some form of implementation-defined diagnostic. However, the test is structured to print a message of the implementation's failure should the test system not recognize the error. The reader is referred to section 10.5 of BSR X3.60.
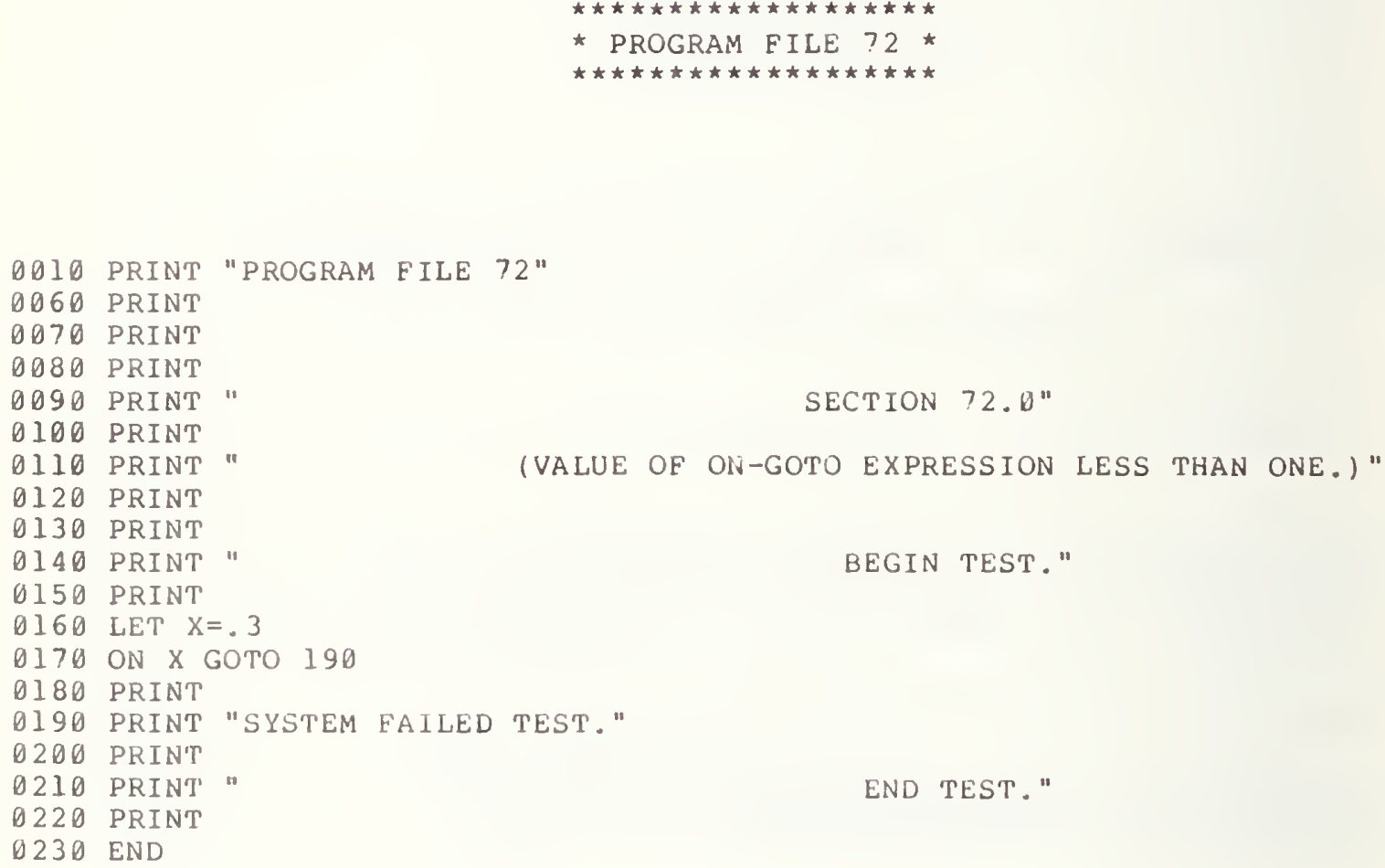
PROGRAM FILE 72

SECTION 72.0

(VALUE OF ON-GOTO EXPRESSION LESS THAN ONE.)

BEGIN TEST.

? ON EVALUATED OUT OF RANGE IN LINE $17 \emptyset$ 
The objective of this test is to compute an integer value for the numerical expression used in an ON-GOTO-statement. In this case the integer value should be greater than the number of line numbers listed in the ON-GOTO-statement. The test determines whether the implementation recognizes this as an exception. The program has a simple variable, $X$, assigned the value 2 in line 170 but an ON-GOTO with one line number in its 1 ist in line 180. Then, $x$ is used as the expression in line 180. On output, there should be some form of implementation-defined diagnostic relating to the error. However, should the implementation fail to recognize the error, a message will be printed to the user. The reader is referred to section 10.5 of BSR $\times 3.60$.

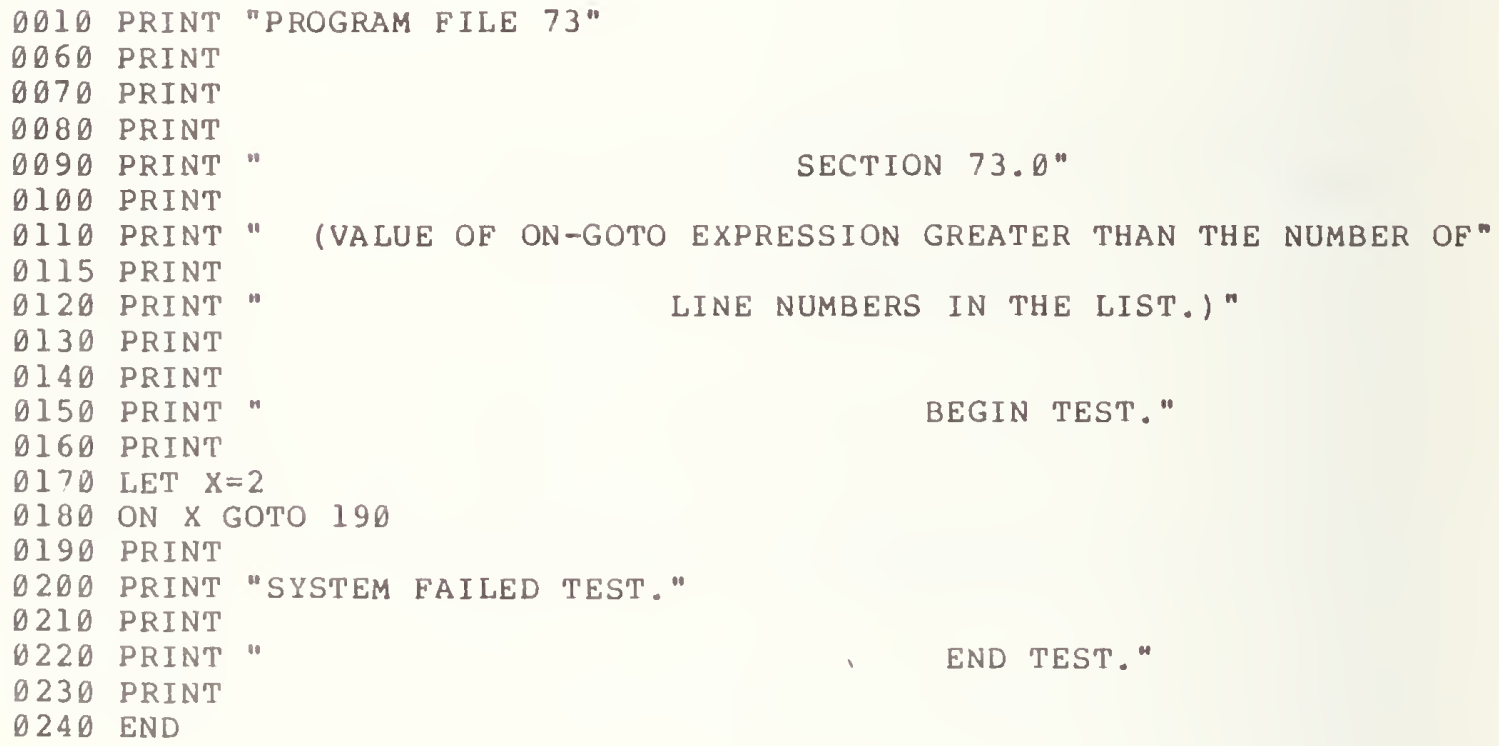


PROGRAM FILE 73

SECTION 73.0

(VALUE OF ON-GOTO EXPRESSION GREATER THAN THE NUMBER OF LINE NUMBERS IN THE LIST.)

BEGIN TEST.

? ON EVALUATED OUT OF RANGE IN LINE 180 
These next eight sections are oriented towards testing (1) whether the READ-statement assigns values, provided by DATA-statements, to variables, and (2) whether the RESTORE-statement enables the rereading of those same values. The values supplied by DATA-statements can be either numeric constants, string constants, or unquoted strings. All of the data from the totality of DATA-statements should be collected together into a data sequence. It should not matter where DATA-statements are located in a program as long as they occur before the END-statement. However, the order in which the different types of data occur should determine the order of the variables within the variable list of the READ-statements. That is, the order of the numeric variables must match that of the numeric constants within the data sequence and the same for string variables. If there are variables in READ-statements with subscripted expresions, then the expressions are evaluated after values have been assigned to any variables preceding those subscripted variables (to the left of them in the list). By the use of the RESTORE-statement, the pointer associated with the data sequence should be reset to the beginning of the data sequence so that the next READ-statement executed will read data from the beginning of the sequence once again. The reader is referred to section 14 of BSR $\times 3.60$ for the specifications.

\subsection{READ/DATA for Numeric Variables}

The objective of this section is to introduce the READ/DATA relationship by assigning numerical constants to both simple and subscripted variables.

\subsubsection{For Simple Variables}

This test determines whether a $l$ ist of numeric constants can be assigned to a list of simple numeric variables through the READ-statement and DATA-statement. The test has three numeric constants in the DATA-statement assigned to three simple variables by a READ. The numeric constants are in the forms NR1, NR2, and NR3. On output there should be a message flagging false assignments by the READ-statement. Each of the error messages should read as follows: READ ASSIGNMENT FOR VARIABLE NUMBER 〈number〉, FAILED. If each variable assignment is proper then the following message should be printed: READ/DATA ASSIGNMENTS FOR SIMPLE VARIABLES, PASSED TEST.

\subsubsection{For Subscripted Variables}

The objective of this section is to execute READ/DATA assignments for both singly and doubly subscripted arrays.

\subsubsection{As One-Dimensional Arrays}

This test uses one-dimensional arrays for four subscripted variables. Two are assigned values by use of LET-statements. These values have also been entered into a DATA-list. The other two variables used in the READ-statement should be assigned the same values as the first two subscripted variables after the READ-statement has been executed. The values of the assignments are checked by use of IF-THEN-statements. The test also 
verifies incidentally that DATA-statements can be placed anywhere in the program before the END-statement. On output, there should be an error message for any faulty READ assignments. Each of the error messages should be printed as follows: READ ASSIGNMENT FOR VARIABLE NUMBER 〈number>, FAILED. If each variable assignment is correct, then the following message should be printed: READ/DATA ASSIGNMENTS FOR ONE-DIMENSIONAL ARRAYS, PASSED.

\subsubsection{As Two-Dimensional Arrays}

In this test, two-dimensional arrays are used in a manner similar to that in 74.1.2.1. Two of the four subscripted variables are assigned values through the use of LET-statements. The remaining two variables, used in the READ-list, should be assigned the same values. On output there should be a printed message for any faulty READ assignment. Each of these error messages should appear as follows: READ ASSIGNMENT FOR VARIABLE NUMBER 〈number〉, FAILED. If each assignment is correctly made, then the following message should be printed: READ/DATA ASSIGNMENTS FOR TWO-DIMENSIONAL ARRAYS, PASSED.

74.2 READ/DATA for String Variables

The object of this test is to assign string constants to string variables by using the READ-statement and DATA-statement. Three string constants ("ASSIGNING", "STRING", and "CONSTANTS") are assigned to three string variables (A\$, B\$, and $C \$$ ). These assignments are then checked. On output there should be an error message for any faulty assignment. Each of these error messages should appear as follows: READ ASSIGNMENT FOR VARIABLE NivisER <number>, FAILED. If there are no faulty assignments, then the following message should be printed: READ/DATA ASSIGNMENTS FOR STRING VARS., PASSED TEST.

\subsection{READ/DATA for Numerical and String Variables Together}

The object of this test is to verify that there should be a single sequence of data items, rather than separate sequences, for string data and for numeric data. However, if the DATA-list is a mixture of numeric constants and string constants, then the order of the mixture of numeric variables and string variables in the READ-list must correspond to the mixture in the DATA-list. That is, the type of a datum in the data sequence must correspond to the type of the variable to which it is to be assigned, (which means numeric variables require numeric constants as data and string variables require quoted strings or unquoted strings as data. On output there should be an error message for any incorrect assignment. Each of the error messages should appear as follows: READ ASSIGNMENT FOR VARIABLE NUMBER <number>, FAILED. If all assignments are correct then the following message should be printed: READ/DATA ASSIGNMENTS FOR NUM/STRG VARS. TOGETHER, PASSED.

\subsection{Evaluation of Subscripted Variables}

This test confirms (1) that subscripted expressions in the variable list are evaluated after values have been assigned to the variables preceding them (that is, to the left of them) in the list, and (2) that any previous LET assignments for the index should be ignored. The test first assigns values 
to the elements of the array $A(I)$ by a LET-statement. After the values have been assigned to the array $A(I)$, the index $I$ is assigned a value by a LET-statement in order to select one of the elements of the array A(I). Then, another value is assigned to the index I by a READ-statement and a DATA-statement. At this point the index value assigned by the LET-statement should be nullified, and the index value for I assigned by the READ and DATA-statements should take precedence. This controls the element assigned to the subscripted variable $A(I)$ in the READ-list. On output one of two possible messages should be printed. If the test fails, then the following message should be printed: EVALUATION OF SUBSCRIPT EXP. IN VARIABLE LISTS, FAILED. If the test is passed, then the following message should be printed: EVALUATION OF SUBSCRIPT EXP. IN VARIABLE LISTS, PASSED.

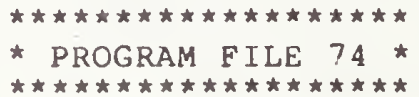

OOID PRINT "PROGRAM FILE 74"

0020 PRINT

0030 PRINT

0040 PRINT

0070 PRINT

0080 PRINT

0090 PRINT

OI00 PRINT"

0110 PRINT

0120 PRINT "

0130 PRINT

0140 LET $K=0$

Ø150 DATA $123456,-4.76567,1.111 \mathrm{E} 33$

0160 READ M, N,O

0170 LET $K=K+1$

0180 IF $M=123456$ THEN 200

0190 GOSUB 270

0200 LET $\mathrm{K}=\mathrm{K}+1$

0210 IF $N=-4.76567$ THEN 230

0220 GOSUB 270

0230 LET $\mathrm{K}=\mathrm{K}+\mathrm{l}$

0240 IF $\mathrm{O}=1.111 \mathrm{E} 33$ THEN 290

0250 GOSUB 270

0260 GOTO 320

0270 PRINT TAB (12); "READ ASS IGNMENT FOR VARIABLE NUMBER"; K;" "FAILED."

6280 RETURN

0290 PRINT "READ/DATA ASSIGNMENTS FOR SIMPLE VARIABLES, PASSED TEST."

0300 PRINT

0310 PRINT "

0320 PRINT

0330 PRINT"

0340 PRINT END TEST."

SECTION 74.1.2: FOR SUBSCRIPTED VARIABLES." 
0410 DATA $-9,-1.75,-8,-.75,-7, .25,-6,1.25,-5,2.25$

0420 FOR $I=1$ TO 15

0430 READ A(I), B (I)

0440 LET $C(I)=I-10$

0450 LET $D(I)=I-2.75$

0460 NEXT I

0470 DATA $-4,3.25,-3,4.25,-2,5.25,-1,6.25,0,7.25$

0480 LET $K=0$

0490 FOR $I=1$ TO 15

0500 LET $K=K+1$

0510 IE $A(I)=C$ (I) THEN 530

0520 GOSUB 620

0530 LET $K=K+1$

0540 IF $B(I)=D(I)$ THEN 560

0550 GOSUB 620

0560 NEXT I

0570 DATA $1,8.25,2,9.25,3,10.25,4,11.25,5,12.25$

0580 IF $F=0$ THEN 650

0590 PRINT

0600 PRINT "

0610 GOTO 680

0620 LET $F=F+1$

0630 PRINT TAB (12); "READ ASS IGNMENT FOR VARIABLE NUMBER";K;" FAILED." 0640 RETURN

0650 PRINT "READ/DATA ASSIGNMENTS FOR ONE-DIMENSIONAL ARRAYS, PASSED." 0660 PRINT

0670 PRINT

0680 PRINT

0690 PRINT

END TEST."

0700 PRINT

$0 ? 10$ PRINT

0720 PRINT

0730 DIM $M(2,15), N(2,15), X(2,15), Y(2,15)$

$0 ? 40$ LET $F=0$

0750 DATA $-1,-4.25,0,-3.25,1,-2.25,2,-1.25,3,-.25,4, .75$

0760 DATA $5,1.75,6,2.75,7,3.75,8,4.75,9,5.75,10,6.75$

0770 FOR $I=1$ TO 2

0780 FOR $J=1$ TO 15

$0790 \operatorname{READ} M(I, J), N(I, J)$

0800 LET $X(I, J)=J-2 * I$

$0810 \operatorname{LET} Y(I, J)=I * J-5.25$

0820 NEXT J

0830 NEXT I

0840 DATA $11,7.75,12,8.75,13,9.75,-3,-3.25,-2,-1.25,-1, .75$

0850 LET $K=0$

0860 FOR $I=1$ TO 2

0870 FOR $\mathrm{J}=1$ TO 15

0880 LET $K=K+1$

0890 IF $M(I, J)=X(I, J)$ THEN 910

0900 GOSUB 1020

0910 LET $K=K+1$ 


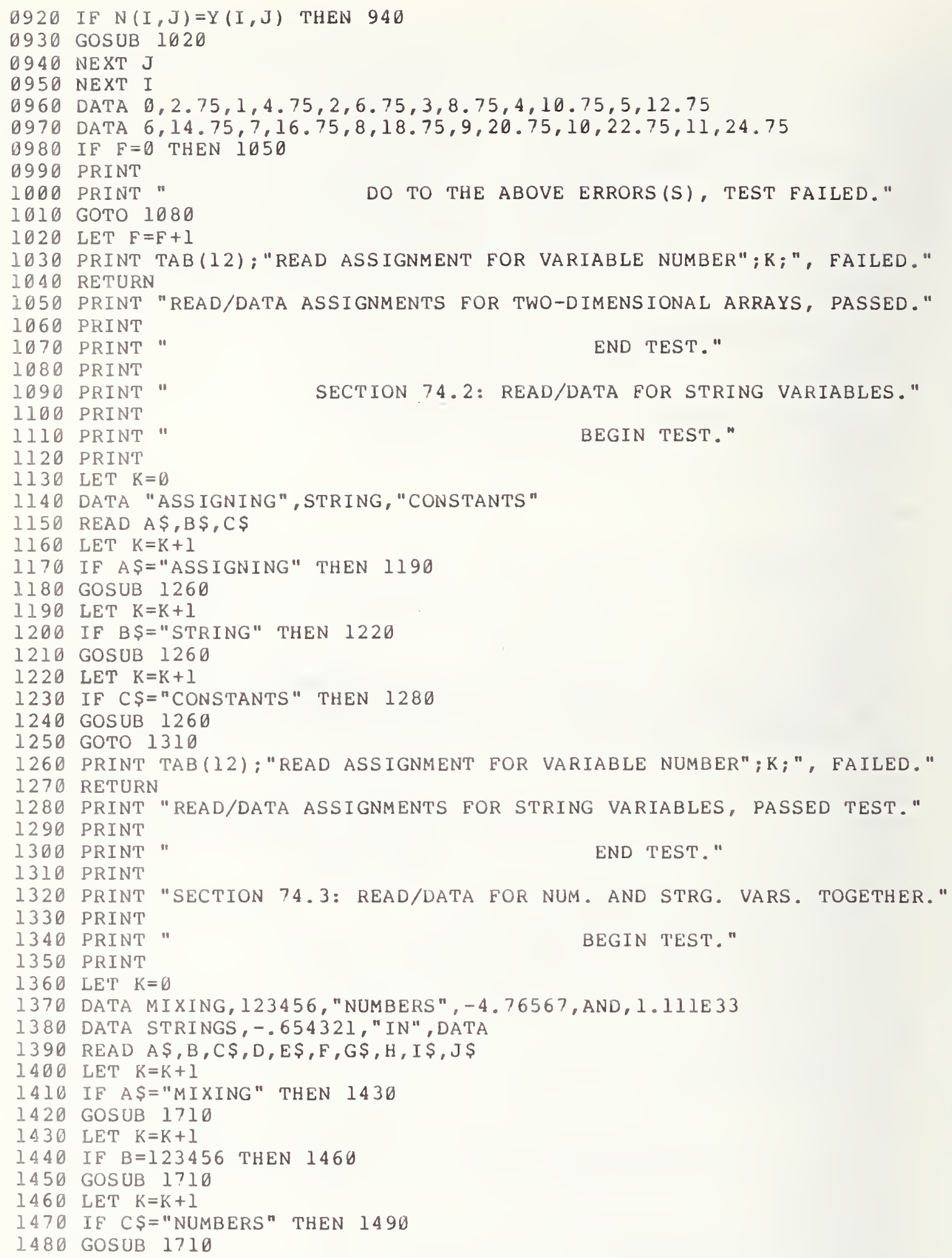


1490 LET $K=K+1$

1500 IF $\mathrm{D}=-4.76567$ THEN 1520

1510 GOSUB 1710

1520 LET $K=K+1$

1530 IF $E \$=" A N D "$ THEN 1550

1540 GOSUB 1710

1550 LET $K=K+1$

1560 IF $F=1.111 E 33$ THEN 1580

1570 GOSUB 1710

1580 LET $K=K+1$

1590 IF G\$="STRINGS" THEN 1610

1600 GOSUB 1710

1610 LET $K=K+1$

1620 IF $\mathrm{H}=-.654321$ THEN 1640

1630 GOSUB 1710

1640 LET $\mathrm{K}=\mathrm{K}+1$

1650 IF I\$="IN" THEN 1670

1660 GOSUB 1710

1670 LET $K=K+1$

1680 IF J $\$=" D A T A "$ THEN 1730

1690 GOSUB 1710

1700 GOTO 1760

1710 PRINT TAB (12); "READ ASS IGNMENT FOR VARIABLE NUMBER";K;", FAILED." 1720 RETURN

1730 PRINT "READ/DATA ASSIGNMENTS FOR NUM/STRG VARS. TOGETHER, PASSED."

1740 PRINT

1750 PRINT

END TEST."

1760 PRINT

1770 PRINT "

1780 PRINT

1790 PRINT"

1. ग0 PRINT

1810 DIM V $(10)$

1820 FOR $I=1$ TO 10

1830 LET $V(I)=I-4 I^{\wedge} 2$

1840 NEXT I

1850 LET $\mathrm{I}=8$

1860 DATA $6,3 E-33$

1870 READ I, V(I)

1880 IF $V(8)<>-248$ THEN 1900

1890 IF $V(6)=3 E-33$ THEN 1920

1900 PRINT " EVALUATION OF SUBSCRIPT EXPS. IN VARIABLE LIST, FAILED."

1910 GOTO 1950

1920 PRINT " EVALUATION OF SUBSCRIPT EXPS. IN VARIABLE LIST, PASSED."

1930 PRINT

1940 PRINT "

1950 PRINT

1960 PRINT

1970 END

END TEST." 
SECPION 74.1: READ/DATA FOR NUMERIC VARIABLES. SECTION 74.1.1: FOR SIMPLE VARIABLES. BEGIN TES'T.

READ/DATA ASSIGNMENTS FOR SIMPLE VARIABLES, PASSED TEST. END TEST.

SECTION 74.1.2: FOR SUBSCRIPTED VARIABLES. SECTION 74.1.2.1: AS ONE-DIMENSIONAL ARRAYS. BEGIN TEST.

READ/DATA ASSIGNMENTS FOR ONE-DIMENSIONAL ARRAYS, PASSED. END TEST.

SECTION 74.1.2.2: AS TWO-DIMENSIONAL ARRAYS. BEGIN TEST.

READ/DATA ASSIGNMENTS FOR TWO-DIMENSIONAL ARRAYS, PASSED. END TEST. SECTION 74.2: READ/DATA FOR STRING VARIABLES. BEGIN TEST.

READ/DATA ASSIGNMENTS FOR STRING VARIABLES, PASSED TEST. END TEST.

SECTION 74.3: READ/DATA FOR NUM. AND STRG. VARS. TOGETHER. BEGIN TEST.

READ/DATA ASSIGNMENTS FOR NUM/STRG VARS. TOGETHER, PASSED. END TEST. SECTION 74.4: EVALUATION OF SUBSCRIPTED VARIABLES. BEGIN TEST. EVALUATION OF SUBSCRIPT EXPS. IN VARIABLE LIST, PASSED. END TEST. 


\subsection{EXCEPTION TEST - READ-STATEMENT ENCOUNTERS INSUFF ICIENT DATA}

The objective of this test is to verify that the implementation will diagnose whether a variable list in a READ-statement requires more data than is present in the remainder of the data sequence and reports this as an exception. The test has a DATA-statement at line 380 which has a DATA-list that is not in one-to-one correspondence with the variable list for the READ-statement at line 390. On output, there should appear some implementation-defined diagnostic reporting the error. However, should the implementation fail to recognize the error, the test has a message that reports test failure. The reader is referred to section 14.5 of BSR $\times 3.60$.

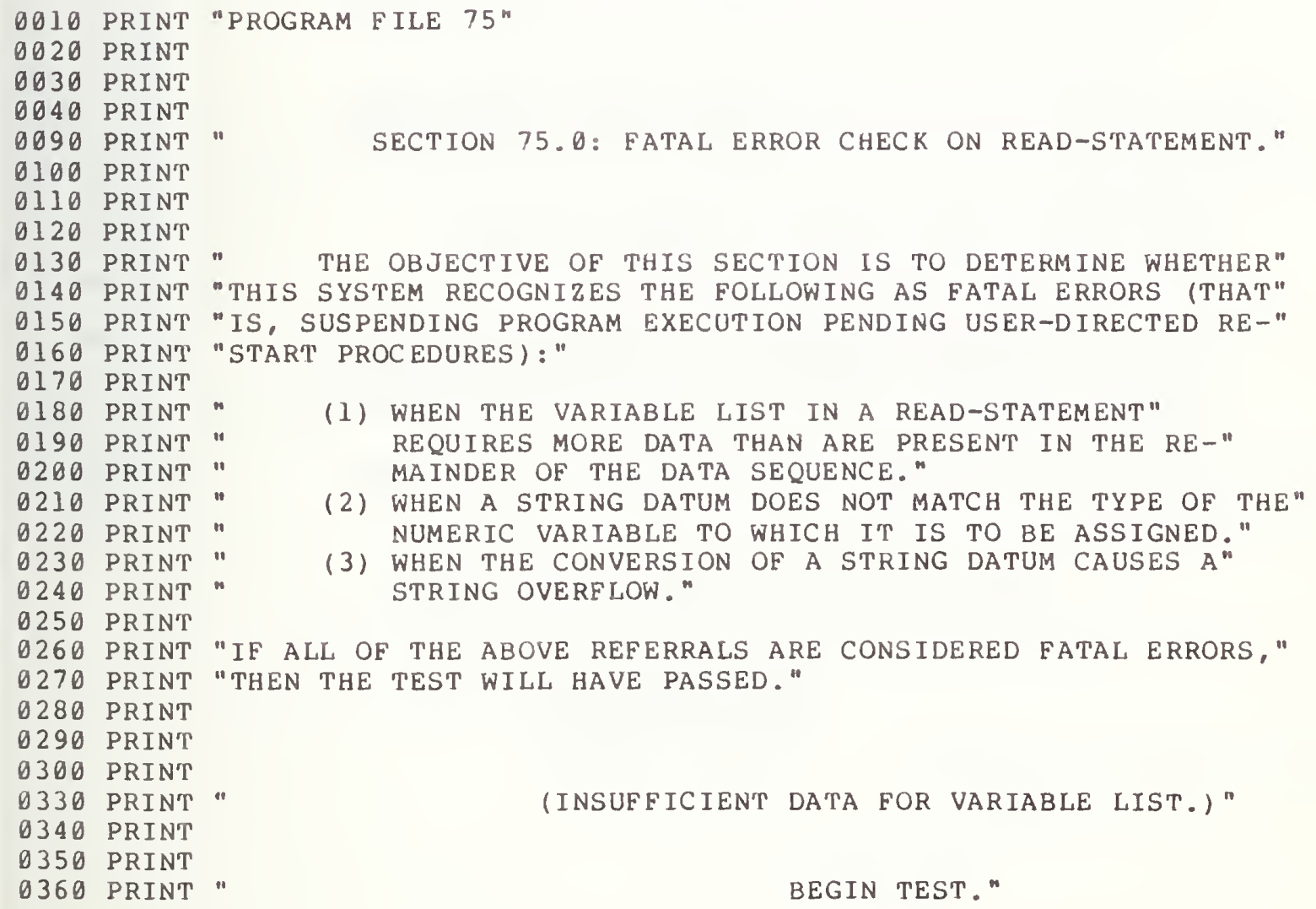


0370 PRINT

0380 DATA $-2,16$

0390 READ $A, B, C$

0400 PRINT "

IF THERE IS A PRINTOUT OF NUMBERS AFTER THIS STATEMENT"

Q 410 PRINT "THEN THE TEST WILl HAVE FAILED."

0420 PRINT A,B,C

0430 PRINT

0440 PRINT"

0450 PRINT

0460 END

END TEST."

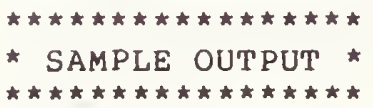

PROGRAM FILE 75

SECTION 75. D: FATAL ERROR CHECK ON READ-STATEMENT.

THE OBJECTIVE OF THIS SECTION IS TO DETERMINE WHETHER THIS SYSTEM RECOGNIZES THE FOLLOWING AS FATAL ERRORS (THAT IS, SUSPENDING PROGRAM EXECUTION PENDING USER-DIRECTED RESTART PROCEDURES):

(1) WHEN THE VARIABLE LIST IN A READ-STATEMENT REQUIRES MORE DATA THAN ARE PRESENT IN THE REMAINDER OF THE DATA SEQUENCE.

(2) WHEN A STRING DATUM DOES NOT MATCH THE TYPE OF THE NUMERIC VARIABLE TO WHICH IT IS TO BE ASSIGNED.

(3) WHEN THE CONVERSION OF A STRING DATUM CAUSES A STRING OVERFLOW.

IF ALL OF THE ABOVE REFERRALS ARE CONSIDERED FATAL ERRORS, THEN THE TEST WILL HAVE PASSED.

\section{(INSUFFICIENT DATA FOR VARIABLE LIST.)}

BEGIN TEST.

? OUT OF DATA IN LINE 390 


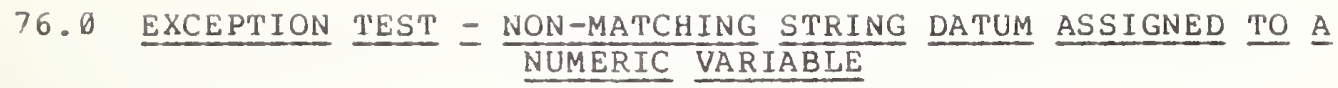

The objective of this test is to determine whether the implementation will recognize the attempt to read a string constant in the data sequence by a numeric variable as an exception. The test attempts to read a quoted string in a DATA-list by a simple numeric variable in a READ-list. On output, there should be some form of implementation-defined diagnostic. However, should the implementation fail to recognize the error, the test has a message printed that tells the user that the implementation failed the test. The reader is referred to section 14.5 of BSR $\times 3.60$.

๑010 PRINT "PROGRAM FILE ?6"

0020 PRINT

0030 PRINT

0040 PRINT

0090 PRINT

0100 PRINT

O110 PRINT "(NON-MATCHING STRING DATUM ASSIGNED TO A NUMERIC VARIABLE.)"

0120 PRINT

D130 PRINT

0140 PRINT

0150 PRINT

0160 DATA "SIX"

0170 READ A

O180 PRINT" " EXECUTION OF PROGRAM WAS NOT SUSPENDED, THEREFORE," OI90 PRINT "THE SYSTEM HAS EAILED THE TEST."

0200 PRINT

0210 PRINT

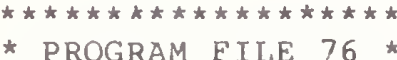

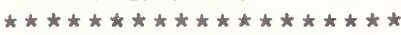

0220 PRINT

END TES'T."

0230 END 
PROGRAM FILE 76

\section{SECTION 76.0}

(NON-MATCHING STRING DATUM ASSIGNED TO A NUMERIC VARIABLE.) BEGIN TEST.

? VARIABLE IN LINE 170 INCOMPATIBLE WITH DATA 
0350 PRINT F\$

0360 PRINT

0370 PRINT "

0380 PRINT

0390 END
END TEST."

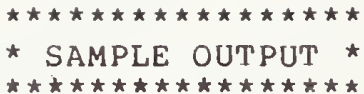

* SAMPLE OUTPUT *

PROGRAM FILE 77

SECTION 77.0

(A STRING OVERELOW.)

\section{BEGIN TEST.}

IF THERE IS A PRINTOUT BELOW THIS PARAGRAPH AND NOT AN INDICATION OE A EATAL ERROR, THEN THIS SYSTEM SATISEIES MORE IN THIS RESPECT THAN IS REQUIRED BY MINIMAL BASIC. THE NUMBERS TOWARD THE CENTER OR IN THE CENTER OE THE ASTERISKS SIGNIFY THE LENGTH OF THE CHARACTER STRINGS ASSOCIATED WITH EACH ASSIGNED STRING VARIABLE.

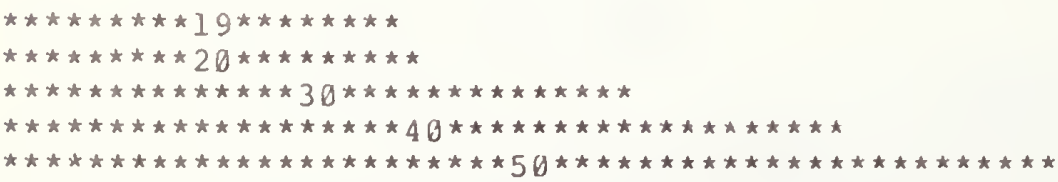

END TEST. 


\subsection{SEMANTIC INTERPRETATION = A NUMERIC VALUE IN A DATA LIST \\ CAUSES AN UNDERFLOW}

This test verifies that the implementation recognizes the semantic interpretation required when a positive numerical constant, which is too small to be represented by the machine, is assigned. The READ/DATA relationship should ignore the value being assigned by making an assignment of zero to the value and continuing the program. The test has a DATA-statement which lists a numerical value of the magnitude 9.0E-99999 at line 360. On output, there should be a message which should tell the user to look for a zero as a printout following that message. If zero is printed, then the implementation will have passed the test. The reader is referred to section 14.4 in BSR $\times 3.60$.

Q0I0 PRINT "PROGRAM FILE 78"

0020 PRINT

0030 PRINT

OQ 40 PRINT

0260 PRINT

0270 PRINT

Q 280 PRINT

Q290 PRINT

0300 PRINT

O310 PRINT

Q320 PRINT

Q330 PRINT

Q34ด PRINT

0350 PRINT

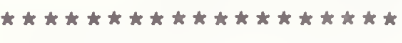

* PROGRAM FILE $78 *$

Q360 DATA 9.0E-99999

0370 READ A

0380 PRINT " IF THE NUMBER PRINTED AFTER THIS STATEMENT IS ZERO,"

0390 PRINT "THEN THE SYSTEM WILL HAVE PASSED THE TEST."

$\emptyset 400$ PRINT A

0410 PRINT

0420 PRINT

0430 PRINT

END TEST."

0440 END 


\author{
SECTION 78.0 \\ (A NUMERIC DATUM CAUSES AN UNDERFLOW.) \\ BEGIN TEST .
}

IF THE NUMBER PRINTED AFTER THIS STATEMENT IS 2ERO, THEN THE SYSTEM WILL HAVE PASSED THE TEST.

$\emptyset$

END TEST. 
This test verifies that the implementation will recognize the assigning, by the READ/DATA relationship, of a number that causes overflow, as an exception. The exception recovery procedure should cause the implementation-defined machine infinity to be assigned instead. The test has a DATA-statement in line 170 which lists a numerical value of magnitude 9.99999E99999. On output, there should be a message telling the user to look for the implementation-defined machine infinity as a printout following the message. If a positive machine infinity is printed, then the implementation will have passed the test. The reader is referred to section 14.5 of BSR $\times 3.60$.

0010 PRINT "PROGRAM FILE 79"

0020 PRINT

0030 PRINT

0040 PRINT

0090 PRINT

OI00 PRINT

0110 PRINT

0120 PRINT

0130 PRINT

0140 PRINT

0150 PRINT

0160 PRINT

0170 DATA 9.99999E99999

0180 READ A

O190 PRINT

0200 PRINT "AND THE THE NUMBER PRINTED BELOW THIS STATEMENT IS POSITIVE

0210 PRINT "WILL HAVE PASSED ON THIS SYSTEM."

0220 PRINT A

0230 PRINT

0240 PRINT

0250 PRINT

END TEST."

0260 END 
PROGRAM FILE 79

\author{
SECTION 79.0 \\ (A NUMERIC DATUM CAUSES AN OVERFLOW, POSITIVE MACHINE \\ INF INITY.) \\ BEGIN TEST.
}

?OVERFLOW IN LINE 180

IF THE NUMBER PRINTED BELOW THIS STATEMENT IS POSITIVE AND THE MACHINE INFINITY FOR THIS SYSTEM, THEN THE TEST WILL HAVE PASSED ON THIS SYSTEM.

1. $70141 \mathrm{E}+38$

END TEST. 


\subsection{EXCEPTION TEST - OVERELOW CAUSED BY A NUMERIC VALUE IN $\bar{A}$ DATA- STATEMENT}

This test verifies that the implementation will assign negative machine infinity when a negative numeric datum causes an overflow. There is a DATA-statement which has the numerical constant $-9.99999 \mathrm{E} 99999$ in line 150. On output, a message should be printed telling the user to look for negative machine infinity. If that value is printed following the message, then implementation will have passed the test. The reader is referred to section 14.5 of BSR $\times 3.60$.

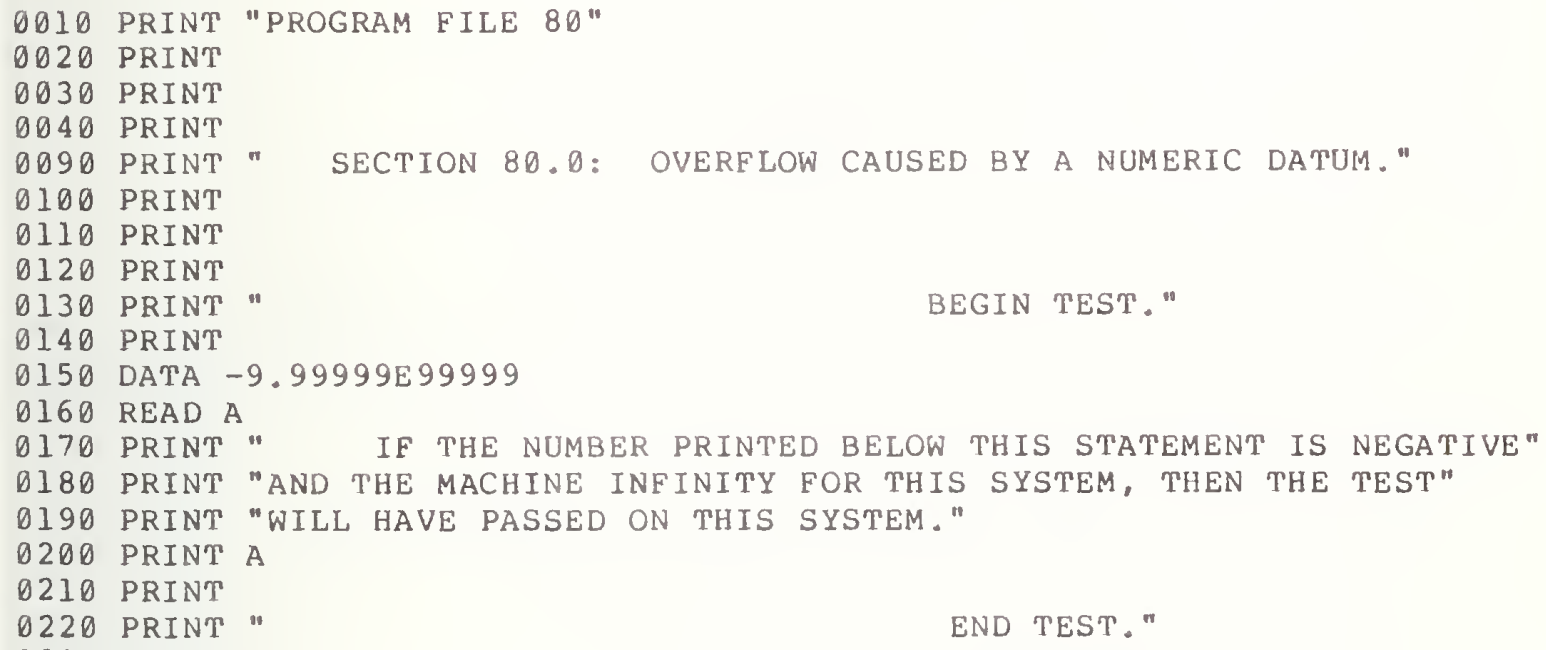


PROGRAM FILE 80

SECTION 80.0: OVERFLOW CAUSED BY A NUMERIC DATUM.

BEGIN TEST.

?OVERELOW IN LINE 160

IF THE NUMBER PRINTED BELOW THIS STATEMENT IS NEGATIVE AND THE MACHINE INFINITY FOR THIS SYSTEM, THEN THE TEST WILL HAVE PASSED ON THIS SYSTEM. $-1.70141 \mathrm{E}+38$

END TEST. 


\subsection{RESTORING READ DATA}

This test verifies that, through the use of the RESTORE-statement, data from the data sequence can be reread. The test on the RESTORE-statement is accomplished by first reading each datum of the DATA-list and then assigning each value read to a variable. These assignments are then checked. If any faulty assignments are made, then an error message should be printed for each incorrect assignment. Each of these error messages should be printed as follows: READ ASSIGNMENT FOR VARIABLE NUMBER <number>, FAILED. If all assignments were correct, then, using the RESTORE-statement, a second set of variables should be assigned the same values as the first. The correctness of the assignments are then checked by IF-THEN comparisons between the values of the first and the second set of variables. If there are any incorrect comparisons, then there should be an error message for each incorrect reassigned value. Each of the error messages should be printed as follows: REREAD ASSIGNMENT FOR VARIABLE NUMBER <number>, FAILED. If all assignments in the rereading process were correct then the following message should be printed: RESTORING DATA TO BE REREAD FOR ASSIGNMENT, PASSED. The reader is referred to section 14.4 of BSR $\times 3.60$.

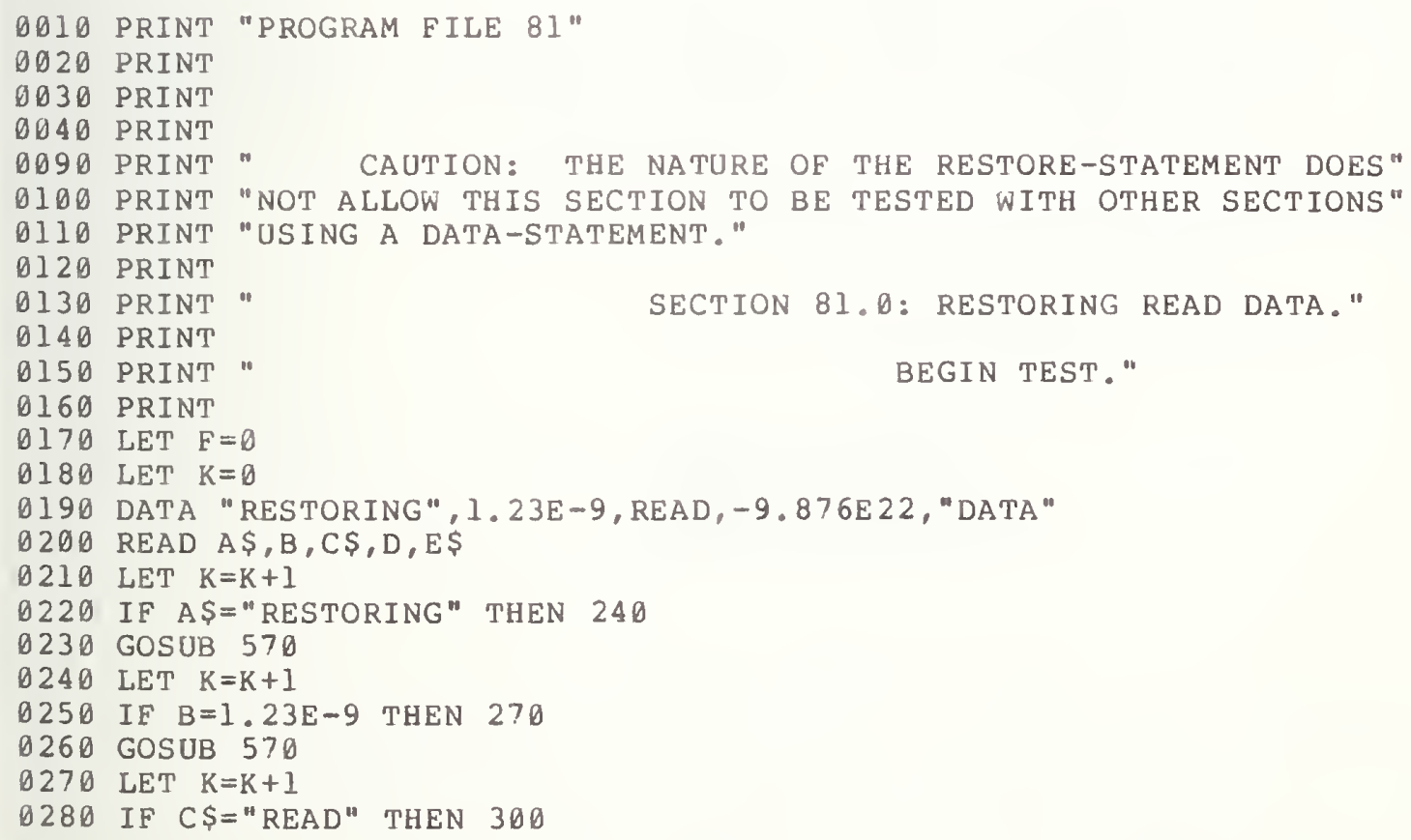


0290 GOSUB $5 ? 0$

0300 LET $K=K+1$

0310 IF $D=-9.876 \mathrm{E} 22$ THEN 330

0320 GOSUB 570

0330 LET $K=K+1$

0340 IF E\$="DATA" THEN 370

0350 GOSUB 570

0360 GOTO 600

$037 \emptyset$ IF $F<>\emptyset$ THEN 600

0380 LET $K=\emptyset$

0390 RESTORE

$\emptyset 40 \emptyset$ READ M\$, N,OS,P,Q\$

$\emptyset 410$ LET $K=K+1$

0420 IF $M \$=A S$ THEN 440

0430 GOSUB 630

0440 LET $\mathrm{K}=\mathrm{K}+1$

0450 IF $\mathrm{N}=\mathrm{B}$ THEN 4 ?0

0460 GOSUB 630

0470 LET $K=K+1$

0480 IF $O \$=C \$$ THEN 500

0490 GOSUB 630

0500 LET $\mathrm{K}=\mathrm{K}+1$

0510 IF $P=D$ THEN 536

0520 GOSUB 630

0530 LET $\mathrm{K}=\mathrm{K}+1$

0540 IF $Q \$=E \$$ THEN 650

0550 GOSUB 630

0560 GOTO 680

0570 LET $\mathrm{F}=\mathrm{G}+1$

6580 PRINT TAB(12),"READ ASSIGNMENT FOR VARIABLE NUMBER";K;", FAILED." 0590 RETURN

$\emptyset 60 \emptyset$ PRINT

$\triangle 610$ PRINT"

0620 GOTO 680

THEREFORE, RESTORE TEST WILL NOT CONTINUE."

0630 PRINT TAB (12), "REREAD ASSignMEnT FOR VARIABle NO.";K;", FAiled."

0640 RETURN

๑550 PRINT "RESTORING READ DATA TO BE REREAD FOR ASSIGNMENT, PASSED." 0660 PRINT

0670 PRINT "

END TEST."

0680 PRINT

0690 PRINT

0700 END

PROGRAM FILE 81

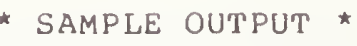

* SAMPLE OUTPUT *

JROGRAM PILE 8 
CAUTION: THE NATURE OF THE RESTORE STATEMENT DOES NOT ALLOW THIS SECTION TO BE TESTED WITH OTHER SECTIONS USING A DATA-STATEMENT.

SECTION 81.0: RESTORING READ DATA.

BEGIN TEST.

RESTORING READ DATA TO BE REREAD FOR ASSIGNMENT, PASSED.

END TEST. 


\subsection{INPUT STATEMENT FOR NUMERIC CONSTANTS}

The next several test sections emphasize user interaction with a running program. This is accomplished through the use of the INPUT-statement (see section 13 of BSR X3.60). By using the INPUT-statement, data can be entered as quoted strings, unquoted strings, numeric constants or a mixture of all three types. However, upon call for data by an input-prompt, there is a restriction on the order in which data is supplied in the input-reply. That is, the type of each datum in the input-reply must correspond to the type of the variable to which it is to be assigned (numeric constants must be supplied as input for numeric variables, and either quoted strings or unquoted strings must be supplied as input for string variables). If the response to input for a string variable is an unquoted string, leading and trailing spaces are to be ignored. Subscript expressions in the variable list should be evaluated after values have been assigned to the variables preceding them, that is, from left to right in the variable list.

The standard specifies that in batch mode, input-reply is requested from an external source by an implementation-defined means. If these tests are $r$ un in batch mode, then the user will have to use the appropriate external source and program the proper data input form before these codes can be executed.

The objective of the program in this section, specifically, is to determine whether the implementation recognizes the assigning of numerical constants by the use of the INPUT-statement.

\subsection{Input of a Numeric Constant}

The objective of this exercise is to test simple interaction by requesting the user to input a single value at a time. The test requests that all three of the numeric constant forms (NR1, NR2, and NR3 forms) be individually entered by the user. Each prompt message (which should be followed by an input-prompt) tells the user what number, and in what form to enter the number for a proper response. To allow for possible data input errors during input-reply responses, each datum is checked by the test for proper format. If an incorrect value is found to have been entered, the user will be given only two more possible chance; to correct his error. If the input is not correct after that, the following message will be printed: FAILURE TO ENTER PROPER DATA. After this message, the test will stop. If all of the proper data is entered, a comparative output should be printed. There are four columns of output. The first specifies the standard value, the second an option, if any, the third reports the system value after input/output conversion, and the final column reports any internal relative error.

\subsection{Input of Numeric Constants As a Line of Data} Separated by Commas

The objective of this test is again to determine whether numeric constants (in either of the three forms NR1, NR2, NR3, or all three) can be assigned by user interaction. In this test, however, the user is requested to enter several numbers separated by commas rather than a single number as above. Except for the input-prompts requiring several numbers $r$ ather than a 
single number, the structure of this test and output is similar to section 82.1.

0010 PRINT "PROGRAM FILE 82"

0020 PRINT

0030 PRINT

0040 PRINT

$\emptyset 080$ PRINT

0090 PRINT

0100 PRINT

$\emptyset 110$ PRINT

0120 PRINT

0130 PRINT

0140 PRINT

0150 PRINT .

* PROGRAM FILE $82 \star \star 2$

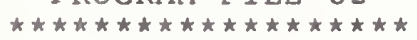

0160 PRINT

SECTION 82.0: INPUT OF NUMERIC CONSTANTS."

0170 PRINT

0180 PRINT

0190 PRINT

0200 DIM E (8), N (8), D (8), Z (8)

0202 DATA $8.13008 \mathrm{E}-7,8.10045 \mathrm{E}-7,8.10005 \mathrm{E}-7,1 \mathrm{E}-7$

0203 DATA $1.52830 \mathrm{E}-7,1.26727 \mathrm{E}-7,1.01256 \mathrm{E}-7,8.10045 \mathrm{E}-7$

0204 FOR $I=1$ TO 8

0205 READ Z(I)

0206 NEXT I

0210 LET $I=1$

0220 LET $C=123$

0230 LET $A \$=" 123 "$

0240 GOSUB 1050

0250 LET $C=-12345$

0260 LET $A \$="-12345^{\prime \prime}$

0270 GOSUB 1050

0280 LET $C=12345.6$

0290 LET A $\$=" 12345.6 "$

0300 GOSUB 1050

0310 LET $C=-99999.9$

0320 LET $A \$="-99999.9 "$

0330 GOSUB 1050

0340 LET $C=6.54321 E-20$

0350 LET A $\$=" 6.54321 \mathrm{E}-20 "$

0360 GOSUB 1050

0370 LET $C=-7.891 E 25$

0380 LET $A \$="-7.891$ E $25 "$

0390 GOSUB 1050

0400 LET $C=-987.6 E-27$ 


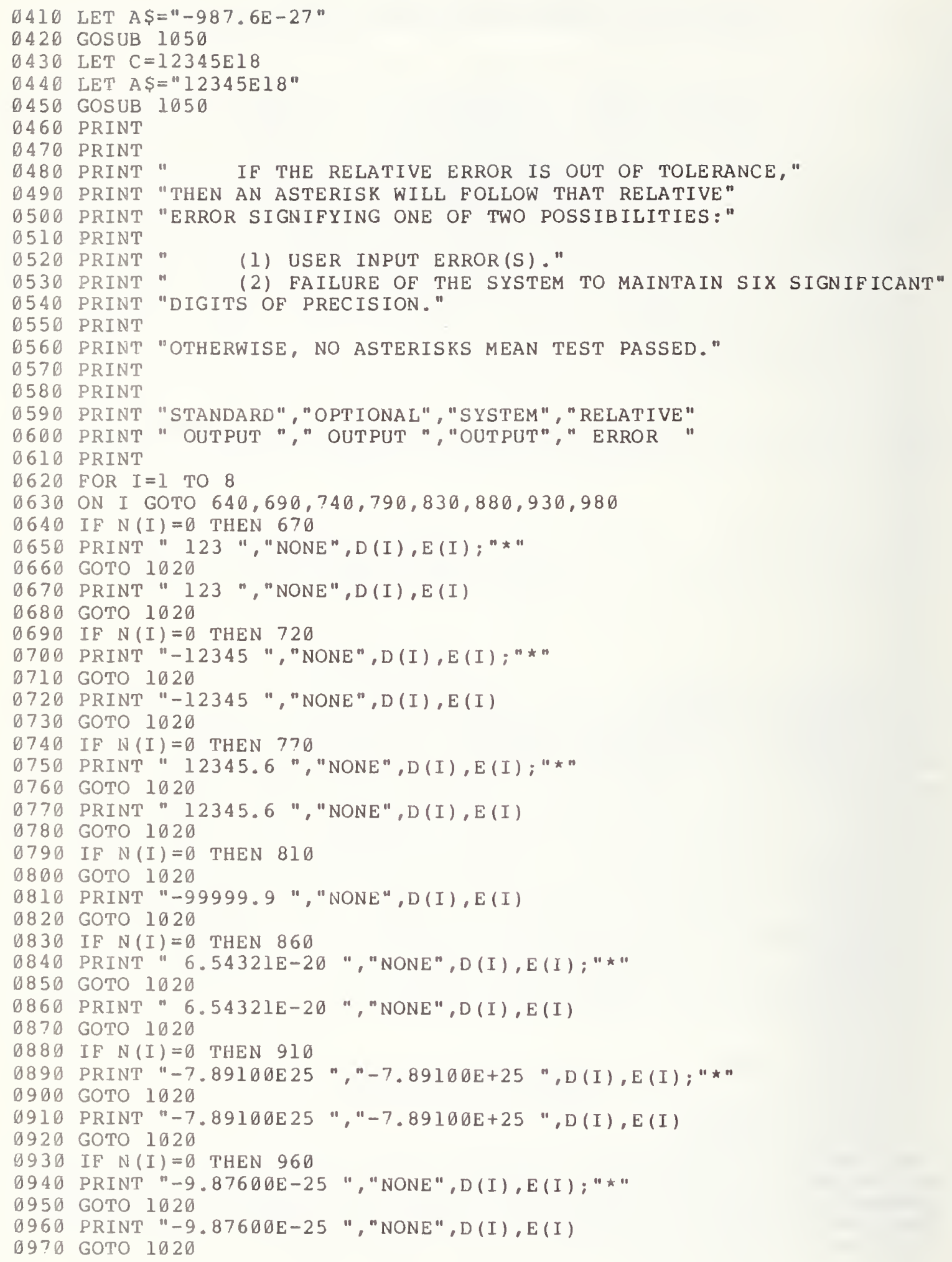




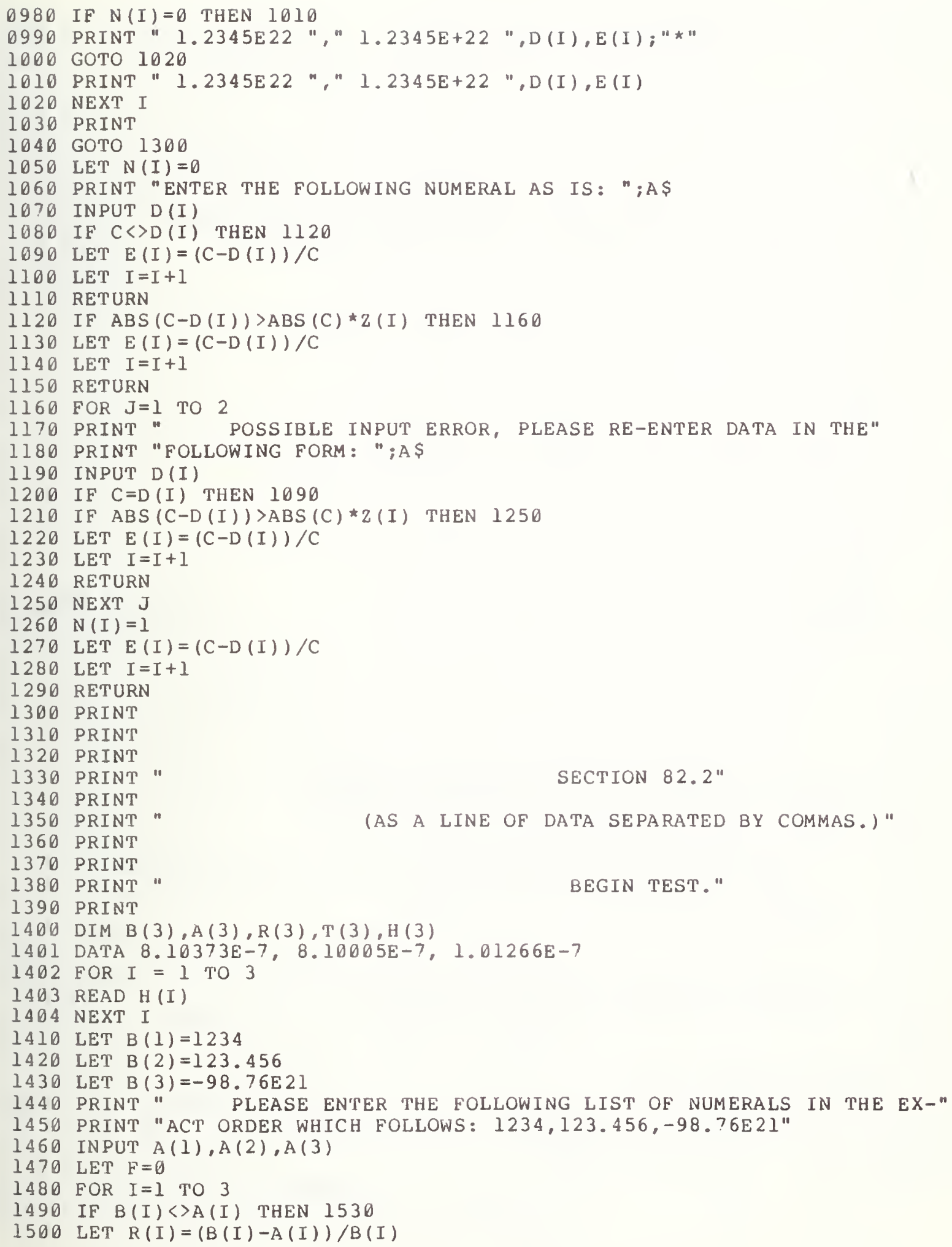




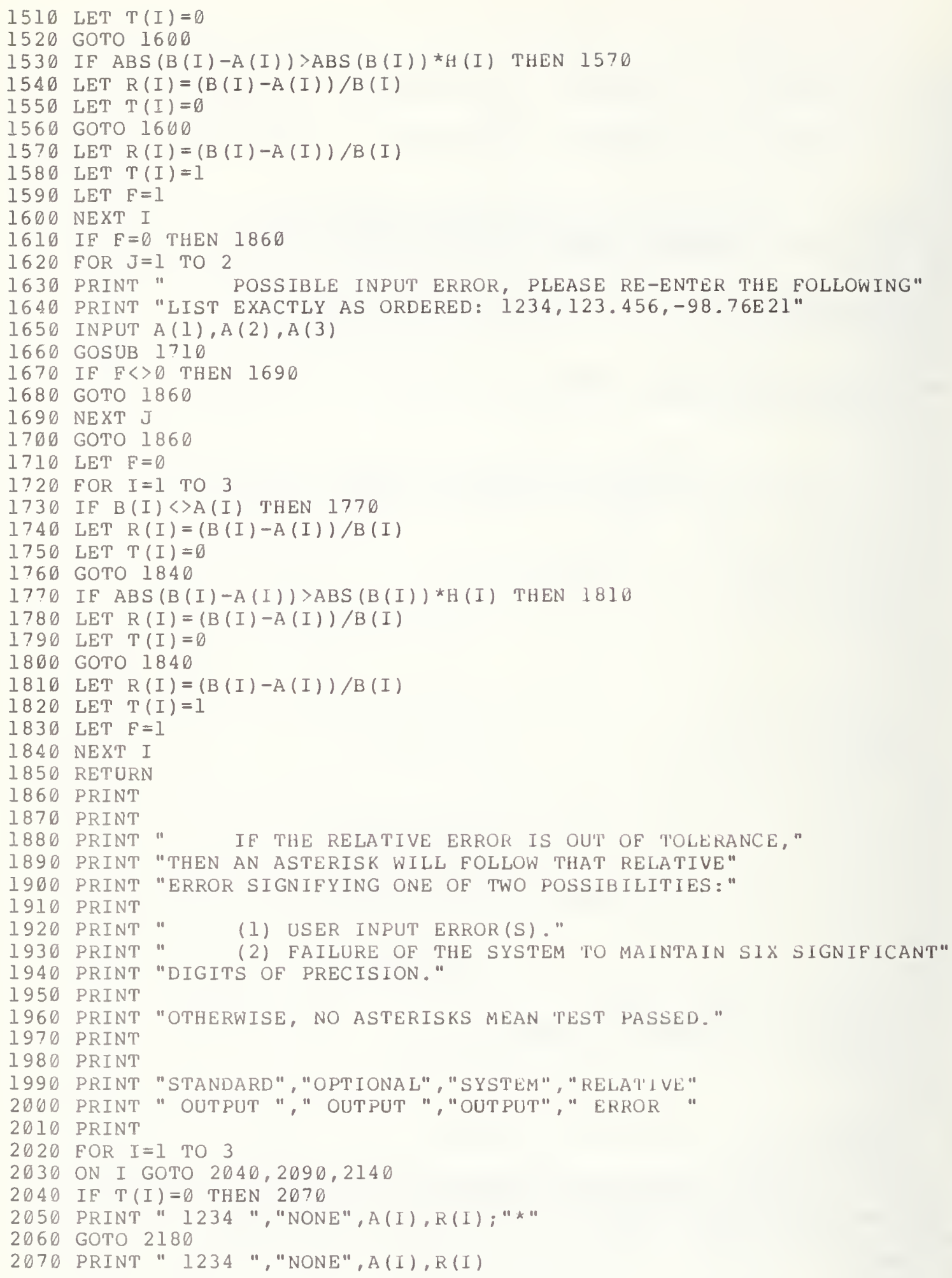


2080 GOTO 2180

2090 IF $T(I)=0$ THEN 2120

2100 PRINT " 123.456 " "NONE",A(I), R(I);"*"

2110 GOTO 2180

2120 PRINT " 123.456 ", "NONE",A(I), R(I)

2130 GOTO 2180

2140 IF $T(I)=0$ THEN 2170

2150 PRINT "-9.87600E 22 ", "-9.87600E+22 ",A(I), R(I);"*

2160 GOTO 2180

2170 PRINT" $-9.87600 \mathrm{E} 22$ ","-9.87600E+22" A(I), R(I)

2180 NEXT I

21.90 PRINT

2200 PRINT

2210 END

PROGRAM FILE 82

SECTION 82.0: INPUT OF NUMERIC CONSTANTS.

SECTION 82.1

(AS A SINGLE DATUM VALUE.)

BEGIN TEST 。

ENTER THE FOLLOWING NUMERAL AS IS: 123

? 123

ENTER THE FOLLOWING NUMERAL AS IS: -12345

$?-12345$

ENTER THE FOLLOWING NUMERAL AS IS: 12345.6

? 12345.6

ENTER THE FOLLOWING NUMERAL AS IS: -99999.9

$?-99999.9$

ENTER THE FOLLOWING NUMERAL AS IS: $6.5432 \mathrm{lE-20}$

?6.54321E-20

ENTER THE FOLLOWING NUMERAL AS IS: $-7.891 E 25$

$?-7.891 \mathrm{E} 25$

ENTER THE FOLLOWING NUMERAL AS IS: $-987.6 \mathrm{E}-27$

$?-987 \cdot 6 \mathrm{E}-27$

ENTER THE FOLLOWING NUMERAL AS IS: $12345 \mathrm{E} 18$ 
IF THE RELATIVE ERROR IS OUT OF TOLERANCE, THEN AN ASTERISK WILL FOLLOW THAT RELATIVE ERROR SIGNIFYING ONE OF TWO POSSIBILITIES:

(1) USER INPUT ERROR(S).

(2) FAILURE OF THE SYSTEM TO MAINTAIN SIX SIGNIFICANT DIGITS OF PRECISION.

OTHERWISE, NO ASTERISKS MEAN TEST PASSED.

\begin{tabular}{|c|c|c|c|}
\hline STANDARD & OPT IONAL & SYSTEM & RELATIVE \\
\hline OUTPUT & OUTPUT & OUTPUT & ERROR \\
\hline 123 & NONE & 123 & $\theta$ \\
\hline-12345 & NONE & -12345 & $\theta$ \\
\hline 12345.6 & NONE & 12345.6 & $\theta$ \\
\hline 99999.9 & NONE & -99999.9 & $\theta$ \\
\hline $6.54321 E-20$ & NONE & $6.54321 \mathrm{E}-20$ & $\theta$ \\
\hline$-7.89100 \mathrm{E} 25$ & $-7.89100 \mathrm{E}+25$ & $-7.89100 E+25$ & 0 \\
\hline$-9.87600 E-25$ & NONE & $-9.87600 \mathrm{E}-25$ & 0 \\
\hline $1.2345 \mathrm{E} 22$ & $1.2345 \mathrm{E}+22$ & $1.23450 E+22$ & 0 \\
\hline
\end{tabular}

SECTION 82.2

(AS A LINE OF DATA SEPARATEd BY COMMAS.)

BEGIN TEST.

PLEASE ENTER THE FOLLOWING LIST OF NUMERALS IN THE EXACT ORDER WHICH FOLLOWS: $1234,123.456,-98.76 \mathrm{E} 21$

? $1234,123.456,-98 . ? 6 \mathrm{E} 21$

IF THE RELATIVE ERROR IS OUT OF TOLERANCE, THEN AN ASTERISK WILL FOLLOW THAT RELATIVE ERROR SIGNIEYING ONE OF TWO POSSIBILITIES:

(1) USER INPUT ERROR(S) .

(2) FAILURE OF THE SYSTEM TO MAINTAIN SIX SIGNIFICANT DIGITS OF PRECISION.

OTHERWISE, NO ASTERISKS MEAN TEST PASSED.

$\begin{array}{llll}\begin{array}{l}\text { STANDARD } \\ \text { OUTPUT }\end{array} & \begin{array}{l}\text { OP'TIONAL } \\ \text { OUTPUT }\end{array} & \begin{array}{l}\text { SYSTEM } \\ \text { OUTPUT }\end{array} & \begin{array}{c}\text { RELATIVE } \\ \text { ERROR }\end{array} \\ 1234 & \text { NONE } & 1234 & 0 \\ 123.456 & \text { NONE } & 123.456 & 0 \\ -9.87600 \mathrm{E} 22 & -9.87600 \mathrm{E}+22 & -9.87600 \mathrm{E}+22 & 0\end{array}$




\subsection{INPUT OF NUMERIC DATA TO SUBSCRIPTED VARIABLES AND UNQUOTED STRINGS}

\subsection{Evaluation of a Subscripted Variable in a Variable List}

This test determines whether the implementation will allow a variable, used in a subscript, to be assigned a value in the same input list as the subscripted variable itself. The assignment of the value must of course be prior to the use of the variable in the subscript.

The test tells the user by input-prompt messages how to enter a 1 ist of ten given values for ten elements of an array A(I). After the proper input of the given list of values has been accomplished, the list will be printed out for user verification. After this printout, the user will be asked by an input-prompt message to choose one of the digits $1,2, \ldots, 10$ and then enter the chosen digit for the value of $I$ in the variable list, and for the variable $A(I)$ in the variable list, enter the value 54.8. After the values for $I$ and $A(I)$ have been entered properly, the elements of the array $A$ (I) will again be printed out for comparison with the first printout of the elements of $A(I)$. The comparison should show that the subscripted element which has the selected I value should now have an assigned value of 54.8 .

\subsection{Allowable Characters for Unquoted String Inputs}

The objective of this test is to assign strings using the INPUT-statement in order to verify that the implementation allows the assigning of all of the characters specified by the standard for unquoted strings. These include all plain-string-characters and the character space (refer to the standard for the description of plain-string-characters). The test uses input-prompt messages to the user informing him which subset of plain string characters should be entered and the form or order in which each subset of characters should be entered for each response. All data are checked for proper form, and, if the data are entered incorrectly, the user will be given three chances to enter them correctly. If the data are still found to be incorrectly entered, the following message will be printed: FAILURE TO ENTER PROPER DATA. The test will then terminate. If the data are entered properly, a printout of the characters will be given. The reader is referred to sections 3 and 13 of BSR $\times 3.60$. 


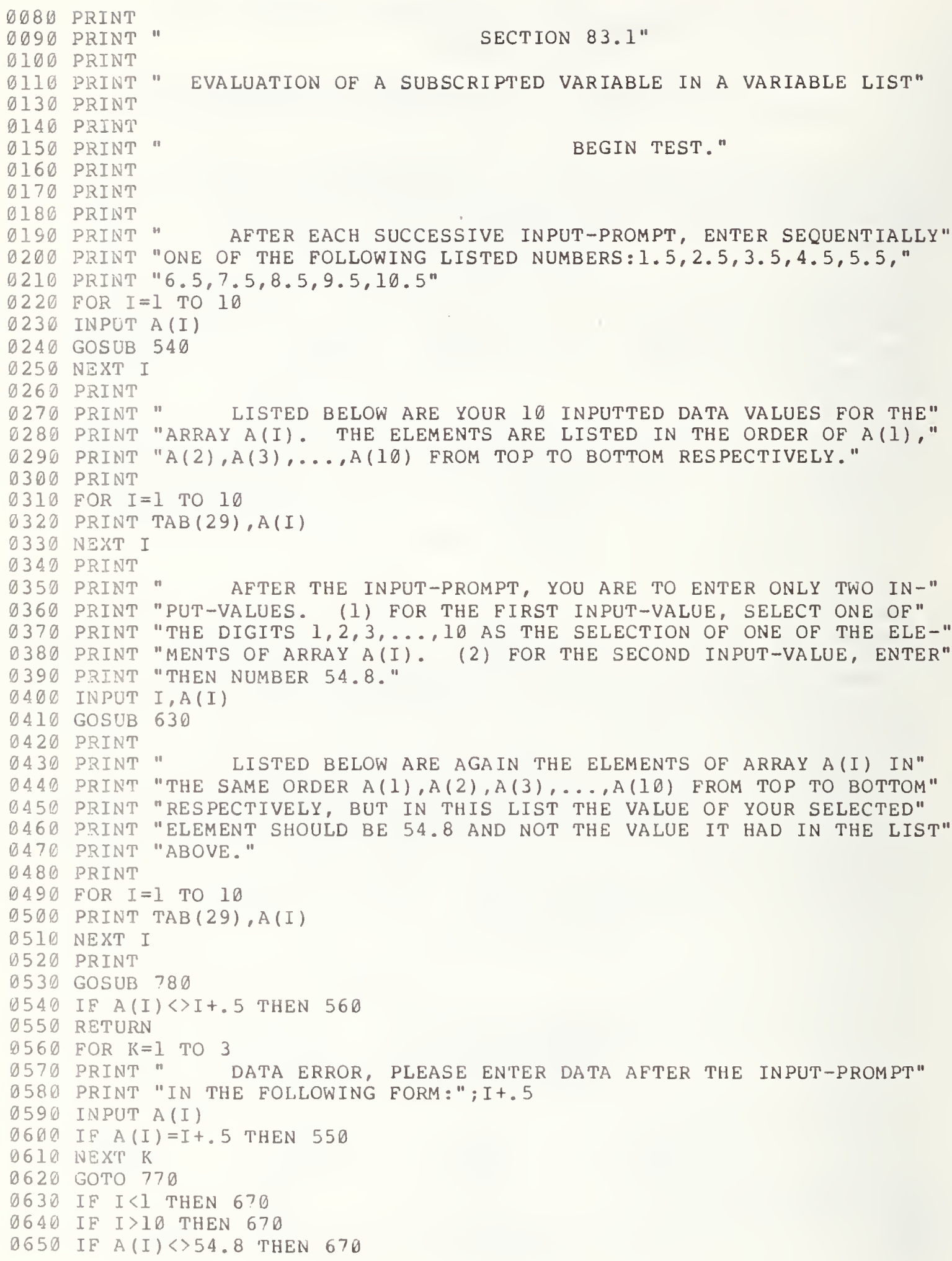


9660 RETURN

0670 FOR J=1 TO 3

B680 PRINT" DATA ERROR, RE-ENTER YOUR SELECTED DIGIT OF THE DIGITS"

0690 PRINT " $1,2,3, \ldots, 10$ AS THE FIRST DATA INPUT AND THE NUMBER 54.8 AS"

D?00 PRINT "THE SECOND DATA ENTRY. PLEASE MAKE ALL ENTRIES AFTER THE"

0710 PRINT "INPUT-PROMPT."

0720 INPUT I, A(I)

D730 IF I<I THEN 760

D740 IF I>10 THEN 760

9750 IF $A(I)=54.8$ THEN 660

1) 760 NEXT J

177@ PRINT "

ด780 PRINT

0790 PRINT "

FAILURE TO ENTER PROPER DATA."

1) 820 PRINT

END TEST."

1830 PRINT

1) 840 PRINT

M 850 PRINT

B860 PRINT

"

SECTION $83.2^{\prime \prime}$

1370 PRINT

(980 PRINT

1890 PRINT

0900 PRINT

D9I0 PRINT

$\triangle 920$ PRINT

D930 PRINT

D 90 PRINT

0950 PRINT

0960 PRINT "ABCDEFGHIJKLM"

ด970 PRINT "NOPQRSTUVWXYZ"

ด980 PRINT " O123456789"

0990 PRINT "*(): $\$=><"$

1000 PRINT "- $8 ;+. ? / "$

1010 INPUT AS

1020 INPUT B\$

1030 INPUT C\$

1040 INPUT D\$

1050 INPUT ES

1060 GOSUB 1380

2070 PRINT

1080 PRINT

1090 PRINT

1100 INPUT F\$

1110 GOSUB 1660

1120 PRINT

1130 PRINT

1140 PRINT

1150 PRINT

1160 PRINT

1170 PRINT

1180 PRINT

1190 PRINT

1200 PRINT

1210 PRINT

1220 PRINT

1230 PRINT

1240 PRINT A\$;B\$;C\$;D\$;E\$

AFTER THE INPUT-PROMPT, ENTER THE DIGIT 1, SPACE OVER" EIGHT SPACES, AND THEN TYPE THE DIGIT I AGAIN."

"UNQUOTED-STRING-CHARACTER= SPACE/PLAIN-STRING-CHARACTER"

" PLAIN-STRING-CHARACTERS ."

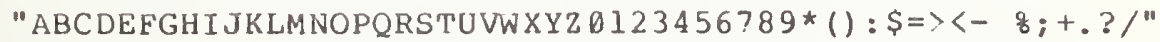

" IF THE LINE OF CHARACTERS PRINTED BELOW, APPEAR IN THE" "SAME FORM AS THE LINE OF CHARACTERS ABOVE, CHECK TEST PASS-" "ED." 


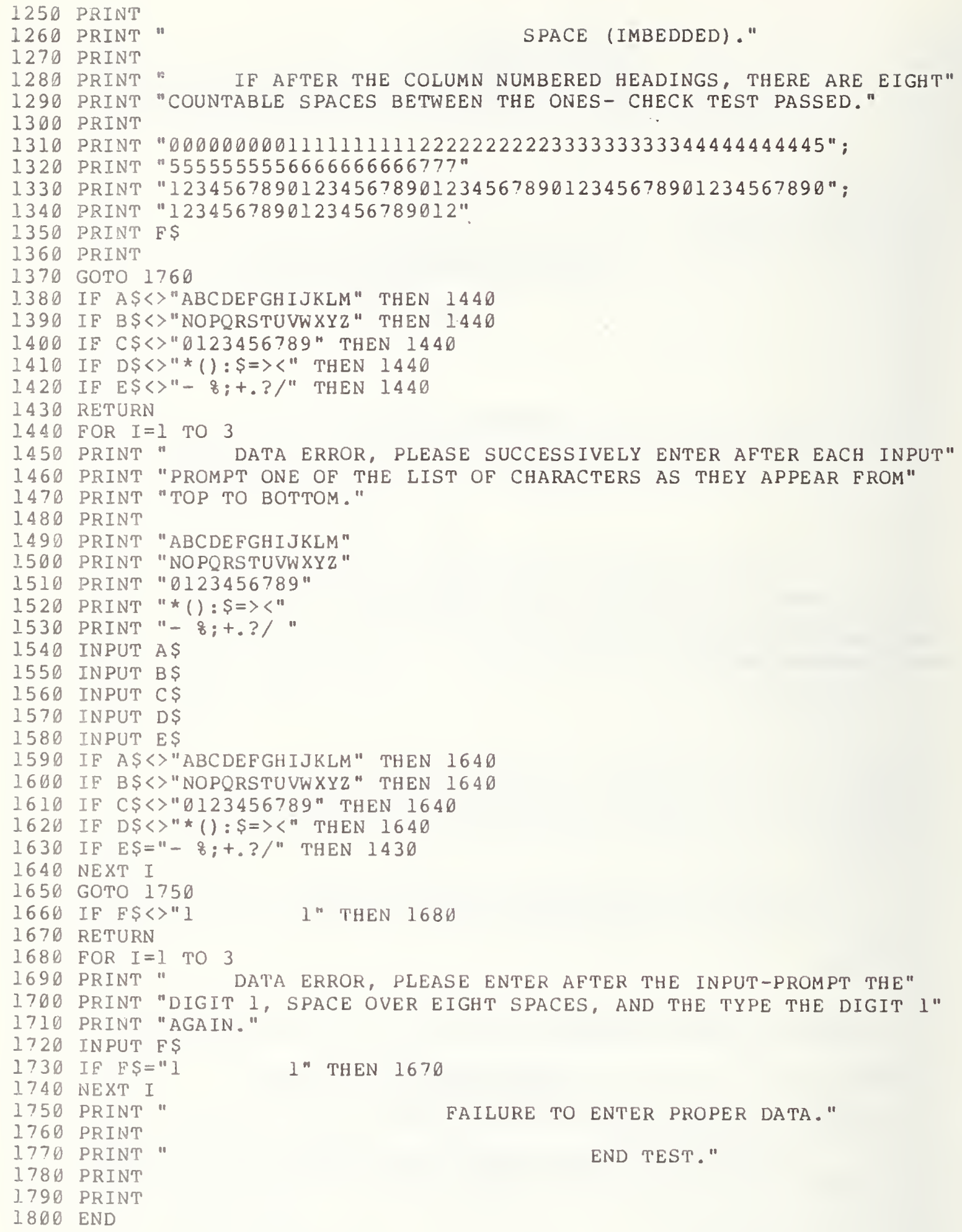

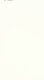




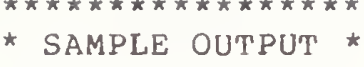

PROGRAM FILE 83

\section{SECTION 83.1}

EVALUATION OF A SUBSCRIPTED VARIABLE IN A VARIABLE LIST

BEGIN TEST.

AFTER EACH SUCCESSIVE INPUT-PROMPT, ENTER SEQUENTIALLY ONE OF THE FOLLOWING LISTED NUMBERS: $1.5,2.5,3.5,4.5,5.5$, $6.5,7.5,8.5,9.5,16.5$

?1. 5

?2. 5

?3. 5

? 4.5

?5. 5

36. 5

?7. 5

? 8.5

?9. 5

? 10.5

LISTED BELOW ARE YOUR 10 INPUTTED DATA VALUES FOR THE ARRAY A(I). THE ELEMENTS ARE LISTED IN THE ORDER OF A(1), $A(2), A(3), \ldots, A(10)$ FROM TOP TO BOTTOM RESPECTIVELY.
1.5
2.5
3. 5
4.5
5. 5
6.5
?. 5
8. 5
9.5
10.5

AFTER THE INPUT-PROMPT, YOU ARE TO ENTER ONLY TWO INPUT-VALUES. (1) FOR THE FIRST INPUT-VALUE, SELECT ONE OF THE DIGITS $1,2,3, \ldots, 10$ AS THE SELECTION OF ONE OF THE ELEMENTS OF ARRAY A(I). (2) FOR THE SECOND INPUT-VALUE, ENTER THEN NUMBER 54.8. $? 5,54.8$

LISTED BELOW ARE AGAIN THE ELEMENTS OF ARRAY A(I) IN THE SAME ORDER A(1),A(2),A(3),...A(10) FROM TOP TO BOTTOM 
RESPECTIVELY, BUT IN THIS LIST THE VALUE OF YOUR SELECTED ELEMENT SHOULD BE 54.8 AND NOT THE VALUE IT HAD IN THE LIST ABOVE.

$$
\begin{aligned}
& 1.5 \\
& 2.5 \\
& 3.5 \\
& 4.5 \\
& 54.8 \\
& 6.5 \\
& 7.5 \\
& 8.5 \\
& 9.5 \\
& 10.5
\end{aligned}
$$

END TEST.

\section{SECTION 83.2}

ALLOWABLE CHARACTERS FOR UNQUOTED STRING INPUTS

\section{BEGIN TEST 。}

AT EACH SUCCESSIVE INPUT-PROMPT, ENTER ONE OF THE ROWS OF CHARACTERS BELOW AS THEY APPEAR FROM TO TO BOTTOM:

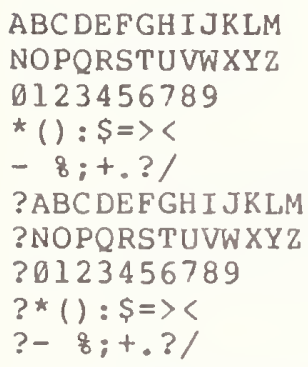
ED.

ABCDEFGHI JKLMNOPQRSTUVWXYZ0123456789* ( ) : \$ =>< \& ; + ? / 
SPACE (IMBEDDED).

IF AFTER THE COLUMN NUMBERED HEADINGS, THERE ARE EIGH $T$ COUNTABle SPACES BETWEEN THE ONES- CHECK TEST PASSED.

घ0000ด0ด0111111111122222222223333333333444444444455555555556666666666777 123456789012345678901234567890123456789012345678901234567890123456789012 1

END TEST. 


\subsection{INPUTTING MIXED DATA}

\subsection{Testing Leading and Trailing Spaces on Unquoted Strings}

This test verifies that the implementation recognizes that leading and trailing spaces should be ignored when used with unquoted strings. The test has messages printed to the user. These instructions supply the information which the user should follow for each input-reply response. On output, the test generates two rows of digits to act as column labels. Following this output, t le user inputs should be printed to verify that trailing and leading spaces are ignored by the implementation. The reader is referred to section 13.4 of BSR $\times 3.60$.

\subsection{Inputting Leading and Trailing Spaces in Quoted Strings}

This test shows that the implementation should recognize all leading and trailing spaces used in quoted strings. The test generates appropriate data input instructions to the user. These instructions supply the information the user should follow for each input-reply response. The test checks the correctness of the input values. Should the user fail to properly enter the data requested according to the printed instructions, the test will terminate its execution by printing the following message: FAILURE TO ENTER PROPER DATA. If the user correctly enters the data two rows of digits should be printed to act as column labels and the results entered by the user.

\subsection{Inputting Mixed Data}

This test shows that numeric constants and string constants can be entered in mixed form as the DATA-list for an input response. All data entered by the user will be checked for proper form as specified by the input-prompt messages. As in the previous tests, if any data is entered incorrectly, the user will be given three chances to enter the data correctly. If after the three chances the data is still entered incorrectly, the following message will be printed: FAILURE TO ENTER PROPER DATA and termination of the test will follow. However, if the data is entered correctly, an output should be printed in two columns. In the first column the required output will be printed and in the second column, the test system output will be printed. 
0030 PRINT

0040 PRINT

0090 PRINT

0100 PRINT

0110 PRINT

0130 PRINT

0140 PRINT

0150 PRINT

0160 PRINT

0170 PRINT

0180 PRINT

0190 PRINT

0200 FOR I=1 TO 3

0210 PRINT "

0220 PRINT "YOUR

0230 PRINT

0240 PRINT

0250 PRINT

0260 PRINT

0270 PRINT

0280 PRINT

0290 PRINT

0300 INPUT

0310 PRINT

0320 PRINT

0330 PRINT

0340 PRINT

0350 PRINT

0360 PRINT

ด ? 0 PRINT

0380 PRINT

0390 PRINT "D0000000011111111112222222222333333333344444444445";

0400 PRINT " $5555555556666666666777 "$

0410 PRINT " 12345678901234567890123456789012345678901234567890 ";

0420 PRINT "1234567890123456789012"

0430 PRINT G\$;H\$

0440 INPUT I $\$$

0450 IF I $\$=" Y E S "$ THEN 490

0460 GOSUB 540

0470 NEXT I

0480 GOTO 650

0490 PRINT"

0500 GOTO 520

0510 PRINT "

0520 PRINT

0530 GOTO 680

0540 PRINT

0550 PRINT"

0560 PRINT

0570 PRINT

0580 PRINT

0590 PRINT

0600 PRINT

0610 PRIN

0620 INPUT JS

0630 IF J\$ $=$ "NO" THEN 510

0640 RETURN

SECTION $84.1 "$

BEGIN TEST."

1) SPACE OVER ABOUT FIVE SPACES, THEN TYPE YOUR"

(2) SPACE OVER ABOUT FIVE SPACES, FOLLOW THIS ACTION"

IF AFTER THE COLUMN NUMBERED HEADINGS, YOUR TWO"

"SELECTED DIGITS ARE PRINTED STARTING IN COLUMN ONE WITHOUT" ANY SPACES SEPARATING THEM, TYPE YES AFTER THE INPUT-PROMPT" "WHICH FOLLOWS, AND IF NOT, TYPE NO."

40

TEST PASSED. "

TEST FAILED."

IF THE OUTPUT WAS INCORRECT BECAUSE YOU DID NOT FOLLOW"

"THE INPUT DIRECTIONS CORRECTLY, THEN YOU SHOULD TYPE YES"

"WHEN THE INPUT-PROMPT APPEARS AFTER THIS PARAGRAPH AND BY"

"DOING SO YOU WILL HAVE ANOTHER CHANCE TO ENTER DATA COR-"

"RECTLY. HOWEVER, IF YOU DID FOLLOW THE INPUT DIRECTIONS"

"CORRECTLY, TYPE A NO WHEN THE INPUT-PROMPT APPEARS AFTER"

"THIS PARAGRAPH." 


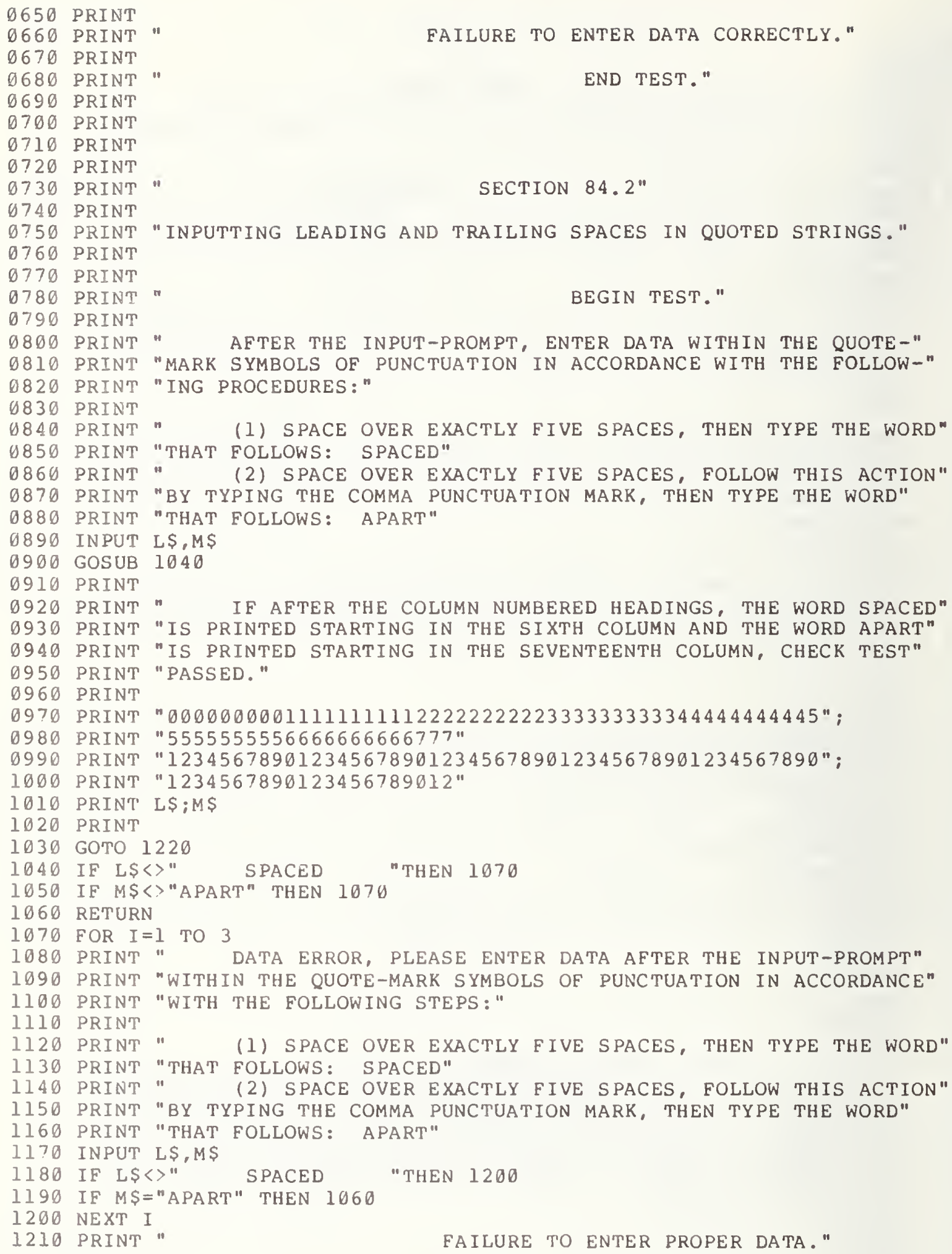


1220 PRINT

1230 PRINT

1240 PRINT

1250 PRINT

1260 PRINT

1270 PRINT

1280 PRINT

1290 PRINT

1293 PRINT

1295 PRINT

1300 PRINT

1310 PRINT

1320 PRINT

1330 PRINT

1340 PRINT

1350 PRINT

1360 PRINT

1370 PRINT

1380 PRINT

1390 PRINT

1400 INPUT

1410 GOSUB

1420 PRINT

1430 PRINT "NEEDED" " SYSTEM"

1440 PRINT "OUTPUT", "OUTPUT"

1450 PRINT

1460 PRINT

1470 PRINT

1480 PRINT

1490 PRINT

1500 GOTO 1710

1510 IF N\$〈>"QUOTED" THEN 1550

1520 IF $O<>1.23456$ THEN 1550

1530 IF PS $<>" U N Q U O T E D "$ THEN 1550

1540 RETURN

1550 FOR $I=1$ TO 3

1560 PRINT " DATA ERROR, PLEASE ENTER DATA AFTER THE INPUT-PROMPT"

1570 PRINT "ACCORDING TO THE STEPS WHICH FOLLOW, AND SEPARATE THE PER-"

1580 PRINT "FORMANCE OF EACH STEP FROM EACH OTHER WITH THE COMMA PUNC-"

1590 PRINT "TUATION MARK:"

1600 PRINT

1610 PRINT "

1620 PRINT "

1630 PRINT"

1640 PRINT

1650 INPUT $N \$, O, P \$$

1660 IF N\$〈> "QUOTED" THEN 1690

1670 IF $0<>1.23456$ THEN 1690

1680 IF PS= "UNQUOTED" THEN 1540

1690 NEXT I

1700 PRINT"

1710 PRINT

1720 PRINT "

1730 PRINT

1740 PRINT

1750 END

END TEST."

SECTION $84.3^{n}$

INPUTTING MIXED DATA."

BEGIN TEST."

AFTER THE INPUT-PROPT, ENTER DATA ACCORDING TO THE"

(1) WITHIN THE QUOTE-MARK SYMBOLS OF PUNCTUATION, TYPE"

(2) TYPE THE NUMERAL THAT FOLLOWS: $1.23456^{\prime \prime}$

(3) TYPE THE WORD THAT FOLLOWS: UNQUOTED"

(1) WITHIN THE QUOTE-MARK SYMBOLS OF PUNCTUATION, TYPE"

WORD THAT FOLLOWS: QUOTED"

(2) TYPE THE NUMERAL THAT FOLLOWS: $1.23456 "$

(3) TYPE THE WORD THAT FOLLOWS: UNQUOTED"

FAILURE TO ENTER PROPER DATA."

END TEST." 


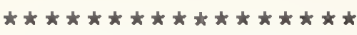

$\star$ SAMPLE OUTPUT $\star$

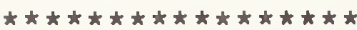

PROGRAM FILE 84

SECTION 84.1

TESTING LEADING AND TRAILING SPACES ON UNQUOTED STRINGS.

BEGIN TEST.

NOTE: INPUT SHOULD NOT EXCEED 72 CHARACTERS PER LINE.

AFTER THE INPUT-PROMPT, AS A CHOICE OF INPUT, MAKE YOUR SELECTION FROM THE DIGITS $0,1,2,3, \ldots, 9$ IN ACCORDANCE WITH THE FOLLOWING STEPS.

(1) SPACE OVER ABOUT FIVE SPACES, THEN TYPE YOUR SELECTED DIGIT.

(2) SPACE OVER ABOUT FIVE SPACES, FOLLOW THIS ACTION BY TYPING THE COMMA PUNCTUATION MARK, THEN TYPE YOUR NEXT SELECTED DIGIT.

? $\quad 2 \quad 8$

IF AFTER THE COLUMN NUMBERED HEADINGS, YOUR TWO SELECTED DIGITS ARE PRINTED STARTING IN COLUMN ONE WITHOUT ANY SPACES SEPARATING THEM, TYPE YES AFTER THE INPUT-PROMPT WHICH FOLLOWS, AND IF NOT, TYPE NO.

000000000111111111122222222223333333333444444444455555555556666666666777 123456789012345678901234567890123456789012345678901234567890123456789012 28 ?YES

TEST PASSED.

END TEST.

SECTION 84.2

INPUTTING LEADING AND TRAILING SPACES IN QUOTED STRINGS.

BEGIN TEST. 
AFTER THE INPUT-PROMPT, ENTER DATA WITHIN THE QUOTEMARK SYMBOLS OF PUNCTUATION IN ACCORDANCE WITH THE FOLLOWING PROCEDURES:

(1) SPACE OVER EXACTLY FIVE SPACES, THEN TYPE THE WORD THAT FOLLOWS: SPACED

(2) SPACE OVER EXACTLY FIVE SPACES, FOLLOW THIS ACTION BY TYPING THE COMMA PUNCTUATION MARK, THEN TYPE THE WORD

THAT FOLLOWS: APART

?" SPACED ", "APART"

IF AFTER THE COLUMN NUMBERED HEADINGS, THE WORD SPACED IS PRINTED STARTING IN THE SIXTH COLUMN AND THE WORD APART IS PRINTED STARTING IN THE SEVENTEENTH COLUMN, CHECK TEST PASSED.

๑00000000111111111122222222223333333333444444444455555555556666666666777 123456789012345678901234567890123456789012345678901234567890123456789012 SPACED APART

END TEST.

SECTION 84.3

INPUTTING MIXED DATA.

BEGIN TEST.

AFTER THE INPUT-PROPT, ENTER DATA ACCORDING TO THE STEPS WHICH FOLLOW, AND SEPARATING THE PERFORMANCE OF EACH STEP FROM EACH OTHER WITH THE COMMA PUNCTUATION MARK:

(1) WITHIN THE QUOTE-MARK SYMBOLS OF PUNCTUATION, TYPE THE WORD THAT FOLLOWS: QUOTED

(2) TYPE THE NUMERAL THAT FOLLOWS: 1.23456

(3) TYPE THE WORD THAT FOLLOWS: UNQUOTED ?"QUOTED", 1.23456 ,UNQUOTED

$\begin{array}{ll}\text { NEEDED } & \text { SYSTEM } \\ \text { OUT PUT } & \text { OUTPUT } \\ & \\ \text { QUOTED } & \text { QUOTED } \\ 1.23456 & 1.23456 \\ \text { UNQUOTED } & \text { UNQUOTED }\end{array}$

END TEST. 


\subsection{EXCEPTION TEST = TYPE OF DATUM INCORRECT}

This test verifies that the implementation recognizes when the type of a datum does not match the type of the variable to which it is assigned (see section 13.5 of BSR X3.60). If an improper datum type is entered, the implementation should consider this an exception. The recovery procedure requires that the user be allowed to resupply the input value.

The test begins with a message asking the user to enter, as an input-reply, the string of characters: SIX. This string is non-numeric, which is not the type the system expects. Thus, the implementation should request a resupply of data. If not, then the implementation does not meet the standard specifications. If the system does ask the user to resupply data, then the user should enter the numeric constant 1.
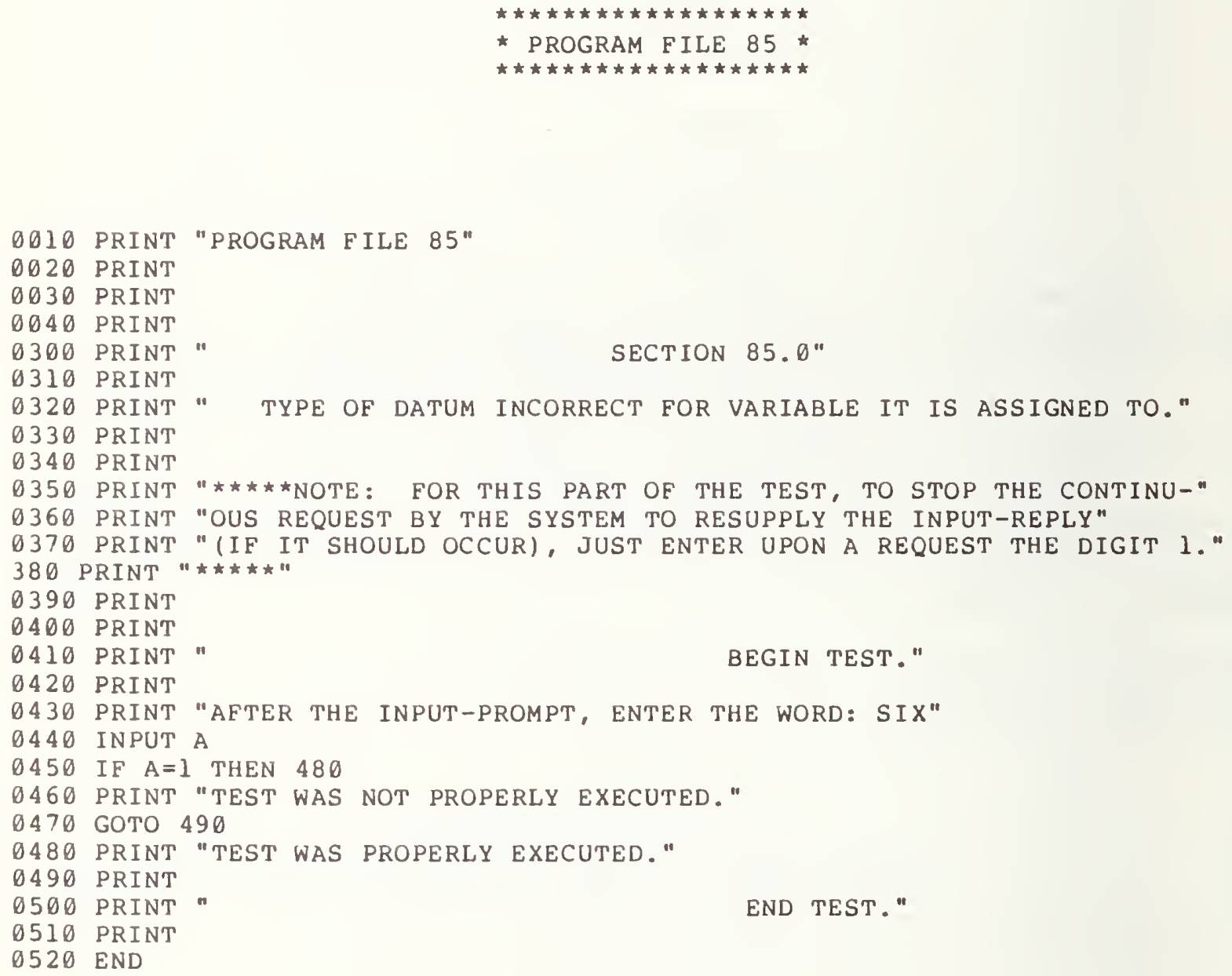
SECTION 85.0

TYPE OF DATUM INCORRECT FOR VARIABLE IT IS ASSIGNED TO.

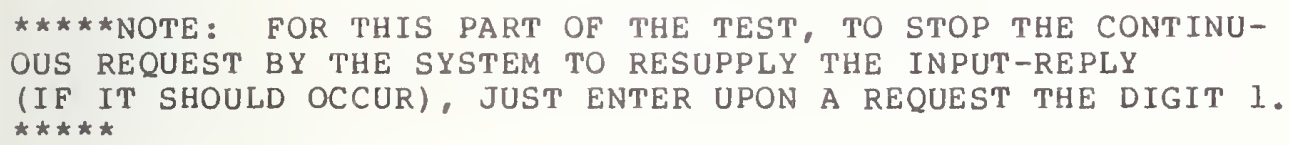

BEGIN TEST.

AFTER THE INPUT-PROMPT, ENTER THE WORD: SIX

?SIX

?ILLEGAL DATA, PLEASE RESUPPLY

?1

TEST WAS PROPERLY EXECUTED.

END TEST. 
The objective of this test is to determine whether the implementation recognizes too much data in the input data-list as an exception (see section 13.5 of BSR X3.60). Upon recognition of the error, the implementation should allow the user to resupply his input data-list. The test has an instruction message that informs the user to input the data-1ist: $5,-35$. The test, however, has only one numeric variable in its variable-list for the INPUT statement. Therefore the user should be requested, by the test system, to resupply the input-list. Once this message appears the test has been passed by the host system. In order to terminate the program the user should enter the constant 1 .

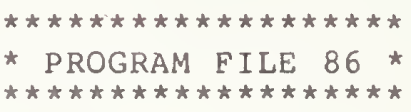

Ø७I0 PRINT "PROGRAM FILE 86"

$\emptyset \emptyset 20$ PRINT

$003 \emptyset$ PRINT

$\emptyset \emptyset 4 \emptyset$ PRINT

OL20 PRINT

Ø130 PRINT

0140 PRINT "

0150 PRINT

$\emptyset 160$ PRINT

0170 PRINT " $* * * *$ NOTE: FOR THIS PART OF THE TEST, TO STOP THE CONTINU-"

$\emptyset 180$ PRINT "OUS REQUEST BY THE SYSTEM--THAT IS, IF IT SHOULD OCCUR--TO"

O190 PRINT "RESUPPLY THE INPUT-REPLY, JUST ENTER UPON A REQUEST THE"

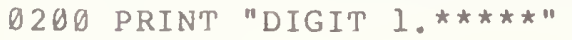

$\emptyset 210$ PRINT

$\emptyset 220$ PRINT

0230 PRINT

0240 PRINT

0250 PRINT "AFTER THE INPUT-PROMPT, ENTER THE NUMBERS AS FOLLOWS: 5, -35"

0260 LET $A=9999$

0270 INPUT A

0280 IF $A=1$ THEN 310

0290 PRINT "TEST WAS NOT EXECUTED PROPERLY."

0300 GOTO 320

$\emptyset 31 \emptyset$ PRINT "TEST WAS EXECUTED PROPERLY."

$\emptyset 320$ PRINT

$\emptyset 330$ PRINT

0340 PRINT

END TEST."

0350 END 


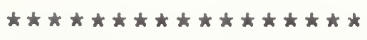

* SAMPLE OUTPUT *

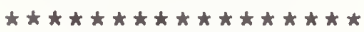

PROGRAM FILE 86

\author{
SECTION 86.0 \\ TOO MUCH DATA IN DATA-LIST.
}

$\star \star \star \star \star N O T E:$ FOR THIS PART OF THE TEST, TO STOP THE CONTINUOUS REQUEST BY THE SYSTEM--THAT IS, IF IT SHOULD OCCUR--TO RESUPPLY THE INPUT-REPLY, JUST ENTER UPON A REQUEST THE

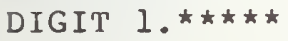

\title{
BEGIN TEST.
}

AFter THE INPUT-PROMPT, ENTER THE NUMBERS AS FOLLOWS: 5, -35 $? 5,-35$

?TOO MUCH DATA. PLEASE RESUPPLY $? 5,-35$

?TOO MUCH DATA. PLEASE RESUPPLY

? 1

TEST WAS EXECUTED PROPERLY

END TEST. 
The objective of this test is to determine whether the implementation will recognize too little data in the input-list as an exception (see section 13.5 of BSR $\times 3.60$ ).

Upon recognition of the error, the implementation should allow the user to resupply the input data. The test has a message printed to the user to enter the number 64. However, the program requires more than one numeric variable in the input-list. Therefore there should be an implementation prompt to resupply the input-list. The user should continue to supply the value 64 several times to determine whether the system continues to prompt. Finally the user should enter the list: 1,2 in order to terminate the test.

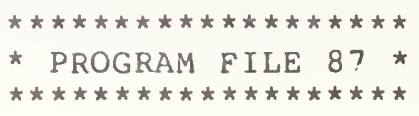

D010 PRINT "PROGRAM FILE 87"

0060 PRINT

0070 PRINT

DO80 PRINT

OO9O PRINT"

OIOO PRINT

OII0 PRINT"

SECTION 8?.0"

0120 PRINT

O 130 PRINT

OI40 PRINT

O150 PRINT

0160 PRINT

0170 PRINT

"*****NOTE: FOR THIS PART OF THE TEST, TO STOP THE CONTINU-"

"OUS REQUEST BY THE SYSTEM--THAT IS, IF IT SHOULD OCCUR--TO"

0180 PRINT

OI90 PRINT

0200 PRINT"

BEGIN TEST."

0210 PRINT

0220 PRINT "AFTER THE INPUT-PROMPT, ENTER THE FOLLOWING NUMBER: 64"

0230 INPUT A,B

0240 IF $A<>1$ THEN 260

0250 IF $B=2$ THEN 280

0260 PRINT "TEST WAS NOT EXECUTED PROPERLY."

0270 GOTO 290

D 280 PRINT "TEST WAS EXECUTED PROPERLY."

0290 PRINT

0300 PRINT"

0310 PRINT

END TEST."

0320 END 
$\star$ SAMPLE OUTPUT *

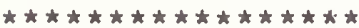

PROGRAM FILE 8 ?

$$
\text { SECTION } 87.0
$$

INSUFFICIENT DATA IN DATA-LIST.

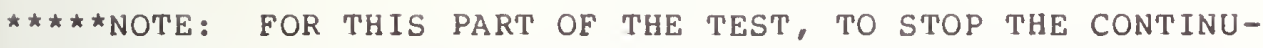
OUS REQUEST BY THE SYSTEM--THAT IS, IF IT SHOULD OCCUR--TO RESUPPLY THE INPUT-REPLY, JUST ENTER UPON A REQUEST THE

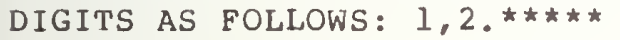

BEGIN TEST.

AFTER THE INPUT-PROMPT, ENTER THE FOLLOWING NUMBER: 64 $? 64$

?INSUFFICIENT DATA IN LIST. PLEASE RESUPPLY. ?64

?INSUFFICIENT DATA IN LIST. PLEASE RESUPPLY.

$? 64$

?INSUFFICIENT DATA IN LIST. PLEASE RESUPPLY.

$? 1,2$

TEST WAS EXECUTED PROPERLY.

END TEST. 
The objective of this test is to determine whether the implementation will diagnose as an exception the input of a numeric value too small to be represented by the test system (see section 13.4 of BSR X3.60). Upon recognition of the exception, the implementation should replace the value with zero and continue the program. The test has a message printed asking the user to input the numerical value of 10.0E-99999. After entering this value the system will test the input variable to determine whether it has been assigned the value 0 . If not, then a message will indicate that the program did not execute properly.

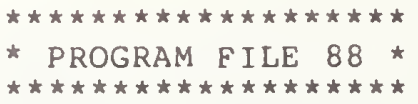

DOIO PRINT "PROGRAM FILE 88"

0020 PRINT

0030 PRINT

0040 PRINT

0090 PRINT

OIOO PRINT

0110 PRINT

0120 PRINT

0130 PRINT

O190 PRINT

D200 PRINT

BEGIN TEST."

D 210 PRINT

0220 PRINT "AFTER THE APPEARANCE OF THE INPUT-PROMPT, ENTER THE FOLLOW-"

0230 PRINT "ING NUMBER: 10.0E-99999"

0240 INPUT A

0250 IF $A=0$ THEN 280

0260 PRINT "TEST WAS NOT EXECUTED PROPERLY."

0270 GOTO 290

0280 PRINT "TEST WAS EXECUTED PROPERLY."

0290 PRINT

0300 PRINT "

0310 PRINT

END TEST."

0320 END

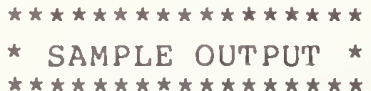


PROGRAM FILE 88

SECTION 88.0

THE CONVERSION OF A NUMERIC DATUM CAUSES AN UNDERFLOW.

BEGIN TEST.

AFTER THE APPEARANCE OF THE INPUT-PROMPT, ENTER THE FOLLOWING NUMBER: $10.0 \mathrm{E}-99999$

?10.0E-99999

TEST WAS EXECUTED PROPERLY.

END TEST. 


\section{EXXEPTION TEST $=$ NUMERIC OVERFLOW}

The objective of this test is to determine whether the implementation will recognize, as an exception, a numeric value in an input-list that is too large to be represented in the test system (see section 13.5 of BSR X3.60). Upon recognition of the error, the implementation should allow the user to resupply the input-list. The test has an instruction printed to the user to enter the value 9.99999E99999. As in section 88.0, the system should prompt the user to resupply data since an overflow was registered. Again in order to terminate the system request the user should type 1.
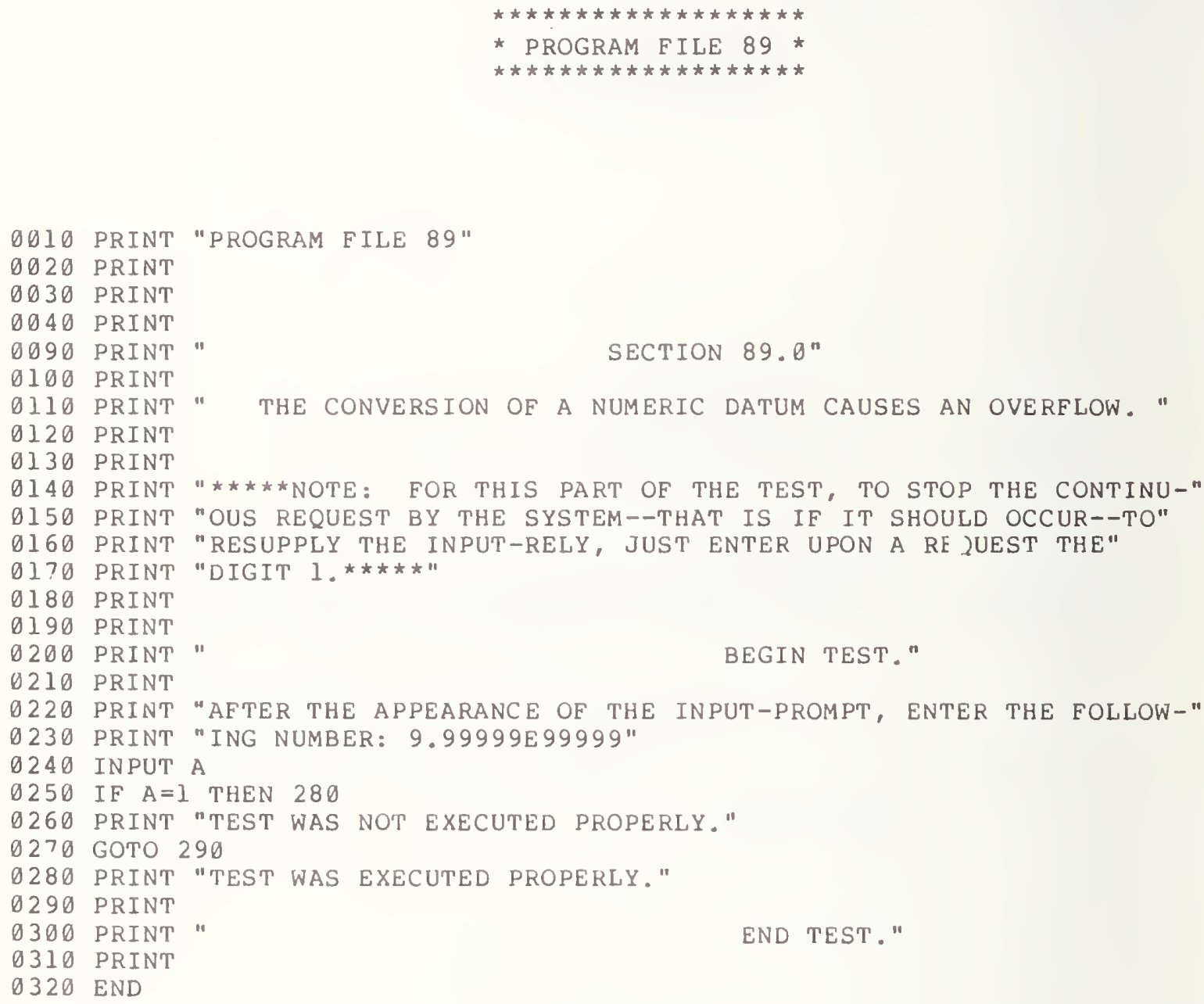
THE CONVERSION OF A NUMERIC DATUM CAUSES AN OVERFLOW.

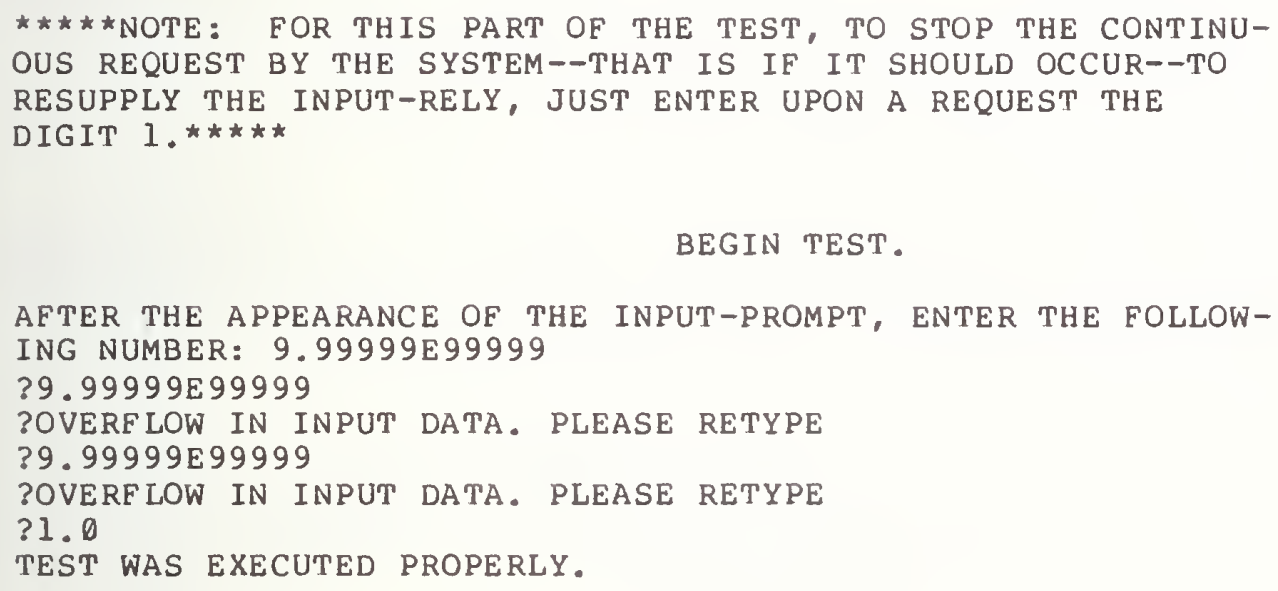

END TEST. 


\subsection{TESTING THE INT AND SGN FUNCTIONS}

90.1 The INT Function

The objective of this test is to use the INT function which returns the largest integer not greater than the argument specified (see section 8 of BSR x3.60). The test uses simple numeric-variables as the argument for the function. Assignments of various numerical values are made to the simple variable used as the argument parameter. On output, the test has three column labels printed. In sequential order the labels should read as follows: ARGUMENT, NEEDED EVALUATION, ACTUAL EVALUATION. The first column lists the values assigned to the function argument. The second lists the required evaluations by INT for each argument. Finally, the third column lists those values generated by the implementation-supplied INT function.

\section{2 The SGN Function}

This test initiates the use of the SGN function, which supplies -1 if the argument is negative, $I$ if the argument is positive and $\theta$ if the argument is 0 . This test, except for the use of the SGN function instead of the INT function, is similar to section 90.1 and has a similarly formatted output.
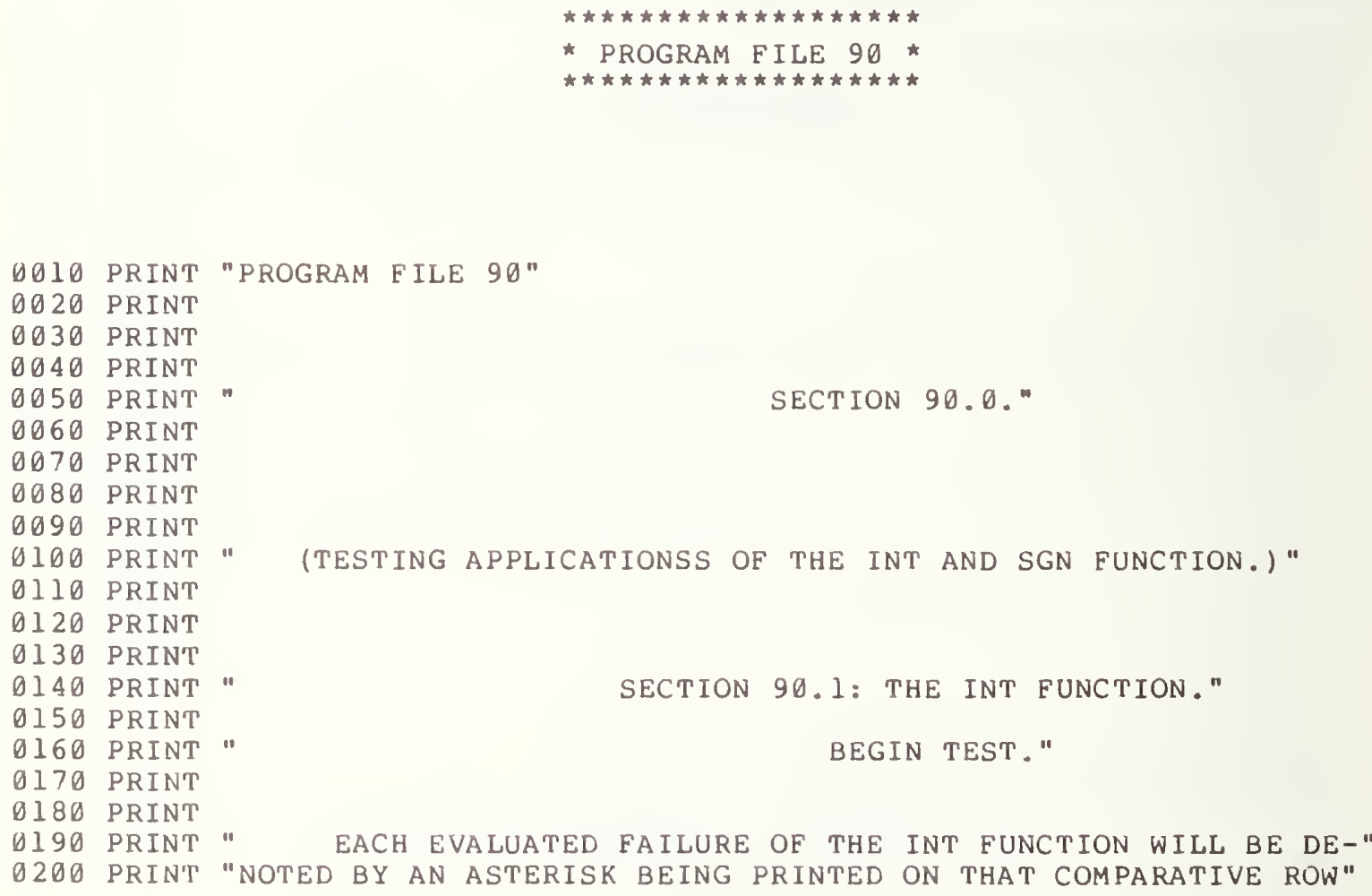
210 PRINT "OF OUTPUT. CHECK TEST PASSED IF THERE ARE NOT ANY ASTER-" $\$ 220$ PRINT "ISKS."

0230 PRINT

0240 PRINT

0250 PRINT " "," NEEDED "," ACTUAL "

0260 PRINT " ARGUMENT ", "EVALUATION" , EVA LUation"

0270 PRINT

0280 FOR I $=1$ TO 10

0290 READ M,N

0300 LET $X=$ INT $(N)$

0310 IF $X<>M$ THEN 340

0320 PRINT N, M,X

0330 GOTO 350

0340 PRINT $N, M, X_{i}{ }^{n * "}$

0350 NEXT I

0360 PRINT

$\emptyset 370$ DATA $1,1.99999,0, .987654,12345,12345.6$

0380 DATA $-1,-.339872,-8,-7.2,-98766,-98765.4$

0390 DATA $-10,-9.99999,127,127.999,-128,-127.999$

0400 DATA $-1,-.987654$

0410 PRINT

0420 PRINT

0430 PRINT

0440 PRINT

0450 PRINT

0460 PRINT

SECTION 90.2: THEN SGN FUNCTION."

0470 PRINT

0480 PRINT

0490 PRINT

0500 PRINT "NOTED BY AN ASTERISK BEING PRINTED ON THAT COMPARATIVE ROW"

0510 PRINT "OF OUTPUT. CHECK TEST PASSED IF THERE ARE NOT ANY ASTER-"

0520 PRINT "ISKS."

0530 PRINT

0540 PRINT

0550 PRINT " "," NEEDED "," ACTUAL "

0560 PRINT " ARGUMENT ", "EVALUATION" " EVALUATION"

0570 PRINT

0580 FORI $=1$ TO 10

0590 READ MI,N I

0600 LET $X I=S G N(N 1)$

0610 IF $X I<M I$ THEN 640

0620 PRINT NI,Ml, Xl

0630 GOTO 650

0640 PRINT NI,Ml,Xl;"*"

0650 NEXT I

0660 PRINT

0670 DATA -1,-.936896, 1, 12345,-1,-1.222

0680 DATA $0,0.00000,1,2.18765,-1,-0.00023$

0690 DATA $1,99999,0,0,-1,-888.99$

0700 DATA $1,1.99999$

0710 PRINT

$0 ? 20$ PRINT

$0 ? 30$ END 
EACH EVALUATED FAILURE OF THE INT FUNCTION WILL BE DENOTED BY AN ASTERISK BEING PRINTED ON THAT COMPARATIVE ROW OF OUTPUT. CHECK TEST PASSED IF THERE ARE NOT ANY ASTERISKS.

\begin{tabular}{lll} 
ARGUMENT & $\begin{array}{c}\text { NEEDED } \\
\text { EVALUATION }\end{array}$ & \multicolumn{1}{c}{ ACTUAL } \\
EVALUATION
\end{tabular}


ISKS .

$\begin{array}{lrr} & \text { NEEDED } & \text { ACTUAL } \\ \text { ARGUMENT } & \text { EVALUATION } & \text { EVALUATION } \\ -0.930896 & -1 & -1 \\ 12345 & 1 & 1 \\ -1.222 & -1 & -1 \\ 0 & 0 & 0 \\ 2.18765 & 1 & 1 \\ -2.30000 \mathrm{E}-4 & -1 & -1 \\ 99999 & 1 & 1 \\ 0 & 0 & 0 \\ -888.99 & -1 & -1 \\ 1.99999 & 1 & 1\end{array}$




\section{0 PRINTING STRINGS BEYOND THE MARGIN}

The objective of this section is to determine how the implementation handles printing beyond its specified margin. Since the margin is implementation defined this section uses specifically constructed long strings, tabbed over a large number of spaces in some of the tests, in order to take into account variable margin specifications. The reader is referred to section 12.4 of BSR $\times 3.60$.

\subsection{Printing Concatenated Strings}

The objective of this test section is to determine how the print delimiters effect printing strings of characters beyond the implementationdefined margin for a given system.

\subsubsection{Using Semicolons with Quoted Strings}

The objective of this test is to verify that the implementation, upon the evaluation of any print item, which generates a string whose length is greater than the implementation-defined margin, will generate an end-of-line each time the columnar. position of the current line exceeds the margin. Printing then must begin at the first position in the next line. The test has several print statements that output string constants of 50 characters each. Each print-list ends with a semicolon, except for the last. The exact output for this test will depend on the implementation-defined margin; however, the output should show a continuous string of digits up to and including the last columnar position for the implementation-defined margin. If there are any characters remaining they must begin in column one of the next line.

\subsubsection{Using Commas with Quoted Strings}

The objective of this test is similar to section 91.1.1. In this test, the print delimiter used is a comma. However, there is a significant amount of difference between the two outputs. For this test the string of digits should not be continuous (i.e., there should be spaces within the string of printed digits). The number of spaces depends on the implementation-defined zone lengths. The output must show that the digits should be printedup to and including the last columnar position for a defined margin, with printing then continuing on the next line.

\subsubsection{Using Semicolons with Assigned Strings}

The objective of this test is to determine whether the assignment of strings that exceed the margin will affect the evaluation of a print-item. The print-list in this exercise generates a string, whose length is greater than the defined margin. The implementation should still generate an end-of-line each time the columnar position of the current line exceeds the margin. The test begins by assigning strings of various lengths to string variables. These strings vary from lengths of 1 character to 18 characters. The assigned variables are then printed using semicolon delimiters. The output for this test should generate a similar display to that described in 
section 91.1 .1$.

\title{
91.1.4 Using Commas with Assigned Strings
}

The objective of this test is similar to section 91.1.3, except, in this test the print separator used in the variable-list for the PRINT statement is the comma. The structure of this test, except for the comma as print-separator, is similar to the structure of test section 91.1.3, however, the strings assigned to the string variables are all of equal length. The output for this test should appear similar to that of section 91.1.2.

\subsection{Simple TAB Tests Beyond The Margin}

The objective of this test section is to determine whether the impleinentation recognizes the standard specified relationship between the TAB argument and the implementation-defined margin .

\subsubsection{TAB Argument is Less Than the Value of the Current Print Position}

The objective of this test is to determine whether the implementation will, upon evaluating a TAB argument whose rounded value is less than the columnar position of the current line, generate an end-of-line and enough spaces to set the columnar position of the new current line to the required position. This test prints a message that there should be no printed characters after the period at the end of the message. If there are, then the tabbing has failed this test.

\subsubsection{TAB Assigned Strings Less Than Current Position}

The objective of this test, except for assigning the string of characters to be tabbed to a string variable, is the same as that for section 91.2.1. In terms of output there should be no difference between this section and the output of section 91.2 .1 .

\author{
UUIO PRINT "PROGRAM FILE $91 "$ \\ 0020 PRINT \\ 0030 PRINT \\ OOU \\ 0120 PRINT \\ SECTION 91.1: CONCATENATED STRINGS." \\ 0130 PRINT \\ 0140 PRINT \\ $\emptyset 150$ PRINT \\ SECTION 91.1.1: USING SEMICOLON, QUOTED STRINGS."
}

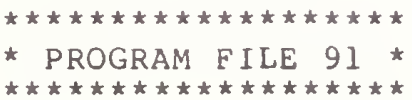

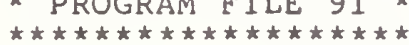




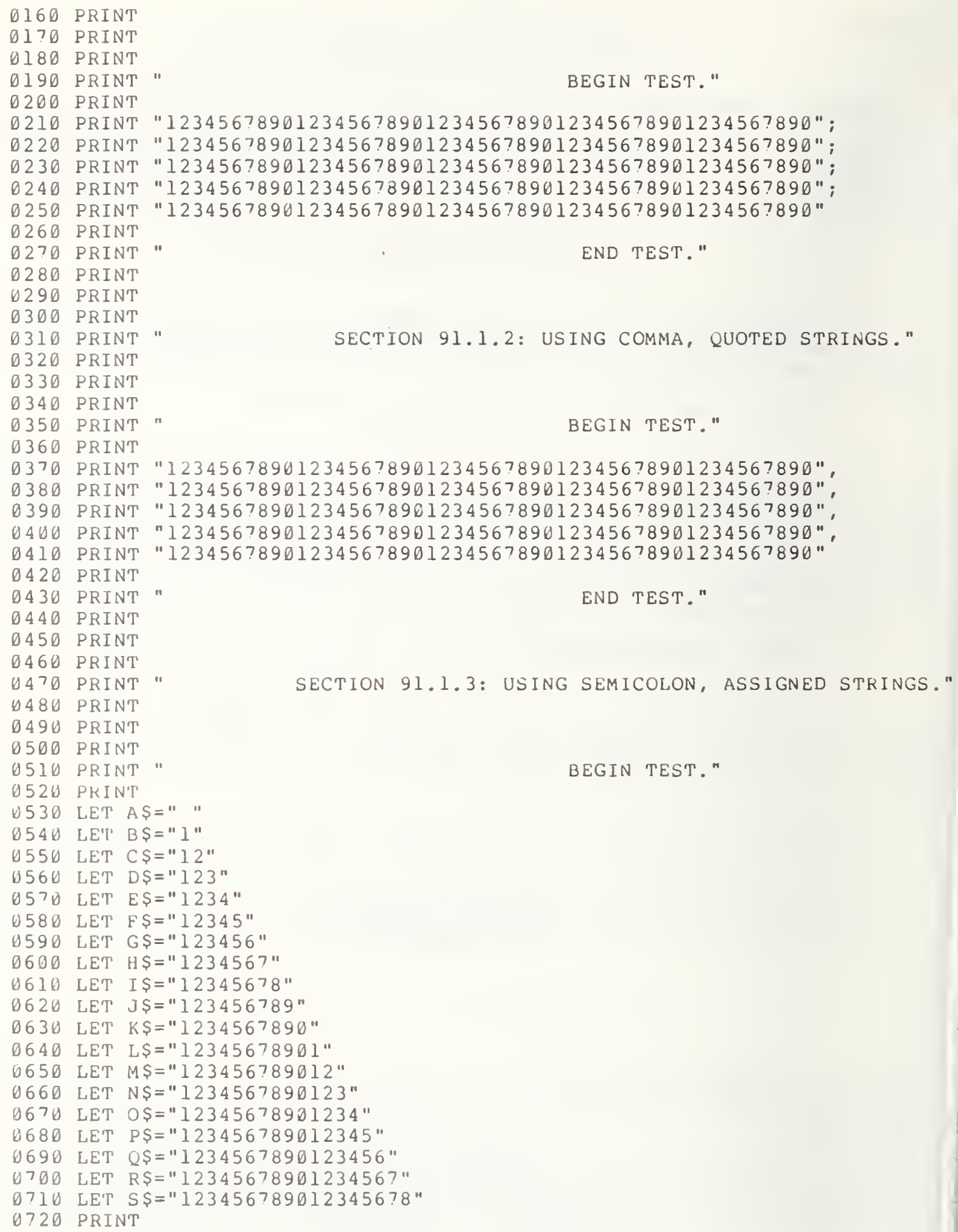


O 730 PRINT AS;BS;CS;DS;ES;FS;GS;HS;IS;JS;KS;LS;MS;N\$;OS;P\$;OS;RS;S\$

$0 ? 40$ PRINT

0750 PRINT

END TEST."

0760 PRINT

$0 ? 7 \emptyset$ PRINT

0780 PRINT

0790 PRINT

0800 PRINT

0810 PRINTT

0820 PRINT

0830 PRINT"

BEGIN TEST."

0840 PRINT

0850 LET $A \$=" 1234567890 "$

0860 LET $B \$=" 1234567890 "$

0870 LET C $\$=" 1234567890 "$

0880 LET DS $=" 1234567890 "$

0890 LET $E \$=" 1234567890$ "

0900 LET $F \$=" 1234567890 "$

0910 LET GS="1234567890"

0920 LET HS="1234567890"

0930 LET I $\$=" 1234567890 "$

0940 LET JS="1234567890"

0950 LET $K S=" 1234567890 "$

0960 LET L\$="1234567890"

0970 LET M\$=" $1234567890 "$

0980 LET $N \$=" 1234567890 "$

0990 PRINT "O0000000011111111112222222222333333333344444444445";

1000 PRINT "5555555556666666666777"

1010 PRINT "12345678901234567890123456789012345678901234567890";

1020 PRINT " 1234567890123456789012 "

1030 PRINT A\$, B\$, C\$, DS, E\$, F\$, G\$, HS, I S,J\$, K\$, LS, MS, N\$

1040 PRINT

1050 PRINT

END TEST."

1060 PRINT

1070 PRINT

1080 PRINT

1090 PRIN'T"

SECTION 91.2: TAB-CALL WITHIN AND BEYOND MARGIN."

1100 PRINT

1116 PRIN'T

1120 PRINT "

1130 PRINT

"SECTION 91.2.1: "TABBING QUOTED STRINGS WHEN TAB-CALL IS"

1140 PRINT

1150 PRINT

1160 PRINT

1170 PRINT

1180 PRINT

1190 PRINT "OUOOUO00011111111112222222222333333333344444444445";

1200 PRINT "5555555556666666666777"

1210 PRINT' "1 12345678901234567890123456789012345678901234567896 ";

1220 PRINT "1234567890123456789012"

1230 PRINT "NO PRINT, THIS LINE, AFTER PERIOD. " TAB (15); "X"

1240 PRINT

1250 PRINT

X ShOUld BE ON LINE FOUR, COLUMN 15."

1260 PRINT

1270 PRINT

END TEST."

1280 PRINT

1290 PRINT 


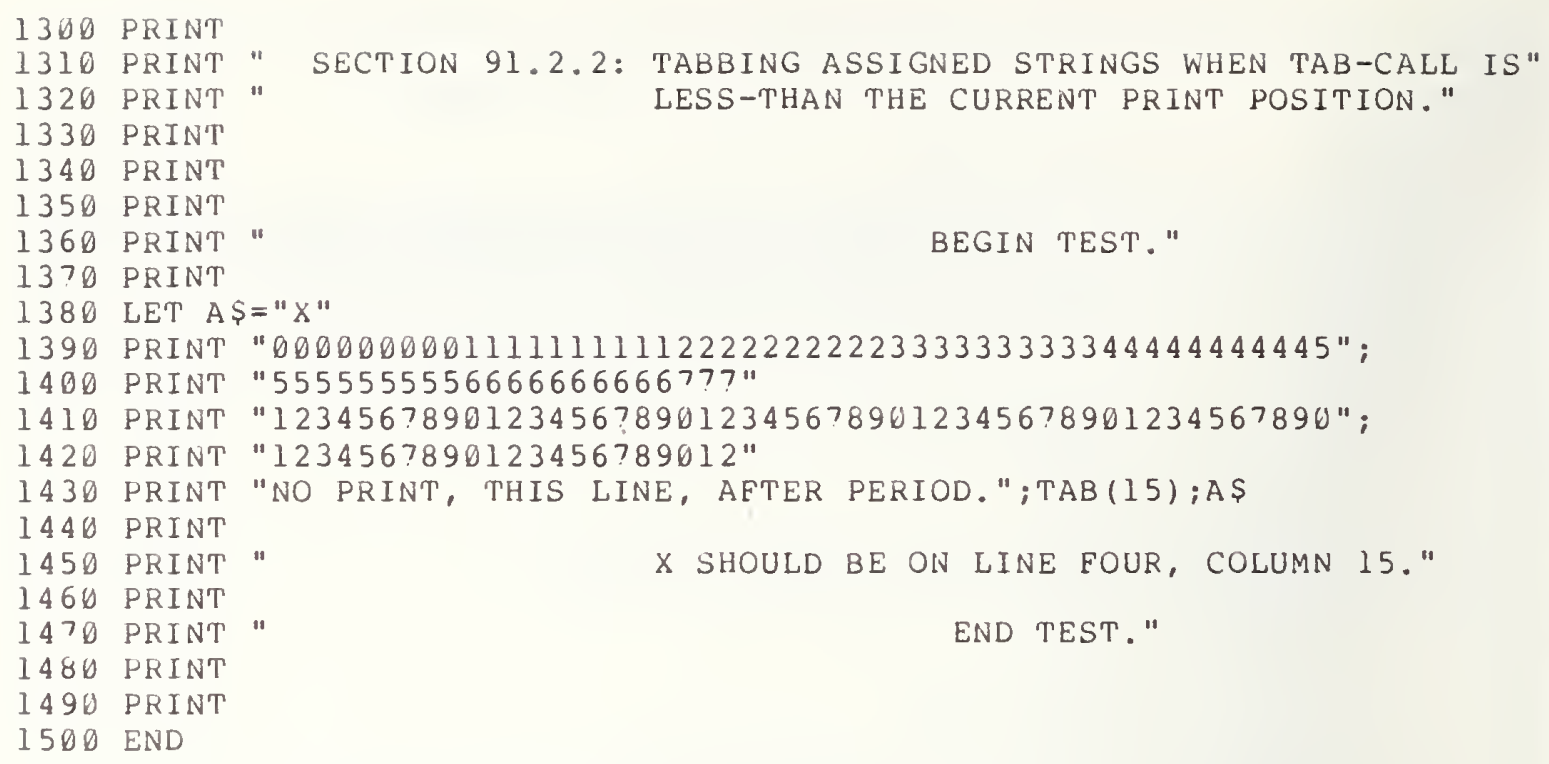

END TEST.

SECTION 91.1.2: USING COMMA, QUOTED STRINGS. 
BEGIN TEST.

$12345678901234567890123456789012345678901234567890 \quad 1234567890123456$ $7890123456789012345678901234567890 \quad 123456789012345678901234567890$ $12345678901234567890 \quad 12345678901234567890123456789012345678901234$ $567890 \quad 12345678901234567890123456789012345678901234567890$

END TEST.

SECTION 91.1.3: USING SEMICOLON, ASSIGNED STRINGS.

BEGIN TEST.

11212312341234512345612345671234567812345678912345678901234567890112345 678901212345678901231234567890123412345678901234512345678901234561234567 8901234567123456789012345678

END TEST.

SECTION 91.1.4: USING COMMA, ASSIGNED STRINGS.

BEGIN TEST.

000000000111111111122222222223333333333444444444455555555556666666666777 123456789012345678901234567890123456789012345678901234567890123456789012 1234567890 1234567890 1234567890 1234567890

1234567890 1234567890

1234567890 1234567890 1234567890 1234567890

1234567890

1234567890 1234567890

1234567890

END TEST.

SECTION 91.2: TAB-CALL WITHIN AND BEYOND MARGIN.

SECTION 91.2.1: TABBING QUOTED STRINGS WHEN TAB-CALL IS LESS-THAN THE CURRENT PRINT POSITION.

BEGIN TEST.

000000000111111111122222222223333333333444444444455555555556666666666777 123456789012345678901234567890123456789012345678901234567890123456789012 NO PRINT, THIS LINE, AETER PERIOD. $X$ 


\section{$X$ SHOULD BE ON LINE FOUR, COLUMN 15. END TEST.}

SECTION 91.2.2: TABBING ASSIGNED STRINGS WHEN TAB-CALL IS LESS-THAN THE CURRENT PRINT POSITION.

\section{BEGIN TEST.}

ด0000ด000111111111122222222223333333333444444444455555555556666666666777 123456789012345678901234567890123456789012345678901234567890123456789012 NO PRINT, THIS LINE, AFTER PERIOD. $\mathrm{X}$

X SHOULD BE ON IINE FOUR, COLUMN 15. END TEST. 


\subsection{Quoted Strings}

The objective of this test is to determine whether the implementation will, upon evaluating a TAB argument whose rounded value is greater than the implementation defined margin, reduce the value of $n$ by an integral multiple of $m$ so that it is in the range $1<=n<=m$. In particular, $n$ should be set equal to $n-m$ *INT $((n-1) / m)$. The reader is referred to section 12.4 of BSR X3.60. The test begins by requesting that the user input the value for the implementation-defined margin. The test then sequentially tabs 100 simple one character strings. Each TAB argument is increased by a value of 13 (i.e., the arguments are sequentially ordered $13,26,39, \ldots, 1300$ ). On output, the test generates column count indices in order to verify each columnar position. Each printout should be sequentially labelled by the digits 1, 2, 3, ..., 100. Upon completion of the tab-call printout, messages should be printed out indicating in which columns the strings should begin.

\section{2 Assigned Strings}

The objective of this test, except for the assigning of the string of characters, that are to be tabbed, to a string variable, is the same as the objective stated for test section 92.1. This test uses READ/DATA statements to assign the strings $A 1, A 2, A 3, \ldots . . A l 00$ to the string variable $A \$$ which is the print-item usea in conjunction with the tab-calls. As in test section 92.1, 100 tabbings are used with the same value increment for the tab arguments. On output this test has a similar format to test 92.1 .

\footnotetext{
0010 PRINT "PROGRAM FILE 92"

0020 PRINT

0030 PRINT

OO4O PRINT

Ø090 PRINT "SECTION 92.1: "TABBING QUOTED STRINGS BEYOND THE CURRENT"

OI00 PRINT" PRINT POSITION AS WELL AS BEYOND THE MAR-"

0110 PRINT

0120 PRINT

0130 PRINT

0140 PRINT

0150 PRINT "

0160 PRINT

0170 PRINT" NOTE: IN ORDER TO GET A PROPER OUTPUT, PLEASE ENTER"

0180 PRINT "THE MARGIN VALUE FOR THIS SYSTEM AFTER THE INPUT-PROMPT"

0200 INPUT $M$

BEGIN TEST." M
} 


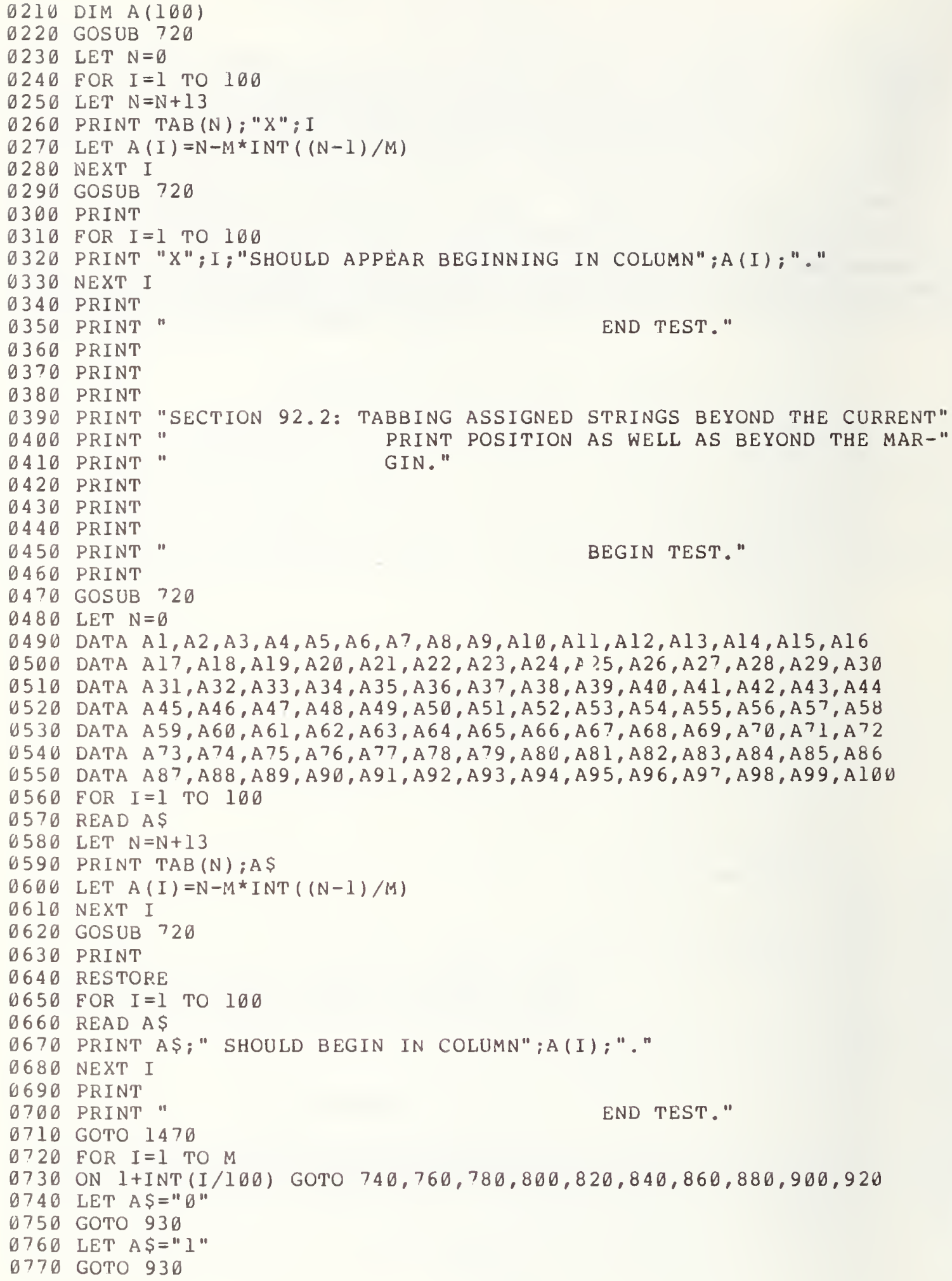




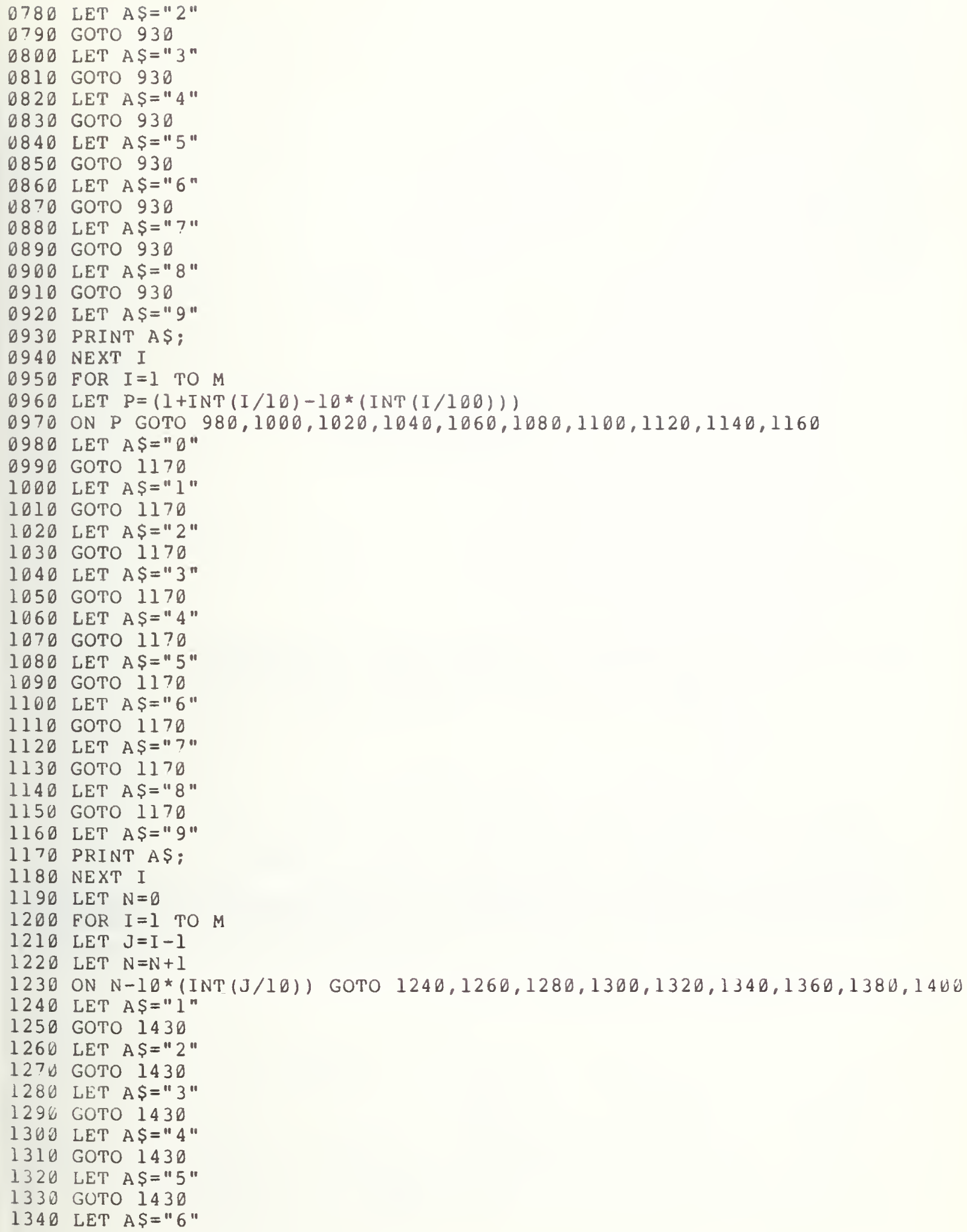




1350 GOTO 1430
1360 LET A $\$=" ? "$
1370 GOTO 1430
1380 LET A $\$=" 8 "$
1390 GOTO 1430
1400 LET A $\$=" 9 "$
1410 GOTO 1430
1420 LET A $\$=" 9 "$
1430 PRINT A\$;
1440 NEXT I
1450 PRINT
1460 RETURN
1470 PRINT
1480 END

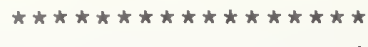

* SAMPLE OUTPUT *

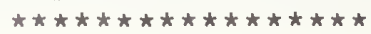

PROGRAM FILE 92

SECTION 92.1: TABBING QUOTED STRINGS BEYOND THE CURRENT PRINT POSITION AS WELL AS BEYOND THE MARGIN.

\section{BEGIN TEST.}

NOTE: IN ORDER TO GET A PROPER OUTPUT, PLEASE ENTER

THE MARGIN VALUE FOR THIS SYSTEM AFTER THE INPUT-PROMPT

$? 72$

000000000000000000000000000000000000000000000000000000000000000000000000 ๑ดดดดดดดด1111111111222222222233333333334444444444555555555566666666667? 123456789012345678901234567899123456789912345678991234567890123456789012

X 1

X 2

X 3

$\times 4$

$\times 5$

$\times 6$

X ?

$\times 8$

$\times 9$

$\times 10$ 
11

$$
\text { X } 12
$$

$\times 13$

$$
\times 14
$$

$$
\times 15
$$

$\times 17$

$$
\text { X } 18
$$

$$
\text { X } 19
$$

$$
\times 20
$$$$
\text { X } 21
$$

22

$$
\text { x } 23
$$

$$
\times 24
$$

$$
\times 25
$$$$
\text { X } 26
$$

X 28

× 29

$$
\times 30
$$$$
\times 31
$$$$
\text { x } 32
$$

33

$$
\text { X } 34
$$

$$
\times 35
$$$$
\text { X } 36
$$

$$
\begin{aligned}
& \times \quad 37 \\
& \hline
\end{aligned}
$$

$$
\text { X } 38
$$

$\times \quad 39$

$$
\times 40
$$$$
\text { X } 41
$$$$
\text { X } 42
$$$$
\times 43
$$

44

$$
\times 45
$$$$
\times 46
$$

$$
\times 47
$$

$$
\begin{array}{r}
\times 48 \\
\hline
\end{array}
$$

$$
\text { X } 49
$$

$\times 50$

$$
\times 51
$$

$$
\text { × } 52
$$

$$
\times 53
$$

$$
\times 54
$$

55

$$
\times 56
$$

$\times 61$

$$
\begin{array}{r}
\times 57 \\
\times 58 \quad \times 59 \\
\times 62 \times 60 \\
\times 63
\end{array}
$$




\section{$\times 65$}

$\times 66$

$\times 67$

× 68

$\times 69$

$\times 70$

x 71

72

$$
\begin{array}{r}
\times 73 \times 74 \\
\times 75 \\
\quad \times 76
\end{array}
$$

$\times 79$

$\times 80$

X 81

$\times 82$

x

83

X 84

X 85

X 86

\begin{tabular}{l}
$\times \quad 87$ \\
\hline
\end{tabular}

X 88

$\times 90$

$\times 91$

$\times 92$

$\times 93$

X

94

$\times 95$

× 96

$\times 97$

X 98

$\begin{array}{r}\times 99 \\ \hline\end{array}$

$\times 100$

000000000000000000000000000000000000000000000000000000000000000000000000 000000000111111111122222222223333333333444444444455555555556666666666777 123456789012345678901234567890123456789012345678901234567890123456789012

$X 1$ SHOULD APPEAR BEGINNING IN COLUMN 13 .

$X 2$ SHOULD APPEAR BEGINNING IN COLUMN 26.

$X 3$ SHOULD APPEAR BEGINNING IN COLUMN 39.

$X 4$ SHOULD APPEAR BEGINNING IN COLUMN 52 .

$X 5$ SHOULD APPEAR BEGINNING IN COLUMN 65.

$X 6$ SHOULD APPEAR BEGINNING IN COLUMN 6 .

$X 7$ SHOULD APPEAR BEGINNING IN COLUMN 19.

$X 8$ SHOULD APPEAR BEGINNING IN COLUMN 32.

$X 9$ SHOULD APPEAR BEGINNING IN COLUMN $45^{\circ}$.

$x 10$ SHOULD APPEAR BEGINNING IN COLUMN $58^{\circ}$.

$x 11$ SHOULD APPEAR BEGINNING IN COLUMN 71 .

$x 12$ SHOULD APPEAR BEGINNING IN COLUMN 12 . 
$X 13$ SHOULD APPEAR BEGINNING IN COLUMN 25.

$X 14$ SHOULD APPEAR BEGINNING IN COLUMN $38^{\circ}$

$X 15$ SHOULD APPEAR BEGINNING IN COLUMN 51.

$X 16$ SHOULD APPEAR BEGINNING IN COLUMN 64.

$\mathrm{X} 17$ SHOULD APPEAR BEGINNING IN COLUMN 5.

$X 18$ SHOULD APPEAR BEGINNING IN COLUMN 18.

$X 19$ SHOULD APPEAR BEGINNING IN COLUMN 31.

$X 20$ SHOULD APPEAR BEGINNING IN COLUMN 44.

$X 21$ SHOULD APPEAR BEGINNING IN COLUMN 5?

$X 22$ SHOULD APPEAR BEGINNING IN COLUMN 70 .

$X 23$ SHOULD APPEAR BEGINNING IN COLUMN 11 .

$X 24$ SHOULD APPEAR BEGINNING IN COLUMN 24.

$X 25$ SHOULD APPEAR BEGINNING IN COLUMN 37.

$X 26$ SHOULD APPEAR BEGINNING IN COLUMN 50.

$X 27$ SHOULD APPEAR BEGINNING IN COLUMN 63.

$X 28$ SHOULD APPEAR BEGINNING IN COLUMN 4 .

X 29 SHOULD APPEAR BEGINNING IN COLUMN $17^{\circ}$.

$x \quad 30$ SHOULD APPEAR BEGINNING IN COLUMN 30 .

$X 31$ SHOULD APPEAR BEGINNING IN COLUMN 43.

$X 32$ SHOULD APPEAR BEGINNING IN COLUMN 56.

$X 33$ SHOULD APPEAR BEGINNING IN COLUMN 69.

$X 34$ SHOULD APPEAR BEGINNING IN COLUMN 10.

$X 35$ SHOULD APPEAR BEGINNING IN COLUMN 23.

$X 36$ SHOULD APPEAR BEGINNING IN COLUMN 36.

$X 37$ SHOULD APPEAR BEGINNING IN COLUMN 49.

$X 38$ SHOULD APPEAR BEGINNING IN COLUMN 62.

$X 39$ SHOULD APPEAR BEGINNING IN COLUMN 3 .

$X 40$ SHOULD APPEAR BEgINNING IN COLUMN $16^{\circ}$.

$X 41$ SHOULD APPEAR BEGINNING IN COLUMN 29.

$X 42$ SHOULD APPEAR BEGINNING IN COLUMN 42.

$X 43$ SHOULD APPEAR BEGINNING IN COLUMN 55.

$X 44$ SHOULD APPEAR BEGINNING IN COLUMN 68 .

$X 45$ SHOULD APPEAR BEgINNING IN COLUMN 9 .

$X 46$ SHOULD APPEAR BEGINNING IN COLUMN 22 .

$X 4$ ? SHOULD APPEAR BEGINNING IN COLUMN 35.

$X 48$ SHOULD APPEAR BEGINNING IN COLUMN 48 .

$X 49$ SHOULD APPEAR BEGINNING IN COLUMN 61.

$X 50$ SHOULD APPEAR BEGINNING IN COLUMN 2 .

$X 51$ SHOULD APPEAR BEGINNING IN COLUMN 15.

$X 52$ SHOULD APPEAR BEGINNING IN COLUMN 28.

$X 53$ SHOULD APPEAR BEGINNING IN COLUMN 41 .

$X 54$ SHOULD APPEAR BEGINNING IN COLUMN 54.

$X 55$ SHOULD APPEAR BEGINNING IN COLUMN 67 .

$X 56$ SHOULD APPEAR BEGINNING IN COLUMN 8 .

$X 57$ SHOULD APPEAR BEGINNING IN COLUMN 21 .

$X 58$ SHOULD APPEAR BEGINNING IN COLUMN 34.

$X 59$ SHOULD APPEAR BEGINNING IN COLUMN 47 .

$X 60$ SHOULD APPEAR BEGINNING IN COLUMN 60.

$X 61$ SHOULD APPEAR BEGINNING IN COLUMN 1 .

$x 62$ SHOULD APPEAR BEGINNING IN COLUMN 14.

$X 63$ SHOULD APPEAR BEGINNING IN COLUMN 27.

$X 64$ SHOULD APPEAR BEGINNING IN COLUMN 40 .

$X 65$ SHOULD APPEAR BEGINNING IN COLUMN 53.

$X 66$ SHOULD APPEAR BEGINNING IN COLUMN 66.

$X 67$ SHOULD APPEAR BEGINNING IN COLUMN $?$.

$X 68$ SHOULD APPEAR BEGINNING IN COLUMN 20.

$X 69$ SHOULD APPEAR BEGINNING IN COLUMN 33. 


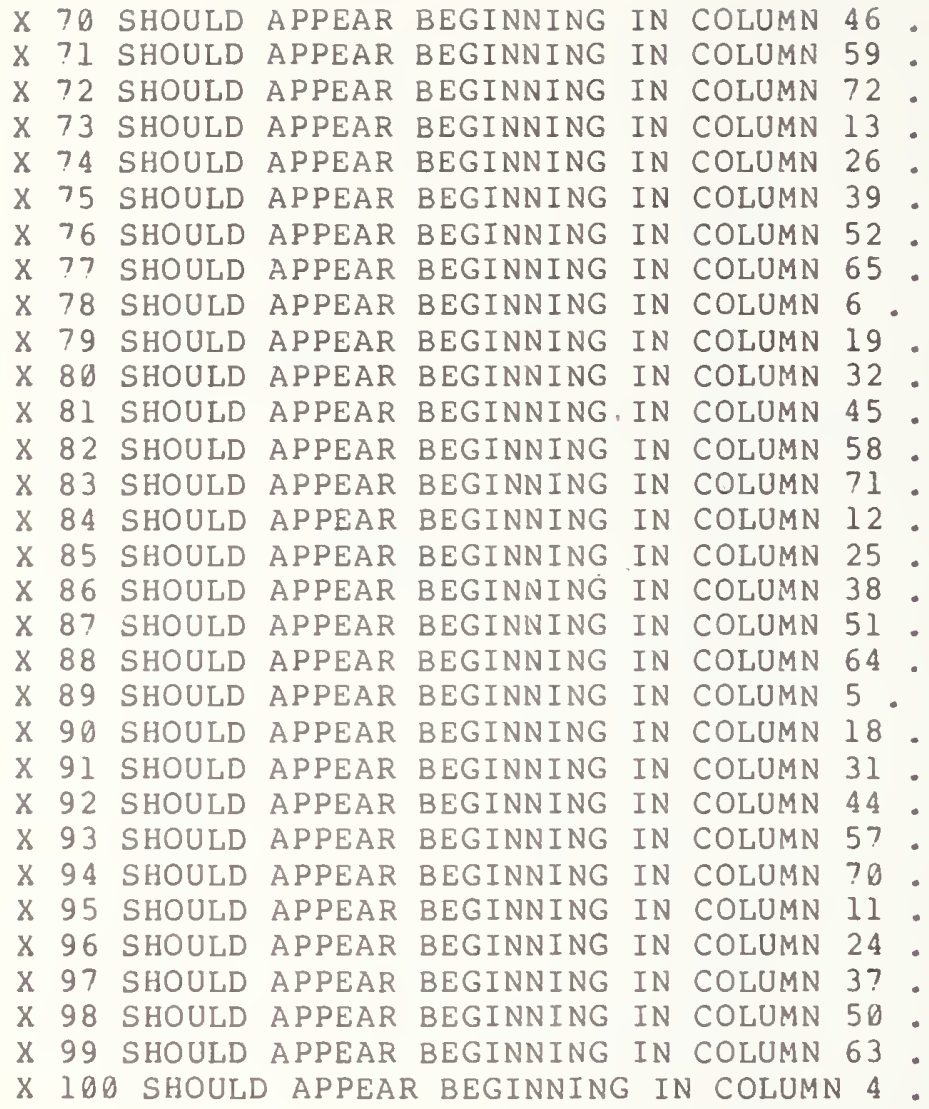

END TEST.

SECTION 92.2: TABBING ASSIGNED STRINGS BEYOND THE CURRENT PRINT POSITION AS WELL AS BEYOND THE MARGIN .

BEGIN TEST .

000000000000000000000000000000000000000000000000000000000000000000000000 ด00000000111111111122222222223333333333444444444455555555556666666666777 123456789012345678901234567890123456789012345678901234567890123456789012

Al

A 2

A 3

A 4

A 6

A 7

A 8 
Alo

A 1

1

A 12

A 13

A 14

A 15

A 16

A 17

A 18

A 19

A 20

A 21

A 22

A 23

A 24

A 25

A 26

A 27

A 28

A 29

A 30

A 31

A 32

A 33

A 34

A 35

A 36

A 37

A 38

A39

A 40

A 41

A 42

A 43

A 44

A 45

A 46

A 47

A 48

A 49

A 50

A 51

A 52

A 53

A 54

A 55

A 56

A 5?

A 58

A 59

A 60

A 61

A 62

A 63

A 64

A 65 
A 67

A 68

A 69

$$
\text { A? } 0
$$

A 기

72

A 73

A 74

A 75

A 76

A 77

A 78

A 79

A 80

A 81

A 82

A 8

A 84

A

3
A 85
A 86
A 87
A. 92
A 93
A 94
A 95
A 96
A 97
A 98
A 99
A100
000000000000000000000000000000000000000000000000000000000000000000000000 00000000011111111112222222222333333333344444444445555555555666666666677 ? 123456789012345678901234567890123456789012345678901234567890123456789012

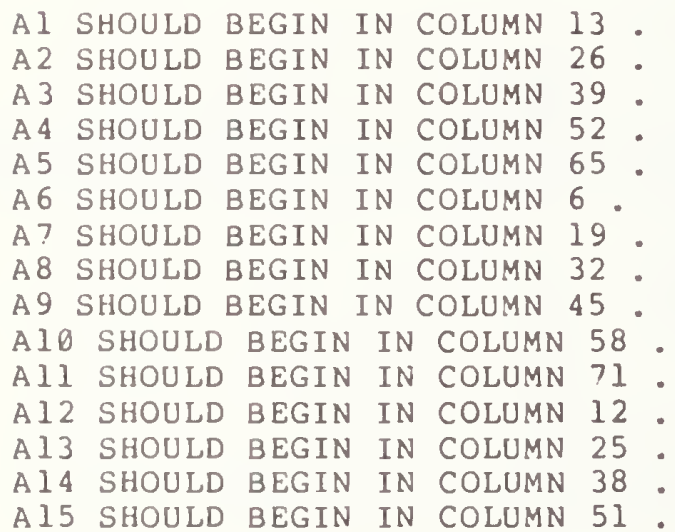


A16 SHOULD BEGIN IN COLUMN 64 .

A 17 SHOULD BEGIN IN COLUMN 5.

A 18 SHOULD BEGIN IN COLUMN 18.

A 19 SHOULD BEGIN IN COLUMN 31 .

A 20 SHOULD BEGIN IN COLUMN 44 .

A21 SHOULD BEGIN IN COLUMN 57 .

A22 SHOULD BEGIN IN COLUMN 70 .

A 23 SHOULD BEGIN IN COLUMN 11.

A24 SHOULD BEGIN IN COLUMN 24.

A25 SHOULD BEGIN IN COLUMN 3?.

A26 SHOULD BEGIN IN COLUMN 50 .

A 27 SHOULD BEGIN IN COLUMN 63.

A28 SHOULD BEGIN IN COLUMN 4 .

A29 SHOULD BEGIN IN COLUMN $17^{\circ}$

A 30 SHOULD BEGIN IN COLUMN $30^{\circ}$

A 31 SHOULD BEGIN IN COLUMN 43 .

A 32 SHOULD BEGIN IN COLUMN 56.

A 33 SHOULD BEGIN IN COLUMN 69.

A 34 SHOULD BEGIN IN COLUMN 10 .

A 35 SHOULD BEGIN IN COLUMN 23 .

A 36 SHOULD BEGIN IN COLUMN 36.

A 37 SHOULD BEGIN IN COLUMN 49.

A38 SHOULD BEGIN IN COLUMN 62 .

A39 SHOULD BEGIN IN COLUMN 3 .

A 49 SHOULD BEGIN IN COLUMN 16.

A41 SHOULD BEGIN IN COLUMN 29.

A42 SHOULD BEGIN IN COLUMN 42 .

A43 SHOULD BEGIN IN COLUMN 55.

A44 SHOULD BEGIN IN COLUMN 68.

A 45 SHOULD BEGIN IN COLUMN 9.

A 46 SHOULD BEGIN IN COLUMN $22^{\circ}$

A 47 SHOULD BEGIN IN COLUMN 35.

A 48 SHOULD BEGIN IN COLUMN 48 .

A49 SHOULD BEGIN IN COLUMN 61.

A50 SHOULD BEGIN IN COLUMN 2 .

A51 SHOULD BEGIN IN COLUMN 15.

A52 SHOULD BEGIN IN COLUMN 28.

A53 SHOULD BEGIN IN COLUMN 41 .

A54 SHOULD BEGIN IN COLUMN 54.

A55 SHOULD BEGIN IN COLUMN 6?.

A56 SHOULD BEGIN IN COLUMN 8 .

A5? SHOULD BEGIN IN COLUMN 21.

A 58 SHOULD BEGIN IN COLUMN 34.

A59 SHOULD BEGIN IN COLUMN 4?.

A 60 SHOULD BEGIN IN COLUMN 60 .

A61 SHOULD BEGIN IN COLUMN 1.

A62 SHOULD BEGIN IN COLUMN 14.

A63 SHOULD BEGIN IN COLUMN $27^{\circ}$

A64 SHOULD BEGIN IN COLUMN $40^{\circ}$

A65 SHOULD BEGIN IN COLUMN 53 .

A66 SHOULD BEGIN IN COLUMN 66.

A 67 SHOULD BEGIN IN COLUMN 7 .

A68 SHOULD BEGIN IN COLUMN $20^{\circ}$

A 69 SHOULD BEGIN IN COLUMN 33 .

A 70 SHOULD BEGIN IN COLUMN 46 .

A71 SHOULD BEGIN IN COLUMN 59.

A72 SHOULD BEGIN IN COLUMN 72 . 
A73 SHOULD BEGIN IN COLUMN 13. A 74 SHOULD BEGIN IN COLUMN 26.

A75 SHOULD BEGIN IN COLUMN 39.

A?6 SHOULD BEGIN IN COLUMN 52 .

A 7 ? SHOULD BEGIN IN COLUMN 65.

A 78 SHOULD BEGIN IN COLUMN 6 .

A 79 SHOULD BEGIN IN COLUMN 19.

A.80 SHOULD BEGIN IN COLUMN 32.

A81 SHOULD BEGIN IN COLUMN 45 .

A82 SHOULD BEGIN IN COLUMN 58 .

A83 SHOULD BEGIN IN COLUMN 71 .

A84 SHOULD BEGIN IN COLUMN 12.

A85 SHOULD BEGIN IN COLUMN 25.

A 86 SHOULD BEGIN IN COLUMN 38 .

A8? SHOULD BEGIN IN COLUMN 51 .

A.88 SHOULD BEGIN IN COLUMN 64.

A89 SHOULD BEGIN IN COLUMN 5.

A90 SHOULD BEGIN IN COLUMN 18.

A91 SHOULD BEGIN IN COLUMN 31.

A92 SHOULD BEGIN IN COLUMN 44 .

A93 SHOULD BEGIN IN COLUMN 5?:

A 94 SHOULD BEGIN IN COLUMN 70 .

A95 SHOULD BEGIN IN COLUMN 11.

A96 SHOULD BEGIN IN COLUMN 24.

A.97 SHOULD BEGIN IN COLUMN 37 .

A98 SHOULD BEGIN IN COLUMN 50.

A99 SHOULD BEGIN IN COLUMN 63.

A100 SHOULD BEGIN IN COLUMN 4 .

END TEST. 


\subsection{EXCEPTION TEST $=$ STRING OVERFLOW}

A preliminary test of acceptable assigned string lengths was done in section 57.0. At that time strings of length $19,20,30,40,50$, and 58 characters were used. Since program lines had to be restricted to 72 characters, inordinately long strings, used as program constants, could not be tested. However, with the INPUT statement longer strings can be introduced. The present test is based upon the assumption that a BASIC processor. will have an input buffer of some maximum length, which may be unknown to the user. But, if the user enters a sufficiently long string, an overflow is inevitable. In order to execute this test one must assume that characters can be continuously typed on a terminal and that a carriage return or line feed character is not introduced into the string unless they are specifically entered by the user (say by a RETURN key). The user begins the test by entering 18 characters. All succeeding entries will be in multiples of 36. The user will then be asked to enter a sequence of strings of increasing length. If no overflow is encountered at an entry the user will be asked to enter a longer string. When a string overflow is finally encountered, the test system must provide a message to the user indicating the overflow and requesting input reentry (see section 13.5 of BSR X3.60). The user should then type STOP since the system would have responded properly to the string overflow. The authors have experienced at least one system that allowed a string entry of more than 145 characters before an overflow message was encountered.

\footnotetext{
10 PRINT "PROGRAM FILE 93"

20 PRINT

30 PRINT

40 PRINT

50 PRINT"

60 PRINT

70 PRINT "CONVERSION OF A STRING INPUT DATUM CAUSES A STRING OVERFLOW"

90 PRINT

100 PRINT

120 PRINT

130 PRINT "THERE ARE TWO CRITERIA THAT MUST BE MET TO PASS THIS TEST. "

135 PRINT "FIRST, IF A STRING OVERELOW IS ENCOUNTERED THEN THE USER "

140 PRINT "MUST BE ALLOWED TO REENTER THE STRING INPUT. SECOND, THE "

145 PRINT "FIRST" STRING INPUT OF 18 CHARACTERS MUST BE ACCEPTED "

150 PRINT "WITHOUT ANY DIAGNOSTIC."

160 PRINT

170 PRINT "UPON ENCOUNTERING AN OVERFLOW AND A REQUEST TO REENTER DATA"

175 PRINT "THE USER SHOULD TYPE STOP, WHICH TERMINATES THE PROGRAM."

180 PRINT
} 


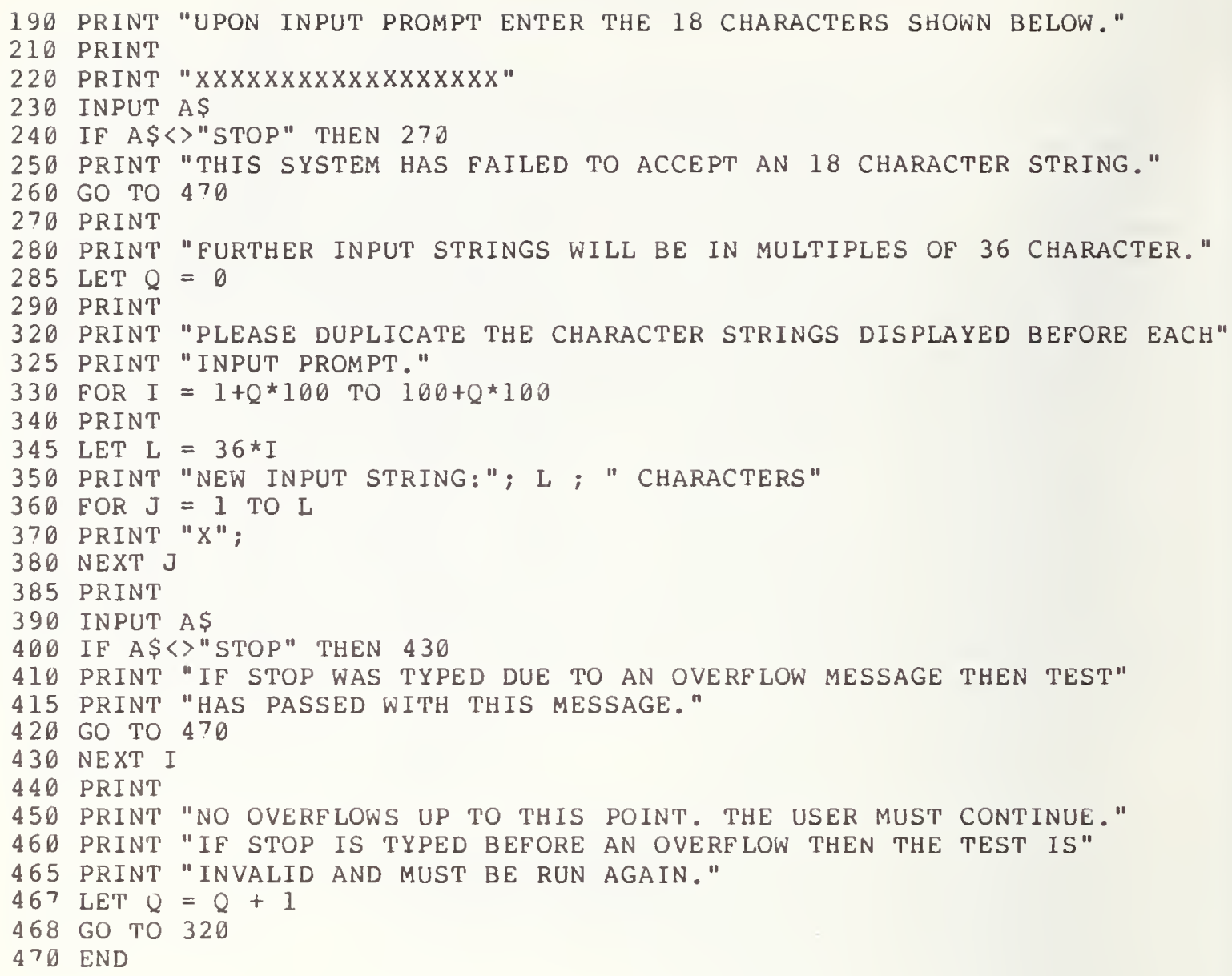


THERE ARE TWO CRITERIA THAT MUST BE MET TO PASS THIS TEST. FIRST, IF A STRING OVERELOW IS ENCOUN'TERED THEN THE USER MUST BE ALLOWED TO REENTER THE STRING INPUT. SECOND, THE FIRS'T STRING INPUT OF 18 CHARACTERS MUST BE ACCEPTED WITHOUT ANY DIAGNOSTIC.

UPON ENCOUNTERING AN OVERFLOW AND A REQUEST TO REENTER DATA THE USER SHOULD TYPE STOP, WHICH TERMINATES THE PROGRAM.

UPON INPUT PROMPT ENTER THE 18 CHARACTERS SHOWN BELOW.

$\mathrm{X} \times \mathrm{XXX \times X \times X \times \times \times X \times X \times X \times}$

? $\times X \times X \times X \times X \times X \times X \times X \times X \times X$

FURTHER INPUT STRINGS WILL BE IN MULTIPLES OF 36 CHARACTER.

PLEASE DUPLICATE THE CHARACTER S'TRINGS DISPLAYED BEFORE EACH INPUT PROMPT.

NEW INPUT STRING: 36 CHARACTERS XXXXXXXXXXXXXXXXXXXXXXXXXXXXXXXXXXXX

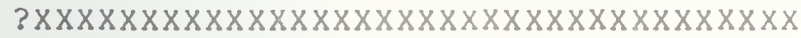

NEW INPUT STRING: 72 CHARACTERS

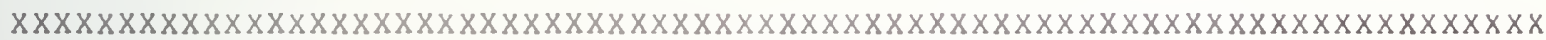

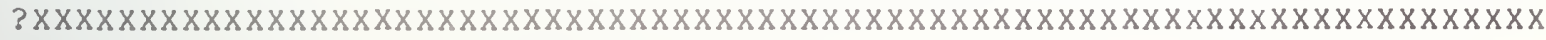
$x$

NEW INPUT STRING: 108 CHARACTERS XXXXXXXXXXXXXXXXXXXXXXXXXXXXXXXXXXXXXXXXXXXXXXXXXXXXXXXXXXXXXXXXXXXXXXXX

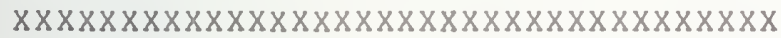

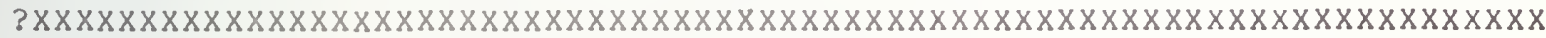
$\mathrm{X} \times \times \times \times \times \times \times \times \times \times \times \times \times \times \times \times \times \times \times \times \times \times \times \times \times \times \times \times \times \times \times \times \times \times \times X$

NEW INPUT STRING: 144 CHARACTERS

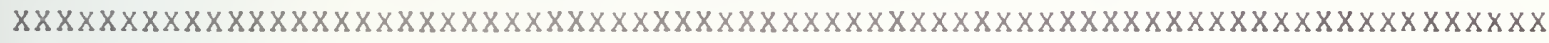

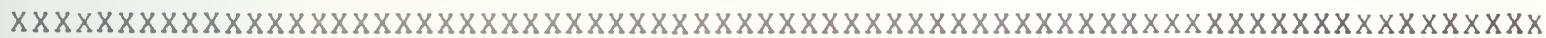
? XXXXXXXXXXXXXXXXXXXXXXXXXXXXXXXXXXXXXXXXXXXXXXXXXXXXXXXXXXXXXXXXXXXXXXX XXXXXXXXXXXXXXXXXXXXXXXXXXXXXXXXXXXXXXXXXXXXXXXXXXXXXXXXXXXXXXXXXXXXXXXX $\mathrm{X}$

NE'W INPUT STRING: 180 CHARACTERS

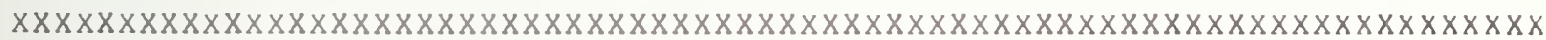

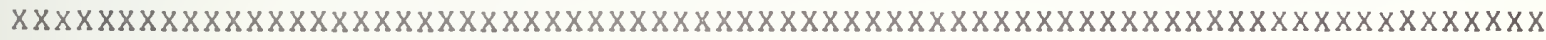
$\mathrm{X} \times \times \times \times \times \times \times \times \times \times \times \times \times \times \times \times \times \times \times \times \times \times \times \times \times \times \times \times \times \times \times \times \times \times$

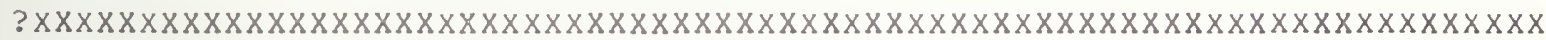

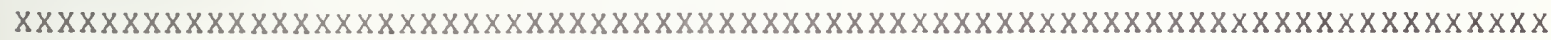
XXXXXXXXXXXXXXXXXXXXXXXXXXXXXXXXXXXXX ?INPUT STRING TOO LONG. PLEASE REENTER. ?STOP 
NBS-IIAA (REV, 7-73)

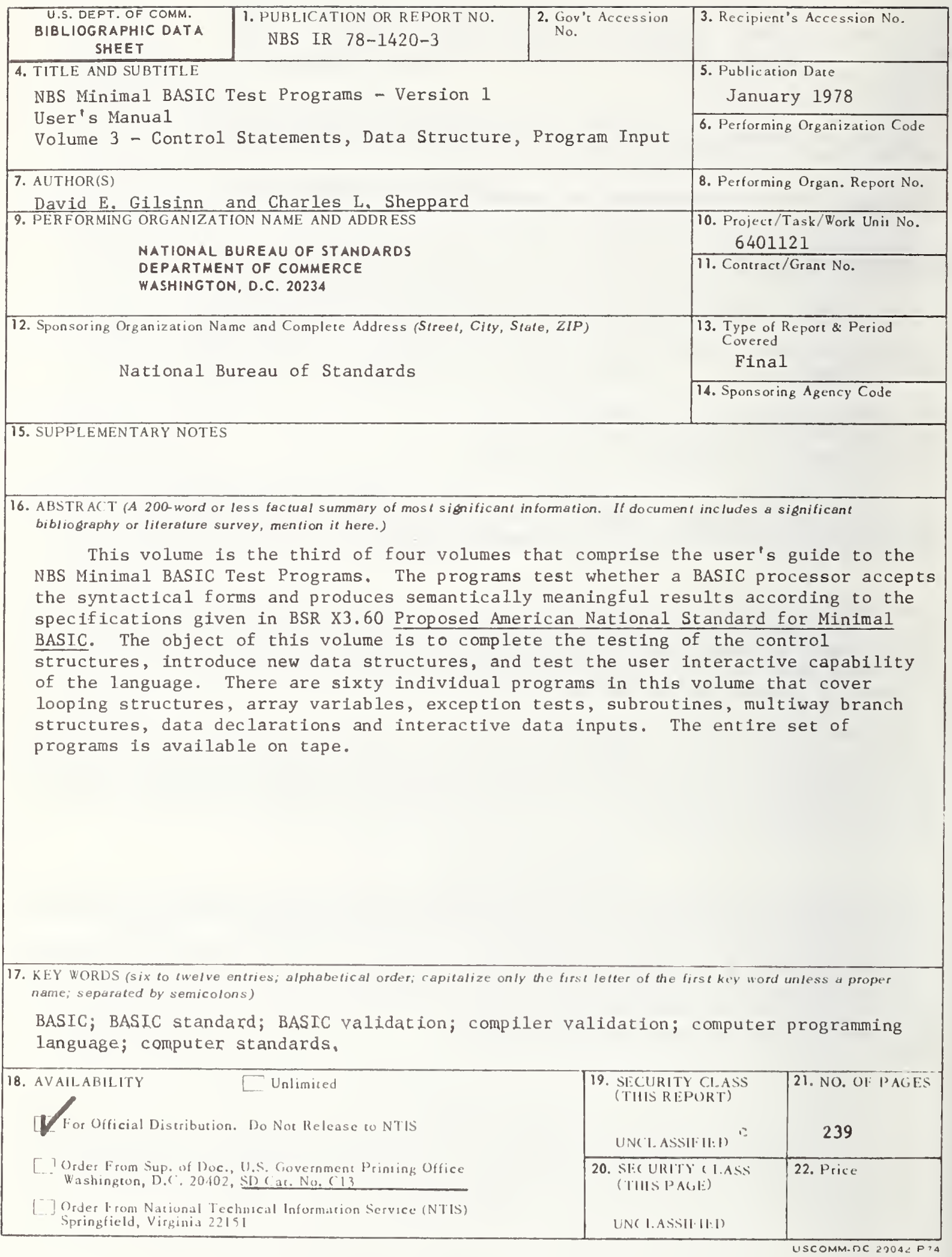

